\title{
Various aspects of quality and safety of colonoscopy
}

Citation for published version (APA):

Reumkens, A. (2021). Various aspects of quality and safety of colonoscopy. [Doctoral Thesis, Maastricht University]. ProefschriftMaken. https://doi.org/10.26481/dis.20210902ar

Document status and date:

Published: 01/01/2021

DOI:

10.26481/dis.20210902ar

Document Version:

Publisher's PDF, also known as Version of record

\section{Please check the document version of this publication:}

- A submitted manuscript is the version of the article upon submission and before peer-review. There can be important differences between the submitted version and the official published version of record.

People interested in the research are advised to contact the author for the final version of the publication, or visit the DOI to the publisher's website.

- The final author version and the galley proof are versions of the publication after peer review.

- The final published version features the final layout of the paper including the volume, issue and page numbers.

Link to publication

\footnotetext{
General rights rights.

- You may freely distribute the URL identifying the publication in the public portal. please follow below link for the End User Agreement:

www.umlib.nl/taverne-license

Take down policy

If you believe that this document breaches copyright please contact us at:

repository@maastrichtuniversity.nl

providing details and we will investigate your claim.
}

Copyright and moral rights for the publications made accessible in the public portal are retained by the authors and/or other copyright owners and it is a condition of accessing publications that users recognise and abide by the legal requirements associated with these

- Users may download and print one copy of any publication from the public portal for the purpose of private study or research.

- You may not further distribute the material or use it for any profit-making activity or commercial gain

If the publication is distributed under the terms of Article $25 \mathrm{fa}$ of the Dutch Copyright Act, indicated by the "Taverne" license above, 


\section{VARIOUS ASPECTS OF QUALITY AND SAFETY OF COLONOSCOPY}





\section{Various aspects of}

\section{quality and safety of colonoscopy}

Ankie Reumkens 


\section{Colofon}

Copyright Ankie Reumkens, Maastricht 2021

All rights reserved. No part of this thesis may be reproduced or transmitted in any form or by any means, without prior permission in writing by the author, or when appropriate, by the publishers of the publications.

ISBN: 978-94-6423-348-3

Cover/design: Ankie Reumkens

Layout: $\quad$ Tiny Wouters

Printed by: $\quad$ ProefschriftMaken | www.proefschriftmaken.nl

The work presented in this thesis was performed within NUTRIM School of Nutrition and Translational Research in Metabolism.

Printing of this thesis was financially supported by: Maastricht University, MUMC+, Zuyderland Medisch Centrum, Nederlandse Vereniging voor Gastroenterologie, Ferring BV and dr. Falk Pharma Benelux B.V. 


\title{
Various aspects of
}

\section{quality and safety of colonoscopy}

\author{
Proefschrift
}

ter verkrijging van de graad van doctor aan de Universiteit Maastricht, op gezag van de Rector Magnificus, Prof.dr. Rianne M. Letschert, volgens het besluit van het College van Decanen,

in het openbaar te verdedigen op donderdag 2 september 2021 om 12.00 uur

door

Ankie Reumkens 


\section{Promotor}

Prof. dr. A.A.M. Masclee

\section{Copromotores}

Dr. C.M. Bakker

Dr. S. Sanduleanu

\section{Beoordelingscommissie}

Prof. dr. L.P.S. Stassen (voorzitter)

Prof. dr. R.J.M.W. Rennenberg

Prof. dr. E.J. Schoon

Prof. dr. M.C.W. Spaander, Erasmus MC Rotterdam

Dr. L.M.G. Moons, UMC Utrecht 
Because dreams bring back all the memories

-Voor mijn opa- 



\section{CONTENTS}

Chapter 1 General introduction 9

$\begin{array}{lll}\text { PART I } & \text { QUALITY OF COLONOSCOPY }\end{array}$

Chapter 2 Epidemiological, clinical and endoscopic aspects of colorectal 29 neuroendocrine neoplasms: a population-based study in the Netherlands

Chapter 3 Improving bowel preparation quality: is a personalized smartphone application the answer?

PART II SAFETY: POST-COLONOSCOPY COMPLICATIONS

Chapter 4 Post-colonoscopy complications: a systematic review, 73 time trends, and meta-analysis of population-based studies

Chapter 5 Electrolyte disturbances after bowel preparation for colonoscopy: $\quad 99$ a systematic review and meta-analysis

Chapter 6 Post-colonoscopy mortality: bowel preparation to blame?

Chapter 7 Prevalence of hypokalemia before and after bowel preparation for colonoscopy - in high risk patients

Chapter 8 Safety of low-volume PEG bowel cleansing preparation

for colonoscopy: identifying patients at risk for hypokalemia

Chapter 9 General discussion

ADDENDUM

Summary

Samenvatting

Impact paragraph

193

List of publications

201

Curriculum Vitae

207

Dankwoord 


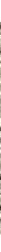




\section{CHAPTER 1}

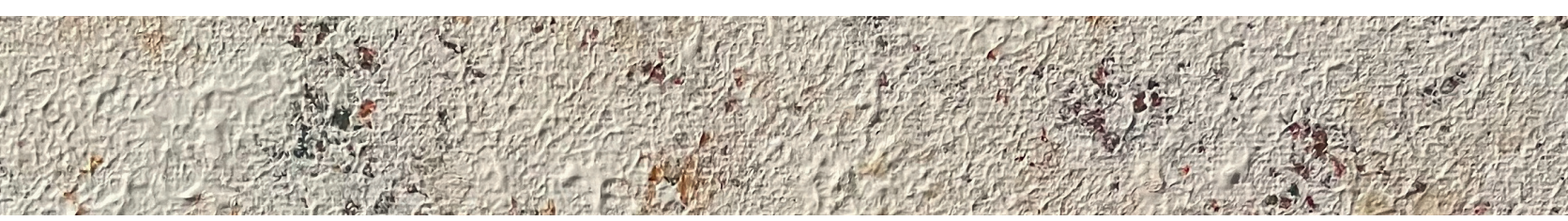

GENERAL INTRODUCTION 
CHAPTER 1 


\section{GENERAL INTRODUCTION}

Colonoscopy is one of the most commonly performed invasive procedures in gastrointestinal endoscopy. For these procedures high patient safety is, unarguably, a prerequisite. The variation in physicians 'performance of colonoscopy is still considerable and requires further attention. The introduction of nationwide large population based colorectal cancer (CRC) screening programs requires high quality and safety standards for colonoscopy procedures. ${ }^{1-4}$

The European Society of Gastrointestinal Endoscopy (ESGE) and United European Gastroenterology (UEG) presented a short list of seven key performance measures for lower gastrointestinal endoscopy. ${ }^{4}$ These seven items are shown in Table 1.1. The terms Quality and Safety of colonoscopy are also the main topics of this thesis (Table 1.1). The American Society of Gastrointestinal Endoscopy (ASGE) included also this seven items in a summary of 15 proposed quality indicators for colonoscopy. ${ }^{5}$

Table 1.1 Key performance measures for lower gastrointestinal endoscopy.

\begin{tabular}{|c|c|c|c|c|}
\hline No & Performance measure & Term & Included & Chapter \\
\hline 1 & $\begin{array}{l}\text { Rate of adequate bowel preparation } \\
\text { (minimum standard 90\%) }\end{array}$ & Quality and safety & This thesis & Chapter 3 \\
\hline 2 & $\begin{array}{l}\text { Cecal intubation rate } \\
\text { (minimum standard 90\%) }\end{array}$ & Quality & & \\
\hline 3 & $\begin{array}{l}\text { Adenoma detection rate } \\
\text { (minimum standard 25\%) }\end{array}$ & Quality & This thesis & Chapter 3 \\
\hline 4 & $\begin{array}{l}\text { Appropriate polypectomy technique } \\
\text { (minimum standard 80\%) }\end{array}$ & Quality and safety & & \\
\hline 5 & $\begin{array}{l}\text { Complication rate } \\
\text { (minimum standard not set) }\end{array}$ & Safety & This thesis & $\begin{array}{l}\text { Chapter } 4,5,6,7 \\
\text { and } 8\end{array}$ \\
\hline 6 & $\begin{array}{l}\text { Patient experience } \\
\text { (minimum standard not set) }\end{array}$ & Quality & This thesis & Chapter 3 \\
\hline 7 & $\begin{array}{l}\text { Appropriate post-polypectomy } \\
\text { surveillance recommendations } \\
\text { (minimum standard not set) }\end{array}$ & Quality and safety & & \\
\hline
\end{tabular}




\section{QUALITY OF COLONOSCOPY}

Colonoscopy is considered the golden standard in diagnosing premalignant lesions and colorectal carcinoma (CRC). Bowel cleansing is an inseparable part of colonoscopy and should be adequate to optimize visualization of the entire colonic mucosa during colonoscopy. Bowel preparation is a burdensome procedure for patients, involving diet modifications and laxative use based on subject's needs.

Ideally, bowel cleansing should clear the complete colon of all solid material and mucus and cause no damage to the colonic mucosa. The safety and efficacy of the colonoscopy are related to the quality of the pre-investigational bowel preparation. Inadequate preparation could lead to missed lesions and result in an increased number of interval CRC. ${ }^{6,7}$

\section{BOWEL CLEANSING PREPARATIONS}

Several bowel cleansing preparations are currently available: the high-volume regimens ( $(\geq 3 \mathrm{~L})$ polyethylene glycol $(\mathrm{PEG})$ and the low-volume regimens as $\mathrm{NaP}$, sodium picosulphate with magnesium citrate (SPMC) and low-volume PEG. ${ }^{8}$

High-volume PEG solutions can cause discomfort, due to unpleasant smell, taste or occurrence of gastrointestinal symptoms, i.e. cramping and bloating. Low volume solutions result in lower prevalences of these side effects. Therefore low volume solutions are increasingly used in many endoscopy units. NaP is known to cause electrolyte disorders in frail patients. ${ }^{9}$ Unlike NaP, SPMC and low-volume PEG solutions provide efficient bowel preparation with only minimal adverse effects. Among the low-volume PEG solutions, a commonly used solution is $2 \mathrm{~L}$ polyethylene glycol with ascorbic acid (PEG-asc) as additive ${ }^{10,11}$ for its more pleasant taste and low risk for side-effects.

\section{Low-volume bowel cleansing preparations}

The most commonly used bowel cleansing agents in the Netherlands are low-volume bowel cleansing preparations, namely: 
1. Low-volume PEG

Low-volume PEG bowel cleansing preparations have been developed to improve patient compliance. The addition of ascorbic acid to low-volume PEG (PEG-asc) has helped to reduce the volume of the preparation to $2 \mathrm{~L}$. Ascorbic acid remains in the colon, because it is not absorbed, employing its osmotic effect, synergistically with PEG. ${ }^{12,13}$ Each liter of PEG + Asc (Moviprep ${ }^{\circledR}$, Norgine, Harefield, United Kingdom) contains $100 \mathrm{~g}$ macrogol 3350, $7.5 \mathrm{~g}$ sodium sulfate, $2.7 \mathrm{~g}$ sodium chloride, $1 \mathrm{~g}$ potassium chloride, $4.7 \mathrm{~g}$ ascorbic acid, $5.9 \mathrm{~g}$ sodium ascorbate, and lemon flavoring. ${ }^{14}$

Recently, a 1 L low-volume PEG-asc solution has been introduced (Plenvu ${ }^{\circledR}$, Norgine, Harefield, United Kingdom) to improve patients' experience in bowel preparation for colonoscopy by reducing the total volume to be consumed. ${ }^{15} \mathrm{Plenvu}^{\circledR}$ is created by increasing the content of ascorbate, which enhances the laxative effect, following the delivery of a smaller volume solution. Plenvu has shown high efficacy in RCTs, and is non-inferior compared to higher-volume solutions ${ }^{16,17}$, but can result in higher bowel cleansing effectiveness. ${ }^{15}$

\section{Sodium picosulfate with magnesium citrate (SPMC)}

SPMC is a low-volume bowel cleansing preparation. The two active ingredients are sodium picosulfate, a bisphenol derivative with chemical name 4,4'-(2-pyridinylmethylene)-bisphenol-bis (hydrogen sulphate)(ester) disodium salt, and light magnesium oxide together with anhydrous citric acid forming magnesium citrate in the gut. The laxative effect is exerted by combination of picosulfate, which after bacterial activation induces inhibition of water absorption and decreases gut transit time and second, by magnesium salt, the osmotically active agent.

Table 1.2 Boston Bowel Preparation Scale.

\begin{tabular}{ll}
\hline Score & Definition \\
\hline 0 & $\begin{array}{l}\text { Unprepared colon segment with mucosa not seen due to solid stool that cannot be cleared } \\
1\end{array}$ \\
$\begin{array}{l}\text { Portion of mucosa of the colon segment seen, but other areas of the colon segment not well seen } \\
\text { due to staining, residual stool and/or opaque liquid }\end{array}$ \\
$\begin{array}{l}\text { Minor amount of residual staining, small fragments of stool and/or opaque liquid, but mucosa of } \\
\text { colon segment seen well }\end{array}$ \\
$\begin{array}{l}\text { Entire mucosa of colon segment seen well with no residual staining, small fragments of stool or } \\
\text { opaque liquid }\end{array}$
\end{tabular}




\section{BOSTON BOWEL PREPARATION SCALE}

The Boston Bowel Preparation Scale (BBPS) is a bowel preparation rating scale that relies on the summation of three individual colonic segment scores for the right, transverse and left colon (Table 1.2). It indicates the degree of bowel visualization. Total BBPS scores have been associated with the clinical outcomes (polyp and adenoma detection rates, surveillance advice, colonoscope insertion and withdrawal times). The BBPS is a validated and reliable instrument for assessing bowel preparation during colonoscopy. ${ }^{18,19}$ The score ranges from 0 to 9 as maximum.

The quality of the bowel preparation is not only dependent on the type of laxative, bus also relies on the laxative schedule and patient satisfaction. Previous studies have evaluated interventions such as strict dietary restrictions (e.g. low-fiber diet vs. clear liquid diet), methods of purgative administration (e.g. single dose vs. split dose), variations in time intervals between bowel preparation and start of the colonoscopy, and in appointment waiting time. ${ }^{20-22}$ Literature data show that inadequate information given pre-colonoscopy ${ }^{23}$, unsedated colonoscopies ${ }^{24}$ and long waiting times ${ }^{25}$ could negatively affect patient satisfaction. Moreover, patient satisfaction is inherently correlated to the patient's compliance to physician-recommended tests or in this case, bowel cleansing schedules. Unsatisfactory colonoscopy experiences could, subsequently, discourage surveillance or adherence to repeat screening colonoscopies.

Up to now, little is known on the effect of the type of patient information and education on the quality of bowel preparation. Numerous strategies to improve bowel preparation have been developed and studied. Most of these strategies aim to inform the patient more extensively about the bowel preparation procedure, remind the patient when action is needed during the days prior to colonoscopy (i.e. start of diet modifications or intake of purgatives) or do both. Several of these strategies, including visual aids, educational videos and SMS reminders, have shown to improve bowel preparation scores when compared to regular instructions. ${ }^{26}$

Current colonoscopy preparation guidelines recommend to provide patients with both verbal and written instructions and acknowledge the added value of educational booklets. ${ }^{27,28} \mathrm{~A}$ new method to inform and instruct patients includes a smartphone application. In 2017, it was reported that $93 \%$ of Dutch adults are in possession of a 
smartphone. Highest density of smartphones was found in younger age groups, but $90 \%$ of people aged $\geq 55$ years have access to a smartphone. ${ }^{29}$ Since it is very common for patients to have a smartphone, there is potential in using this modern technology to improve bowel preparation for colonoscopy.

\section{RECOGNITION OF COLORECTAL NEUROENDOCRINE NEOPLASMS: ESSENTIAL FOR HIGH-QUALITY PERFORMANCE PROCEDURES}

Neuroendocrine neoplasms (NENs) comprise a group of rare tumors arising from cells of the nervous and endocrine system. The annual incidence of all NENs is reported as 6.98 per 100,000 inhabitants owing to the increased diagnosis of early-stage disease and possibly stage migration. ${ }^{30}$ Although, NENs can develop in most organs, the gastrointestinal tract is the most common origin. Thus far, colorectal NENs have not received as much attention as neuroendocrine tumors at other sites.

Recently, the World Health Organization (WHO) has released the last NENclassification update, including two classes of epithelial NENs, namely welldifferentiated and poorly differentiated ${ }^{31}$ (Table 1.3).

First, the well-differentiated group is referred to as NET and is subdivided based on proliferation assessed by mitotic count and Ki-67 index, into a) well-differentiated NET G1 (Ki-67 <2\%, mitotic index $<2 / 10$ high power fields (HPF)) b) well-differentiated NET G2 (Ki67 3-20\%, mitotic index 2-20/10 HPF) and c) well-differentiated NET G3 (Ki-67 $>20 \%$, mitotic index $>20 / 10 \mathrm{HPF}) .{ }^{32}$ Second, the poorly differentiated group is referred to as NEC and exists of two separate morphologic types: a) small cell carcinoma (SCNEC) and b) large cell carcinoma (LCNEC) (Ki67 >20\%, mitotic index >20/10 HPF). ${ }^{33}$ 
Table 1.3 ENETS/WHO nomenclature and classification of NENs arising in the gastrointestinal tract.

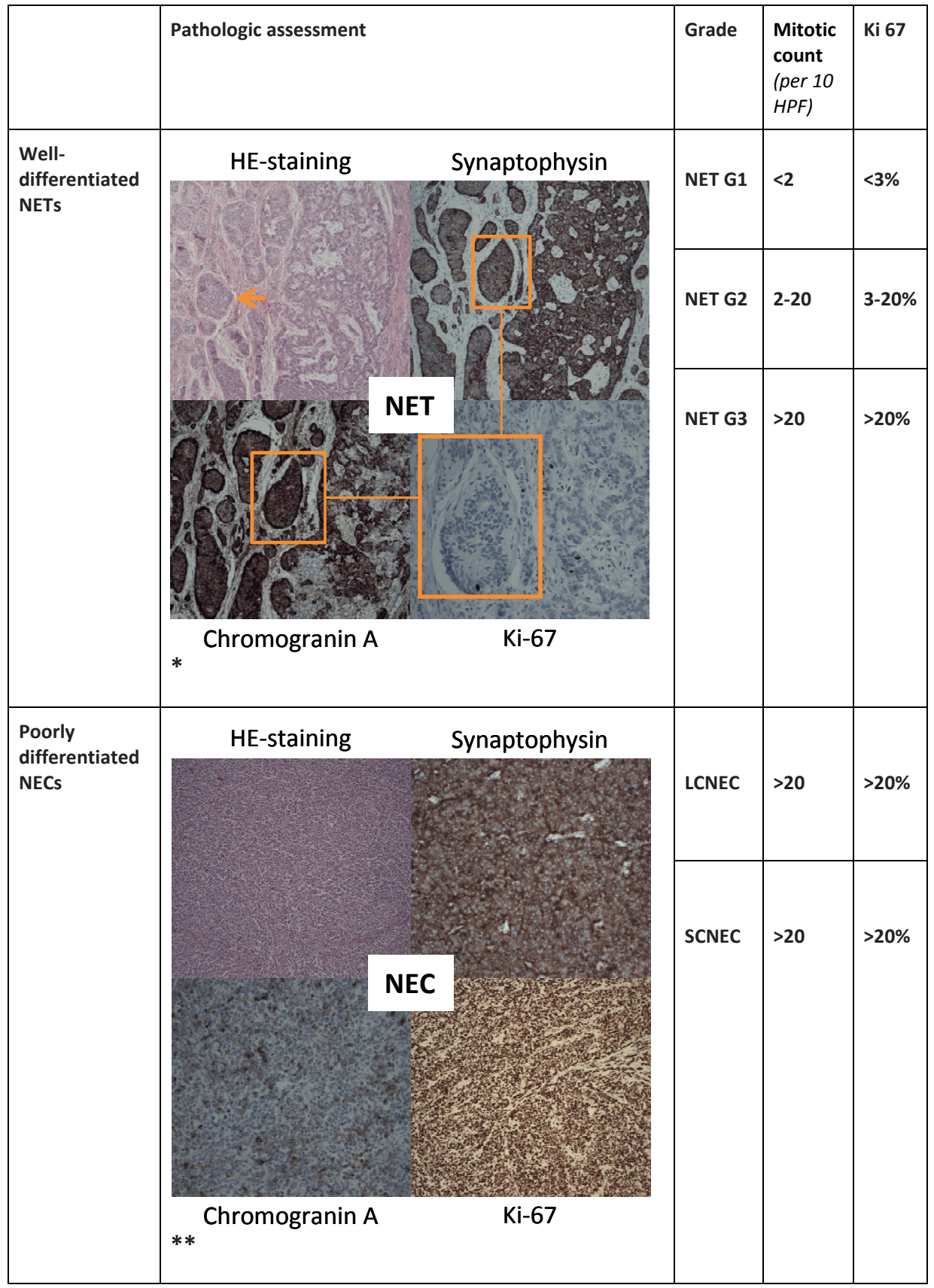

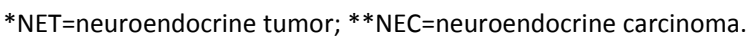


Because of intensified colorectal cancer (CRC) screening and large-scale surveillance colonoscopy programs, colorectal NENs are being increasingly detected. As a result of these programs, colorectal NENs could be diagnosed at earlier stages and thereby lead to improved survival. Therefore, endoscopists should be aware of the characteristics of NEN and they should be able to recognize NENs during colonoscopy. Recently a 10-fold increase in the age-adjusted incidence of rectal NENs has been observed. ${ }^{34}$ In the past, biopsy results were needed before diagnosis of a rectal NET was suspected. Nowadays, presence of rectal NENs is already suspected based on their endoscopic appearance and endoscopic resection can be performed at the index procedure. Rectal NETs typically appear as small yellowish (lipoma-like) sessile polyps. In rectal NETs $>1 \mathrm{~cm}$, often a depressed central area is shown. While recognition and classification (i.e. Paris, Kudo system) of adenomatous polyps by endoscopists has become common practice, recognition of NET is still poor with room for improvement. Endoscopic training programmes should include NET recognition modules, but more links to existing guidelines and more images to improve recognition of NET lesions are required. $^{35}$

\section{DIAGNOSIS AND TREATMENT OF NENS}

\section{COLON}

Mostly, colonic NENs are diagnosed at colonoscopy or at biopsy. Well-differentiated colonic NETs are rare and outnumbered by poorly differentiated colonic NECs. ${ }^{35}$ In addition, a 68DOTATOC-PET-CT should be performed to complete staging of these tumors. Endoscopic resection of proximal colonic NENs is rarely performed; surgical resection is still being considered as first and main therapy in case of localised disease. ${ }^{36}$ Up to $85 \%$ of patients have metastases at the time of colonic NEN diagnosis and therefore systemic chemotherapy is the most used treatment regimen. ${ }^{37}$

\section{RECTUM}

Mostly, rectal well-differentiated NETs are diagnosed during endoscopy. In the past, biopsies were needed to suspect the diagnosis. Nowadays, NETs can be suspected based on their typical appearances at endoscopy. Distinguishing NETs from other lesions is important, to allow careful planning of resection. After recognition during 
the first, initial procedure, a plan for endoscopic resection can be made. It is important to perform this resection radically, because local resection of a small rectal well-differentiated NET is considered as final, definite treatment. The therapeutic options to remove these tumors are increasing and include snare polypectomy, endoscopic mucosal resection (EMR), endoscopic submucosal dissection (ESD), capassisted EMR, transanal endoscopic microsurgery (TEM) and transanal minimally invasive surgery (TAMIS) or total mesorectal excision (TME). The exact role of these techniques in all grades and stages of rectal NETs remains to be determined. ${ }^{36}$ In recent guidelines, no attention is given to the performance of endoscopists in recognizing NETs. Education of endoscopists in recognition of NENs is an important goal. $^{35}$

\section{SAFETY OF COLONOSCOPY}

Colonoscopy is an invasive procedure, associated with risks and complications. Postcolonoscopy complications include perforation, bleeding, post-polypectomy syndrome, sedation-related complications (i.e. cardiopulmonary disorders), bowel preparation related complications (i.e. electrolyte disorders) and mortality. In general endoscopy practice, the proportion of post-colonoscopy complications varies widely. $^{32-55}$ The American Society for Gastrointestinal Endoscopy (ASGE) and the American College of Gastroenterology (ACG) Task Force on Quality in Endoscopy recommend that the post-polypectomy bleeding rate and post-colonoscopy perforation should be $\leq 1$ per 100 and $\leq 1$ per 500 colonoscopies respectively and $\leq 1 / 1,000$ for post-colonoscopy perforation in screening colonoscopies. ${ }^{38,39}$

\section{PERFORATION}

In diagnostic procedures, perforations can occur by mechanical damage of the colonic wall or by excessive air insufflation. Therapeutic interventions during colonoscopy that involve dilatation or electrocoagulation, increase the risk for perforations. ${ }^{40}$

\section{BLEEDING}

Bleeding can occur immediately after a polypectomy procedure due to damaging a blood vessel or to inadequate cauterization of a blood vessel. In delayed bleeding, the 
bleeding can be caused by mechanical stress on the cautery-induced ulcer that can lead to damage of the underlying vessel, by the extension of a thermal necrosis zone, or by restarting anticoagulation therapy. Therefore, small, non-pedunculated polyps are removed by cold snaring, without cautery. This may lead to a reduction in the risk to develop late bleeding. ${ }^{41}$ Small bleedings after polypectomy that are adequately managed during the procedure are not considered as a complication. Bleedings that occur up to 2 weeks after the procedure and bleedings presenting afterwards through visible blood loss or melena, requiring transfusion, surgery or further endoscopic therapy are defined as post-polypectomy bleedings and are also considered as a complication of colonoscopy. ${ }^{42}$

\section{HYPOKALEMIA}

High safety is a prerequisite for colonoscopy and largely represented by the safety of bowel preparations based on PEG. The development of bowel preparations based on PEG allow a high flow of liquids to clean the bowel without generating significant electrolyte and fluid shifts. ${ }^{43,44}$ Especially, PEG bowel preparations have been shown to successfully minimize the loss of electrolytes including potassium, since they are isotonic and contain an adequate supplementation of electrolytes. ${ }^{45}$ Therefore, they are widely recommended as preferred regimen for healthy patients and patients with comorbidities as renal or cardiovascular diseases. ${ }^{46}$ Non-PEG regimens, such as NaP are considered to result in higher rates of electrolyte disturbances or dehydration, requiring special precautions. ${ }^{47}$ Nevertheless, previous studies have shown that PEGbased bowel preparation can lead to hypokalemia, especially in hospitalized, elderly patients. ${ }^{48}$

Hypokalemia can increase the risk for ventricular arrhythmias and sudden cardiac death by an imbalance in resting membrane potential difference, depolarization and cellular hyperpolarity. Mostly, hypokalemia remains asymptomatic due to mild alterations. ${ }^{8,49,50}$ However, larger alterations could lead not only to symptoms such as fatigue, muscle weakness and constipation but also to life-threating respiratory complications and cardiac arrhythmias. ${ }^{8,49}$ Hypokalemia in general is defined as a potassium value $<3.5 \mathrm{mmol} / \mathrm{L}$. Severe hypokalemia is defined as a potassium value $<2.5 \mathrm{mmol} / \mathrm{L}$ and moderate hypokalemia as <3.0 mmol/L. Between 3.6 and $5.0 \mathrm{mmol} / \mathrm{L}$ serum potassium levels are considered to be in the normal range. Hypokalemia is especially a risk factor in patients with a pre-existing vulnerable 
cardiac status (i.e. a medical history of arrhythmias, congestive heart failure and/or digoxin use), since these patients are at higher risk to develop cardia arrhythmias. ${ }^{51}$

\section{MORTALITY}

Mortality is defined as a post-colonoscopy complication, when a patient deceases within 30 days post-colonoscopy. Fortunately, deaths resulting from colonoscopyrelated complications are rare, but can occur ${ }^{52,53}$. The mortality rates reported in the literature range from $0.007-0.07 \%{ }^{54}$ 


\section{AIMS AND OUTLINES OF THIS THESIS}

In this thesis, our aim was to investigate in more detail two aspects of quality of colonoscopy. The first aspect is related to recognizing a rare colorectal disorder: colorectal neuroendocrine neoplasms. This was done by focusing on epidemiology, clinical, endoscopic and histopathologic features of colorectal neuroendocrine neoplasms in a unique cohort of colorectal neoplasm. The second aspect is related to use and validation of a personalized smartphone application to optimize bowel cleansing.

In the second part of the thesis we focus on safety: post-colonoscopy complications, especially bowel cleansing related electrolyte disorders with focus on hypokalemia.

\section{QUALITY: COLORECTAL NEUROENDOCRINE NEOPLASMS \& IMPROVING BOWEL PREPARATION}

In the first part of this thesis we focus on two aspects related to QUALITY of colonoscopy: the recognition of colorectal neuroendocrine neoplasms (Chapter 2) and improving quality of bowel preparation (Chapter 3 ). Accurate diagnosis is a critical first step to optimize clinical outcomes and to reach high quality colonoscopy standards. Up to now, endoscopic appearance of neuroendocrine neoplasms has only been described in case reports and has not systematically been examined in population-based studies, related to tumor grade and tumor site. In Chapter 2 our aim is to describe endoscopic appearance, the prevalence, and survival of colorectal NENs. Since adequate bowel preparation is essential for optimal visualization of the entire colonic mucosa, we aimed to compare a personalized smartphone application in addition to verbal instructions and printed written instructions for bowel preparation in improving bowel preparation quality (Chapter $\mathbf{3}$ ).

\section{SAFETY: POST-COLONOSCOPY COMPLICATIONS}

In the second part (Chapters 4-8) of this thesis we focus on monitoring and reporting of post-colonoscopy complications in routine endoscopic practice. Chapter 4 is an overview of the current literature of post-colonoscopy complications, i.e. perforations, bleeding and mortality. In Chapter 5, we systematically review the current literature on electrolyte disturbances after several bowel preparations for colonoscopy, as post-colonoscopy complications. Chapter 6 describes two cases of severe post-colonoscopy hypokalemia with fatal outcome due to hypokalemia after 
bowel cleansing with PEG-asc. This prompted us to explore in more detail the magnitude of hypokalemia and risk factors for hypokalemia associated with lowvolume polyethylene glycol bowel preparation in hospitalized patients and patients receiving diuretics, described in Chapter 7. In this high-risk population, we report a relative high prevalence of hypokalemia after bowel cleansing, prompting us to perform a prospective study in a non-selected colonoscopy cohort to identify patients at risk of developing hypokalemia before and after bowel cleansing with low-volume polyethylene glycol with ascorbic acid (PEG-asc) (Chapter 8).

Finally, in Chapter 9 we discuss the main findings of this thesis and their potential implications for colonoscopy practice. Furthermore, we put these findings into perspective and define important clinical and research questions on quality and safety of colonoscopy in the coming years. 


\section{REFERENCES}

1. Kaminski MF, Thomas-Gibson S, Bugajski M, et al. Performance measures for lower gastrointestinal endoscopy: a European Society of Gastrointestinal Endoscopy (ESGE) Quality Improvement Initiative. Endoscopy 2017;49:378-397.

2. Rex DK, Bond JH, Winawer S, et al. Quality in the technical performance of colonoscopy and the continuous quality improvement process for colonoscopy: recommendations of the U.S. Multi-Society Task Force on Colorectal Cancer. Am J Gastroenterol 2002;97:1296-1308.

3. Minoli G, Meucci G, Prada A, et al. Quality assurance and colonoscopy. Endoscopy 1999;31:522-527.

4. Kaminski MF, Thomas-Gibson S, Bugajski M, et al. Performance measures for lower gastrointestinal endoscopy: a European Society of Gastrointestinal Endoscopy (ESGE) quality improvement initiative. United European Gastroenterol J 2017;5:309-334.

5. Rex DK, Schoenfeld PS, Cohen J, et al. Quality indicators for colonoscopy. Gastrointest Endosc 2015; 81:31-53.

6. Chokshi RV, Hovis CE, Hollander T, et al. Prevalence of missed adenomas in patients with inadequate bowel preparation on screening colonoscopy. Gastrointest Endosc 2012;75:1197-1203.

7. le Clercq CM, Bouwens MW, Rondagh EJ, et al. Postcolonoscopy colorectal cancers are preventable: a population-based study. Gut 2014;63:957-963.

8. Tan JJ, Tjandra JJ. Which is the optimal bowel preparation for colonoscopy - a meta-analysis. Colorectal Dis 2006;8:247-258.

9. Ainley EJ, Winwood PJ, Begley JP. Measurement of serum electrolytes and phosphate after sodium phosphate colonoscopy bowel preparation: an evaluation. Dig Dis Sci 2005;50:1319-1323.

10. Aoun E, Abdul-Baki H, Azar C, et al. A randomized single-blind trial of split-dose PEG-electrolyte solution without dietary restriction compared with whole dose PEG-electrolyte solution with dietary restriction for colonoscopy preparation. Gastrointest Endosc 2005;62:213-218.

11. Jansen SV, Goedhard JG, Winkens B, et al. Preparation before colonoscopy: a randomized controlled trial comparing different regimes. Eur J Gastroenterol Hepatol 2011;23:897-902.

12. Fujita I, Akagi Y, Hirano J, et al. Distinct mechanisms of transport of ascorbic acid and dehydroascorbic acid in intestinal epithelial cells (IEC-6). Res Commun Mol Pathol Pharmacol 2000;107:219-231.

13. Johnson DA, Barkun AN, Cohen LB, et al. Optimizing adequacy of bowel cleansing for colonoscopy: recommendations from the US multi-society task force on colorectal cancer. Gastroenterology 2014; 147:903-924.

14. Corporaal S, Kleibeuker JH, Koornstra JJ. Low-volume PEG plus ascorbic acid versus high-volume PEG as bowel preparation for colonoscopy. Scand J Gastroenterol 2010;45:1380-1386.

15. Maida M, Sinagra E, Morreale GC, et al. Effectiveness of very low-volume preparation for colonoscopy: A prospective, multicenter observational study. World J Gastroenterol 2020;26: 1950-1961

16. DeMicco MP, Clayton LB, Pilot J, et al. Novel $1 \mathrm{~L}$ polyethylene glycol-based bowel preparation NER1006 for overall and right-sided colon cleansing: a randomized controlled phase 3 trial versus trisulfate. Gastrointest Endosc 2018;87:677-687.e673.

17. Bisschops R, Manning J, Clayton LB, et al. Colon cleansing efficacy and safety with 1 L NER1006 versus 2 L polyethylene glycol + ascorbate: a randomized phase 3 trial. Endoscopy 2019;51:60-72.

18. Calderwood $\mathrm{AH}$, Jacobson BC. Comprehensive validation of the Boston Bowel Preparation Scale. Gastrointest Endosc 2010;72:686-692.

19. Calderwood AH, Schroy PC, 3rd, Lieberman DA, et al. Boston Bowel Preparation Scale scores provide a standardized definition of adequate for describing bowel cleanliness. Gastrointest Endosc 2014;80: 269-276. 
20. Chang CW, Shih SC, Wang HY, et al. Meta-analysis: The effect of patient education on bowel preparation for colonoscopy. Endosc Int Open 2015;3:E646-652.

21. Park JS, Sohn Cl, Hwang SJ et al. Quality and effect of single dose versus split dose of polyethylene glycol bowel preparation for early-morning colonoscopy. Endoscopy 2007;39:616-619.

22. Gimeno-Garcia AZ, de la Barreda Heuser R, Reygosa C, et al. Impact of a 1-day versus 3-day lowresidue diet on bowel cleansing quality before colonoscopy: a randomized controlled trial. Endoscopy 2019;51(7):628-636.

23. Luck A, Pearson S, Maddern G, et al. Effects of video information on precolonoscopy anxiety and knowledge: a randomised trial. Lancet (London, England) 1999;354:2032-2035.

24. McQuaid KR, Laine L. A systematic review and meta-analysis of randomized, controlled trials of moderate sedation for routine endoscopic procedures. Gastrointest Endosc 2008;67:910-923.

25. Armstrong D, Barkun AN, Chen $\mathrm{Y}$, et al. Access to specialist gastroenterology care in Canada: the Practice Audit in Gastroenterology (PAGE) Wait Times Program. Can J Gastroenterol 2008;22:155-160.

26. Liu Z, Zhang MM, Li YY, et al. Enhanced education for bowel preparation before colonoscopy: A stateof-the-art review. J Dig Dis 2017;18:84-91.

27. Committee ASoP, Saltzman JR, Cash BD, et al. Bowel preparation before colonoscopy. Gastrointest Endosc 2015;81:781-794.

28. Hassan C, Bretthauer M, Kaminski MF, et al. Bowel preparation for colonoscopy: European Society of Gastrointestinal Endoscopy (ESGE) guideline. Endoscopy 2013;45:142-150.

29. Deloitte. 2017 Global Mobile Consumer Survey: The Netherlands. In; 2017.

30. Vecchio R, Ferrara M, Mosca F, et al. Lipomas of the large bowel. Eur J Surg 1996;162:915-919.

31. Kim JY, Hong SM, Ro JY. Recent updates on grading and classification of neuroendocrine tumors. Ann Diagn Pathol 2017;29:11-16.

32. Bosman FT CFHH, Theise ND. WHO classification of tumours of the digestive system. 4th ed. Lyon: IARC Press, 2010.

33. Rindi G, Klimstra DS, Abedi-Ardekani B, et al. A common classification framework for neuroendocrine neoplasms: an International Agency for Research on Cancer (IARC) and World Health Organization (WHO) expert consensus proposal. Mod Pathol 2018;31:1770-1786.

34. Basuroy R, Haji A, Ramage JK, et al. Review article: the investigation and management of rectal neuroendocrine tumours. Aliment Pharmacol Ther 2016;44:332-345.

35. Ramage JK, Valle JW, Nieveen van Dijkum EJM, et al. Colorectal Neuroendocrine Neoplasms: Areas of Unmet Need. Neuroendocrinology 2019;108:45-53.

36. Ramage JK, De Herder WW, Delle Fave G, et al. ENETS Consensus Guidelines Update for Colorectal Neuroendocrine Neoplasms. Neuroendocrinology 2016;103:139-143.

37. Garcia-Carbonero R, Sorbye H, Baudin E, et al. ENETS Consensus Guidelines for High-Grade Gastroenteropancreatic Neuroendocrine Tumors and Neuroendocrine Carcinomas. Neuroendocrinology 2016;103:186-194.

38. Rex DK, Petrini JL, Baron TH, et al. Quality indicators for colonoscopy. Am J Gastroenterol 2006;101: 873-885.

39. Rex DK, Schoenfeld PS, Cohen J, et al. Quality indicators for colonoscopy. Am J Gastroenterol 2015; 110:72-90.

40. Panteris V, Haringsma J, Kuipers EJ. Colonoscopy perforation rate, mechanisms and outcome: from diagnostic to therapeutic colonoscopy. Endoscopy 2009;41:941-951.

41. Fisher DA, Maple JT, Ben-Menachem T, et al. Complications of colonoscopy. Gastrointest Endosc 2011;74:745-752.

42. Paraskeva KD, Paspatis GA. Management of bleeding and perforation after colonoscopy. Expert Rev Gastroenterol Hepatol 2014;8:963-972. 
43. Hassan C, Condorelli G, Repici A. Bowel preparation for colonoscopy and hypokalemia: at the heart of the problem! Gastrointest Endosc 2017;86:680-683.

44. Fordtran JS, Hofmann AF. Seventy Years of Polyethylene Glycols in Gastroenterology: The Journey of PEG 4000 and 3350 From Nonabsorbable Marker to Colonoscopy Preparation to Osmotic Laxative. Gastroenterology 2017;152:675-680.

45. Thomas G, Brozinsky S, Isenberg JI. Patient acceptance and effectiveness of a balanced lavage solution (Golytely) versus the standard preparation for colonoscopy. Gastroenterology 1982;82:435-437.

46. Johnson DA, Barkun AN, Cohen LB, et al. Optimizing adequacy of bowel cleansing for colonoscopy: recommendations from the U.S. multi-society task force on colorectal cancer. Gastrointest Endosc 2014;80:543-562.

47. Hassan C, East J, Radaelli F, et al. Bowel preparation for colonoscopy: European Society of Gastrointestinal Endoscopy (ESGE) Guideline - Update 2019. Endoscopy 2019;51:775-794.

48. Ho JM, Juurlink DN, Cavalcanti RB. Hypokalemia following polyethylene glycol-based bowel preparation for colonoscopy in older hospitalized patients with significant comorbidities. Ann Pharmacother 2010;44:466-470.

49. Hoorn EJ, Tuut MK, Hoorntje SJ, et al. Dutch guideline for the management of electrolyte disorders-2012 revision. Neth J Med 2013;71:153-165.

50. Cohn JN, Kowey PR, Whelton PK, et al. New guidelines for potassium replacement in clinical practice: a contemporary review by the National Council on Potassium in Clinical Practice. Arch Intern Med 2000;160:2429-2436.

51. Nilsson E, Gasparini A, Arnlov J, et al. Incidence and determinants of hyperkalemia and hypokalemia in a large healthcare system. Int J Cardiol 2017;245:277-284.

52. Singh $\mathrm{H}$, Penfold RB, DeCoster $\mathrm{C}$, et al. Colonoscopy and its complications across a Canadian regional health authority. Gastrointest Endosc 2009;69:665-671.

53. Sewitch MJ, Jiang M, Joseph L, et al. Rate of serious complications of colonoscopy in Quebec. Can J Gastroenterol 2012;26:611-613.

54. Levy I, Gralnek IM. Complications of diagnostic colonoscopy, upper endoscopy, and enteroscopy. Best Pract Res Clin Gastroenterol 2016;30:705-718. 


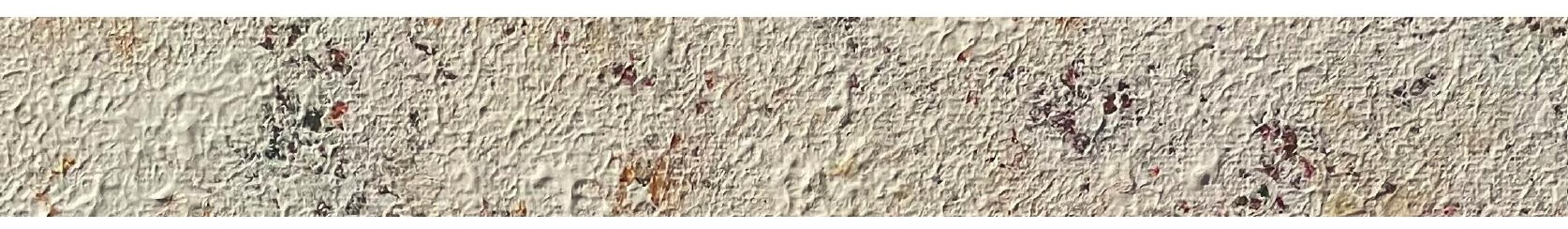




\section{PART I}

\section{QUALITY OF COLONOSCOPY}




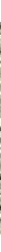




\section{CHAPTER 2}

EPIDEMIOLOGICAL, CLINICAL AND ENDOSCOPIC

CHARACTERISTICS OF COLORECTAL

NEUROENDOCRINE NEOPLASMS:

A POPULATION-BASED STUDY IN THE NETHERLANDS

A. Reumkens, P. Sastrowijoto, H.I. Grabsch, D. Goudkade, C.M.C. le Clercq, C.M. Bakker, E.T.P. Keulen, R.J.J. de Ridder, W.W. de Herder, B. Winkens,

S. Sanduleanu, J.de Vos-Geelen, A.A.M. Masclee 


\section{ABSTRACT}

\section{Background and study aims}

Neuroendocrine neoplasms (NEN) account for a small number of colorectal neoplasms. Endoscopic detection is essential for diagnosis, treatment and follow-up. Little is known about incidence of NENs in colonoscopy populations, and relationship between clinical, endoscopic and histopathology features. We evaluated epidemiology, endoscopic and clinical characteristics of colorectal NENs in a population-based cohort.

\section{Patients and methods}

Medical records of NEN cases were cross-linked with the national pathology database from January 2001 to December 2015, in the South Limburg county, the Netherlands, covering four endoscopy units. Senior pathologists reviewed and classified NENs using WHO $5^{\text {th }}$ edition (2019) guidelines.

\section{Results}

The number of colorectal NEN diagnoses was stable over time with 0.6 NEN per 1,000 colonoscopies. A total of 85 patients with NEN were detected: 65 neuroendocrine tumors (NETs) and 20 poorly differentiated neuroendocrine carcinomas (NECs). Rectal NETs were usually small sessile/submucosal lesions with yellowish (lipoma-like) colour. Colonic NETs were larger sessile/submucosal lesions with darker colour compared to background. Colorectal NECs presented as large, dark coloured lesions with ulcerated/necrotizing areas.

\section{Conclusions}

Our population-based data point to a stable and low incidence of 0.6 NEN per 1,000 colonoscopies in the Netherlands. Rectal NETs mainly present as small sessile yellowish lesions. Colonic NETs present as larger and darker lesions than background mucosa and NECs as darker lesions than background with ulceration/ necrosis. Standardized endoscopic characterization of colorectal NENs is necessary to improve recognition of these lesions and provide a basis for evidence-based treatment and surveillance recommendations. 


\section{INTRODUCTION}

Neuroendocrine neoplasms (NENs) comprise a rare group of morphologically and biologically heterogeneous malignant tumors. ${ }^{1}$ The 2010 and $20195^{\text {th }}$ edition World Health Organization (WHO) classification of gastrointestinal tumors subdivide neuroendocrine neoplasma (NENs) into well-differentiated neuroendocrine tumours (NETs), which are subclassified as grade (G) 1-3 NETs based on their Ki67 index (Table 2.1), and poorly differentiated neuroendocrine carcinomas (NECs), which are subclassified as small cell neuroendocrine carcinoma (SCNEC) or large cell neuroendocrine carcinoma (LCNEC). ${ }^{2}$

Colorectal NENs are classified according to primary site, e.g. colon or rectum, in relationship to their different natural history. ${ }^{3}$ Rectal NENs are mostly small and generally G1 and G2 NETs, while colonic NENs are often larger and poorly differentiated (NECs) showing a more aggressive behavior. ${ }^{4}$

Previous population-based studies indicate that NENs account for less than $1 \%$ of all colorectal tumors. ${ }^{5,6}$ The incidence of NENs in the general population is rising. ${ }^{7}$ The vast majority of colorectal NENs is asymptomatic and is found incidentally at colonoscopy. ${ }^{8}$ With the implementation of population-based colorectal cancer (CRC) screening programmes, the incidence of colorectal NENs has increased from 0.4 per 1,000 colonoscopies to 0.6 per 1,000 colonoscopies. $^{9-11}$ Rectal NETs diagnosed through CRC screen programmes or diagnosed at surveillance colonoscopies were detected at an earlier stage and were smaller in size compared to rectal NETs detected at non-screening colonoscopies. ${ }^{9,12}$ Early detection of colorectal NENs is important, since up to $20 \%$ of all NEN patients present with metastases at the time of diagnosis, depending on tumor site (colon>rectum) and tumor size. ${ }^{13,14}$ For early detection it is essential to describe and become familiar with the endoscopic appearance of colorectal NENs and apply for the most appropriate resection technique: endoscopic mucosal resection (EMR), endoscopic submucosal dissection (ESD) or surgery. ${ }^{3,15}$ Because of overall low prevalence, studies on endoscopic characteristics of NENs are limited ${ }^{16,17}$, and data based on the $5^{\text {th }}$ edition WHO classification are lacking. ${ }^{18}$

An accurate diagnosis is the critical first step to optimize clinical outcomes of patients with NENs. Endoscopic appearance has only been described in case reports ${ }^{19}$ and has not been examined in population-based studies or related to grade of differentiation (i.e. G1, G2, G3, based on Ki67). ${ }^{20}$ In this population-based cohort study our aim was 
to describe the incidence of colorectal NENs, clinical characteristics (including survival) and their endoscopic appearance.

\section{PATIENTS AND METHODS}

\section{STUDY POPULATION AND DESIGN}

This is a multicenter study involving three large-volume hospitals and one diagnostic center in the Netherlands. The three hospitals include one academic center (Maastricht University Medical Center+) and two regional hospitals (Zuyderland Medical Center Heerlen, previously Atrium Medical Center, and Zuyderland Medical Center Sittard-Geleen, previously Orbis Medical Center). The diagnostic center is located in Maastricht (Diagnostic Center Maastricht, Maastricht). All hospitals are located in the county of South Limburg in the Netherlands. The total county population consists of approximately 605,000 inhabitants and has a low net migration rate of 6-13 per 1000 inhabitants per year (according to the Central Office of Statistics, the Netherlands). The study was approved by the Institutional Review Board of the participating hospitals and was registered in The Netherlands Trial Registry NTR4844 and NTR3093.

Data from the national population-based pathology database (PALGA, IZV 2016-47) were obtained for all patients diagnosed with a colorectal neuroendocrine neoplasm (i.e. carcinoids, neuroendocrine tumors, and neuroendocrine carcinomas originating from colon or rectum) from January 1, 2001 to December 31, 2015. We cross-linked the national population-based pathology database (PALGA) and hospital records, including colonoscopy reports, to retrieve all unique cases of colorectal NENs diagnosed in the county between 2001 and 2015. Inclusion criteria were (1) diagnosis of colorectal NEN based on histology of material obtained during colonoscopy and (2) availability of follow up data. Patients who directly underwent surgery due to colonic obstruction and in whom a colonoscopy had not been performed, were excluded $(n=3)$ (Figure 2.1). Patients with colorectal metastases of other origin, or NEN other than colon or rectum (i.e. appendix, ileum, $n=63$ ), and external referrals (index colonoscopy performed in another hospital and incomplete survival data, $n=6$ ) were excluded. 
Table 2.1 GEP-NEN nomenclature, 5th ed. WHO classification (2019)

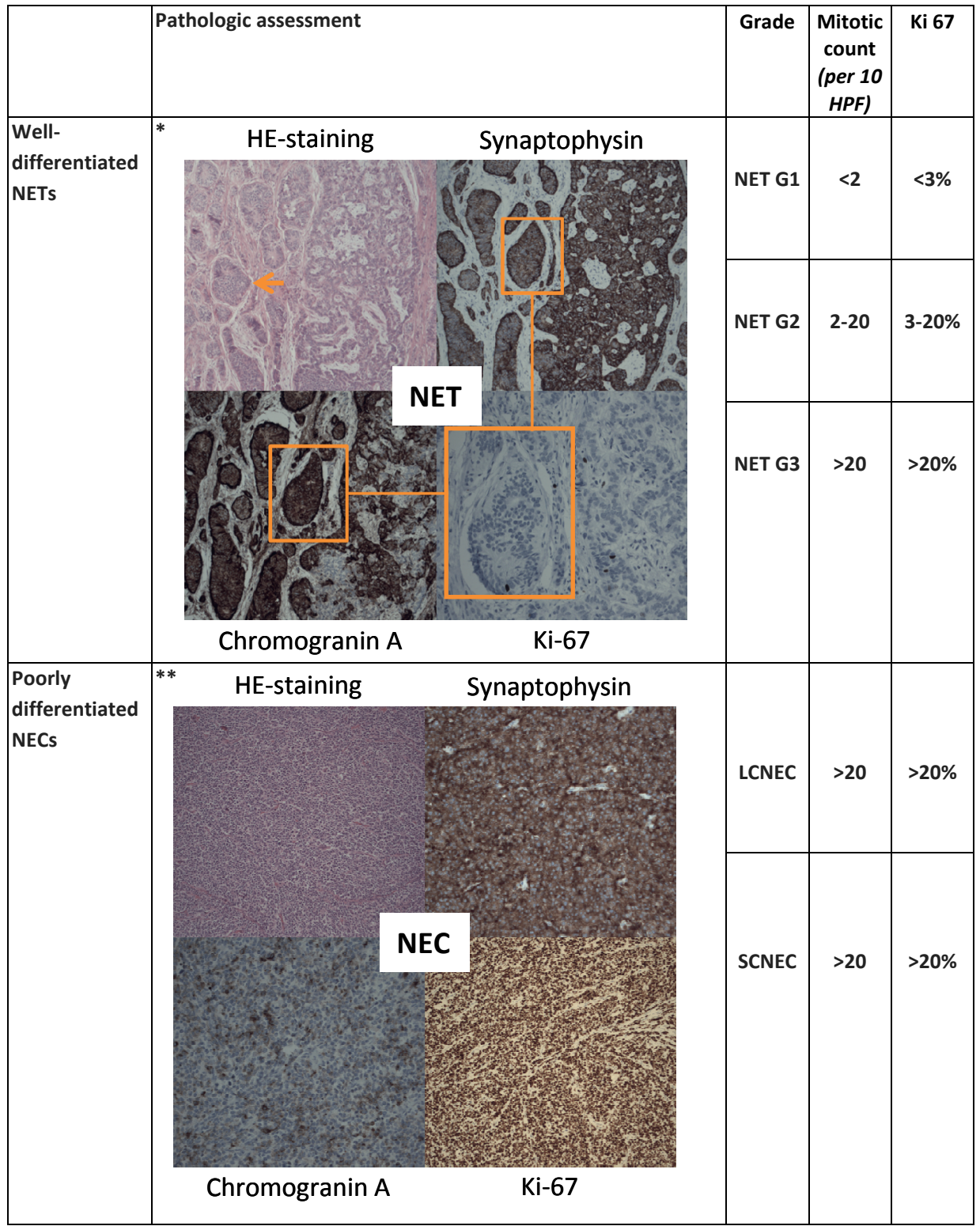

* NET G1 (based on Ki-67 and mitotic count). The HE-staining shows abnormal tumor cells, surrounded by normal cells. Both synaptophysin and chromogranin A staining visualize neuroendocrine tumor cells positive; ** NEC. The HE-staining shows no normal cells anymore. Synaptophysin and chromogranin A staining are both positive. The Ki-67 is in nearly all cells positive in this case. 
We collected clinical data from medical charts, endoscopy and histology reports, regarding macroscopic appearance of the NENs, tumor location, size, stage, treatment, surveillance and patient characteristics (gender, age, medication use, medical history, smoking status, family history, and comorbidities, survival).

\section{DEFINITIONS AND PATHOLOGIC ASSESSMENT}

We defined the colorectal NENs according to the $5^{\text {th }}$ edition WHO classification (2019) (Table 2.1). ${ }^{18}$ Second, the poorly differentiated group is designated as NEC and subdivided based on morphologic types as small cell carcinoma (SCNEC) or large cell carcinoma (LCNEC) (both Ki67 $>20 \%$ or mitotic index $>20 / 10 \mathrm{HPF}){ }^{1}$

Haematoxylin and eosin-stained slides were evaluated and scored by a consultant pathologist with a special interest in gastrointestinal pathology and a random set was reviewed by a second consultant pathologist. In addition, a synaptophysin staining was available to confirm neuroendocrine differentiation and a Ki67 stain to calculate the Ki-67 proliferation index. The colorectal neuroendocrine neoplasm grading after pathology review is used to generate the results.

\section{ENDOSCOPIC APPEARANCE}

As there was no endoscopic classification on NENs available, items of the Paris Classification $^{21}$, the BLI (Blue Light Imaging) Adenoma Serrated International Classification (BASIC) ${ }^{22}$, and the NBI (Narrow Band Imaging) International Colorectal Endoscopic (NICE) classification were used $^{23}$ to retrospectively describe NENs based on colonoscopy reports and the saved photo documentation of the endoscopic procedure. Lipoma-like lesions were defined as yellowish, submucosal lesions.

\section{STUDY ENDPOINTS AND STATISTICAL ANALYSIS}

Primary endpoints of this study were (1) epidemiological characteristics, (2) clinical and endoscopic characteristics of NENs. For survival analysis, time to event was calculated from the date of diagnosis to the time of death from any cause, based on of the Municipal Personal Records Database or censored at 20 April 2020. Numerical data are presented as mean \pm standard deviation (SD) and range or median with interquartile range (IQR). Differences in numerical variables between groups were assessed using independent-samples t-test or Mann-Whitney $U$ tests as appropriate, 
while chi square $\left(\mathrm{X}^{2}\right)$ or Fisher's exact tests were used for categorical variables. FisherFreeman-Halton were used for categorical variables with more than two categories.

Kaplan-Meier survival analysis was used to estimate overall survival (OS) of patients with G1 and G2 or G3 NENs. Survival distributions were compared using the log rank test and Cox regression analyses. Hazard ratios (HR) with $95 \%$ confidence interval $(\mathrm{Cl})$ and corresponding $p$-values were presented. P-values $\leq 0.05$ were considered statistically significant. Analyses were conducted using IBM SPSS Statistics for Windows version 26.0 (SPSS, IBM Corp., Armonk, NY, USA).

\section{RESULTS}

\section{EPIDEMIOLOGY}

Of the 147,577 colonoscopies performed in the period from January 2001 to December 2015 in the South Limburg county, we identified a total of 85 patients who had been diagnosed with a NEN (Figure 2.1). The total number of colonoscopies per year increased gradually over the 15-year during study period (Figure 2.2). The number of diagnosed NENs remained relatively stable with an average incidence of 0.6 NENs per 1,000 colonoscopies per year.

147,577 patients who underwent colonoscopy in South-Limburg, from 2001-2015

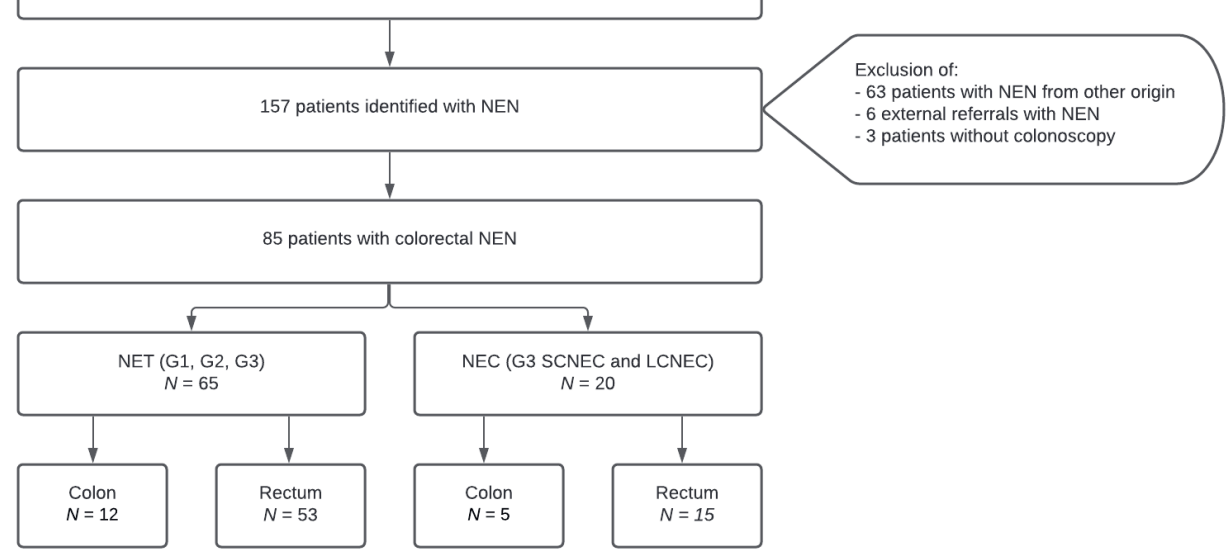

Figure 2.1 Study flowchart colorectal NEN. 


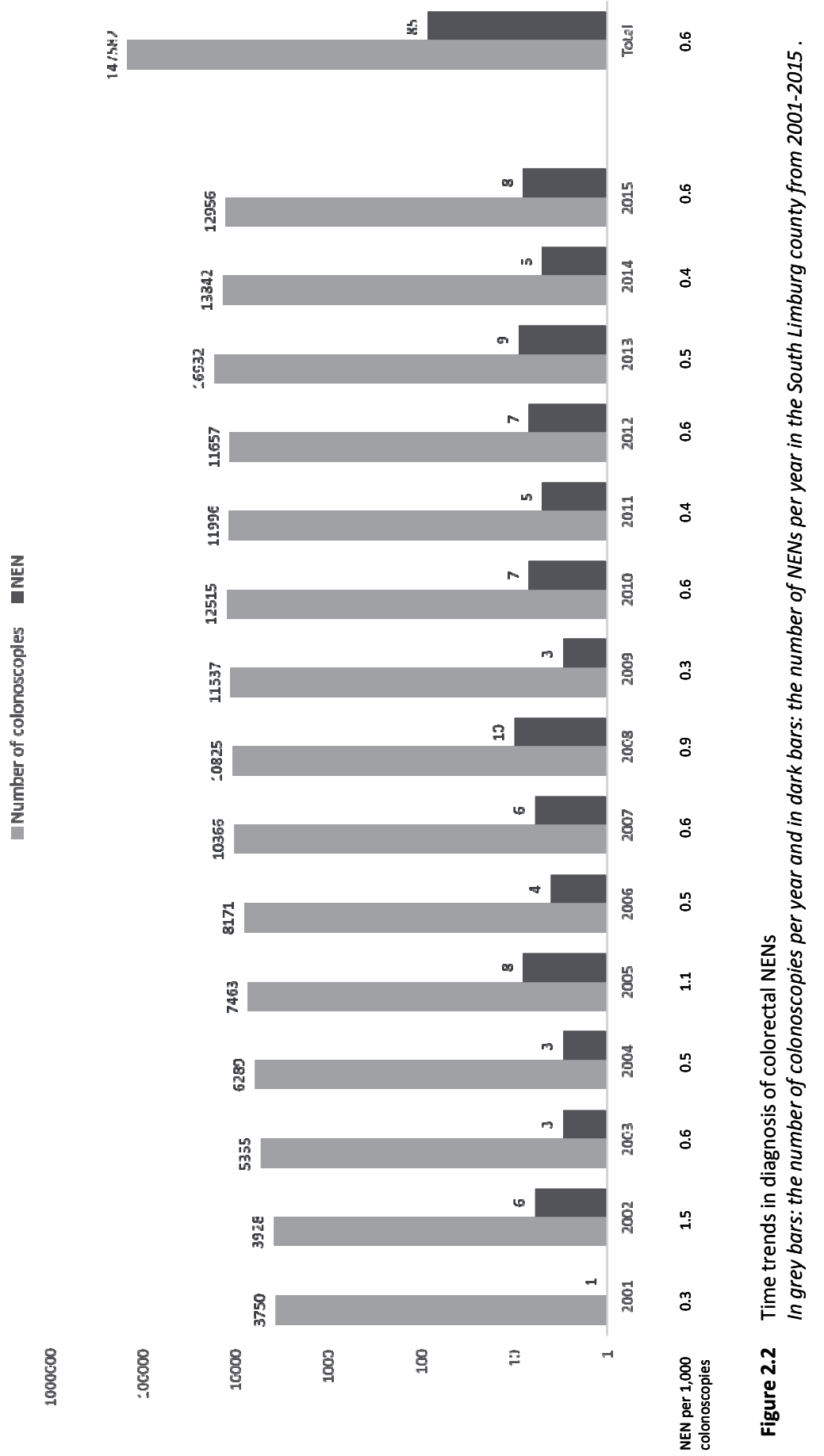




\section{CLINICAL FEATURES OF NEN PATIENTS}

The 85 patients ( 65 with NETs and 20 with NECs) had a mean age of $61.8 \pm 11.6$ years

(range: $33-86$ years) and $51.8 \%$ was male. In 17 patients (20\%) the NEN was localized in the colon, and 68 patients (80\%) had a rectal NEN. Of the 68 rectal NENs $66 \%$ $(n=45)$ were G1, $12 \%(n=8)$ G2, 0\% $(n=0)$ G3 NET, and $22 \%(n=15)$ NEC G3 after pathology review (Tables 2.2 and 2.3). Of the 17 colonic NENs, 65\% (n=11) were G1, $0 \%(n=0)$ G2, 6\% $(n=1)$ G3 NET, and 29\% ( $n=5)$ G3 NEC (Tables 2.2 and 2.3). Of the colonic NEC patients, $80 \%$ had gastrointestinal symptoms (i.e. hematochezia or changed stool habits) vs $100 \%$ of the rectal NEC patients (Table 2.3 ).

Table 2.2 Characteristics of NETs.

\begin{tabular}{|c|c|c|c|c|c|}
\hline & \multicolumn{4}{|c|}{ Tumor site } & \multirow{3}{*}{$p$-value } \\
\hline & \multicolumn{2}{|c|}{ Colon } & \multicolumn{2}{|c|}{ Rectum } & \\
\hline & $\mathrm{N}=12$ & $\%$ & $\mathrm{~N}=53$ & $\%$ & \\
\hline Age, mean (years) \pm SD (range) & \multicolumn{2}{|c|}{$62 \pm 12(39-79)$} & \multicolumn{2}{|c|}{$58 \pm 10(33-80)$} & 0.34 \\
\hline Gender, male & 7 & 58.3 & 25 & 47.2 & 0.54 \\
\hline NET grade & & & & & 0.089 \\
\hline Grade 1 & 11 & 91.7 & 45 & 84.9 & \\
\hline Grade 2 & 0 & 0 & 8 & 15.1 & \\
\hline Grade 3 & 1 & 8.3 & 0 & 0 & \\
\hline Indication for colonoscopy & & & & & 0.55 \\
\hline Symptoms & 9 & 75.0 & 41 & 77.4 & \\
\hline Screening & 1 & 8.3 & 1 & 1.9 & \\
\hline Surveillance & 2 & 16.7 & 11 & 20.8 & \\
\hline \multicolumn{6}{|l|}{ Tumor size } \\
\hline Median, IQR, $\mathrm{mm}$ & \multicolumn{2}{|c|}{$33(5-40)$} & \multicolumn{2}{|c|}{$6(3-9)$} & $0.006^{*}$ \\
\hline Category & & & & & $0.001 *$ \\
\hline$<1 \mathrm{~cm}$ & 4 & 33.3 & 41 & 77.4 & \\
\hline $1-2 \mathrm{~cm}$ & 0 & 0 & 9 & 17.0 & \\
\hline$>2 \mathrm{~cm}$ & 8 & 66 & 3 & 5.7 & \\
\hline \multicolumn{6}{|l|}{ Tumor site colon } \\
\hline Caecum & 10 & 83.3 & - & - & - \\
\hline Ascending & 0 & 0 & - & - & - \\
\hline Transverse & 0 & 0 & - & - & - \\
\hline Sigmoid & 2 & 16.7 & - & - & - \\
\hline \multicolumn{6}{|l|}{ Endoscopic features } \\
\hline \multicolumn{6}{|l|}{ Morphology } \\
\hline Submucosal/sessile lesion & 11 & 91.7 & 53 & 100 & 0.19 \\
\hline (Pseudo)depression or donut-shaped & 3 & 25.0 & 15 & 28.3 & 1.00 \\
\hline Regular surface & 9 & 75.0 & 51 & 96.2 & $0.040 *$ \\
\hline Vessels: prominent, yes & 4 & 80.0 & 23 & $23 / 24=95.8$ & 0.32 \\
\hline Lipoma-like & 2 & 16.7 & 45 & 84.9 & $<0.001^{*}$ \\
\hline Colour & & & & & $0.001^{*}$ \\
\hline Yellowish colour & 4 & 33.3 & 45 & 84.9 & \\
\hline Darker than background & 8 & 66.7 & 8 & 15.1 & \\
\hline \multicolumn{6}{|l|}{ Stage } \\
\hline Lymph node metastasis & 4 & 33.3 & 3 & 5.7 & $0.018^{*}$ \\
\hline Distant metastasis & 2 & 16.7 & 4 & 7.5 & 0.31 \\
\hline Total & 4 & 33.3 & 4 & 7.5 & $0.033^{*}$ \\
\hline
\end{tabular}


Table 2.3 Characteristics of NECs.

\begin{tabular}{|c|c|c|c|c|c|}
\hline & \multicolumn{4}{|c|}{ Tumor site } & \multirow{3}{*}{$p$-value } \\
\hline & \multicolumn{2}{|l|}{ Colon } & \multicolumn{2}{|c|}{ Rectum } & \\
\hline & $\mathrm{N}=5$ & $\%$ & $\mathrm{~N}=15$ & $\%$ & \\
\hline Age, mean (years) $\pm S D$ (range) & \multicolumn{2}{|c|}{$69 \pm 4(63-75)$} & \multicolumn{2}{|c|}{$72 \pm 10(53-86)$} & 0.54 \\
\hline Gender, male & 4 & 80.0 & 8 & 53.3 & 0.60 \\
\hline \multicolumn{6}{|l|}{ NEC } \\
\hline LCNEC & 3 & 60.0 & 9 & 60.0 & 1.00 \\
\hline SCNEC & 2 & 40.0 & 6 & 40.0 & 1.00 \\
\hline \multicolumn{6}{|l|}{ Indication for colonoscopy } \\
\hline Symptoms & 4 & 80.0 & 15 & 100 & 1.00 \\
\hline Screening & 0 & 0 & 0 & 0 & 1.00 \\
\hline Surveillance & 1 & 20.0 & 0 & 0 & 1.00 \\
\hline \multicolumn{6}{|l|}{ Tumor size } \\
\hline Median, IQR, mm & \multicolumn{2}{|c|}{$48(33-59)$} & \multicolumn{2}{|c|}{$50(30-80)$} & 0.44 \\
\hline \multicolumn{6}{|l|}{ Category } \\
\hline$<1 \mathrm{~cm}$ & 0 & 0 & 0 & 0 & 1.00 \\
\hline $1-2 \mathrm{~cm}$ & 0 & 0 & 1 & 6.7 & 1.00 \\
\hline$>2 \mathrm{~cm}$ & 5 & 100 & 14 & 93.3 & 1.00 \\
\hline \multicolumn{6}{|l|}{ Tumor site colon } \\
\hline Caecum & 2 & 40.0 & - & - & - \\
\hline Ascending & 1 & 20.0 & - & - & - \\
\hline Transverse & 1 & 20.0 & - & - & - \\
\hline Sigmoid & 1 & 20.0 & - & - & - \\
\hline \multicolumn{6}{|l|}{ Endoscopic features } \\
\hline \multicolumn{6}{|l|}{ Morphology } \\
\hline Submucosal lesion & $0 * *$ & 0 & $0 * *$ & 0 & \\
\hline (Pseudo)Depression & 4 & 80.0 & 13 & 86.7 & 1.00 \\
\hline Irregular surface & 4 & 80.0 & 13 & 86.7 & 1.00 \\
\hline Regular surface & 1 & 20.0 & 2 & 13.3 & \\
\hline Ulceration/necrosis & 4 & 80.0 & 13 & 86.7 & 1.00 \\
\hline Semi-circular & 3 & 60.0 & 5 & 33.3 & 0.35 \\
\hline Stenosis & 0 & 0 & 5 & 33.3 & 0.27 \\
\hline \multicolumn{6}{|l|}{ Colour } \\
\hline Yellowish colour & 0 & 0 & 0 & 0 & \\
\hline Darker than background & 5 & 100.0 & 15 & 100.0 & \\
\hline \multicolumn{6}{|l|}{ Stage } \\
\hline Lymph node metastasis & 1 & 20.0 & 3 & 20.0 & 1.00 \\
\hline Distant metastasis & 2 & 40.0 & 8 & 53.3 & 0.61 \\
\hline Total & 3 & 60.0 & 9 & 60.0 & 1.00 \\
\hline
\end{tabular}

\section{RECTAL VERSUS COLONIC NETS G1, G2 AND G3}

Macroscopically, NETs and NECs were different tumors (Figures 2.3-2.5 and Tables 2.2-2.3). The most common NET in the colon and rectum was $G 1$ (colon $91.7 \%$ and rectum $84.9 \%$ ), while G2 and G3 NENs were rare (Table 2.2). Colonic NETs were larger compared to rectal NETs (33 mm IQR 5-40, vs. $6 \mathrm{~mm}$ IQR 3-9) $(p=0.006)$. Rectal NETs were mostly sessile/submucosal tumors and (Figure 2.3) had more frequently a 
regular surface compared to colonic NETs (96.2 vs. 75.0\%, $p=0.040$ ) (Table 2.2), and a yellowish colour (84.9 vs. $33.3 \%, p=0.001)$ and were therefore more frequently described as lipoma-like ( $84.9 \%$ vs. $16.7 \%, p<0.001)$.

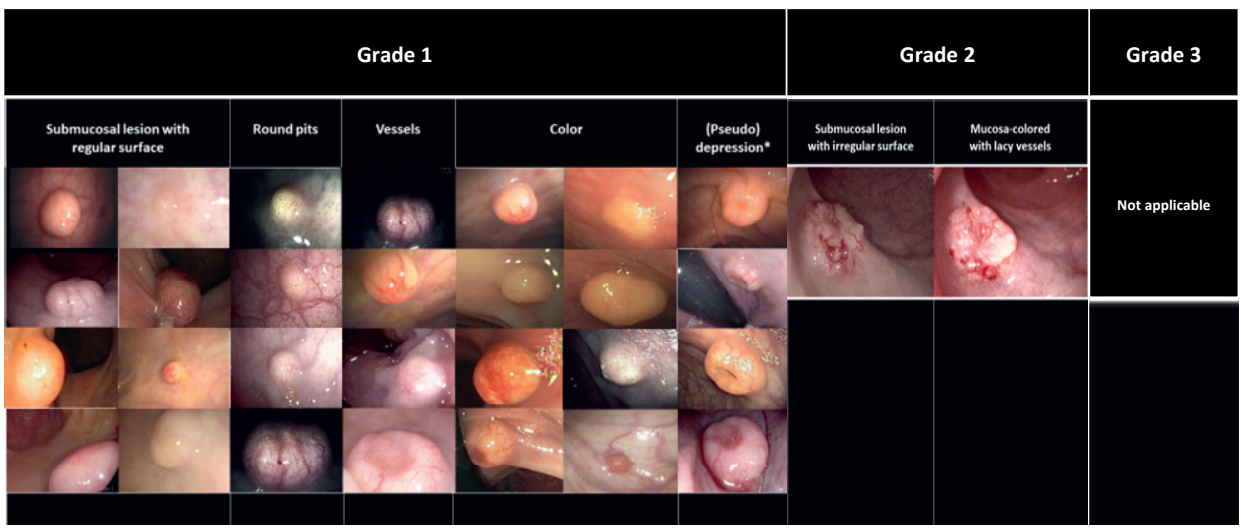

Figure 2.3 Macroscopy of rectal NETs. *Central (pseudo)depression is also described as donut-shaped.

Colonic NETs (Figure 2.4) were most frequently located in the cecum (83.3\%), 66\% were relatively large $(>2 \mathrm{~cm})$ sessile/submucosal lesions and were more frequently darker than background mucosa compared to rectal NETs (66.7 vs. $15.1 \%, p=0.001$ ) (Table 2.2). There were no significant differences in the presence of prominent vessels, (pseudo)depression, and pit pattern between rectal and colonic NEN (Table 2.2, Figure 2.3 and 2.4).

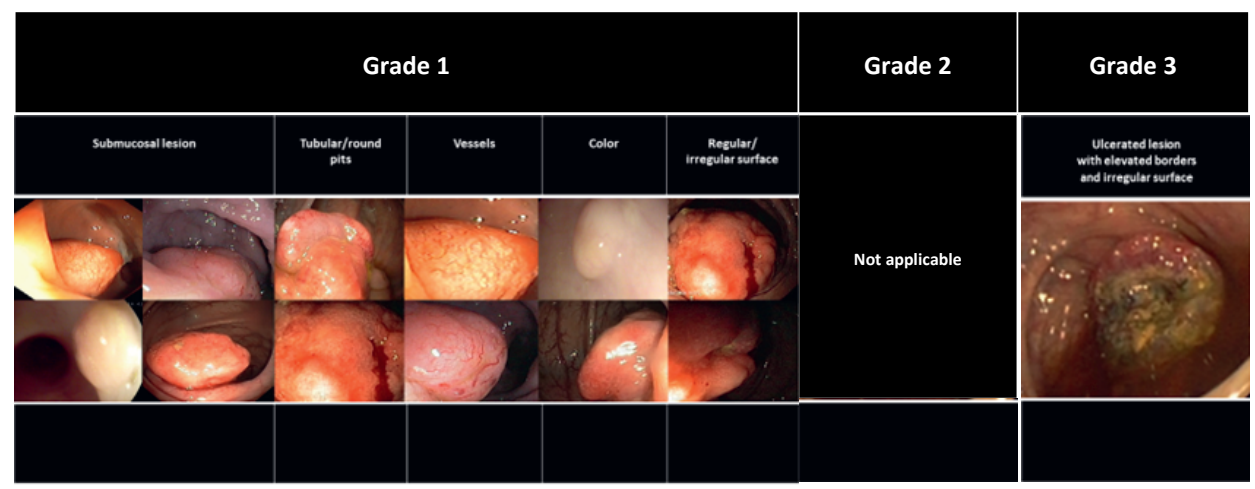

Figure 2.4 Macroscopy of colonic NETs. 
The percentage of locoregional lymph node metastases (N1) at diagnosis was higher in colonic NETs (33.3\%) vs. rectal NETs $(5.7 \%)(p=0.018)$. The majority of the rectal NETs was removed endoscopically (86.8\%) (Table 2.2 ), while the majority of the colonic NETs required surgery (58.3\%).

\section{RECTAL VERSUS COLONIC NECS}

NECs were endoscopically darker than background mucosa in $80 \%$ of the colonic and $60 \%$ of the rectal NECs (Table 2.3, Figure 2.5). The majority of the NECs was associated with ulceration or necrosis ( $80 \%$ in both the colon and rectum group). There was no statistically significant difference in tumor size for colonic and rectal NECs (48 mm IQR 33-59 vs $50 \mathrm{~mm}$ IQR $30-80 \mathrm{~mm}, p=0.44)$. Three (60\%) of the colonic NECs and 9 (60\%) of the rectal NECs were LCNECs (Table 2.3). Colorectal LCNECs and SNECS do not differ with respect to irregular surface, (pseudo)depression, ulceration, necrosis or colour (Figure 2.5).

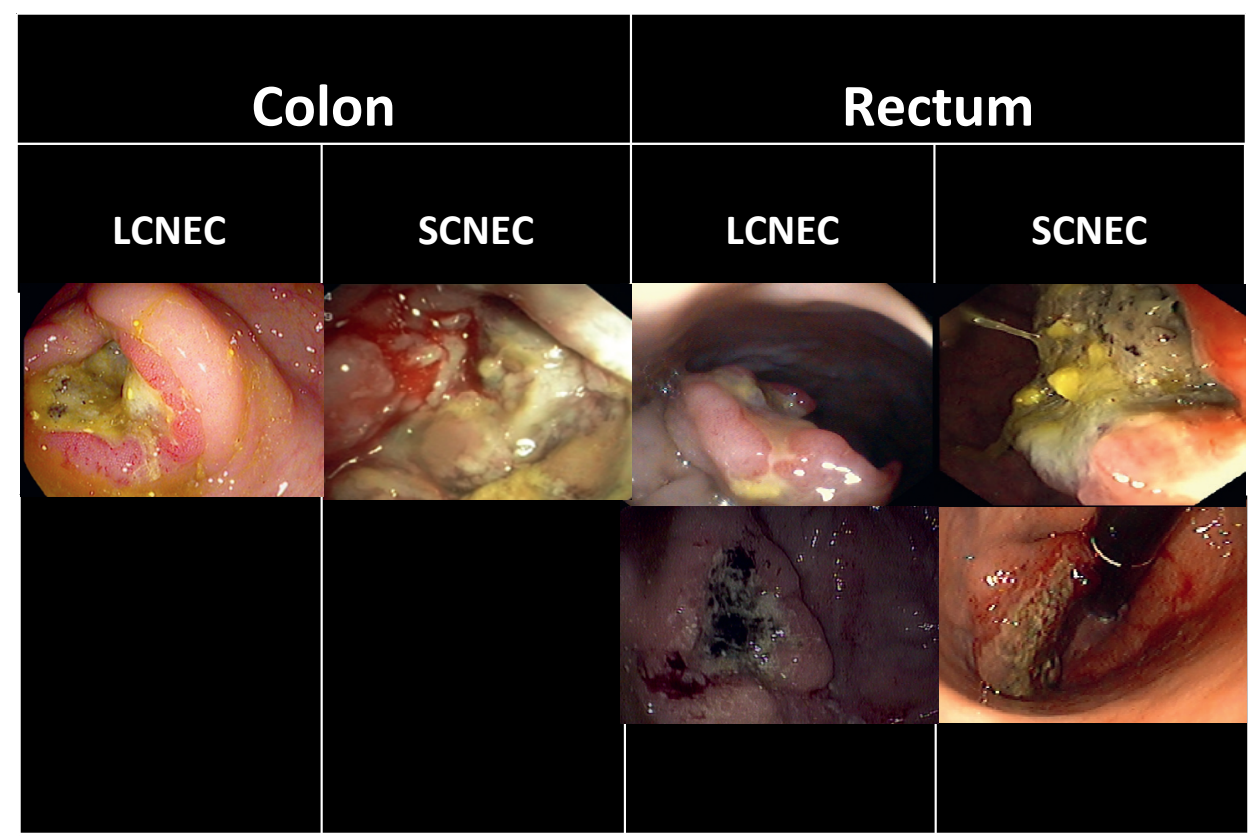

Figure 2.5 Macroscopy of colorectal NEC (LCNEC vs SCNEC). NECs are usually large in size, darker than background mucosa and associated with ulceration or necrosis. 


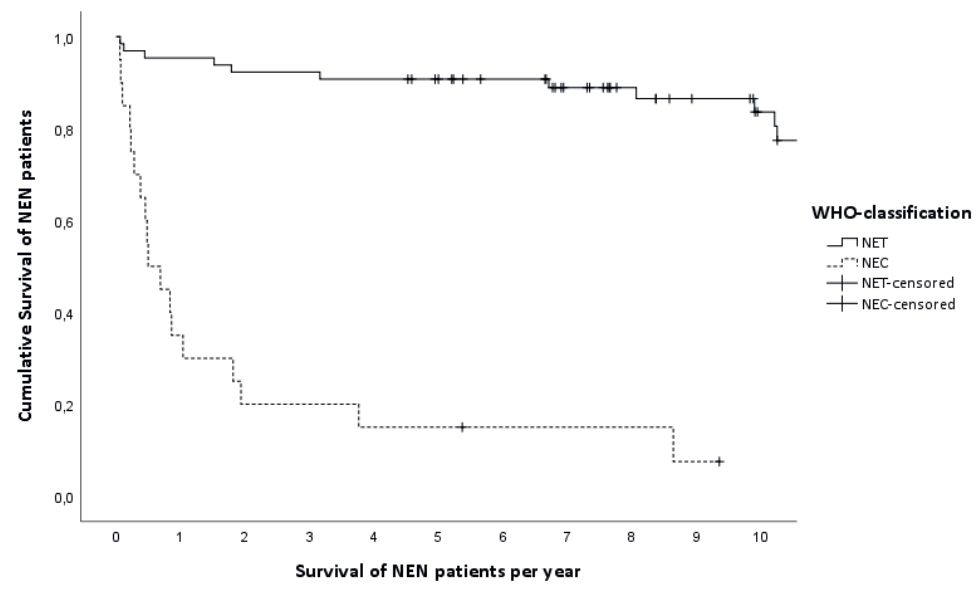

\begin{tabular}{|l|c|c|c|c|c|c|c|c|c|c|c|c|c|c|c|c|}
\hline & \multicolumn{10}{|c|}{ Year } \\
\hline No at risk & 0 & 1 & 2 & 3 & 4 & 5 & 6 & 7 & 8 & 9 & 10 & 11 & 12 & 13 & 14 & 15 \\
\hline NET & 65 & 62 & 60 & 59 & 59 & 59 & 58 & 58 & 57 & 56 & 54 & 53 & 52 & 52 & 52 & 52 \\
& & & & & & & & & & & & & & & & \\
\hline NEC & 20 & 7 & 4 & 4 & 3 & 3 & 2 & 2 & 2 & 1 & - & - & - & - & - & - \\
\hline
\end{tabular}

Figure 2.6 Survival of colorectal NET vs NEC patients, corrected for age and gender. Patients received treatment according to guidelines.

\section{SURVIVAL}

Median follow-up time was 7.0 (IQR 2.0-11.0) years. The median follow-up time of patient with G1, G2, or G3 NETs was 8.8 (IQR 5.9-11.5) years and for NEC patients 0.5 (IQR 0.3-1.4) years.

Of all NET G1, G2 and G3 patients 1-, 3-, and 5-year overall survival was 95, 91, and $91 \%$, and of NEC 1-, 3-, and 5-year overall survival was 35, 20, and 15\% respectively (Figure 2.6). With respect to location: of all colonic NET G1, G2 and G3 patients 1-, 3and 5-year overall survival was 83,83 and $83 \%$ respectively, and of rectal NET 98, 94 and $92 \%$ respectively $(p=0.47$ ). Overall survival rates for poorly differentiated NECs were similar with respect to tumor site (colon vs. rectum). 


\section{DISCUSSION}

Highly relevant findings in our population based study are that 1) the incidence of NENs is low and relatively stable and 2) an endoscopic signature is provided for colorectal NETs and NECs.

In a comprehensive data collection based on our clinical practice over the past 15 years, we characterized the endoscopic and histologic features of NETs and NECs according to the $5^{\text {th }}$ edition WHO classification. ${ }^{18}$ Rectal NETs present mostly as small sessile/submucosal yellowish (lipoma-like) lesions with regular surface. Colonic NETs present mostly as larger sessile lesions, with irregular surface in $25 \%$, prominent vessels, and more often darker (than background), than yellowish or lipoma-like colour. NECs present as darker (than background mucosa) larger lesions with ulcerative-necrotizing features, both for rectal and colonic NECs.

Based on reports from Asia and the United States, the number of detected colorectal NENs is rising, which is due to an increase in the number of colonoscopies. ${ }^{19,24}$ With an average of 0.6 NEN per 1,000 colonoscopies, the incidence of NENs is slightly higher compared to the study of Korse et al, which reported an incidence of 0.43 colorectal NENs per 1,000 colonoscopies $(0.33 / 1000$ for NETs and $0.10 / 1000$ for NECs), in the Netherlands in the period 2001-2010. ${ }^{25}$ The slightly higher incidence in our study may be related to the implementation of the CRC programme in the Netherlands that occurred after 2010. This is confirmed by data from the UK where implementation of the CRC screening programme has led to a higher ratio of identified NETs (0.6 per 1,000 colonoscopies) compared to data from the general UK population. ${ }^{11}$

Diagnosis and management of colorectal neuroendocrine neoplasms is challenging because of the low incidence, limited data on endoscopic appearance, on combined endoscopy and histopathology based diagnosis and optimal therapeutic approach. ${ }^{3,16,26}$ Missing a NEN can potentially result in worse outcome and should be prevented. The first step is, to create awareness by endoscopists in recognizing colorectal NENs during endoscopy. The second step is to adequately resect suspicious NEN lesions in the colon and rectum and thereby limit the metastatic risk. ${ }^{20,27}$ Metastatic risk has been associated with the tumor grade (Ki-67), presence of lymphovascular invasion and of a central depression in the lesion. ${ }^{13,28}$ Awareness by the endoscopist with recognition of these endoscopic lesions can result in early detection of well-differentiated NENs and radical endoscopic resections in a first or second attempt. ${ }^{32}$ Previous studies did not fully characterize the macroscopic 
appearances of NEN subtypes. ${ }^{17,29}$ Highly relevant is that rectal NETs are distinguishable from other polyps and tumors, based on their yellowish (lipoma-like) colour, sessile or submucosal appearance usually with a depressed central area when larger than $1 \mathrm{~cm} .{ }^{17}$ Relevant is also that colorectal NETs should be distinguished from lipomas. With reported prevalences of $0.2-4.4 \%^{30}$, colonic lipomas are characterized by an intact mucosa and the diagnosis is suggested based on the "pillow sign" (tumor indents when depressed using the biopsy forceps) or the "naked fat sign" with extrusion of yellowish fat after repeated biopsy. ${ }^{31,32}$ Vessel distribution appears to be similar to the surrounding mucosa. ${ }^{32}$ In contrast to lipomas, NETs have a more pronounced vessel pattern compared to the surrounding mucosa and the "pillow sign" and "naked fat sign" are lacking. Data on how often a lipoma-like lesion eventually appears to be a NEN are still lacking. All yellowish lesions in the rectum visualized during colonoscopy, (without the pillow and/or naked fat sign) should potentially be considered as NET and planned for resection. In contrast to smaller rectal NETs, colonic NETs are often larger than $2 \mathrm{~cm}$, and show less lipoma-like characteristics, as confirmed by our data. ${ }^{33}$

Colorectal NECs have macroscopic features that are quite different from NETs. NECs appear as large, darker than background-coloured mucosa, ulcerated or necrotic lesions and are therefore difficult to distinguish from colorectal cancers. Historically seen, tumor size has always been a main predictor for survival and metastatic patterns of NENs. ${ }^{4}$

Colonic NETs are more aggressive and have worse prognosis compared with rectal NETs, as was confirmed in our study. Survival of NETs is generally more favorable than NECs, because of their more slowly growing character compared to fast and aggressive tumor growth of NECs. ${ }^{34}$ Our population-based data confirm these findings and those of the previously reported survival data in the SEER Program. ${ }^{6}$

Even with early detection of NENs, metastasized disease can be present. In metastasized disease, treatment (surgical or systemic) may prolong survival. Therefore, it is highly relevant to detect these NENs at an early stage. As treatment, and thereby prognosis, of colonic and rectal NENs is different and depends on size, local extent, grade and stage ${ }^{29}$, optimal endoscopical and histological diagnosis is required. ${ }^{18}$ Surveillance recommendations after complete resection of neuroendocrine neoplasms vary across international guidelines ${ }^{3,26}$, probably due to inconsistencies in definitions and diagnosis and limitations in the available data. 
For those reasons European Neuroendocrine Tumor Society (ENET) members have started to develop a training program in NET recognition for endoscopists. ${ }^{35}$ In future studies, NENs have to be defined using WHO-terms, diagnosed using the WHOrecommended stains (i.e. synapthophysin), and mitotic count and the Ki-67 index should be determined. ${ }^{36,37}$

Strengths of our study are the regional population-based character with analysis of all colorectal NENs identified in our practices over a period of 15 years. We reviewed clinical and endoscopic features of NENs and graded them on histopathology according to the newest WHO-classification.

The current study has several limitations. First, despite this large colonoscopy database, the number of NETs examined in our study was small, and is in line with previous studies. NETs could have been missed or underreported during endoscopy, because of insufficient awareness of the endoscopist. Second, the CRC screening programme in the Netherlands has started in 2014, and only 2 years of screening were included in the 15 year study period. The period after 2015 was used to obtain adequate data for follow up. Third, during the second half of our study period high definition (HD) endoscopy was gradually implemented, so only a subset of photos was collected and stored at HD quality. Optimal HD photo and video documentation will help lead to more detailed description of endoscopic characteristics and can be used for training purposes.

Colorectal NENs should be described according to the most recent WHO-classification to assume uniform definitions and diagnosis. This will lead to further standardisation and help to improve management and uniform surveillance recommendations in the guidelines on colorectal NENs.

In conclusion, our population-based data point to relatively stable and low incidence of 0.6 NEN per 1,000 colonoscopies in the Netherlands. Rectal NETs mainly present as small sessile yellowish lesions. Colonic NETs present as larger and darker lesions than the background mucosa and NECs as darker lesions than the background with ulceration/ necrosis. Adequate management of NENs require training of endoscopists in recognition of specific features, followed by en-bloc resection and histological diagnosis. Training of the endoscopists in recognition of NENs using videos and e-learnings will provide the basis for appropriate endoscopic diagnosis and resection and for evidence-based surveillance recommendations. 


\section{REFERENCES}

1. Rindi G, Klimstra DS, Abedi-Ardekani B et al. A common classification framework for neuroendocrine neoplasms: an International Agency for Research on Cancer (IARC) and World Health Organization (WHO) expert consensus proposal. Mod Pathol 2018; 31: 1770-1786

2. Bosman FT CFHH TN. WHO classification of tumours of the digestive system. Lyon: IARC Press 2010; 4th ed:

3. Caplin M, Sundin A, Nillson O et al. ENETS Consensus Guidelines for the management of patients with digestive neuroendocrine neoplasms: colorectal neuroendocrine neoplasms. Neuroendocrinology 2012; 95: 88-97

4. Ramage JK, De Herder WW, Delle Fave G et al. ENETS Consensus Guidelines Update for Colorectal Neuroendocrine Neoplasms. Neuroendocrinology 2016; 103: 139-143

5. Leoncini $E$, Boffetta $P$, Shafir $M$ et al. Increased incidence trend of low-grade and high-grade neuroendocrine neoplasms. Endocrine 2017; 58: 368-379

6. Yao JC, Hassan M, Phan A et al. One hundred years after "carcinoid": epidemiology of and prognostic factors for neuroendocrine tumors in 35,825 cases in the United States. J Clin Oncol 2008; 26: 3063 3072

7. Fraenkel M, Kim M, Faggiano A et al. Incidence of gastroenteropancreatic neuroendocrine tumours: a systematic review of the literature. Endocr Relat Cancer 2014; 21: R153-163

8. Chung TP, Hunt SR. Carcinoid and neuroendocrine tumors of the colon and rectum. Clin Colon Rectal Surg 2006; 19: 45-48

9. Scherübl H. Rectal carcinoids are on the rise: early detection by screening endoscopy. Endoscopy 2009; 41: 162-165

10. Scherubl H, Kloppel G. [Rectal carcinoids on the rise - update]. Zeitschrift fur Gastroenterologie 2009; 47: 365-371

11. Basuroy R, O'Donnell CM, Srirajaskanthan R et al. Ileocolonic neuroendocrine tumours identified in the English bowel cancer screening programme. Colorectal disease : the official journal of the Association of Coloproctology of Great Britain and Ireland 2018; 20: 085-091

12. Derikx LA, Vierdag WM, Kievit $W$ et al. Is the prevalence of colonic neuroendocrine tumors increased in patients with inflammatory bowel disease? International journal of cancer Journal international du cancer 2016; 139: 535-542

13. Hofland J, Kaltsas G, de Herder WW. Advances in the Diagnosis and Management of WellDifferentiated Neuroendocrine Neoplasms. Endocr Rev 2020; 41: 371-403

14. Concors SJ, Sinnamon AJ, Folkert IW et al. Predictors of Metastases in Rectal Neuroendocrine Tumors: Results of a National Cohort Study. Diseases of the colon and rectum 2018; 61: 1372-1379

15. Shimizu T, Tanaka S, Haruma K et al. Growth characteristics of rectal carcinoid tumors. Oncology 2000; 59: 229-237

16. Shim KN, Yang SK, Myung SJ et al. Atypical endoscopic features of rectal carcinoids. Endoscopy 2004; 36: 313-316

17. Eggenberger JC. Carcinoid and other neuroendocrine tumors of the colon and rectum. Clin Colon Rectal Surg 2011; 24: 129-134

18. Nagtegaal ID, Odze RD, Klimstra D et al. The 2019 WHO classification of tumours of the digestive system. Histopathology 2020; 76: 182-188

19. Jung YS, Yun KE, Chang Y et al. Risk factors associated with rectal neuroendocrine tumors: a crosssectional study. Cancer epidemiology, biomarkers \& prevention : a publication of the American Association for Cancer Research, cosponsored by the American Society of Preventive Oncology 2014; 23: 1406-1413

20. O'Toole D, Kianmanesh R, Caplin M. ENETS 2016 Consensus Guidelines for the Management of Patients with Digestive Neuroendocrine Tumors: An Update. Neuroendocrinology 2016; 103: 117-118

21. [Anonymous]. Update on the paris classification of superficial neoplastic lesions in the digestive tract. Endoscopy 2005; 37: 570-578 
22. Bisschops R, Hassan C, Bhandari P et al. BASIC (BLI Adenoma Serrated International Classification) classification for colorectal polyp characterization with blue light imaging. Endoscopy 2018; 50: 211220

23. Patrun J, Okreša L, Iveković H et al. Diagnostic Accuracy of NICE Classification System for Optical Recognition of Predictive Morphology of Colorectal Polyps. Gastroenterol Res Pract 2018; 2018: 7531368

24. Taghavi S, Jayarajan SN, Powers BD et al. Examining rectal carcinoids in the era of screening colonoscopy: a surveillance, epidemiology, and end results analysis. Diseases of the colon and rectum 2013; 56: 952-959

25. Korse CM, Taal BG, van Velthuysen ML et al. Incidence and survival of neuroendocrine tumours in the Netherlands according to histological grade: experience of two decades of cancer registry. European journal of cancer (Oxford, England : 1990) 2013; 49: 1975-1983

26. Anthony LB, Strosberg JR, Klimstra DS et al. The NANETS consensus guidelines for the diagnosis and management of gastrointestinal neuroendocrine tumors (nets): well-differentiated nets of the distal colon and rectum. Pancreas 2010; 39: 767-774

27. Kuiper T, van Oijen MGH, van Velthuysen MF et al. Endoscopically removed rectal NETs: a nationwide cohort study. International journal of colorectal disease 2021; 36: 535-541

28. Konishi T, Watanabe T, Kishimoto $J$ et al. Prognosis and risk factors of metastasis in colorectal carcinoids: results of a nationwide registry over 15 years. Gut 2007; 56: 863-868

29. Hrabe J. Neuroendocrine Tumors of the Appendix, Colon, and Rectum. Surg Oncol Clin N Am 2020; 29: 267-279

30. Vecchio R, Ferrara M, Mosca F et al. Lipomas of the large bowel. Eur J Surg 1996; 162: 915-919

31. Law YY, Patel R, Cusick $M$ et al. A case of colonic intussusception and obstruction secondary to giant colonic lipoma. J Surg Case Rep 2020; 2020: rjaa429

32. Hsu-Heng Y. Colonic lipoma. Video Journal and Encyclopedia of GI Endoscopy 2014; 1: 661-662

33. Ford MM. Neuroendocrine Tumors of the Colon and Rectum. Diseases of the colon and rectum 2017; 60: 1018-1020

34. Arnold R. Endocrine tumours of the gastrointestinal tract. Introduction: definition, historical aspects, classification, staging, prognosis and therapeutic options. Best practice \& research Clinical gastroenterology 2005; 19: 491-505

35. Ramage JK, Valle JW, Nieveen van Dijkum EJM et al. Colorectal Neuroendocrine Neoplasms: Areas of Unmet Need. Neuroendocrinology 2019; 108: 45-53

36. Gao W, Liu SM, Lu HZ et al. [Analysis of clinicopathological features of intestinal neuroendocrine neoplasms]. Zhonghua zhong liu za zhi [Chinese journal of oncology] 2012; 34: 450-456

37. Wang AY, Ahmad NA. Rectal carcinoids. Current opinion in gastroenterology 2006; 22: 529-535 


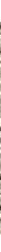




\section{CHAPTER 3}

\section{THE EFFECTS OF A PERSONALIZED SMARTPHONE APPLICATION ON BOWEL PREPARATION QUALITY: A RANDOMIZED CONTROLLED TRIAL}

Q.E.W. van der Zander, A. Reumkens, B. van de Valk, B. Winkens, A.A.M. Masclee, R.J.J. de Ridder JMIR Mhealth and Uhealth 2021 [Accepted] 


\section{ABSTRACT}

\section{Background}

Adequate bowel preparation is essential for visualization of the colonic mucosa during colonoscopy.

\section{Objectives}

Aim of this study was to compare instructions provided via a personalized smartphone application with regular written instructions for bowel preparation in improving bowel preparation quality, and to evaluate patient satisfaction concerning the bowel preparation procedure.

\section{Methods}

Eligible patients scheduled for an outpatient colonoscopy were randomized to the smartphone application or control group. Both groups received identical face-to-face education from a research physician including instructions about the colonoscopy procedure, diet restrictions, and intake of the laxative. In addition, the control group received written information, whereas the smartphone application group was instructed to use the smartphone application instead of the written information. All patients used bisacodyl and sodium picosulfate with magnesium citrate as laxative. Quality of bowel preparation was scored using the Boston Bowel Preparation Scale by blinded endoscopists. Patient satisfaction was measured by the patient satisfaction questionnaire-18 (PSQ-18).

\section{Results}

In total 87 patients participated in the smartphone application group and 86 in the control group. The mean total Boston bowel preparation scale was significantly higher in the smartphone application group $(8.3 \pm 0.9)$ compared to the control group (7.9 $\pm 1.2, p=0.03)$. The right colon showed a significantly higher bowel preparation score in the smartphone application group $(2.7 \pm 0.5$ vs. $2.5 \pm 0.6, p=0.04)$. General patient satisfaction was high for the smartphone application group $(4.4 \pm 0.7)$, but showed no significant difference compared to the control group $(4.3 \pm 0.8,0=0.32)$.

\section{Conclusions}

Our personalized smartphone application significantly improved bowel preparation quality, in particular in the right colon, but does not further improve patient satisfaction compared to patients receiving regular written instructions. 


\section{INTRODUCTION}

Colonoscopy is considered the gold standard in diagnosing colorectal pathology. The efficacy and safety of colonoscopy are related to the quality of the pre-investigational bowel preparation. Adequate bowel preparation is essential for optimal visualization of the colonic mucosa during colonoscopy. Inadequate bowel preparation is associated with the risk of missing clinically relevant lesions, procedural difficulties, prolonged procedural time, an increased number of interval colorectal carcinomas, and additional healthcare costs. ${ }^{1-6}$ Currently reported rates of inadequate bowel preparation range from $18-35 \%{ }^{1,7}$ leaving room for improvement.

Previous studies have evaluated various factors that can negatively affect bowel preparation such as dietary restrictions (low-fiber vs clear liquid diet), laxative administration (single vs split dose), inadequate information pre-colonoscopy, and long waiting times. ${ }^{8-12}$ In addition, bowel preparation quality depends on patient's tolerability to the laxative and patient satisfaction. Patient satisfaction is inherently correlated to patient's compliance with physician-recommended bowel preparation schedules.

Strategies to improve bowel preparation aim to inform patients more extensively about the preparation procedure and remind patients when action is needed (i.e. start of diet modifications and intake of the laxative). Several of these strategies, including visual aids, educational videos, and short message service (SMS) reminders, have provided better bowel preparation quality when compared with regular instructions. ${ }^{13}$ Current colonoscopy preparation guidelines recommend to provide patients with both verbal and written instructions and acknowledge the added value of providing educational booklets. ${ }^{14,15}$

A new method of informing and instructing patients is via a personalized smartphone application. In 2017, 93\% of all Dutch adults possessed a smartphone. The highest percentage of smartphone use was found in younger age groups, but $90 \%$ of people aged $\geq 55$ years had access to a smartphone. ${ }^{16}$ Therefore, there is potential in using this technology to improve bowel preparation quality for colonoscopy. This study aimed to investigate the quality of bowel preparation and patient satisfaction in patients using a newly developed, personalized smartphone application in addition to verbal instructions compared with regular verbal and written instructions. 


\section{METHODS}

\section{STUDY DESIGN}

This prospective, endoscopist-blinded, randomized controlled trial was conducted at the Maastricht University Medical Center+ (MUMC+), Maastricht, the Netherlands, from August 2018 to November 2019. The study was in accordance with the declaration of Helsinki ${ }^{17}$ as well as the General Data Protection Regulation. ${ }^{18}$ The Medical Ethical Review Committee of the Maastricht University Medical Center (MEC 16-4-141) approved the study, which is registered at ClinicalTrials.gov (NCT03677050).

\section{SUBJECTS}

Patients $\geq 18$ years, in the possession of a smartphone, and referred to the outpatient clinic for a colonoscopy screening visit by their general practitioner or by the Dutch colorectal cancer screening program, were eligible to participate. All included patients provided written informed consent.

\section{RANDOMIZATION AND GROUP DESCRIPTION}

At our institute, patient education occurs during a screening visit at the outpatient clinic 1-4 weeks before colonoscopy. During this visit, patients were randomly assigned to the smartphone application group or the control group using a computergenerated randomization list in a 1:1 sequence based on the order of inclusion. Patients from both groups received a hyperlink to an online educational video explaining the colonoscopy procedure. Patients in the control group received verbal and written information concerning the diet restrictions, the bowel preparation schedule and the laxative. Patients in the smartphone application group had to install the application on their Android or iOS smartphones which was accessible by a quick response code (Prepit ${ }^{\circledR}$, Ferring B.V., Hoofddorp, the Netherlands). Instead of the written instructions, patients in the smartphone application group received information and instructions via the smartphone application. The content of the information and instructions provided via the smartphone application was equal to the written instructions of the control group. However, the information was presented in a more visual way, i.e. providing pictograms of low-fiber food products and images of the desired stool consistency after ingestion of the laxative. Furthermore, the smartphone application provided the patients with personalized 
notifications about the steps of bowel preparation tailored to the exact colonoscopy date and time (Figure 3.1). It did not take extra time to provide the explanation via the smartphone application compared to the explanation given via the written instructions.

\begin{tabular}{|c|c|c|c|c|c|}
\hline Your colonoscopy appointment $\equiv$ & Educational material & & & Schedule & $\equiv$ \\
\hline & Why this app and who is it for? & \# & $00: 00$ & Start low-fibre diet & x \\
\hline \multirow{2}{*}{$\begin{array}{l}\text { Enter the date and time of your } \\
\text { colonoscopy appointment. }\end{array}$} & Why is a clean bowel important? & \multirow[t]{2}{*}{ 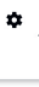 } & \multirow[t]{2}{*}{$\begin{array}{l}\text { 18:00 } \\
\text { 12. sep. } 2018\end{array}$} & \multirow[t]{2}{*}{$\begin{array}{l}\text { Stop eating solid food and } \\
\text { drink only clear liquid }\end{array}$} & $>$ \\
\hline & $\begin{array}{l}\text { When is the bowel } \\
\text { successfully cleansed? }\end{array}$ & & & & \\
\hline 䛔 13. sep. 2018 & $\begin{array}{l}\text { One to two weeks before the } \\
\text { colonoscopy }\end{array}$ & 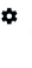 & $\begin{array}{l}\text { 18:00 } \\
\text { 12. sep. } 2018\end{array}$ & 1st sachet of PICOPREP® & 2 \\
\hline (L) 12:00 & Five days before the colonoscopy & \multicolumn{3}{|c|}{ Hydration phase 1} & \\
\hline The recommended time for each step in your & Three days before the colonoscopy & 田 & \multicolumn{2}{|r|}{ 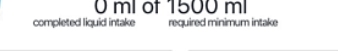 } & \\
\hline $\begin{array}{l}\text { based on this and shown in your tailored } \\
\text { schedule. }\end{array}$ & One day before the colonoscopy & \multirow[t]{2}{*}{ * } & \multirow[t]{2}{*}{$\begin{array}{l}\text { 08:00 } \\
\text { 13. sep. 2018 }\end{array}$} & \multirow[t]{2}{*}{ 2nd sachet of PICOPREP $\circledast$} & \multirow[t]{2}{*}{$>$} \\
\hline $\begin{array}{l}\text { If you need to change the time of your } \\
\text { colonoscopy, go to "Settings" and then " }\end{array}$ & On the day of the colonoscopy & & & & \\
\hline Reset current schedule' & & \multirow{2}{*}{ 甫 } & \multicolumn{2}{|c|}{ Hydration phase 2} & \\
\hline Save time and date & & & conder & & \\
\hline
\end{tabular}

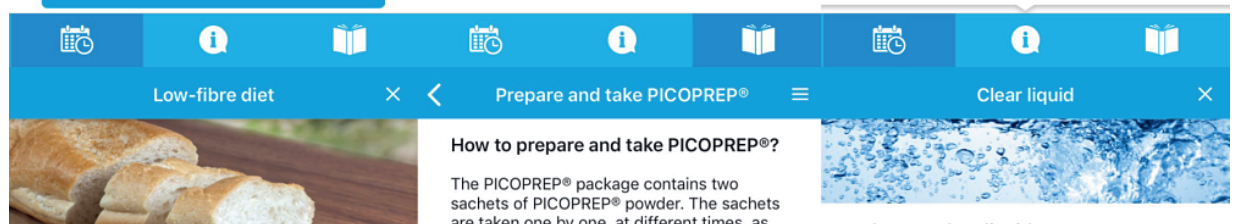
sachets of PICOPREP 2 powder. The sachets are taken one by one, at different times, as indicated in your Schedule in this app.

What are clear liquids?

Low-fibre diet as recommended: To ensure the intended effect, it is important to follow these instructions for both the 1st - Rice bubbles or cornflakes (use and the 2 nd sachet: reduced fat milk only

- Boiled eggs (not fried), omelettes

Pour $150 \mathrm{ml}$ of cold water in a glass

- Pasta (not made of

wholemeal flour)

- White bread or toast (not high fibre)

- Plain crackers (not wholemeal or multi grain)

- Plain scones (no sultanas or dates)

- Plain biscuits, no whole grain (Maria)

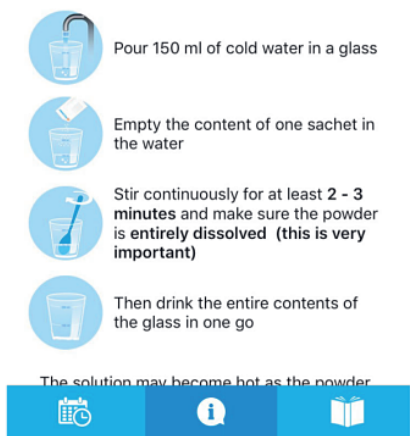

To stay hydrated it is important to not only drink water. Examples of clear liquid:

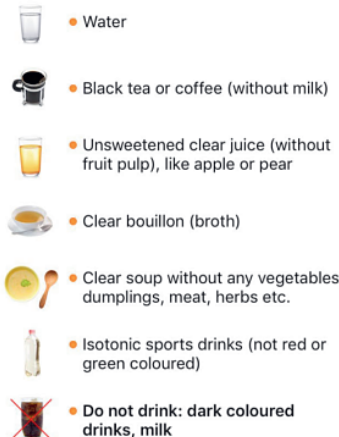

Figure 3.1 Smartphone application screenshots. (A) Date and time entry, (B) educational tools, (C) date and time specific bowel preparation schedule, (D) examples of low-fiber diet, (E) Picoprep preparation instructions, and (F) examples of clear liquids. 


\section{BOWEL PREPARATION SCHEDULE AND INSTRUCTIONS}

Instructions were delivered face-to-face by two research physicians (QZ and BV). Patients were instructed to follow a low-fiber diet two days prior to the colonoscopy. All patients were prescribed sodium picosulfate with magnesium citrate (SPMC) in a split-dose regimen of two doses, consisting of $10.0 \mathrm{mg}$ sodium picosulfate, $3.5 \mathrm{~g}$ magnesium oxide, and 12.0 g citric acid (Picoprep ${ }^{\circledR}$, Ferring B.V., Hoofddorp, the Netherlands). Patients scheduled for a colonoscopy in the morning or early afternoon were instructed to take the first SPMC dose the evening before and the second dose the morning of the colonoscopy. For colonoscopies scheduled in the afternoon, patients had to take both SPMC doses the morning of the examination with a 2-5 hour interval between both doses. All patients were also given $10.0 \mathrm{mg}$ of bisacodyl as additive to the first SPMC dose.

\section{OUTCOMES}

The primary outcome was bowel preparation quality assessed by the Boston Bowel Preparation Scale (BBPS). The BBPS is a validated and reliable scale which rates bowel cleanliness for each colonic segment (right, transverse, and left) after washing, suctioning, and cleaning maneuvers have been performed by the endoscopist. ${ }^{19}$ Each segment is scored on a scale from 0-3 (3 being the cleanest). ${ }^{20,21}$ Segment scores are summed to calculate the total BBPS, ranging from 0-9. Bowel preparation was considered adequate when total scores were $\geq 6$ and all segment scores were $\geq 2$. This cut-off value has been shown to be adequate in detecting polyps $>5 \mathrm{~mm} .^{20-22}$ Endoscopists were blinded regarding the study groups. Secondary endpoints were: adenoma detection rate (ADR), polyp detection rate (PDR), cecal intubation time, and withdrawal time. ADR and PDR were calculated by dividing the number of patients with at least 1 adenoma and/or polyp by the total number of colonoscopy patients (based on the histological diagnosis according to the revised Vienna classification). ${ }^{23,24}$ Withdrawal time included the time-period from starting withdrawal from the cecum to final inspection of the rectum, including time spent on washing, suctioning, and polypectomies.

Patient satisfaction concerning the bowel preparation procedure was evaluated using a self-assessed paper questionnaire. For this questionnaire, items from the Patient Satisfaction Questionnaire-18 (PSQ-18) were transformed to bowel preparation education purposes. ${ }^{25}$ Scores for the following subscales were calculated by averaging 
the scores of the relevant questions: general satisfaction (items 3 and 6), technical quality (items 8 and 9), communication (items 1 and 2), time spent on education (item 7), and convenience (items 4 and 5). The responses to all items were given on a 5-point Likert scale, ranging from strongly agree to strongly disagree. Patients in the smartphone application group were also asked to rate the user friendliness and design of the smartphone application on a 10-point scale. For the questionnaire, please see the Multimedia appendix.

\section{STATISTICAL ANALYSIS AND SAMPLE SIZE}

Sample size calculation was performed using PS Power and Sample Size Program version 3.1.2. In order to detect a difference of 0.75 in total BBPS between both groups with a significance level $(\alpha)$ of .05 and a power of $80 \%, 82$ completers per group were needed. ${ }^{26,27}$ To account for patients dropping out, 90 patients per group were enrolled.

Intention-to-treat analyses were performed. Descriptive statistics are presented as mean \pm standard deviation (SD) or as number of patients (\%). Differences between study groups were analyzed using independent-samples t-test for numerical variables and Chi-square test or Fisher's exact test for categorical variables. Post-hoc analyses were performed for subgroup analyses. Two-sided $P$-values $\leq 0.05$ were considered statistically significant. Statistical analyses were performed with IBM SPSS Statistics for Windows version 25 .

\section{RESULTS}

\section{STUDY POPULATION}

Patients who underwent a colonoscopy at the MUMC+ between August 2018 and November 2019 were screened for eligibility. In total 90 patients were included in the smartphone application group and 90 in the control group (Figure 3.2). Seven patients were excluded. Patient characteristics are provided in Table 3.1. No significant differences were observed between the smartphone application and the control group for baseline characteristics. Patients in both groups had the same level of experience in using medical smartphone applications. 


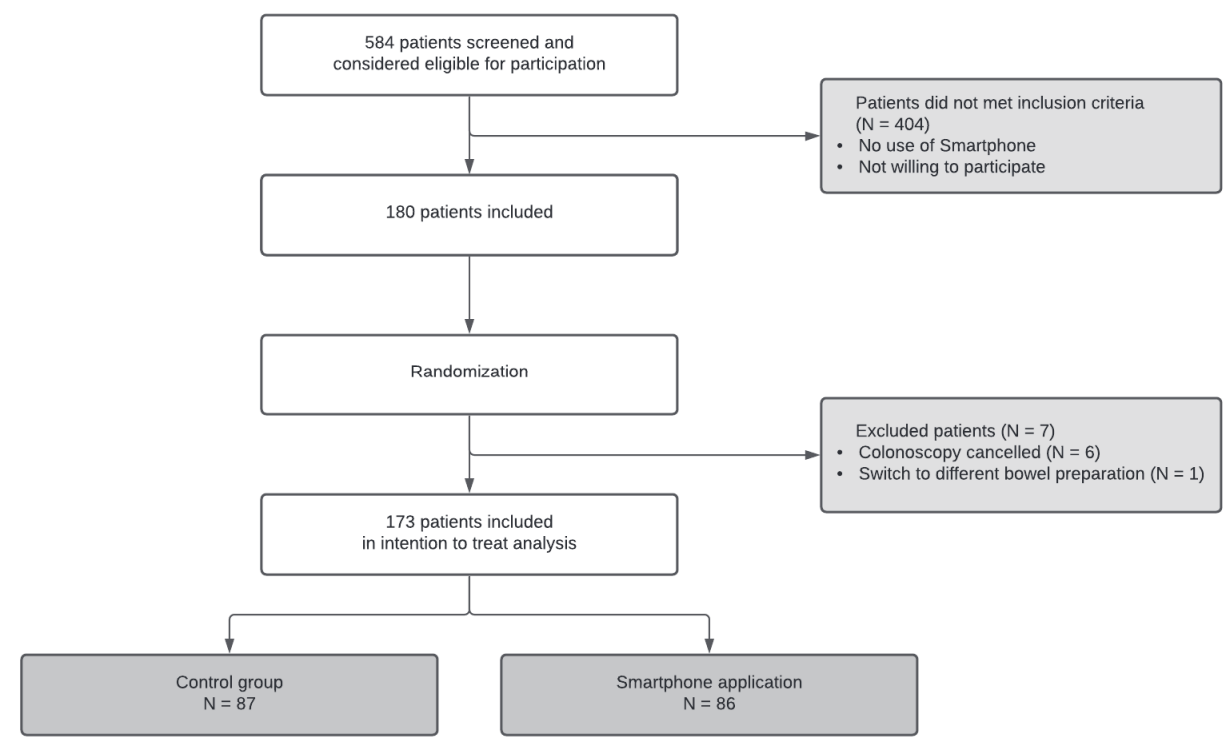

Figure 3.2 Study flowchart of patient enrolment and inclusion.

\section{BOSTON BOWEL PREPARATION SCALE}

Colonoscopies were performed by 25 different endoscopists (gastroenterologists and fellows) who rated the BBPS. All endoscopists were experienced in scoring the BBPS. The mean total BBPS in the smartphone application group was significantly higher compared to the control group $(8.3 \pm 0.9$ vs. $7.9 \pm 1.2, p=0.03)$. Mean right colon segment scores were also significantly higher in the smartphone application group (2.7 \pm 0.5 vs. $2.5 \pm 0.6, p=0.04)$. No significant differences were observed for mean transverse colon and left colon segment scores (Table 3.2). One patient in the smartphone application group and four patients in the control group had inadequate bowel preparation scores $(p=0.18)$. Logistic regression analyses, in order to reveal independent predictors for inadequate bowel preparation, could not be performed because of this low number. 
Table 3.1 Baseline characteristics of patients in the smartphone application group versus patients in the control group.

\begin{tabular}{|c|c|c|c|}
\hline & $\begin{array}{c}\text { Smartphone } \\
\text { application group } \\
\mathrm{N}=87\end{array}$ & $\begin{array}{l}\text { Control } \\
\text { group } \\
\mathrm{N}=86\end{array}$ & $p$-value \\
\hline Age in years, mean $( \pm S D)$ & $56.9(10.8)$ & $57.1(12.4)$ & 0.92 \\
\hline Age $<65$ years, yes $\mathrm{n}(\%)$ & $63(77.8)$ & $57(70.4)$ & 0.28 \\
\hline Age $\geq 65$ years, yes $n(\%)$ & $18(22.2)$ & $24(29.6)$ & 0.28 \\
\hline Gender, female n (\%) & $37(42.5)$ & $34(39.5)$ & 0.69 \\
\hline Body mass index in $\mathrm{kg} / \mathrm{m}^{2}$, mean $( \pm \mathrm{SD})$ & $26.1(4.6)$ & $25.7(3.6)$ & 0.56 \\
\hline Indication for colonoscopy, n (\%) & & & 0.25 \\
\hline National screening program & $29(33.3)$ & $21(24.4)$ & \\
\hline Surveillance & $17(19.5)$ & $25(29.1)$ & \\
\hline Symptoms & $41(47.1)$ & $40(46.5)$ & \\
\hline Waiting time in days, mean $( \pm S D)^{a}$ & $26.8(17.6)$ & $31.6(24.6)$ & 0.14 \\
\hline Previous colonoscopy, yes n (\%) & $34(39.1)$ & $37(43.0)$ & 0.60 \\
\hline Gastrointestinal history, yes $\mathrm{n}(\%)^{\mathrm{b}}$ & 37 (42.5) & $43(50.0)$ & 0.32 \\
\hline Diverticulosis & $10(11.5)$ & $16(18.6)$ & 0.19 \\
\hline Constipation & $14(16.1)$ & $18(20.9)$ & 0.41 \\
\hline Abdominal and/or pelvic surgery ${ }^{c}$ & $22(25.3)$ & $16(18.6)$ & 0.28 \\
\hline Comorbidities, yes $n(\%)^{d}$ & $45(51.7)$ & $37(43.0)$ & 0.25 \\
\hline Level of education, $n$ (\%) & & & 0.37 \\
\hline High school & $15(19.7)$ & $9(12.9)$ & \\
\hline Secondary vocational education & $28(36.8)$ & $24(33.8)$ & \\
\hline University (of applied sciences) & $33(43.4)$ & $38(53.5)$ & \\
\hline Experienced in using smartphone applications, yes $\mathbf{n}(\%)$ & $76(98.7)$ & $59(85.5)$ & 0.003 \\
\hline More than 10 applications & $52(69.3)$ & $43(72.9)$ & 0.65 \\
\hline Prior medical smartphone application use, yes $\mathrm{n}(\%)$ & $7(9.1)$ & $8(11.6)$ & 0.62 \\
\hline
\end{tabular}

SD: standard deviation. ${ }^{a}$ Waiting time defined as the time between screening visit and colonoscopy; 'Inflammatory bowel disease and stenosis did not occur in any patients' medical history; 'Abdominal and/or pelvic surgery included colectomy, abdominal uterus extirpation, prostatectomy, appendectomy, nephrectomy, cholecystectomy, and cesarean section; ${ }^{\mathrm{d} C o m o r b i d i t i e s}$ included hypertension, cardiovascular disease, chronic pulmonary disease, renal disease, liver disease, psychiatric disease, and diabetes mellitus.

Table 3.2 Bowel preparation scores for the smartphone application group versus the control group ${ }^{\mathrm{a}}$.

\begin{tabular}{cccc}
\hline & $\begin{array}{c}\text { Smartphone application group } \\
\mathrm{N}=81\end{array}$ & $\begin{array}{c}\text { Control group } \\
\mathrm{N}=81\end{array}$ & $p$-value \\
\hline Total BBPS, mean ( $\mathbf{S D})$ & $8.3(0.9)$ & $7.9(1.2)$ & 0.03 \\
BBPS right colon & $2.7(0.5)$ & $2.5(0.6)$ & 0.04 \\
BBPS transverse colon & $2.8(0.4)$ & $2.8(0.4)$ & 0.34 \\
BBPS left colon & $2.8(0.4)$ & $2.6(0.5)$ & 0.07 \\
Adequate bowel preparation, $\mathbf{n}(\mathbf{\%})^{\mathbf{b}}$ & $80(98.8)$ & $77(95.1)$ & $0.18^{\mathrm{c}}$ \\
Total BBPS $\geq 6$ & $81(100.0)$ & $79(97.5)$ & $0.25^{c}$ \\
All segment scores $\geq 2$ & $80(98.8)$ & $77(95.1)$ & $0.18^{\mathrm{c}}$ \\
\hline
\end{tabular}

BBPS: Boston bowel preparation scale; SD: standard deviation. ${ }^{a}$ Analyses for BBPS included only complete colonoscopies (successful cecal intubation). Missing data was equally distributed between the smartphone application group $(n=5)$ and the control group $(n=5)$. Analyses including incomplete colonoscopies, showed

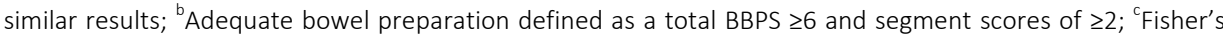
exact test. 
Subgroup analyses were performed for morning and afternoon colonoscopies, age below and above 65 years, and colonoscopy waiting time exceeding one month or not (because of an increased risk of forgetting preparation instructions over time) (Table 3.3). These analyses showed that patients $<65$ year in the smartphone application group had a significantly higher mean total ( $8.4 \pm 0.9$ vs. $7.9 \pm 1.1, p=0.01)$ and right BBPS $(2.8 \pm 0.4$ vs. $2.5 \pm 0.6, p=0.01)$ compared to the control group. Patients in the smartphone application group having an afternoon colonoscopy, also had a significantly higher mean total and right BBPS. Furthermore, patients with a colonoscopy waiting time $>1$ month in the smartphone application group had a significantly higher mean total BBPS and a significantly cleaner left colon compared to the control group. No significant differences were observed for morning colonoscopies, age $\geq 65$ years, and colonoscopies performed within one month.

\section{COLONOSCOPY QUALITY PARAMETERS}

The cecal intubation rate was $93.1 \%$ in the smartphone application group and $94.2 \%$ in the control group ( $p=0.77$ ) (Table 3.4). Eleven colonoscopies were incomplete due to severe pain sensations $(n=6)$, stenosis $(n=3)$, and technical difficulties $(n=2)$. No colonoscopies were aborted because of inadequate bowel preparation. Mean withdrawal time did not significantly differ between the smartphone application group and the control group (Table 3.4). Both ADR and PDR were higher in patients using the smartphone application compared to patients in the control group, but not significantly different. 
Table 3.3 Subgroup analysis for the smartphone application group versus the control group ${ }^{\mathrm{a}}$.

\begin{tabular}{|c|c|c|c|}
\hline Subgroup analyses & $\begin{array}{l}\text { Smartphone application } \\
\text { group } \\
N=81\end{array}$ & $\begin{array}{l}\text { Control } \\
\text { group } \\
\mathrm{N}=81\end{array}$ & $p$-value \\
\hline Afternoon colonoscopy, yes n (\%) & $37(45.7)$ & $35(43.2)$ & $0.75^{b}$ \\
\hline Total BBPS, mean ( \pm SD) & $8.3(1.0)$ & $7.7(1.3)$ & 0.03 \\
\hline BBBS right colon & $2.7(0.5)$ & $2.4(0.6)$ & 0.04 \\
\hline BBPS transverse colon & $2.8(0.4)$ & $2.7(0.5)$ & 0.50 \\
\hline BBPS left colon & $2.8(0.4)$ & $2.5(0.6)$ & 0.02 \\
\hline Morning colonoscopy, yes n (\%) & $44(54.3)$ & $46(56.8)$ & $0.75^{b}$ \\
\hline Total BBPS, mean ( \pm SD) & $8.3(0.9)$ & $8.1(1.0)$ & 0.37 \\
\hline BBBS right colon & $2.7(0.5)$ & $2.6(0.5)$ & 0.38 \\
\hline BBPS transverse colon & $2.8(0.4)$ & $2.8(0.4)$ & 0.49 \\
\hline BBPS left colon & $2.8(0.4)$ & $2.7(0.5)$ & 0.73 \\
\hline Age $<65$ years, yes $n(\%)$ & $63(77.8)$ & $57(70.4)$ & $0.28^{b}$ \\
\hline Total BBPS, mean $( \pm S D)$ & $8.4(0.9)$ & $7.9(1.1)$ & 0.01 \\
\hline BBBS right colon & $2.8(0.4)$ & $2.5(0.6)$ & 0.01 \\
\hline BBPS transverse colon & $2.8(0.4)$ & $2.7(0.4)$ & 0.17 \\
\hline BBPS left colon & $2.8(0.4)$ & $2.7(0.5)$ & 0.14 \\
\hline Age $\geq 65$ years, yes $n(\%)$ & $18(22.2)$ & $24(29.6)$ & $0.28^{b}$ \\
\hline Total BBPS, mean ( \pm SD) & $7.9(1.0)$ & $7.9(1.3)$ & 0.94 \\
\hline BBBS right colon & $2.4(0.6)$ & $2.5(0.6)$ & 0.61 \\
\hline BBPS transverse colon & $2.7(0.5)$ & $2.8(0.4)$ & 0.61 \\
\hline BBPS left colon & $2.7(0.5)$ & $2.6(0.5)$ & 0.37 \\
\hline Colonoscopy waiting time >1 month, yes $\mathrm{n}(\%)$ & $27(33.3)$ & $36(44.4)$ & $0.15^{b}$ \\
\hline Total BBPS, mean ( \pm SD) & $8.3(0.8)$ & $7.7(1.1)$ & 0.02 \\
\hline BBBS right colon & $2.6(0.6)$ & $2.4(0.6)$ & 0.31 \\
\hline BBPS transverse colon & $2.9(0.4)$ & $2.7(0.5)$ & 0.21 \\
\hline BBPS left colon & $2.9(0.4)$ & $2.5(0.5)$ & 0.004 \\
\hline Colonoscopy waiting time $\leq 1$ month, yes $\mathrm{n}(\%)$ & $54(66.7)$ & $45(55.6)$ & $0.15^{b}$ \\
\hline Total BBPS, mean ( \pm SD) & $8.3(1.0)$ & $8.1(1.2)$ & 0.38 \\
\hline BBBS right colon & $2.7(0.5)$ & $2.6(0.6)$ & 0.12 \\
\hline BBPS transverse colon & $2.8(0.4)$ & $2.8(0.4)$ & 0.83 \\
\hline BBPS left colon & $2.7(0.4)$ & $2.7(0.5)$ & 0.94 \\
\hline
\end{tabular}

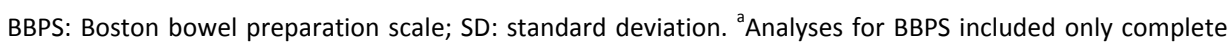
colonoscopies (successful cecal intubation). Missing data was equally distributed between the smartphone application group $(n=6)$ and the control group $(n=5)$. Analyses including incomplete colonoscopies, showed similar results; ${ }^{b}$ Chi-square test comparing presence in specific subgroups (afternoon vs morning, age $<65$ years vs. age $\geq 65$ years, and colonoscopy waiting time $\leq 1$ month vs colonoscopy waiting time $>1$ month, respectively) between smartphone application and control group. 
Table 3.4 Colonoscopy quality parameter details for the smartphone application versus the control group.

\begin{tabular}{|c|c|c|c|}
\hline & $\begin{array}{c}\text { Smartphone } \\
\text { application group } \\
N=87\end{array}$ & $\begin{array}{l}\text { Control group } \\
\qquad \begin{array}{l}N=86\end{array}\end{array}$ & $p$-value \\
\hline Cecal intubation rate, $\mathrm{n}(\%)$ & $81(93.1)$ & $81(94.2)$ & 0.77 \\
\hline Withdrawal time in minutes, mean $( \pm S D)^{a}$ & $15.8(8.6)$ & $14.0(9.1)$ & 0.20 \\
\hline Adenoma detection rate (ADR), $\mathrm{n}(\%)^{\mathrm{b}}$ & $35(43.2)$ & $27(33.3)$ & 0.20 \\
\hline Polyp detection rate (PDR), $n(\%)^{b}$ & $44(54.3)$ & $36(44.4)$ & 0.20 \\
\hline
\end{tabular}

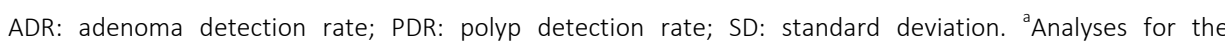
withdrawal time were performed for $n=78$ in the smartphone group and $n=80$ in the control group; ${ }^{b}$ Analyses for adenoma and polyp detection rate included only complete colonoscopies (successful cecal intubation). Missing data was equally distributed between the smartphone application group $(n=6)$ and the control group $(n=5)$. Analyses including incomplete colonoscopies, showed similar results.

\section{PATIENT SATISFACTION}

Response rates of the patient satisfaction questionnaire were $85.1 \%(n=74)$ in the smartphone application group and $82.6 \%(n=71)$ in the control group $(p=0.66)$. On a 5 -point Likert scale, the general satisfaction was $4.4 \pm 0.7$ in the smartphone application group and $4.3 \pm 0.8$ in the control group $(p=0.32)$. No significant differences in patient satisfaction were observed concerning technical quality, communication, time spent on education, and convenience (Table 3.5). The majority of the smartphone application users was willing to use the application again for eventual future colonoscopies $(4.5 \pm 0.6)$ and rated the added value of the smartphone application $4.4 \pm 0.7$. On a 10-point scale, user friendliness and design of the smartphone application were rated $8.7 \pm 1.1$ and $8.7 \pm 1.2$, respectively. 
Table 3.5 Patient satisfaction according to the PSQ-18 questionnaire and patient satisfaction on smartphone application use ${ }^{a}$.

\begin{tabular}{|c|c|c|c|}
\hline & $\begin{array}{c}\text { Smartphone } \\
\text { application group } \\
\text { Mean ( } \pm \text { SD) } \\
N=74\end{array}$ & $\begin{array}{c}\text { Control } \\
\text { group } \\
\text { Mean }( \pm \mathrm{SD}) \\
\mathrm{N}=71 \\
\end{array}$ & $p$-value \\
\hline \multicolumn{4}{|l|}{ PSQ-18 (5-point scale) } \\
\hline General satisfaction & $4.4(0.7)$ & $4.3(0.8)$ & 0.32 \\
\hline Technical quality & $4.5(0.7)$ & $4.5(0.6)$ & 0.70 \\
\hline Communication & $4.6(0.5)$ & $4.7(0.6)$ & 0.52 \\
\hline Time spent on education & $4.6(0.7)$ & $4.7(0.6)$ & 0.45 \\
\hline Convenience & $4.4(0.7)$ & $4.5(0.6)$ & 0.45 \\
\hline \multicolumn{4}{|c|}{ Patient satisfaction on smartphone application use (5-point scale) ${ }^{b}$} \\
\hline Added value of the smartphone application & $4.4(0.7)$ & & \\
\hline Willingness to use the application for future colonoscopies & $4.5(0.6)$ & & \\
\hline Ease of downloading and using & $4.6(0.7)$ & & \\
\hline Clear overview of times to use laxative & $4.6(0.7)$ & & \\
\hline \multicolumn{4}{|l|}{ Patient satisfaction on smartphone application use (10-point scale) } \\
\hline Ease of use in general & $8.7(1.1)$ & & \\
\hline Design & $8.7(1.2)$ & & \\
\hline
\end{tabular}

PSQ: Patient Satisfaction Questionnaire; SD: standard deviation. ${ }^{a}$ Analyses for patient satisfaction included only complete questionnaires. Analyses including incomplete questionnaires, showed similar results; ${ }^{b}$ Analyses for patient satisfaction on smartphone application use was based on $\mathrm{N}=78$ complete questionnaires.

\section{DISCUSSION}

\section{PRINCIPAL RESULTS}

Adequate bowel preparation is an important quality indicator for colonoscopy. Key finding of this study is the significantly higher mean total BBPS in patients using a personalized smartphone application for bowel preparation instructions compared to patients using regular verbal and written information. Patient satisfaction did not further improve for smartphone application users compared to patients receiving regular written instructions.

\section{COMPARISON WITH PRIOR WORK}

The finding of a significantly higher mean total BBPS in the smartphone application group compared to the control group is in line with previous studies. ${ }^{2,28,29}$ The mean total BBPS in the control groups of these studies ranged from 5.8 to 7.2. Although the mean total BBPS in our control group was high with a mean score of 7.9 , the 
smartphone application still had added value (mean total BBPS 8.3). In particular, the mean BBPS of the right colon was significantly higher in the smartphone application group versus the control group. This finding has clinical relevance because the right colon is considered more difficult to clean ${ }^{30}$ and the polyp detection rate in the right colon improves with improvement of BBPS of the right colon. ${ }^{31}$

The European Society of Gastrointestinal Endoscopy (ESGE) recommends the use of enhanced instructions for bowel preparation. Methods such as telephone calls, visual aids, educational videos, and SMS reminders help to improve bowel preparation quality compared to regular instructions. ${ }^{1,2,4,13,30,32-34}$ Possible advantages of smartphone applications are that they are more easily understandable, accessible, and interactive. Another benefit is that automatic alerts, reminders, and notifications remind patients to start and adhere to the steps of the bowel preparation schedule more precisely ${ }^{35,36}$ without consuming valuable time and resources, as is the case with telephone calls ${ }^{13,32}$, making smartphone applications easier to implement into daily clinical practice. Furthermore, the smartphone application provided a personalized bowel preparation schedule for each patient. The different steps of the bowel preparation procedure were adapted to the exact date and time of the colonoscopy. Whereas, written instructions were general for morning and afternoon colonoscopies and indicated no exact date.

Previous studies included relatively young patients with mean ages between 42 and 55 years. ${ }^{2,26,32,33}$ In this study, no maximum age for participation was stated, so older age groups, who might be less familiar with smartphone applications, were also included. Jeon et al. (2019) used smartphone mobile messenger to educate patients and found that this approach was useful with respect to the quality of bowel preparation for the younger age group ( $<40$ years), but not for patients aged $>40$ years. $^{34}$ In our study, subgroup analysis showed significantly higher total mean BBPS and right colon segment scores for patients $<65$ years old using the smartphone application compared to the control group. In addition to the study of Jeon et al., these significantly higher mean BBPS scores indicate that the use of a smartphone application is a feasible method not only for patients aged $<40$ years, but in patients up to 65 years old. For patients $\geq 65$ years, no significant differences in mean BBPS were found, although their number was low. Further research focusing on elderly patients ( $\geq 65$ years old) is needed to investigate the usefulness of a smartphone application among those patients. 
In the present study, the BBPS was used to measure bowel cleansing. A systematic review by Parmar et al. (2016) revealed that the BBPS is the most thoroughly validated scale and should therefore be used in clinical practice. ${ }^{19}$ It should be noted that the BBPS is scored after appropriate washing and suctioning steps have been performed. Therefore, differences in initial bowel preparation could have been masked by variations in the extent of endoscopist's washing and suctioning actions. However, because blinded endoscopists performed colonoscopies in both groups, potential differences in extent of washing and suctioning were eliminated.

The minimum standard rate for adequate bowel preparation of $\geq 90 \%$, a set criterion by the ESGE guidelines ${ }^{37}$, was reached in both the smartphone application and the control group. In five patients $(3 \%)$ the colon was inadequately prepared. In the literature, the reported numbers are higher, up to $35 \% .^{7,10,13,32}$ In this study, predictors for inadequate bowel preparation could not be identified because of the low numbers. In two meta-analyses, three groups of predictors for inadequate bowel preparation were identified: patients' characteristics (increasing age, male gender, and higher BMI); clinical conditions (constipation, diabetes mellitus, hypertension, cirrhosis, stroke, and dementia); and medication use (narcotics and tricyclic antidepressants). ${ }^{38,39}$ Other studies also reported low level of education, low socioeconomic status, low health literacy, and low patient motivation in health promotion as influencing factors. ${ }^{13,32}$

ADR and cecal intubation rate are indicators for colonoscopy quality. ${ }^{22}$ Guo et al. (2020) found a significantly higher ADR in the smartphone application group compared to the control group $(21.4 \%$ vs. $12.8 \%$ respectively, $p=0.03,) .{ }^{40}$ Although in this study higher ADR and PDR were observed in the smartphone application group, the observed differences were not statistically significant. It should be noted that this study was not powered to detect significant differences in ADR and PDR. A recent meta-analysis found that patients who had received enhanced instructions (social media apps, short message services (SMS), and telephone calls), had higher cecal intubation rates $(\mathrm{OR} 2.77,95 \% \mathrm{Cl}$ 1.73-4.42, p<0.001) compared with patients receiving regular verbal and written instructions[4]. None of the cases in our study in which the cecum was not reached was due to inadequate bowel preparation, even though it has been reported as a major factor in the literature. ${ }^{41}$

Bowel preparation procedures may cause discomfort. The main discomforts patients report relate to uncertainties with respect to dietary recommendations and adverse gastrointestinal symptoms owing to laxative use. ${ }^{30}$ Patient education by means of a 
smartphone application may help resolving these uncertainties. Indeed, the willingness to repeat the preparation procedure is higher for patients receiving enhanced bowel preparation instructions compared to regular instructions (OR 1.91, 95\% Cl 1.20-3.04, $p=0.01) .{ }^{4}$ High patient satisfaction can therefore help to increase patient participation for surveillance colonoscopies. In our control group, patient satisfaction was already high and did further increase when using the smartphone application.

\section{STRENGTHS AND LIMITATIONS}

This study has several strengths. Selection bias was avoided in three ways. First, inclusion concerned screening, surveillance, and symptomatic patients of both morning and afternoon colonoscopies. Second, patients were not excluded in the case of a history of abdominal surgery, diverticulosis, stenosis, or constipation, in comparison to most other studies. ${ }^{2,27,28,32,42}$ Third, the application was available for smartphones with both the operating systems of Android and iOS, in contrast to the study by Lorenzo-Zuniga et al. (2015)..$^{33}$ Furthermore, no maximum age for participation was stated. All the above mentioned decisions in methodology, add to the generalizability of our findings.

This study has also certain limitations. First, compliance to the steps of the bowel preparation schedule was not controlled in either group. While it is known that approximately $30 \%$ of patients with poor bowel preparation fail to follow instructions prior to the colonoscopy. ${ }^{43}$ Second, patients were not blinded for the intervention. Third, a large number of endoscopists assessed the BBPS, potentially leading to a larger variability in scoring and possibly causing bias. Notwithstanding, all endoscopists were trained and experienced in using the BBPS in order to uniform scoring, thereby reflecting daily endoscopic practice in a teaching hospital. Fourth, selection bias may have occurred since only $31 \%$ of the screened patients visiting our pre-screen facility were eligible for inclusion. Most likely, only patients with an affinity for smartphone use were willing to participate, lowering the generalizability of this study. However, the group of smartphone users will only increase in the future, making smartphone applications for bowel preparation a valuable tool for the improvement of bowel preparation quality. Fifth, the study was performed single center, limiting its generalizability. 


\section{CONCLUSION}

In conclusion, this study has shown that using our personalized smartphone application significantly improved bowel preparation quality, in particular in the right colon and could improve polyp detection in de right colon. Patient satisfaction was equal in the personalized smartphone application group compared to patients receiving regular verbal and written instructions. Smartphone applications are an easy to use tool to improve patients' bowel preparation education and quality, making implementation in clinical practice feasible. 


\section{REFERENCES}

1. Hassan C, East J, Radaelli F, Spada C, Benamouzig R, Bisschops R, et al. Bowel preparation for colonoscopy: European Society of Gastrointestinal Endoscopy (ESGE) Guideline - Update 2019. Endoscopy. 2019;51(8):775-794

2. Cho J, Lee S, Shin JA, Kim JH, Lee HS. The Impact of Patient Education with a Smartphone Application on the Quality of Bowel Preparation for Screening Colonoscopy. Clin Endosc. 2017;50(5):479-85.

3. Clark BT, Rustagi T, Laine L. What level of bowel prep quality requires early repeat colonoscopy: systematic review and meta-analysis of the impact of preparation quality on adenoma detection rate. Am J Gastroenterol. 2014;109(11):1714-1723.

4. Guo X, Yang Z, Zhao L, Leung F, Luo H, Kang X, et al. Enhanced instructions improve the quality of bowel preparation for colonoscopy: a meta-analysis of randomized controlled trials. Gastrointest Endosc. 2017;85(1):90-97.e6.

5. Chokshi RV, Hovis CE, Hollander T, Early DS, Wang JS. Prevalence of missed adenomas in patients with inadequate bowel preparation on screening colonoscopy. Gastrointest Endosc. 2012;75(6):1197-1203.

6. le Clercq CM, Bouwens MW, Rondagh EJ, Bakker CM, Keulen ET, de Ridder RJ, et al. Postcolonoscopy colorectal cancers are preventable: a population-based study. Gut. 2014;63(6):957-963.

7. Harewood GC, Sharma VK, de Garmo P. Impact of colonoscopy preparation quality on detection of suspected colonic neoplasia. Gastrointest Endosc. 2003;58(1):76-79.

8. Armstrong D, Barkun AN, Chen $Y$, Daniels S, Hollingworth R, Hunt RH, et al. Access to specialist gastroenterology care in Canada: the Practice Audit in Gastroenterology (PAGE) Wait Times Program. Can J Gastroenterol. 2008;22(2):155-160.

9. Luck A, Pearson S, Maddern G, Hewett P. Effects of video information on precolonoscopy anxiety and knowledge: a randomised trial. Lancet (London, England). 1999;354(9195):2032-2035.

10. Chang CW, Shih SC, Wang HY, Chu CH, Wang TE, Hung CY, et al. Meta-analysis: The effect of patient education on bowel preparation for colonoscopy. Endosc Int Open. 2015;3(6):E646-652.

11. Park JS, Sohn CI, Hwang SJ, Choi HS, Park JH, Kim HJ, et al. Quality and effect of single dose versus split dose of polyethylene glycol bowel preparation for early-morning colonoscopy. Endoscopy. 2007;39(7):616-619. PMID: 17611916. doi: 10.1055/s-2007-966434.

12. Gimeno-Garcia AZ, de la Barreda Heuser R, Reygosa C, Hernandez A, Mascareno I, Nicolas-Perez D, et al. Impact of a 1-day versus 3-day low-residue diet on bowel cleansing quality before colonoscopy: a randomized controlled trial. Endoscopy. 2019;51(7):628-636.

13. Liu Z, Zhang MM, Li YY, Li LX, Li YQ. Enhanced education for bowel preparation before colonoscopy: A state-of-the-art review. J Dig Dis. 2017;18(2):84-91.

14. Committee ASoP, Saltzman JR, Cash BD, Pasha SF, Early DS, Muthusamy VR, et al. Bowel preparation before colonoscopy. Gastrointest Endosc. 2015;81(4):781-794.

15. Hassan C, Bretthauer M, Kaminski MF, Polkowski M, Rembacken B, Saunders B, et al. Bowel preparation for colonoscopy: European Society of Gastrointestinal Endoscopy (ESGE) guideline. Endoscopy. 2013;45(2):142-150.

16. Deloitte. 2017 Global Mobile Consumer Survey: The Netherlands. 2017; Available from: https://www2.deloitte.com/nl/nl/pages/technologie-media-telecom/articles/global-mobileconsumer-survey.html.

17. World Medical Association Declaration of Helsinki: ethical principles for medical research involving human subjects. JAMA. 2013;310(20):2191-2194.

18. European Parliament and the Council of the European Union, General Data Protection Regulation (GDPR), (2016).

19. Parmar R, Martel M, Rostom A, Barkun AN. Validated Scales for Colon Cleansing: A Systematic Review. Am J Gastroenterol. 2016;111(2):197-204; quiz 5.

20. Calderwood AH, Schroy PC, 3rd, Lieberman DA, Logan JR, Zurfluh M, Jacobson BC. Boston Bowel Preparation Scale scores provide a standardized definition of adequate for describing bowel cleanliness. Gastrointest Endosc. 2014;80(2):269-276. 
21. Clark BT, Protiva P, Nagar A, Imaeda A, Ciarleglio MM, Deng Y, et al. Quantification of Adequate Bowel Preparation for Screening or Surveillance Colonoscopy in Men. Gastroenterology. 2016;150(2):396405; quiz e14-5.

22. Kastenberg D, Bertiger G, Brogadir S. Bowel preparation quality scales for colonoscopy. World J Gastroenterol. 2018;24(26):2833-2843.

23. Schlemper RJ, Riddell RH, Kato Y, Borchard F, Cooper HS, Dawsey SM, et al. The Vienna classification of gastrointestinal epithelial neoplasia. Gut. 2000;47(2):251-255.

24. Rex DK, Ponugoti PL. Calculating the adenoma detection rate in screening colonoscopies only: Is it necessary? Can it be gamed? Endoscopy. 2017;49(11):1069-1074.

25. Marshall GNH, R.D. The Patient Satisfaction Questionnaire Short-Form (PSQ-18). RAND. 1994.

26. Park JS, Kim MS, Kim H, Kim SI, Shin $\mathrm{CH}$, Lee HJ, et al. A randomized controlled trial of an educational video to improve quality of bowel preparation for colonoscopy. BMC Gastroenterol. 2016;16(1):64.

27. Liu X, Luo H, Zhang L, Leung FW, Liu Z, Wang X, et al. Telephone-based re-education on the day before colonoscopy improves the quality of bowel preparation and the polyp detection rate: a prospective, colonoscopist-blinded, randomised, controlled study. Gut. 2014;63(1):125-130.

28. Walter B, Frank R, Ludwig L, Dikopoulos N, Mayr M, Neu B, et al. Smartphone Application to Reinforce Education Increases High-Quality Preparation for Colorectal Cancer Screening Colonoscopies in a Randomized Trial. Clin Gastroenterol Hepatol. 2021;19(2):331-338.e5

29. Wang SL, Wang Q, Yao J, Zhao SB, Wang LS, Li ZS, et al. Effect of WeChat and short message service on bowel preparation: an endoscopist-blinded, randomized controlled trial. Eur J Gastroenterol Hepatol. 2019;31(2):170-177.

30. Walter B, Klare P, Strehle K, Aschenbeck J, Ludwig L, Dikopoulos N, et al. Improving the quality and acceptance of colonoscopy preparation by reinforced patient education with short message service: results from a randomized, multicenter study (PERICLES-II). Gastrointest Endosc. 2019;89(3):506513.e4.

31. Clark BT, Laine L. High-quality Bowel Preparation Is Required for Detection of Sessile Serrated Polyps. Clin Gastroenterol Hepatol. 2016;14(8):1155-1162.

32. Sharara Al, Chalhoub JM, Beydoun M, Shayto RH, Chehab H, Harb AH, et al. A Customized Mobile Application in Colonoscopy Preparation: A Randomized Controlled Trial. Clin Transl Gastroenterol. 2017;8(1):e211.

33. Lorenzo-Zuniga V, Moreno de Vega V, Marin I, Barbera M, Boix J. Improving the quality of colonoscopy bowel preparation using a smart phone application: a randomized trial. Dig Endosc. 2015;27(5): 590-595.

34. Jeon SC, Kim JH, Kim SJ, Kwon HJ, Choi YJ, Jung K, et al. Effect of Sending Educational Video Clips via Smartphone Mobile Messenger on Bowel Preparation before Colonoscopy. Clin Endosc. 2019;52(1):53-58.

35. Desai M, Nutalapati V, Bansal A, Buckles D, Bonino J, Olyaee M, et al. Use of smartphone applications to improve quality of bowel preparation for colonoscopy: a systematic review and meta-analysis. Endosc Int Open. 2019;7(2):E216-E224.

36. Lee YJ, Kim ES, Choi JH, Lee KI, Park KS, Cho KB, et al. Impact of reinforced education by telephone and short message service on the quality of bowel preparation: a randomized controlled study. Endoscopy. 2015;47(11):1018-1027.

37. Kaminski MF, Thomas-Gibson S, Bugajski M, Bretthauer M, Rees CJ, Dekker E, et al. Performance measures for lower gastrointestinal endoscopy: a European Society of Gastrointestinal Endoscopy (ESGE) Quality Improvement Initiative. Endoscopy. 2017;49(4):378-397.

38. Gandhi K, Tofani C, Sokach C, Patel D, Kastenberg D, Daskalakis C. Patient Characteristics Associated With Quality of Colonoscopy Preparation: A Systematic Review and Meta-analysis. Clin Gastroenterol Hepatol. 2018;16(3):357-369.e10.

39. Mahmood S, Farooqui SM, Madhoun MF. Predictors of inadequate bowel preparation for colonoscopy: a systematic review and meta-analysis. Eur J Gastroenterol Hepatol. 2018;30(8):819-26.

40. Guo B, Zuo X, Li Z, Liu J, Xu N, Li X, et al. Improving the quality of bowel preparation through an app for inpatients undergoing colonoscopy: A randomized controlled trial. J Adv Nurs. 2020;76(4):1037-1045. 
41. Aslinia F, Uradomo L, Steele A, Greenwald BD, Raufman JP. Quality assessment of colonoscopic cecal intubation: an analysis of 6 years of continuous practice at a university hospital. Am J Gastroenterol. 2006;101(4):721-731.

42. Back SY, Kim HG, Ahn EM, Park S, Jeon SR, Im HH, et al. Impact of patient audiovisual re-education via a smartphone on the quality of bowel preparation before colonoscopy: a single-blinded randomized study. Gastrointest Endosc. 2018;87(3):789-799.e4.

43. Nguyen DL, Wieland M. Risk factors predictive of poor quality preparation during average risk colonoscopy screening: the importance of health literacy. J Gastrointestin Liver Dis. 2010;19(4): 369-372.

44. Eysenbach G. CONSORT-EHEALTH: improving and standardizing evaluation reports of Web-based and mobile health interventions. J Med Internet Res. 2011;13(4):e126. 


\section{MULTIMEDIA APPENDIX OF SUPPLEMENTARY FILES}

Patient satisfaction questionnaire (PSQ-18).

\section{MULTIMEDIA APPENDIX OF SUPPLEMENTARY FILES}

Consort-eHealth checklist. ${ }^{44}$ 


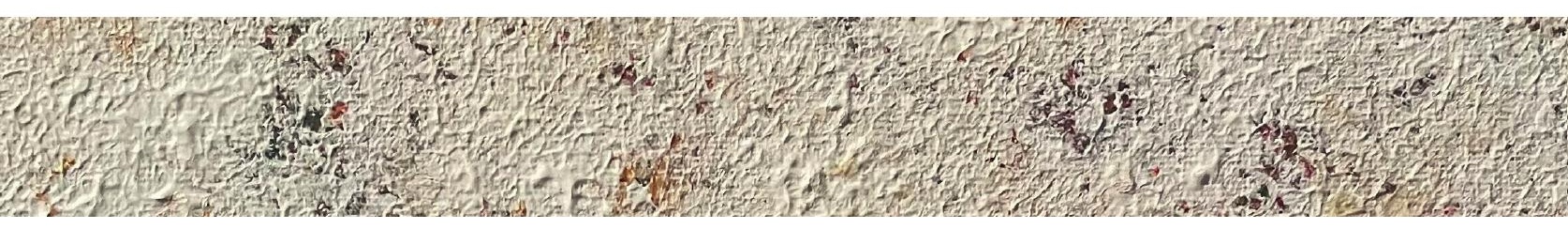




\section{PART II}

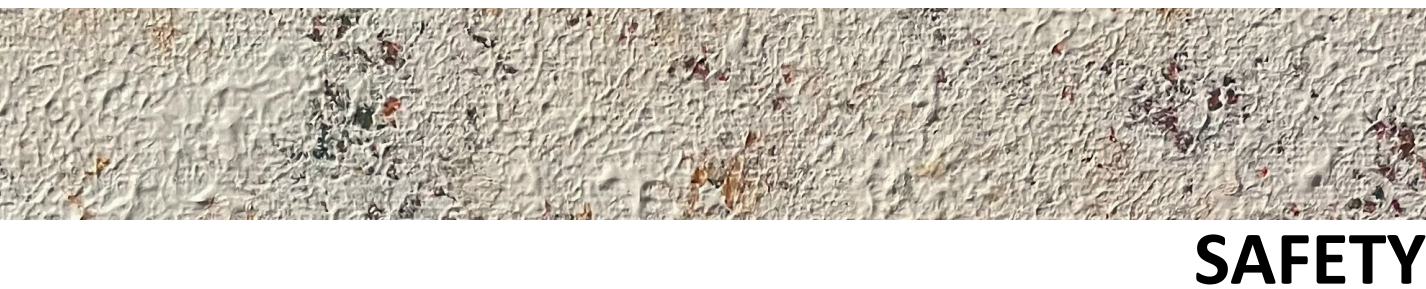

POST-COLONOSCOPY COMPLICATIONS 


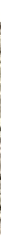




\section{CHAPTER 4}

POST-COLONOSCOPY COMPLICATIONS:

A SYSTEMATIC REVIEW, TIME-TRENDS AND

META-ANALYSIS OF POPULATION-BASED STUDIES

A. Reumkens, E.J.A. Rondagh, C.M. Bakker, B. Winkens,

A.A.M. Masclee, S. Sanduleanu

Am J Gastroenterol 2016;111(8):1092-1101 


\section{ABSTRACT}

\section{Objective}

Many studies around the world addressed the post-colonoscopy complications, but their pooled prevalence and time-trends are unknown. We performed a systematic review and meta-analysis of population-based studies to examine the pooled prevalence of post-colonoscopy complications (perforation, bleeding, mortality), stratified by colonoscopy indication. Temporal variability in complication rate was assessed.

\section{Design}

We queried Pubmed, Embase and the Cochrane library for population-based studies examining post-colonoscopy complications (within 30 days), performed from 2001 to 2015 and published by December 1, 2015. We determined pooled prevalence of perforations, post-colonoscopy bleeding, post-polypectomy bleeding and mortality.

\section{Results}

We retrieved 1074 studies, of which 21 met the inclusion criteria. Overall, pooled prevalences for perforation, post-colonoscopy bleeding and mortality were $0.5 / 1,000$ (95\% Cl 0.4-0.7); 2.6/1,000 (95\% Cl 1.7-3.7); and 2.9/100,000 (95\% Cl 1.1-5.5) colonoscopies. Colonoscopy with polypectomy was associated with a perforation rate of $0.8 / 1,000$ (95\% $\mathrm{Cl} 0.6-1.0)$ and a post-polypectomy bleeding rate of 9.8/1,000 (95\% $\mathrm{Cl}$ 7.7-12.1). Complication rate was lower for screening/surveillance than for diagnostic examinations. Time-trend analysis showed that post-colonoscopy bleeding declined from 6.4 to $1.0 / 1,000$ colonoscopies, while the perforation and mortality rates remained stable from 2001 to 2015. Overall, considerable heterogeneity was observed in most of the analyses.

\section{Conclusions}

Worldwide, the post-colonoscopy complication rate remained stable or even declined over the past 15 years. The findings of this meta-analysis encourage continued efforts to achieve and maintain safety targets in colonoscopy practice. 


\section{INTRODUCTION}

Colonoscopy is one of the most commonly performed examinations and patient safety is, unarguably, a prerequisite. The post-colonoscopy complication rate should be minimized, irrespective of the indication, i.e. screening, surveillance, symptoms and/or therapy. ${ }^{1}$ Because colorectal cancer (CRC) screening and colonoscopy surveillance are increasingly endorsed worldwide, both the volume of examinations and clinical challenges at patient level increase., ${ }^{2,3}$ Older age, comorbidity and use of anticoagulant therapy increase the risk of harms during colonoscopy. ${ }^{4}$

In general practice, the proportion of post-colonoscopy complications varies widely. Post-colonoscopy perforation rate ranges from 0 to $1.7 / 1,000$ colonoscopies $^{5-23}$, postcolonoscopy bleeding rate from 0 to $22.3 / 1,000$ colonoscopies $^{4-11,13-18,20-22,24,25}$, and mortality rate from 0 to $2.0 / 1,000$ colonoscopies. ${ }^{4-6,8-21,25}$ In screening populations, an overall post-colonoscopy complication rate of $2.8 / 1,000$ procedures has been reported. ${ }^{26}$ In symptomatic populations, the risk of complications can be even higher, especially in older patients. ${ }^{22}$ Overall, 26.0/1,000 patients aged 65+ years develop post-colonoscopy complications. Patients aged $80+$ years have a higher risk of perforation than younger patients (1.5 perforations/1,000 patients; $95 \% \mathrm{Cl} 1.1-1.9$ vs. $<1.0$ perforations $/ 1,000$ patients; $95 \% \mathrm{Cl} 0.9-1.5){ }^{27}$

Over the past years, gastrointestinal professional societies around the world adopted safety standards for colonoscopy practice. The American Society for Gastrointestinal Endoscopy (ASGE)/ American College of Gastroenterology (ACG) Task Force on Quality in Endoscopy recommends that the post-polypectomy bleeding rate and postcolonoscopy perforation should be $\leq 1 / 100$ and $\leq 1$ per 500 colonoscopies $(\leq 1 / 1,000$ in screening). ${ }^{28,29}$ In screening colonoscopy, the European Society of Gastrointestinal Endoscopy (ESGE) proposes that bleeding should require surgery in $\leq 5 / 100$ and perforation in $\leq 1 / 1,000 .^{30}$ In an audit of post-colonoscopy complications before the start of the national CRC screening, the British Society of Gastroenterology (BSG) reported post-colonoscopy bleeding, post-polypectomy bleeding, perforation and mortality rates of $1.4 / 1,000,3.4 / 1,000,1 / 769$ and $1 / 1,537 .^{31}$

To date, there has been no systematic review with meta-analysis of data to estimate the post-colonoscopy complication rate in routine clinical practice. A number of 
studies can be considered outdated given the ongoing efforts to improve colonoscopy practice. Many studies reported the overall risk of post-colonoscopy bleeding, perforation and mortality, but did not stratify it by colonoscopy indication. Patientand operator-dependent factors affecting the complication rate were not explicitly addressed. It is also unclear whether improvements in colonoscopy training and technological progress over the past years lead to a change in post-colonoscopy complication rate. ${ }^{32,33}$ Although colonoscopy as a tool will never be perfect, its safety is critical and should be monitored. It is important to establish evidence-based metrics for post-colonoscopy complications to better inform patient consent to colonoscopy. Herein, we present a systematic review and meta-analysis of population-based studies examining the pooled prevalence rate of post-colonoscopy complications (perforation, bleeding, mortality), stratified by colonoscopy indication.

We address temporal trends in incidence of post-colonoscopy complications over the past 15 years.

\section{METHODS}

We employed PRISMA methodology for conducting and reporting a systematic review and meta-analysis. ${ }^{34}$ We applied a local protocol for conducting a meta-analysis as described elsewhere. ${ }^{35}$ A data-extraction form was used (available on request).

\section{SELECTION CRITERIA}

We included population-based studies of post-colonoscopy complications in patients undergoing colonoscopy from January 2001 until December 2015. We defined postcolonoscopy complications as perforations, post-colonoscopy bleeding or mortality occurring within 30 days, regardless of colonoscopy indication. Prospective and retrospective studies were included. Post-colonoscopy perforation was defined as symptoms and presence of X-ray abnormalities (i.e. intra-abdominal free air) requiring hospitalization or surgery. Post-colonoscopy bleeding was defined as bleeding after colonoscopy with/without polypectomy requiring hospitalization, emergency room visit, need for a repeat colonoscopy or transfusion of packed red blood cells. Bleeding which could be treated during index colonoscopy and was stopped before the end of the procedure was not included. Mortality was defined as death occurring within 3 months after a colonoscopy as a consequence of cardiorespiratory events, 
perforation or bleeding related to the procedure. Screening colonoscopies were those performed in patients with a positive fecal occult blood test or fecal immunochemical test. In the case of colonoscopies performed for symptoms, most common indications were rectal bleeding, altered bowel habits, anemia and bowel complaints. Studies examining post-polypectomy complications only were analyzed separately.

We included patients who underwent colonoscopy from January 2001 to December 2015 , because of significant evolutionary changes over this time-period, i.e. progress in endoscopic equipment and improvement of education and colonoscopy training, in particular the adoption of new endoscopic resection techniques. Therefore, we excluded studies of those patients examined before January 1, 2001. In case of multiple studies from the same group, we included the most recent and most extensive data. To mitigate selection bias, we also excluded those studies of patients referred for endoscopic resection of colorectal polyps, if they were not populationbased. Population-based studies of patients who underwent colonoscopy with polypectomy only were included.

\section{SEARCH STRATEGY}

We conducted a comprehensive search of Pubmed, the Cochrane library and Ovid EMbase until 01 December 2015. We used the following keywords and medical subject heading terms: (Colonoscopy OR screening colonoscopy OR surveillance colonoscopy) AND (adverse events OR complication) AND (mortality OR cardiovascular complications OR pulmonary complications OR colonic perforation OR perforation OR gastrointestinal bleeding OR bleeding complication OR post-polypectomy bleeding). Studies published in English language were included. The reference list of all eligible studies was reviewed to identify additional studies.

Two reviewers (A.R. and E.R.), independently, screened all abstracts. Review articles, case reports, studies investigating other primary or secondary outcomes then complications, studies investigating treatment of complications and sedation-related complications only were excluded. The full text of the remaining studies was examined to determine whether it contained relevant information. If there was discrepancy between the two study investigators, then the senior author (S.S.) reviewed and data were discussed to reach consensus. 


\section{DATA EXTRACTION AND QUALITY ASSESSMENT}

The following data were independently abstracted onto a standardized form: study characteristics (primary author, time period of study, year of publication, country of the population studied), study design (retrospective vs prospective study), characteristics of the study population (total number of patients undergoing colonoscopy, indication for colonoscopy, age of patients, gender, polyp size, site, type of polypectomy, use of anticoagulants), type and frequency of complications (i.e. perforations, bleedings, deaths) and operator-dependent factors which can affect the outcomes, i.e. educational background (gastroenterologist, surgeon, trainee) and volume of colonoscopies.

We systematically assessed the quality of the studies using published criteria ${ }^{34,36-38}$ for evaluating prevalence studies. To comprehensively assess the quality of clinical studies we used the Newcastle-Ottawa Scale (NOS) ${ }^{39}$ in conjunction with the Loney's $\mathrm{scale}^{36}$, as summarized in the Supplementary Table S4.3. Again, in case of discrepancy in quality assessment between the 2 study investigators, the senior investigator reviewed the data and agreement was obtained.

\section{ENDPOINTS}

Primary aim was to estimate pooled prevalence of post-colonoscopy bleeding, postpolypectomy bleeding, perforation and mortality rates. In an attempt to provide tailored safety metrics, we stratified the data by colonoscopy indication.

Secondary aim was to explore time-trends in post-colonoscopy complication rate per year of colonoscopy.

\section{STATISTICAL ANALYSIS}

Random effects model was used to calculate the pooled perforation rate and postcolonoscopy bleeding rate with corresponding $95 \%$ confidence intervals $(\mathrm{Cl})$. Because low rates were expected, Arcsin transformations were applied. ${ }^{40}$ The results, after back-conversion are presented as the original scale. Mean age was added as a covariate to the random effects model. The differences between subgroups (screening/surveillance vs symptoms; with vs without polypectomy) were tested using a logistic mixed-effects model with a random effect for study group. Heterogeneity among the studies was measured using $\mathrm{I}^{2}$ statistics. ${ }^{41}$ Funnel plots with Egger's test 
were constructed to test the effect of publication bias. Pooled overall prevalence of post-colonoscopy bleeding, post-polypectomy bleeding, perforation and mortality in the entire population were calculated, subdivided according to colonoscopy indication. Screening and surveillance were merged as one indication because in a significant number of studies data was presented in this way. For the time-trend analysis, starting year of inclusion was entered as a covariate in the meta-regression analysis. We did not perform an analysis based on the year of publication as this does not inform on the time of patient inclusion.

Statistical analyses were performed using the metafor package ${ }^{42}$ and Ime4 package ${ }^{43}$ in R statistics 3.1.2. ${ }^{44}$ Pooled meta-analyses data were presented as forest plots.

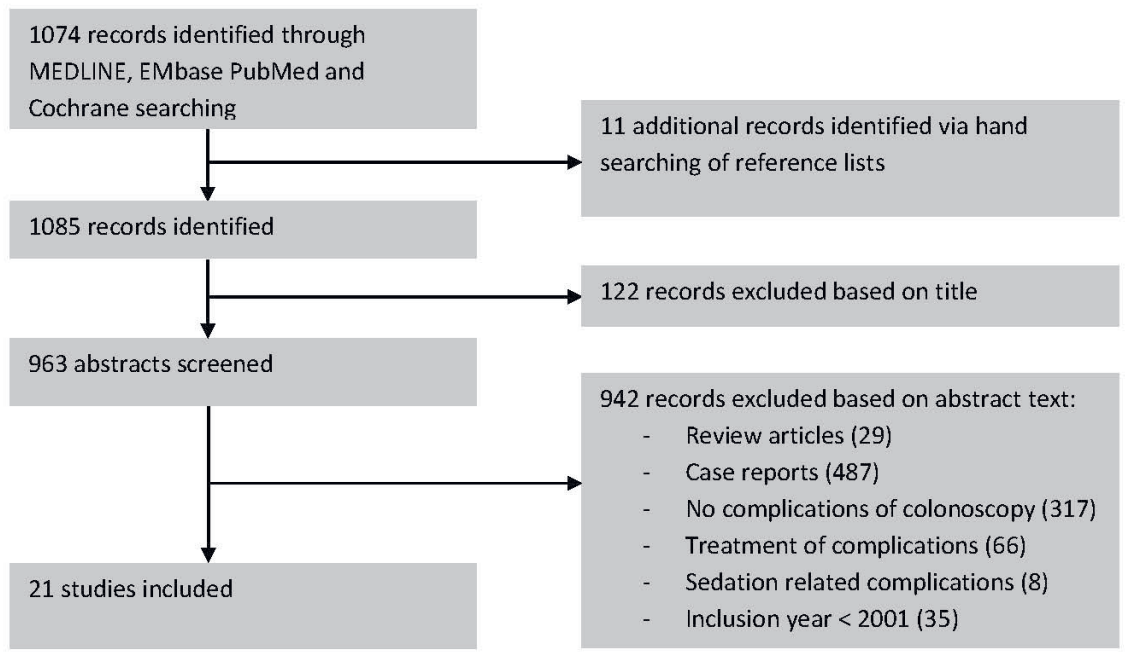

Figure 4.1 Study flow diagram of the inclusion and exclusion of studies for systematic review and metaanalysis for adverse events post-colonoscopy.

\section{RESULTS}

Search strategy and selection of studies are shown in Figure 4.1. EMbase search resulted in 722 studies. A similar search in Pubmed provided 731 studies, while Cochrane search provided 17 studies. Duplicates were traced and deleted. A total of 1074 studies were analyzed. Eleven additional studies were identified after reviewing the reference lists, resulting in 1085 studies. Studies were excluded after title or abstract screening $(n=1031)$ or full text evaluation $(n=33)$, by the two investigators independently. 
In total, 21 studies were analyzed, including 1,966,340 colonoscopies performed over the period spanning from January 1, 2001 to August 31, 2012 (publication date until December 1, 2015. Summary data are described in Supplementary Table S4.1.

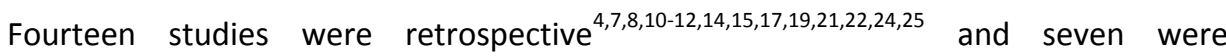
prospective studies. $5,6,9,13,16,18,20$ There were four studies from the United States $^{5,12,17,22}$, three from Canada ${ }^{15,20,21}$, ten from Europe $6-11,13,16,18,19$, three from South-Korea ${ }^{14,24,25}$ and one from New Zealand (4).

Mean age of the study populations varied from 50.4 to 70.0 years ${ }^{4,6,10,14-21,24,25}$ (median age, 57 to 75 years ${ }^{5,9,13,16,21}$ ). $51.5 \%$ were males. ${ }^{4-9,11-22,24,25}$ Overall, the mean pooled colonoscopic completion rate was 93.1\% (range 50.0-99.0\%). 5,6,8,9,11-13,15,16,21,24 In 8 studies colonoscopy was performed for symptoms, screening/surveillance, and therapeutic indications. ${ }^{6,7,12,15-17,20,22}$ Two studies examined symptomatic and therapeutic colonoscopies ${ }^{19,21}$, two symptomatic and screening/surveillance ${ }^{9,13}$, five only screening/surveillance $5,8,10,11,18$ and four only therapeutic colonoscopy (population-based studies of patients undergoing polypectomy). ${ }^{4,14,24,25}$

\section{COMPLICATION RATE}

Overall, the perforation rate was $0.5 / 1,000$ colonoscopies $(95 \% \mathrm{Cl} 0.4-0.7)^{5-13,15-19,21,22}$ (Figure 4.2A). Bleeding rate after colonoscopy (including polypectomy and nonpolypectomy related bleeding) was $2.6 / 1,000$ colonoscopies $(95 \% \mathrm{Cl} 1.7-$

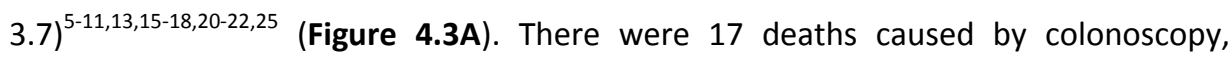
corresponding with a mortality rate of $2.9 / 100,000$ colonoscopies $(95 \% \mathrm{Cl} 1.1$ 5.5). ${ }^{4-6,8-21,25}$

Table 4.1 shows post-colonoscopy complication rates stratified by colonoscopyindication. Perforation rate was higher after colonoscopy with versus without polypectomy $\left(0.8 / 1,000\right.$ colonoscopies $(95 \% \mathrm{Cl} 0.6-1.0)^{5,6,8,10-12,14,17-22}$ (Figure 4.2B) versus $0.4 / 1,000$ colonoscopies (95\% $0.2-0.8)^{5,6,8,10-12,17-22}$ (Figure 4.2C), $p=0.07$ ). Notably, bleeding rate was significantly higher after colonoscopy with versus without polypectomy $(9.8 / 1,00095 \% \mathrm{Cl} \text { 7.7-12.1) })^{4-6,8,10,11,14,16-18,20,22,24,25}$ (Figure 4.3B) versus $0.6 / 1,000$ (95\% Cl 0.2-1.1), $p<0.001)^{5,6,8,10,11,16-18,20,22,24}$ (Figure 4.3C). Unfortunately, not all studies provided indication-specific data (i.e. colonoscopy performed for screening/ surveillance or symptoms; and colonoscopy with vs without polypectomy). Out of 21 studies, 13 presented data for post-polypectomy perforations 
(646,396 patients), 14 for post-polypectomy bleeding (527,838 patients), and 18 for complication-related mortality $(949,209$ patients) (Table 4.1).

In screening/surveillance setting, perforation and post-colonoscopy bleeding occurred in $0.3 / 1,000(95 \% \mathrm{Cl} 0.2-0.5)^{5,6,8-12,17-20,22}$ and $2.4 / 1,000(95 \% \mathrm{Cl} 0.9-4.6)^{5,6,8,10,11,13,18,20,22}$ (mortality rates not applicable). In symptomatic patients, such complications occurred in $1.3 / 1,000(95 \% \mathrm{Cl} 0.6-2.3)^{6,9,12,17,19,22}$ and $4.6 / 1,000(95 \% \mathrm{Cl} 0.1-15.8)^{6,9,13,20,22}$ colonoscopies (mortality rates not applicable). Perforation $(p<0.001)$ and bleeding $(p<0.001) \quad$ occurred significantly more often in symptomatic than screening/surveillance colonoscopies. Heterogeneity across studies was high for perforations $\left(I^{2}=88.95 \%\right)$ and bleedings $\left(I^{2}=99.15 \%\right)$, but was very low for mortality $\left(I^{2}=10.14 \%\right)$ (Figures 4.2-4.4). Funnel plots are shown in Supplementary Figure S4.1. Egger's test showed no asymmetry for perforations $(z=1.14, p=0.25)$ and significant asymmetry for post-colonoscopy bleeding $(z=4.19, p<0.001)$.

Finally, we conducted a sensitivity analysis (Supplementary Table S4.5), showing that inclusion of low bias studies only does not change the results of the study.

Table 4.1 Complication rates per colonoscopy indication.

\begin{tabular}{|c|c|c|c|c|c|c|c|c|c|c|c|c|}
\hline & \multicolumn{7}{|c|}{ Overall } & \multicolumn{5}{|c|}{ Indication for colonoscopy } \\
\hline & \multicolumn{2}{|l|}{ All } & \multicolumn{2}{|c|}{$\begin{array}{c}\text { With } \\
\text { polypectomy** }\end{array}$} & \multicolumn{2}{|c|}{$\begin{array}{c}\text { Without } \\
\text { polypectomy** }\end{array}$} & & \multicolumn{2}{|c|}{$\begin{array}{l}\text { Screening/ } \\
\text { Surveillance }\end{array}$} & \multicolumn{2}{|l|}{ Symptoms } & \\
\hline & $95 \% \mathrm{Cl}$ & $\mathrm{N}^{*}$ & $95 \% \mathrm{Cl}$ & $\mathrm{N}^{*}$ & $95 \% \mathrm{Cl}$ & $\mathrm{N}^{*}$ & $p$-value & $95 \% \mathrm{Cl}$ & $\mathrm{N}^{*}$ & $95 \% \mathrm{Cl}$ & $\mathrm{N}^{*}$ & $p$-value \\
\hline $\begin{array}{l}\text { Perforation } \\
\text { (per 1,000 } \\
\text { colonoscopies) }\end{array}$ & $0.5(0.4-0.7)$ & 16 & $0.8(0.6-1.0)$ & 13 & $0.4(0.2-0.8)$ & 12 & 0.07 & $0.3(0.2-0.5)$ & 12 & $1.3(0.6-2.3)$ & 6 & $<0.001$ \\
\hline $\begin{array}{l}\text { Bleeding } \\
\text { (per 1,000 } \\
\text { colonoscopies) }\end{array}$ & $2.6(1.7-3.7)$ & 16 & $9.8(7.7-12.1)$ & 14 & $0.6(0.2-1.1)$ & 11 & $<0.001$ & $2.4(0.9-4.6)$ & 9 & $4.6(0.1-15.8)$ & 5 & $<0.001$ \\
\hline $\begin{array}{l}\text { Mortality } \\
\text { (per 100,000 } \\
\text { colonoscopies) }\end{array}$ & $2.9(1.1-5.5)$ & 18 & NA & & NA & & & NA & & NA & & \\
\hline
\end{tabular}

${ }^{*} \mathrm{~N}=$ number of studies included in analysis (data available); ${ }^{* *}$ Irrespective of indication; NA = not applicable.

\section{TIME-TREND ANALYSIS}

The overall prevalence of post-colonoscopy and post-polypectomy bleeding declined over the past 15 years, from 6.4 to $1.0 / 1,000$ colonoscopies ( $p=0.07$ ) (Figure 4.4B). The perforation rate $(p=0.81)$ and mortality rate remained stable $(p=0.41)$ (Figure 4.4A and $4.4 \mathrm{C})$. 
A

Forest plot: Pooled perforation rate

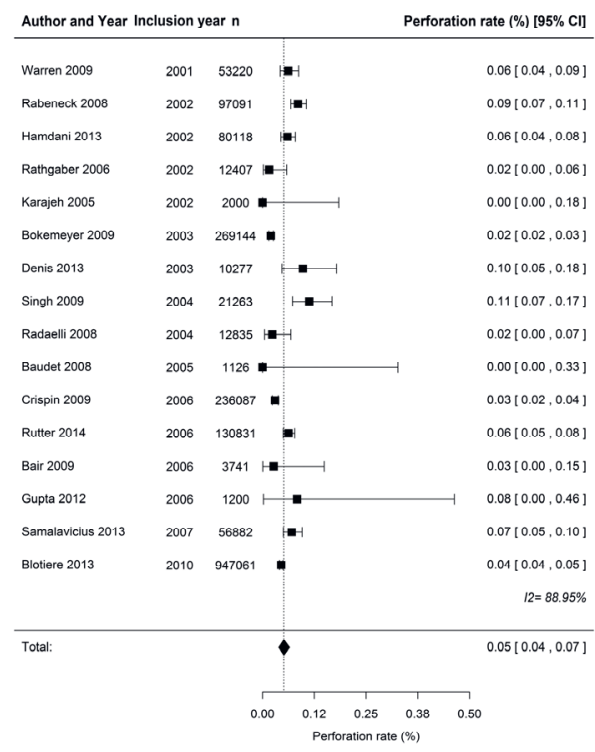

B Forest plot: Pooled post-polypectomy perforation rate $\quad$ C Forest plot: Pooled perforation rate without polypectomy

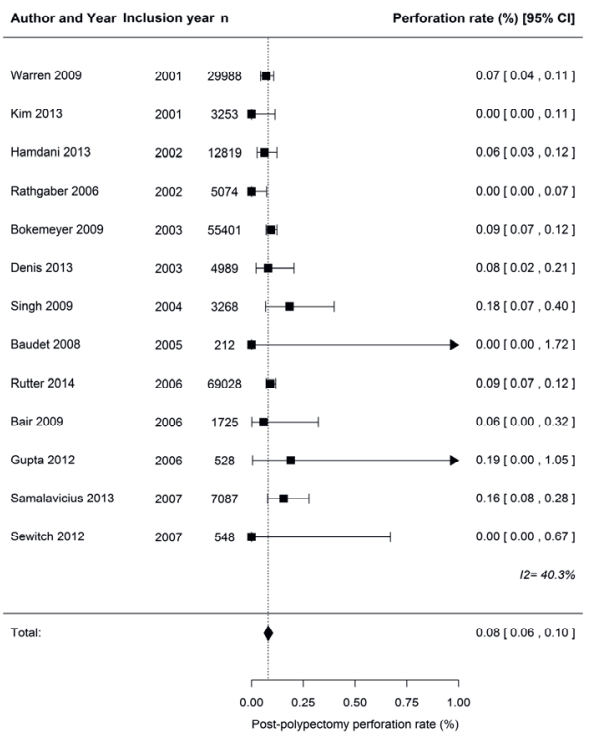

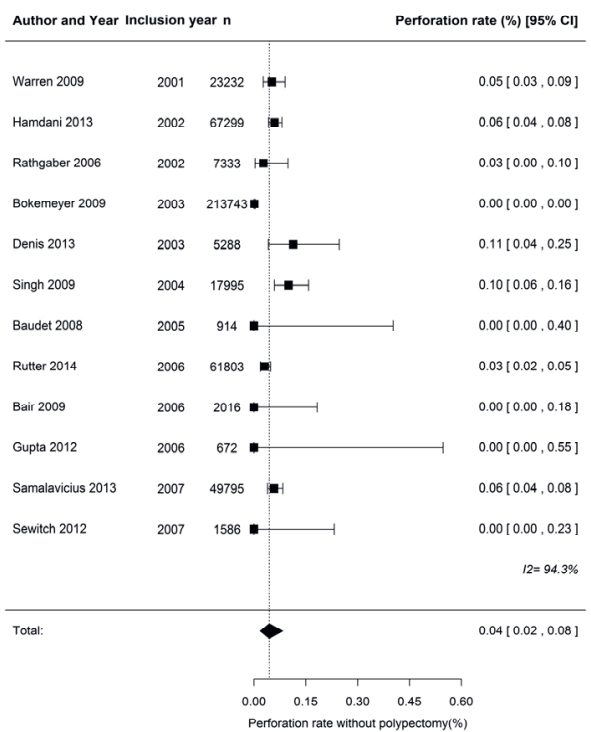

Figure 4.2 Pooled prevalences of overall post-colonoscopy perforations (A), sub divided in, perforations after colonoscopy with (B), and without (C) polypectomy. 


\section{A Forest plot: Pooled post-polypectomy bleeding rate}
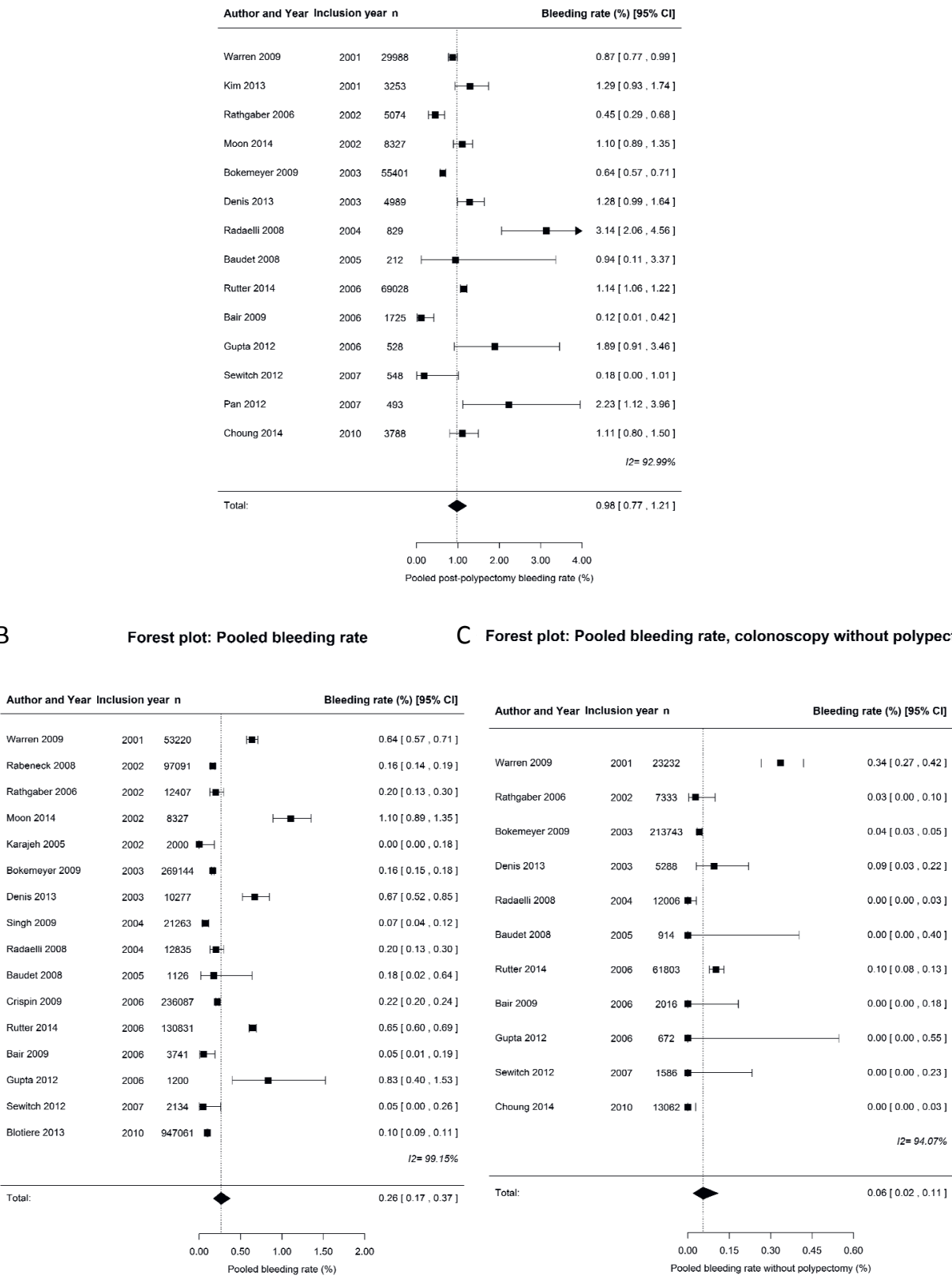

Figure 4.3 Pooled prevalences of post-colonoscopy bleeding (A), sub divided in bleeding after colonoscopy with (B) and without (C) polypectomy. 

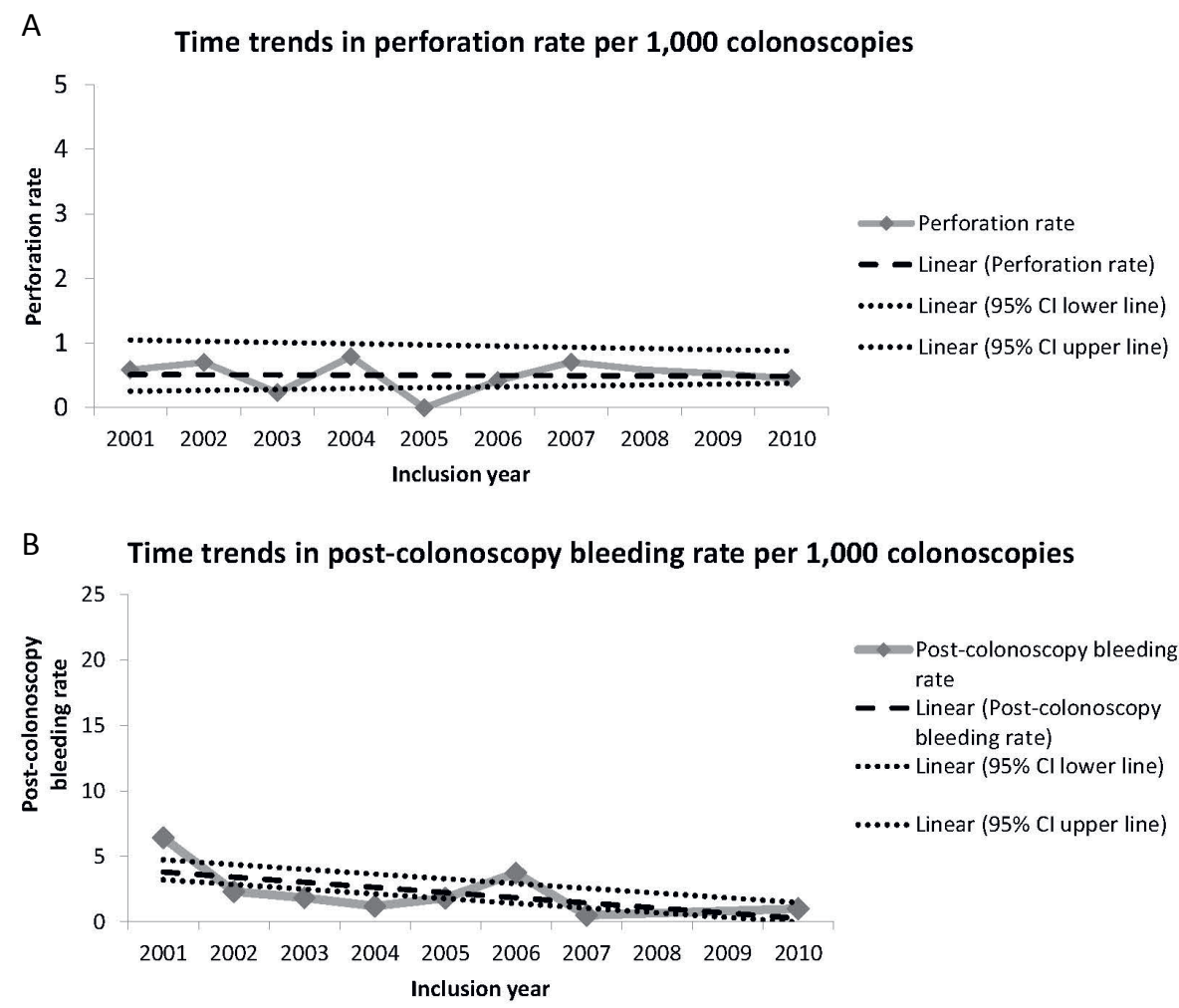

C Time trends in mortality rate per 100,000 colonoscopies

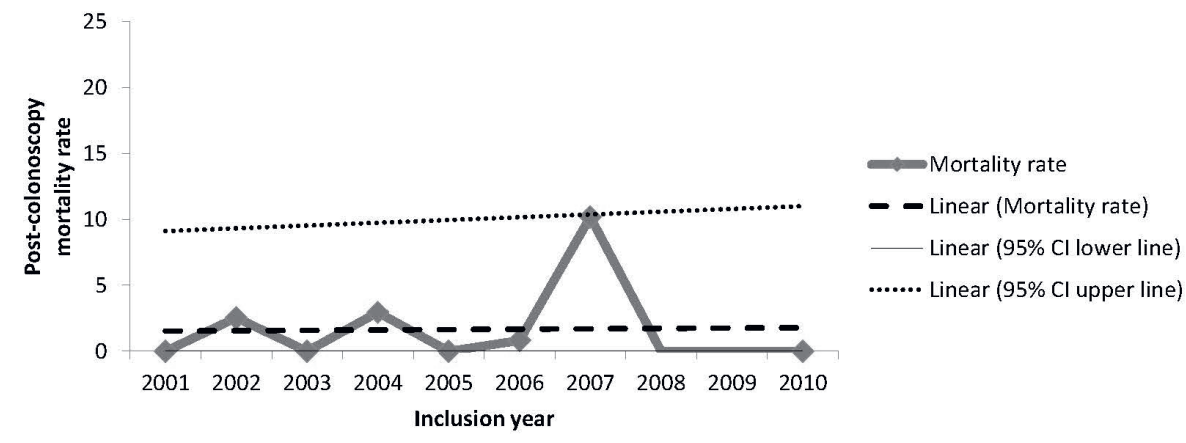

Figure 4.4 Time-trends of complication prevalences, divided per inclusion year. Time-trends in perforation rates (A), in bleeding (B) and mortality (C). 


\section{DISCUSSION}

This systematic review and meta-analysis of population-based studies confirms that colonoscopy is a safe procedure worldwide. Because of the increasing volume and technical difficulty of the examinations in the era of CRC screening and postpolypectomy surveillance, it is important to continuously monitor safety metrics in colonoscopy practice, and, where possible, to improve. Temporal variability should be assessed to retrace performance gaps and solve them. Time-trends analysis showed that the post-colonoscopy bleeding rate decreased from 6.4 to $1.0 / 1,000$ colonoscopies, while perforation and mortality rates remained stable low over the past 15 years. Noteworthy, we found that post-colonoscopy complication rate vary widely according to colonoscopy indication. For example, post-colonoscopy bleeding occurs in 2.6/1,000; 2.4/1,000; 4.6/1,000; and 9.8/1,000 colonoscopies (irrespective of indication); screening/surveillance; symptoms; and post-polypectomy procedures.

An important finding of this systematic review is the clinical decline in postcolonoscopy bleeding over the past 15 years. This is in contrast with the substantial rise of the overall polypectomy rate, especially endoscopic resection of larger nonpedunculated polyps (previously referred for surgical resection). Intuitively, an increase in volume and technical difficulty of polypectomy would lead to a higher rate of complications. Older patient age and comorbidity would also increase this risk. Despite more frequent and more challenging procedures, our meta-analysis shows a stabilizing trend for perforations and mortality and an even decreasing rate of postcolonoscopy bleeding. Such outcomes are most likely due to continuous improvement in colonoscopy equipment (i.e. adoption of high-definition colonoscopes), techniques (i.e. introduction of $\mathrm{CO} 2$ instead of air insufflation) and especially better training including knowledge and technical skills. ${ }^{23,33,45,46}$ Nowadays, submucosal saline solution injection and clipping are more frequently employed to prevent or treat bleeding or perforation. Notwithstanding, training and proficiency in performance of endoscopic resection techniques vary greatly even amongst experienced colonoscopists. ${ }^{47,48}$ Gastrointestinal professional societies now recommend practical guidelines to optimize the effectiveness and safety of polypectomy in routine practice. $^{29,47,49}$ Systematic training of endoscopic resection techniques is increasingly implemented (hands-on training, video-training) (50)). All in all, these efforts help to disseminate practical skills and improve the safety of colonoscopy in routine clinical 
practice. $^{51,52}$ Worldwide, gastroenterologists and surgeons perform the vast majority of colonoscopies. Objective measurement of key performance indicators (cecal intubation and adenoma detection rates) showed lower performance for surgical than gastroenterological trainees and specialists. ${ }^{46}$ In some countries, colonoscopy practice is restricted to board certified gastroenterologists. ${ }^{7,10}$ Besides common complications, if colonoscopy is performed by a non-gastroenterologist, interval carcinomas are also more often identified. ${ }^{53,54}$ Differences in endoscopist training, volume of procedures and experience can partly explain such disparities in outcomes.

Studies reported that a volume of procedures greater than 300 colonoscopies per year is significantly associated with decreased risks of complications. ${ }^{15,16,21,24,53}$ A study by Rabeneck et al showed that colonoscopists in the lowest volume quintile $(<141$ colonoscopies/year) have significantly ( $p<0.001$ ) greater odds (OR: $2.96,95 \% \mathrm{Cl} 1.57$ 5.61) of complications than those in the highest volume quintile $\quad>379$ colonoscopies/year). ${ }^{15}$ To ensure the quality and safety of colonoscopy, the European Guidelines for Quality Assurance in Colorectal Cancer Screening recommend at least 300 colonoscopies/endoscopist per year. ${ }^{55}$ High-volume colonoscopists may have a significant role in clinical training of gastroenterology fellows to ultimately ensure procedure-specific competence.

\section{IMPLICATIONS FOR CLINICAL PRACTICE}

Recent guidelines propose benchmarks for quality assurance in colonoscopy. ${ }^{29,30}$ To our knowledge, meta-analysis data examining colonoscopy safety benchmarks around the globe are not yet available. This systematic review and meta-analysis of population-based studies shows that pooled prevalence of perforations is $0.5 / 1,000$ colonoscopies, for all examinations, consistent with previously recommended benchmarks. Noteworthy, the perforation rate for screening/ surveillance colonoscopy is approximately 4-fold lower than that for diagnostic examinations $\left(0.3 / 1,000\right.$ vs. $1.3 / 1,000$ examinations, $p<0.001 .^{9-12,18,22}$ Although not uniformly reported in all studies, the post-polypectomy perforation rate is estimated at $0.8 / 1,000$ colonoscopies. Overall post-colonoscopy bleeding is identified in $2.6 / 1,000$; 2.4/1,000; 4.6/1,000; and 9.8/1,000 colonoscopies for all indications; screening/surveillance; symptoms; and post-polypectomy, respectively. Mortality post-colonoscopy is found 2.9/100,000 colonoscopies for all indications; and was not applicable for screening/surveillance and symptoms. Table 4.1 summarizes the pooled 
prevalence of post-colonoscopy complications, as derived from our meta-analysis. Such information is a first step to develop evidence-based international benchmarks.

The time-trend graph on perforation rate shows one extreme, in 2005 , in the study by Baudet et al. ${ }^{6}$, in which no perforations were found. This is probably because of the exclusion of ASA III patients and those with previous colonic surgery and the small number of endoscopists and procedures included. Undoubtedly, studies examining only colonoscopies with polypectomy will identify more complications than those without polypectomies, in keeping with the findings of this meta-analysis. $\left(^{4,6,11,14}\right.$

Strengths of this systematic review reside in the inclusion of population-based studies, which increases generalizability of findings to routine clinical practice. We present indication-specific pooled prevalence of post-colonoscopy complications and a timetrend analysis of their evolution from 2001 to 2015.

There are several limitations to our study. First, there is a possibility that complications are underreported. It is also possible that the available data emerge from most experienced, most quality- and safety -driven practices around the globe. Real-life post-colonoscopy complication rate could be higher. Some studies included self-reported complications by physicians, while others complications retrieved from insurance claims data. Not all studies used uniform definitions to ascribe complications. For example, some studies did not define post-colonoscopy complications as those identified $\leq 30$ days after the examination, but $\leq 7$ days $s^{7,12,25}$ and $\leq 14$ days $^{16,24}$ (Supplementary Table S4.2). Sensitivity analyses after exclusion of these studies showed similar results. Therefore, we included these studies, keeping in mind a possible underreporting of complications due to a shorter follow-up. Unfortunately, very few studies included information on endoscopists' background, training and volume of procedures. Use of anticoagulant therapy was not consistently mentioned. A better understanding of these factors may help to target training programs and improve the clinical protocols. Again, not all studies examined all colonoscopies performed for all indications. There were studies which examined complication risk in colonoscopies with polypectomy only. Of note, heterogeneity was high amongst studies on perforation and bleeding (Figure 4.2A-4.3C). Not all studies reported both events. Differences in study populations, sample size, indication for colonoscopy could explain the heterogeneity (Supplementary Table S4.2 and Supplementary Table Ss4.3). 
Furthermore, we examined the effect of mean age on prevalence of perforations, post-colonoscopy bleeding and mortality in a single variable meta-regression analysis, which did not change the results (Supplementary Table S4.4). No significant funnel plot asymmetry was seen for perforations, while post-colonoscopy bleeding showed significant funnel plot asymmetry, probably caused by the high heterogeneity (Supplementary Figure S4.1). Sensitivity analysis was performed to assess the effect of including low bias studies only, which again did not change the results of the study (Supplementary Table S4.5).

Ideally, future studies on post-colonoscopy complications should use uniform definitions. Monitoring and reviewing process should be standardized. Postpolypectomy complications need special attention and should be reported separately. ${ }^{56}$ Post-polypectomy syndrome, cardiopulmonary complications, serious electrolyte disturbances and post-colonoscopy colorectal cancer (PCCRC) rates should also be reported. Multifactorial etiology of PCCRCs is described contributing to missed or incompletely resected lesions.

In conclusion, colonoscopy conditions have changed substantially over the past decade and, likewise, the complication rate changed. Unfortunately, not every colonoscopy-related complication is systematically recorded and reviewed in routine practice. Definitions of complications are not identical worldwide. To analyze and compare complication rate in the future it is important to apply worldwide agreed definitions. It is important to record, track and review all post-colonoscopy complications to reveal performance gaps that can be addressed to improve clinical outcomes. We expect that such approach will reduce patient risk in the future. This is the first systematic review and meta-analysis presenting time-trends of postcolonoscopy complications stratified by indication for colonoscopy. Despite increasing numbers and technical difficulty of colonoscopy over the past years, the postcolonoscopy complication rate remained relatively stable or even declined, likely reflecting positive changes and improvements in colonoscopy practice. 


\section{STUDY HIGHLIGHTS}

\section{WHAT IS CURRENT KNOWLEDGE}

1. Colonoscopy is one of the most commonly performed endoscopic procedures in clinical practice and safety is considered as a prerequisite. Post-colonoscopy complication rates must be minimized, irrespective of the indication, i.e. screening, surveillance, symptoms or therapy.

2. As the volume of colonoscopy procedures are increasing due to the rise of CRC screening and surveillance, an increasing number of asymptomatic, healthy individuals will be exposed to colonoscopy and risk of potential harm.

\section{WHAT IS NEW HERE}

1. Worldwide, colonoscopy is a safe diagnostic, screening, surveillance and therapeutic procedure. Pooled prevalences for perforation, post-colonoscopy bleeding and mortality are $0.05 \%, 0.26 \%$ and $0.0029 \%$ respectively.

2. Over the past 15 years, the post-colonoscopy bleeding rate decreased from 6.4 to 1.0/1000 colonoscopies, while perforation and mortality rates remained stable low. Changes in colonoscopy training and equipment could play a significant role.

3. Monitoring and reviewing of post-colonoscopy complications should become standard of care to retrace performance gaps and continuously improve the safety of colonoscopy. 


\section{REFERENCES}

1. Fisher DA, Maple JT, Ben-Menachem T, et al. Complications of colonoscopy. Gastrointest Endosc 2011;74:745-752.

2. Price J, Campbell C, Sells J, et al. Impact of UK Colorectal Cancer Screening Pilot on hospital diagnostic services. J Public Health (Oxf) 2005;27:246-253.

3. Jemal A, Siegel R, Ward E, et al. Cancer statistics, 2008. CA Cancer J Clin 2008;58:71-96.

4. Pan $A$, Schlup $M$, Lubcke $R$, et al. The role of aspirin in post-polypectomy bleeding--a retrospective survey. BMC Gastroenterol 2012;12:138.

5. Bair D, Pham J, Seaton MB, et al. The quality of screening colonoscopies in an office-based endoscopy clinic. Can J Gastroenterol 2009;23:41-47.

6. Baudet JS, Diaz-Bethencourt D, Aviles J, et al. Minor adverse events of colonoscopy on ambulatory patients: the impact of moderate sedation. Eur J Gastroenterol Hepatol 2009;21:656-661.

7. Blotiere PO, Weill A, Ricordeau P, et al. Perforations and haemorrhages after colonoscopy in 2010: a study based on comprehensive French health insurance data (SNIIRAM). Clin Res Hepatol Gastroenterol 2014;38:112-117.

8. Bokemeyer B, Bock H, Huppe D, et al. Screening colonoscopy for colorectal cancer prevention: results from a German online registry on 269000 cases. Eur J Gastroenterol Hepatol 2009;21:650-655.

9. Crispin A, Birkner B, Munte A, et al. Process quality and incidence of acute complications in a series of more than 230,000 outpatient colonoscopies. Endoscopy 2009;41:1018-1025.

10. Denis B, Gendre I, Sauleau EA, et al. Harms of colonoscopy in a colorectal cancer screening programme with faecal occult blood test: a population-based cohort study. Dig Liver Dis 2013;45: 474-480.

11. Gupta S, Saunders BP, Fraser C, et al. The first 3 years of national bowel cancer screening at a single UK tertiary centre. Colorectal Dis 2012;14:166-173.

12. Hamdani U, Naeem R, Haider F, et al. Risk factors for colonoscopic perforation: a population-based study of 80118 cases. World J Gastroenterol 2013;19:3596-3601.

13. Karajeh MA, Sanders DS, Hurlstone DP. Colonoscopy in elderly people is a safe procedure with a high diagnostic yield: a prospective comparative study of 2000 patients. Endoscopy 2006;38:226-230.

14. Kim JH, Lee HJ, Ahn JW, et al. Risk factors for delayed post-polypectomy hemorrhage: a case-control study. J Gastroenterol Hepatol 2013;28:645-649.

15. Rabeneck L, Paszat LF, Hilsden RJ, et al. Bleeding and perforation after outpatient colonoscopy and their risk factors in usual clinical practice. Gastroenterology 2008;135:1899-1906, 1906 e1.

16. Radaelli F, Meucci G, Minoli G. Colonoscopy practice in Italy: a prospective survey on behalf of the Italian Association of Hospital Gastroenterologists. Dig Liver Dis 2008;40:897-904.

17. Rathgaber SW, Wick TM. Colonoscopy completion and complication rates in a community gastroenterology practice. Gastrointest Endosc 2006;64:556-562.

18. Rutter MD, Nickerson C, Rees CJ, et al. Risk factors for adverse events related to polypectomy in the English Bowel Cancer Screening Programme. Endoscopy 2014;46:90-97.

19. Samalavicius NE, Kazanavicius D, Lunevicius R, et al. Incidence, risk, management, and outcomes of iatrogenic full-thickness large bowel injury associated with 56,882 colonoscopies in 14 Lithuanian hospitals. Surg Endosc 2013;27:1628-1635.

20. Sewitch MJ, Jiang M, Joseph L, et al. Rate of serious complications of colonoscopy in Quebec. Can J Gastroenterol 2012;26:611-613.

21. Singh $\mathrm{H}$, Penfold RB, DeCoster $\mathrm{C}$, et al. Colonoscopy and its complications across a Canadian regional health authority. Gastrointest Endosc 2009;69:665-671.

22. Warren JL, Klabunde CN, Mariotto $A B$, et al. Adverse events after outpatient colonoscopy in the Medicare population. Ann Intern Med 2009;150:849-57, W152.

23. Bielawska B, Day AG, Lieberman DA, et al. Risk factors for early colonoscopic perforation include nongastroenterologist endoscopists: a multivariable analysis. Clin Gastroenterol Hepatol 2014;12:85-92.

24. Choung BS, Kim SH, Ahn DS, et al. Incidence and risk factors of delayed postpolypectomy bleeding: a retrospective cohort study. J Clin Gastroenterol 2014;48:784-789. 
25. Moon HS, Park SW, Kim DH, et al. Only the size of resected polyps is an independent risk factor for delayed postpolypectomy hemorrhage: a 10-year single-center case-control study. Ann Coloproctol 2014;30:182-185.

26. Whitlock EP, Lin JS, Liles E, et al. Screening for colorectal cancer: a targeted, updated systematic review for the U.S. Preventive Services Task Force. Ann Intern Med 2008;149:638-658.

27. Day LW, Kwon A, Inadomi JM, et al. Adverse events in older patients undergoing colonoscopy: a systematic review and meta-analysis. Gastrointest Endosc 2011;74:885-896.

28. Rex DK, Petrini JL, Baron TH, et al. Quality indicators for colonoscopy. Am J Gastroenterol 2006;101:873-885.

29. Rex DK, Schoenfeld PS, Cohen J, et al. Quality indicators for colonoscopy. Am J Gastroenterol 2015;110:72-90.

30. Rembacken B, Hassan C, Riemann JF, et al. Quality in screening colonoscopy: position statement of the European Society of Gastrointestinal Endoscopy (ESGE). Endoscopy 2012;44:957-968.

31. Bowles CJ, Leicester R, Romaya C, et al. A prospective study of colonoscopy practice in the UK today: are we adequately prepared for national colorectal cancer screening tomorrow? Gut 2004;53: 277-283.

32. Iqbal CW, Chun YS, Farley DR. Colonoscopic perforations: a retrospective review. J Gastrointest Surg 2005;9:1229-1235: discussion 1236.

33. Anderloni A, Jovani M, Hassan C, et al. Advances, problems, and complications of polypectomy. Clin Exp Gastroenterol 2014;7:285-296.

34. Moher D, Liberati A, Tetzlaff J, et al. Preferred reporting items for systematic reviews and metaanalyses: the PRISMA statement. Int J Surg 2010;8:336-341.

35. Voorham QJ, Rondagh EJ, Knol DL, et al. Tracking the molecular features of nonpolypoid colorectal neoplasms: a systematic review and meta-analysis. Am J Gastroenterol 2013;108:1042-1056.

36. Loney PL, Chambers LW, Bennett KJ, et al. Critical appraisal of the health research literature: prevalence or incidence of a health problem. Chronic Dis Can 1998;19:170-176.

37. Lovell RM, Ford AC. Prevalence of gastro-esophageal reflux-type symptoms in individuals with irritable bowel syndrome in the community: a meta-analysis. Am J Gastroenterol 2012;107:1793-1801; quiz 1802.

38. Singh S, Singh PP, Murad $\mathrm{MH}$, et al. Prevalence, risk factors, and outcomes of interval colorectal cancers: a systematic review and meta-analysis. Am J Gastroenterol 2014;109:1375-1389.

39. Stang A. Critical evaluation of the Newcastle-Ottawa scale for the assessment of the quality of nonrandomized studies in meta-analyses. Eur J Epidemiol 2010;25:603-605.

40. Miller JJ. The inverse of the Freeman-Tukey double arcsine transformation. American Statistician;32:138.

41. Neyeloff JL, Fuchs SC, Moreira LB. Meta-analyses and Forest plots using a microsoft excel spreadsheet: step-by-step guide focusing on descriptive data analysis. BMC Res Notes 2012;5:52.

42. Viechtbauer $W$. Conducting meta-analyses in $R$ with the metafor package. Journal of Statistical Software 2010;36:1-48.

43. Bates D, Maechler M, Bolker B, et al. Fitting Linear Mixed-Effects Models Using Ime4. Journal of Statistical Software 2015;67:1-48.

44. R TR. A Language and Environment for Statistical Computing. R Foundation for Statistical Computing. R Foundation for Statistical Computing 2015.

45. Gupta AK, Melton $\amalg, 3 r$, Petersen GM, et al. Changing trends in the incidence, stage, survival, and screen-detection of colorectal cancer: a population-based study. Clin Gastroenterol Hepatol 2005;3:150-158.

46. Leyden JE, Doherty GA, Hanley A, et al. Quality of colonoscopy performance among gastroenterology and surgical trainees: a need for common training standards for all trainees? Endoscopy 2011;43: 935-940.

47. Pohl H, Srivastava A, Bensen SP, et al. Incomplete polyp resection during colonoscopy-results of the complete adenoma resection (CARE) study. Gastroenterology 2013;144:74-80 e1.

48. Asfaha S, Alqahtani S, Hilsden RJ, et al. Assessment of endoscopic training of general surgery residents in a North American health region. Gastrointest Endosc 2008;68:1056-1062. 
49. Rutter MD, Chattree A, Barbour JA, et al. British Society of Gastroenterology/Association of Coloproctologists of Great Britain and Ireland guidelines for the management of large nonpedunculated colorectal polyps. Gut 2015;64:1847-1873.

50. Rex DK. Colonoscopic Polypectomy. ASGE Endoscopic Learning Library 2007;Avialable at: http://www.asge.org/ell.list.aspx.

51. Singh N, Harrison M, Rex DK. A survey of colonoscopic polypectomy practices among clinical gastroenterologists. Gastrointest Endosc 2004;60:414-418.

52. Chandran S, Parker F, Vaughan R, et al. The current practice standard for colonoscopy in Australia. Gastrointest Endosc 2014;79:473-479.

53. Rabeneck L. Endoscopist specialty: a quality indicator at the population level. Clin Gastroenterol Hepatol 2014;12:93-94.

54. Cooper GS, Xu F, Barnholtz Sloan JS, et al. Prevalence and predictors of interval colorectal cancers in medicare beneficiaries. Cancer 2012;118:3044-3052.

55. Hassan C, Bretthauer M, Kaminski MF, et al. Bowel preparation for colonoscopy: European Society of Gastrointestinal Endoscopy (ESGE) guideline. Endoscopy 2013;45:142-150.

56. Sanduleanu S, Masclee AM, Meijer GA. Interval cancers after colonoscopy-insights and recommendations. Nat Rev Gastroenterol Hepatol 2012;9:550-554. 


\section{SUPPLEMENTARY DATA}

A

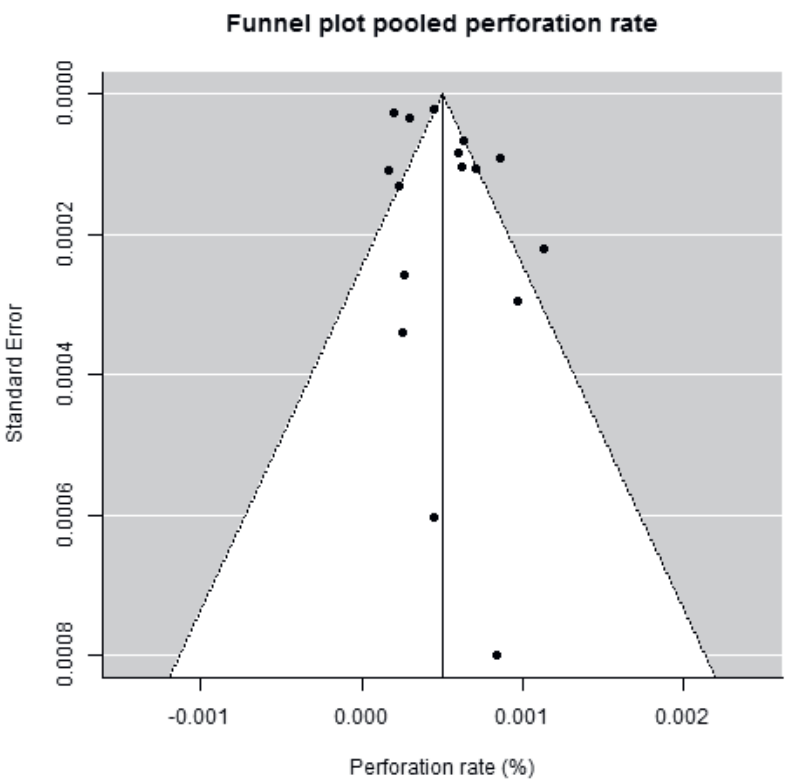

B

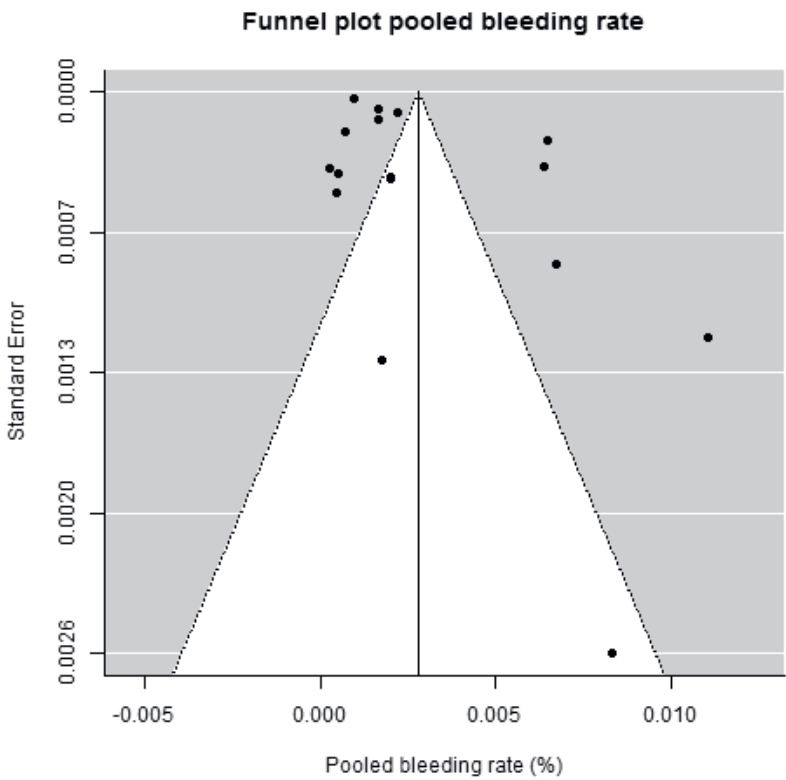

Figure S4.1 Funnel plots of post-colonoscopy perforation (A) and bleeding rate (B). 


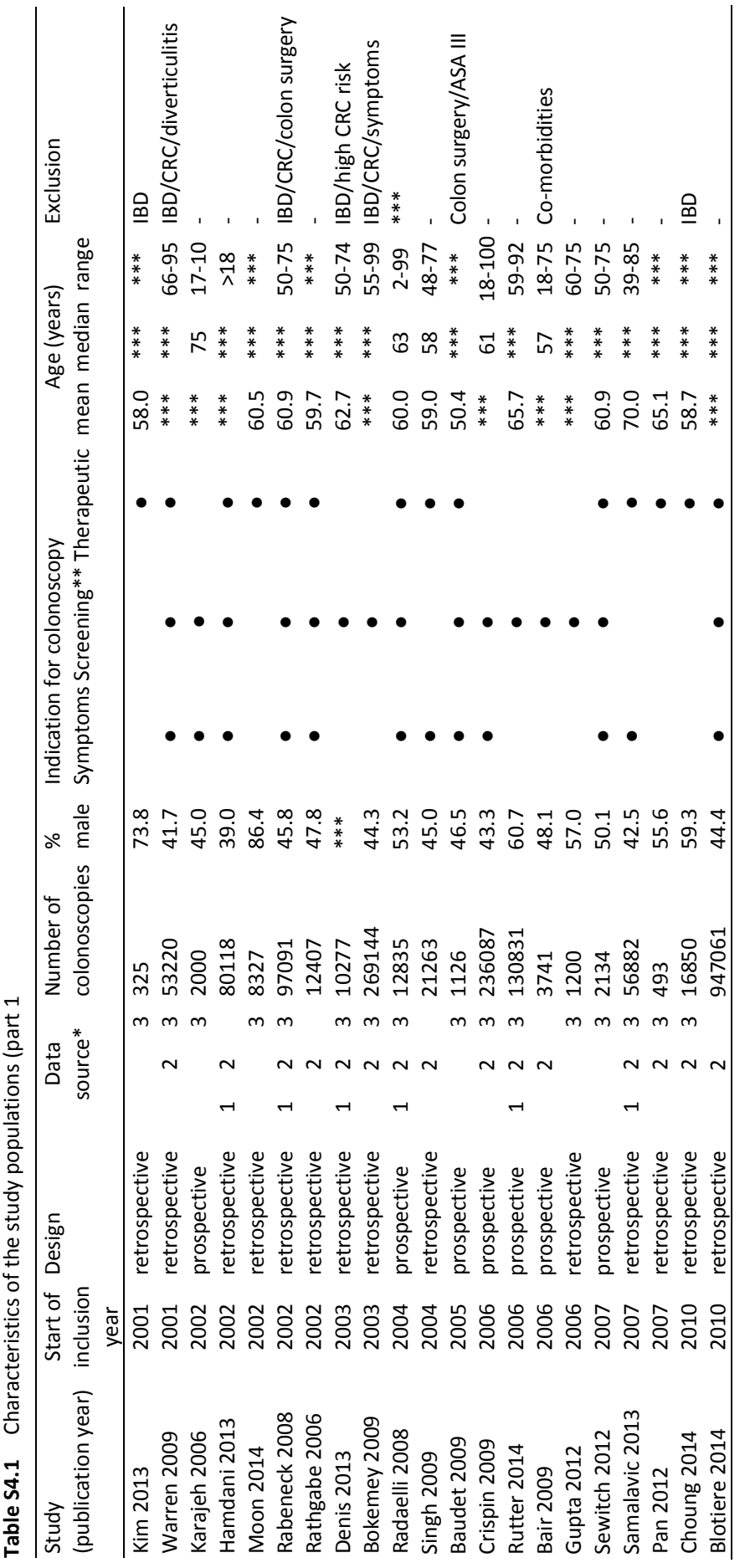




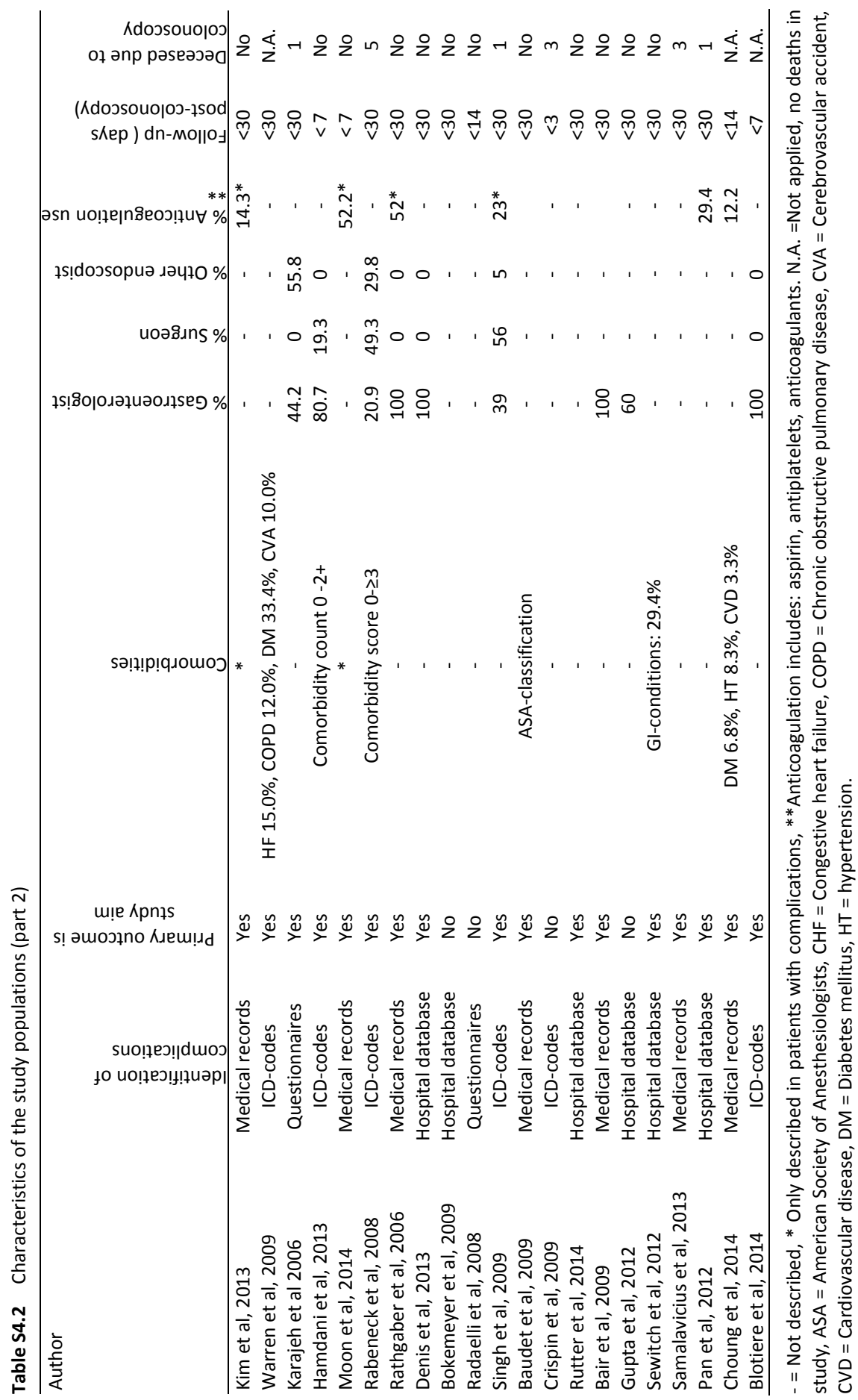




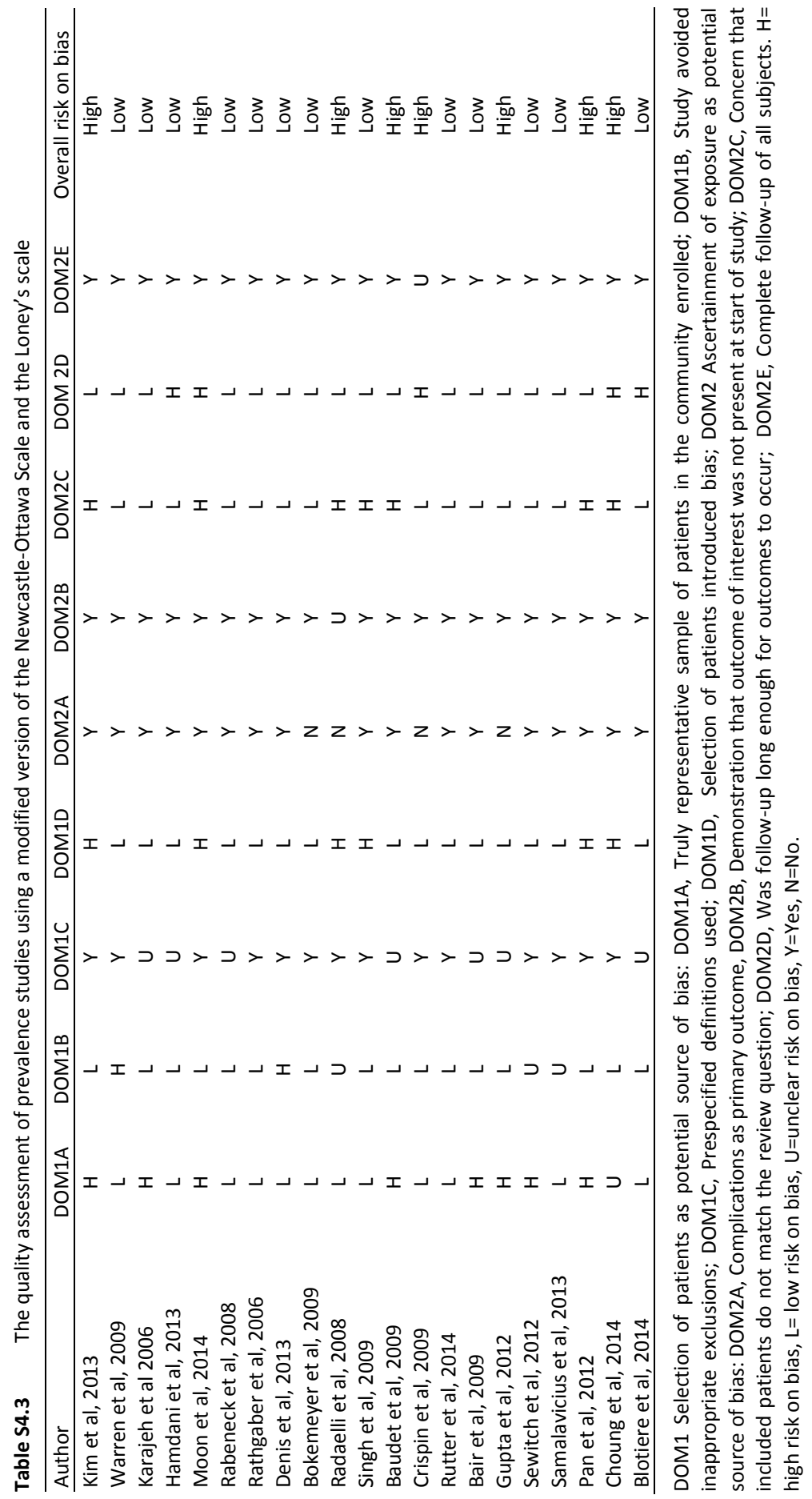


Table S4.4 Meta-regression analysis for mean age.

\begin{tabular}{lcc}
\hline & \multicolumn{2}{c}{ Overall } \\
\cline { 2 - 3 } & $N$ & $p$-value \\
\hline Perforation & 11 & 0.81 \\
Bleeding & 12 & 0.89 \\
Mortality & 15 & 0.69 \\
\hline
\end{tabular}

$\mathrm{N}=$ Number of studies available; N.A.= Not applicable.

Table S4.5 Sensitivity analysis on prevalences in all studies versus studies with low risk on bias.

\begin{tabular}{lcccccc}
\hline & \multicolumn{3}{c}{ In all studies } & \multicolumn{3}{c}{ In low bias studies } \\
\cline { 2 - 7 } & $N$ & $\%$ & $95 \% \mathrm{Cl}$ & $N$ & $\%$ & $95 \% \mathrm{Cl}$ \\
\hline Perforation & 16 & 0.05 & $(0.04-0.07)$ & 12 & 0.06 & $(0.04-0.07)$ \\
Bleeding & 16 & 0.26 & $(0.17-0.37)$ & 11 & 0.21 & $(0.11-0.34)$ \\
Mortality & 18 & 0.0029 & $(0.0011-0.0055)$ & 11 & 0.0029 & $(0.0008-0.0063)$ \\
\hline
\end{tabular}

$\mathrm{N}=$ number of studies included in analysis. 


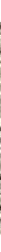




\section{CHAPTER 5}

\section{ELECTROLYTE DISTURBANCES AFTER BOWEL PREPARATION FOR COLONOSCOPY: A SYSTEMATIC REVIEW AND META-ANALYSIS}

A. Reumkens, Q.E.W. van der Zander, B. Winkens, R.M. Bogie, C.M. Bakker, S. Sanduleanu, A.A.M. Masclee 


\section{ABSTRACT}

\section{Background and study aims}

We conducted a systematic review and meta-analysis of population-based studies to explore pooled prevalence and magnitude of electrolyte changes after bowel preparation for colonoscopy.

\section{Patients and methods}

Pubmed and Cochrane were queried for population-bases studies examining changes in electrolyte values after bowel preparation, published by January $20^{\text {th }}, 2021$. We report prevalences of serum hypokalemia, hyponatremia, hyperphosphatemia, and hypocalcemia after bowel preparation and changes in mean electrolyte values after vs. before bowel preparation using sodium phosphate $(\mathrm{NaP})$ and polyethylene glycol (PEG).

\section{Results}

Fifteen studies met the inclusion criteria; 152,865 unique patients were included. Overall, hypokalemia was found in $14.6 \%$ (95\% Cl 4.8-28.1) in the NaP group vs. $3.7 \%$ (95\% $\mathrm{Cl} 0.1-10.4)$ in the PEG group. The magnitude of potassium decrease after NaP bowel preparation was significantly increased compared to PEG (mean difference $-0.38 ; 95 \% \mathrm{Cl}-0.49--0.27, p<0.001$ ). No study reported on major complications.

\section{Conclusions}

Hypokalemia was found in $14.6 \%$ of patients after bowel preparation with $\mathrm{NaP}$ and in $3.7 \%$ of patients with PEG. The magnitude of the potassium decrease after NaP was significantly higher compared to PEG. These data provide additional evidence to support the recommendation of the ESGE against use of NaP for bowel preparation. 


\section{INTRODUCTION}

Colonoscopy is considered as a safe procedure. An optimally cleansed bowel is a prerequisite for diagnosis and treatment of colorectal disorders. However, bowel preparation should not cause clinically important shifts in systemic electrolytes, in fluids, or in patient comfort.

Two main groups of bowel preparation solutions are available: the high-volume and low-volume solutions. High-volume polyethylene glycol (PEG) is included in the highvolume bowel preparation solutions, while sodium phosphate (NaP), low-volume PEG, and sodium picosulfate with magnesium citrate (SPMC) are included in the lowvolume bowel preparation solutions.

High-volume PEG solutions may cause discomfort, due to unpleasant smell, taste or occurrence of gastrointestinal symptoms, i.e. cramping and bloating. Due to lower prevalences of these side effects with low volume solutions, these solutions are increasingly used in endoscopy units. SPMC and low-volume PEG solutions provide efficient bowel preparation with only minimal adverse effects. Among the low-volume PEG solutions, a commonly used solution is $2 \mathrm{~L}$ polyethylene glycol with ascorbic acid (PEG-asc) as additive ${ }^{1,2}$ for its more pleasant taste and low risk for side-effects.

Bowel preparations may cause electrolyte disturbances which remain asymptomatic and unrecognized in the majority of cases. A recent publication reported on two patients who died because of cardiac arrhythmias that occurred after low-volume PEG resulting in severe post-colonoscopy hypokalemia. ${ }^{3}$ This publication was the first to report on patients with fatal consequences of electrolyte disturbances after bowel preparation for colonoscopy.

Up to now, the extent, magnitude, and risk factors for electrolyte disturbances remain unclear. In a meta-analysis, Tan and colleagues have studied the mean differences in serum potassium levels occurring in patients before vs. after bowel preparation with $\mathrm{NaP}$ or PEG. Based on sixteen studies, the authors concluded that decreases in serum potassium levels were significantly more often associated with use of NaP than with use of PEG solutions. ${ }^{4}$ However, the pooled prevalence of electrolyte disturbances was not evaluated in their study. Apart from this meta-analysis, only a few small 
sample size population-based studies have examined the frequency of electrolyte disturbances and mean differences in serum electrolyte levels after vs. before bowel preparation. $^{5}$ Current clinical guidelines do not include recommendations on electrolyte measurement before or after bowel preparation for colonoscopy. The ESGE guideline strongly recommends against the use of $\mathrm{NaP}$, while the evidence level for this recommendation is low. ${ }^{6}$ Therefore, we conducted a systematic review and meta-analysis of population-based studies examining the pooled prevalence rate of electrolyte disturbances after bowel preparation. In addition, pooled changes in mean electrolyte levels after vs. before bowel preparation were analyzed.

\section{MATERIALS AND METHODS}

The PRISMA methodology was employed for reporting systematic reviews ${ }^{7}$ (Supplementary). A local protocol for conducting a meta-analysis was applied, which is available on request. ${ }^{8,9}$

\section{SELECTION CRITERIA}

The studies included in this systematic review are population-based studies of plasma electrolyte disorders or serum electrolyte measurement after bowel preparation. Randomized, retrospective, and prospective studies were included. We report on a) studies that evaluated serum electrolyte measurements after bowel preparation vs. before bowel preparation and b) studies that examine prevalences of serum electrolyte disorders after bowel preparation. We defined serum electrolyte measurements as measurement of one or more of the following: potassium, sodium, magnesium, phosphorus, and/or calcium. Electrolyte concentrations had to be checked both before and after bowel preparation. Prevalences of serum electrolyte disorders were defined as the prevalence of hypokalemia (serum potassium $<3.5 \mathrm{mmol} / \mathrm{L}$ or $\mathrm{mEq} / \mathrm{L}$ ), hyponatremia (serum sodium $<135 \mathrm{mmol} / \mathrm{L}$ or $\mathrm{mEq} / \mathrm{L}$ ), or hypernatremia (serum sodium $>150 \mathrm{mmol} / \mathrm{L}$ or $\mathrm{mEq} / \mathrm{L}$ ) after bowel preparation. Definitions of electrolyte disorders were equal among the included studies. 


\section{SEARCH STRATEGY}

A systematic search was conducted in Pubmed and the Cochrane Library using search terms as 'colonoscopy' and 'hypokalemia' or 'potassium'. We retrieved key original population-based studies, whenever available up to January $20^{\text {th }}, 2021$. The following key words were used: Colonoscopy AND (bowel cleansing OR bowel preparation) AND (potassium OR hypokalemia) AND (sodium OR hyponatremia) including corresponding Mesh terms. Studies in English language were included. We reviewed all reference lists of eligible studies identifying additional population-based studies.

Case reports, review articles, studies reporting bowel preparation quality, studies investigating bowel preparation effects on electrolytes for other purposes than colonoscopy, and studies only reporting mean serum electrolyte values after bowel preparation were excluded. Studies investigating only prevalences of electrolyte disorders after bowel preparation were included.

Two reviewers (A.R. and Q.Z.) screened all studies independently. Study characteristics (first author, year of publication, country); study design (randomized controlled trial, prospective cohort study, retrospective cohort study); study outcomes (mean electrolyte values with standard deviations (SD), when available; prevalence of electrolyte disorders), and mean age with ranges were retrieved. In case of discrepancy between the two reviewers, a senior investigator (S.S.) reviewed the data to achieve consensus.

e used published criteria ${ }^{7,10-12}$ to evaluate the quality of clinical prevalence studies. The most suitable subsets of questions of the QUADAS- 2 tool ${ }^{13}$ and the Loney's scale ${ }^{10}$ were used, as summarized in the Supplementary Table S5.1.

\section{ENDPOINTS}

Primary endpoint was to estimate pooled prevalences of hypokalemia after bowel preparation and to calculate pooled changes in mean potassium values after vs. before bowel preparation.

Secondary endpoint was to estimate pooled prevalences after bowel preparation and pooled changes in mean electrolyte values after vs. before bowel preparation for sodium, magnesium, phosphorus, and calcium. 


\section{STATISTICAL ANALYSIS}

Random effects model was used to calculate pooled prevalences of electrolyte disorders and corresponding $95 \%$ confidence intervals (CI) from meta-analysis. Double Arcsin transformations for these prevalences were applied because of the low expected prevalences and possibly negative lower limits of the confidence intervals. Using double Arcsin back-conversion, prevalences were translated to the original scale. ${ }^{14,15}$ Heterogeneity among the studies was measured using $I^{2}$ statistics. ${ }^{16}$ Pooled overall prevalences of hypokalemia, hyponatremia, hyperphosphatemia, and hypocalcemia were calculated. From the studies that included both groups ( $\mathrm{NaP}$ and PEG) pooled Odds Ratios (ORs), corresponding $95 \% \mathrm{Cls}$ and p-values were computed using a random effects model. Pooled changes in mean electrolyte values after vs. before bowel preparation were calculated for potassium, sodium, magnesium, phosphorus, and calcium. In case standard deviations were not reported, standard deviations were estimated using information such as standard errors, $95 \% \mathrm{Cl}$, or test results, where possible. Pooled mean difference in change scores between $\mathrm{NaP}$ and PEG were obtained using a random effects model. We followed the Cochrane handbook (section 16.1.3.2) in imputing standard deviations for change scores using a correlation coefficient from another study. ${ }^{17}$ Statistical analyses were performed using the metafor package ${ }^{18}$ in $\mathrm{R}$ statistics $3.1 .2 .^{19}$ Pooled meta-analysis data were presented in forest plots and tables.

\section{RESULTS}

\section{INCLUDED STUDIES}

The study selection flowchart is shown in Figure 5.1. Pubmed search resulted in 103 studies and Cochrane search in 7 studies. Six duplicates were traced and deleted. A total of 104 studies were identified, of those 44 studies could be excluded based on title. Six additional records were identified via hand searching of reference lists. Of the 66 screened abstracts, 51 were excluded (i.e. 2 reviews, 2 case reports, 38 studies that contained only information on bowel preparation, 7 studies reported only differences in electrolytes (no means) or only means after bowel preparation, and 2 studies did not report standard deviations or provided no information to estimate standard deviations ${ }^{20,21}$. 


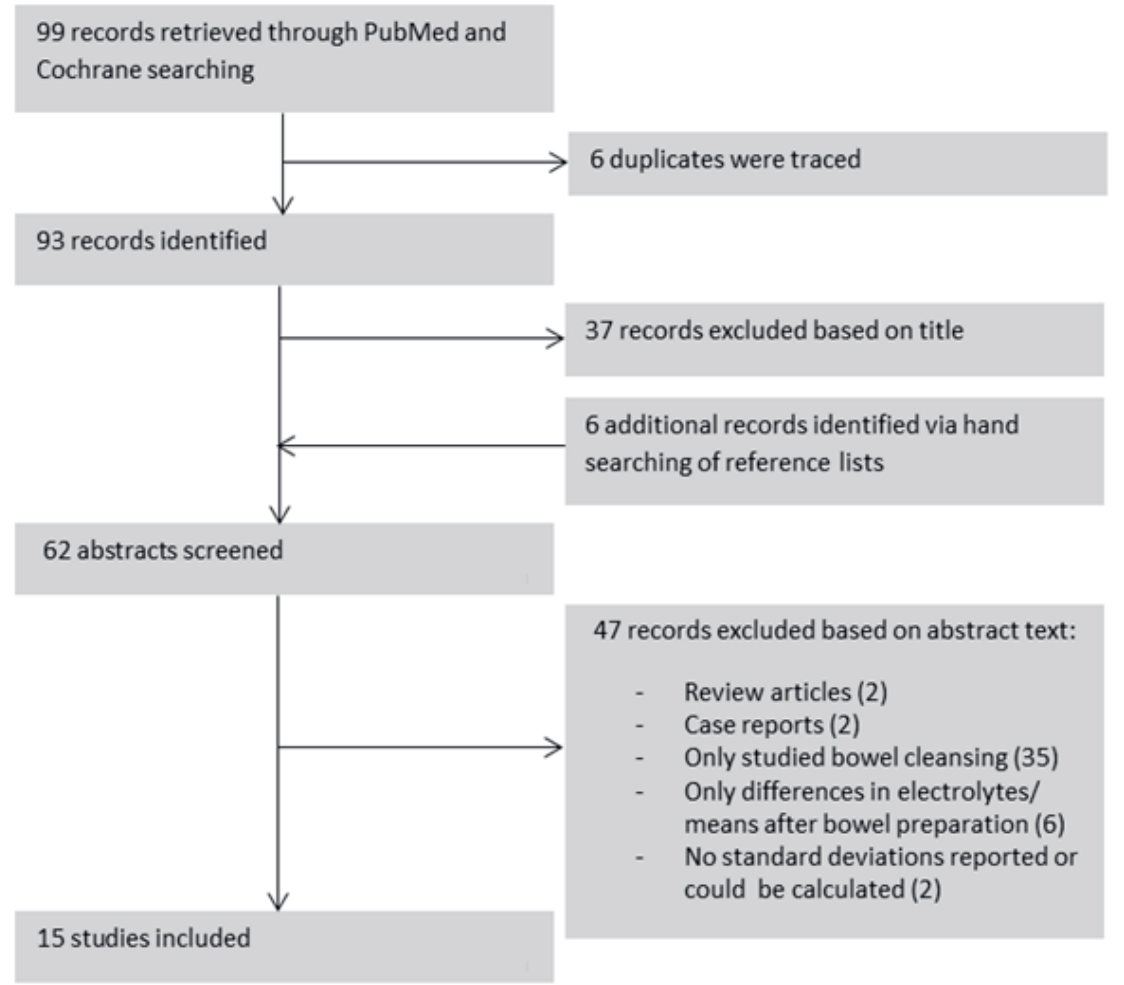

Figure 5.1 Study selection flowchart of studies who examined pooled prevalence and magnitude of electrolyte changes after bowel preparation for colonoscopy.

Summary data of the 15 included studies are described in Table 5.1. All studies were published between January $1^{\text {st }}, 1995$ and January $21^{\text {st }}, 2021 .^{22-36}$ Nine studies were randomized controlled trials ${ }^{23,25,26,28,30-33,36}, 4$ were prospective cohort studies ${ }^{22,24,29,35}$, and 2 were retrospective cohort studies. ${ }^{27,34}$ Six studies originated from Europe $^{22,26,28,30,31,35}, 4$ from the United States ${ }^{25,29,32,36}, 2$ from Asia ${ }^{23,27}, 2$ from Canada $^{33,34}$, and 1 from the Middle East. ${ }^{24}$ Overall, 152,865 (range 32-147,832) unique patients were included in the studies ${ }^{22-36}$ (Table 5.1). In the included studies, mean age of subjects varied from 46.9 to 80.5 years $^{22-26,28-36}$ (Table 5.1). Ten studies reported means of serum electrolytes, mostly with changes after vs. before bowel preparation $^{23-26,28-32,36}$; eleven studies reported prevalences of electrolyte disorders after bowel preparation. ${ }^{22,24,25,27-31,33-35}$ 


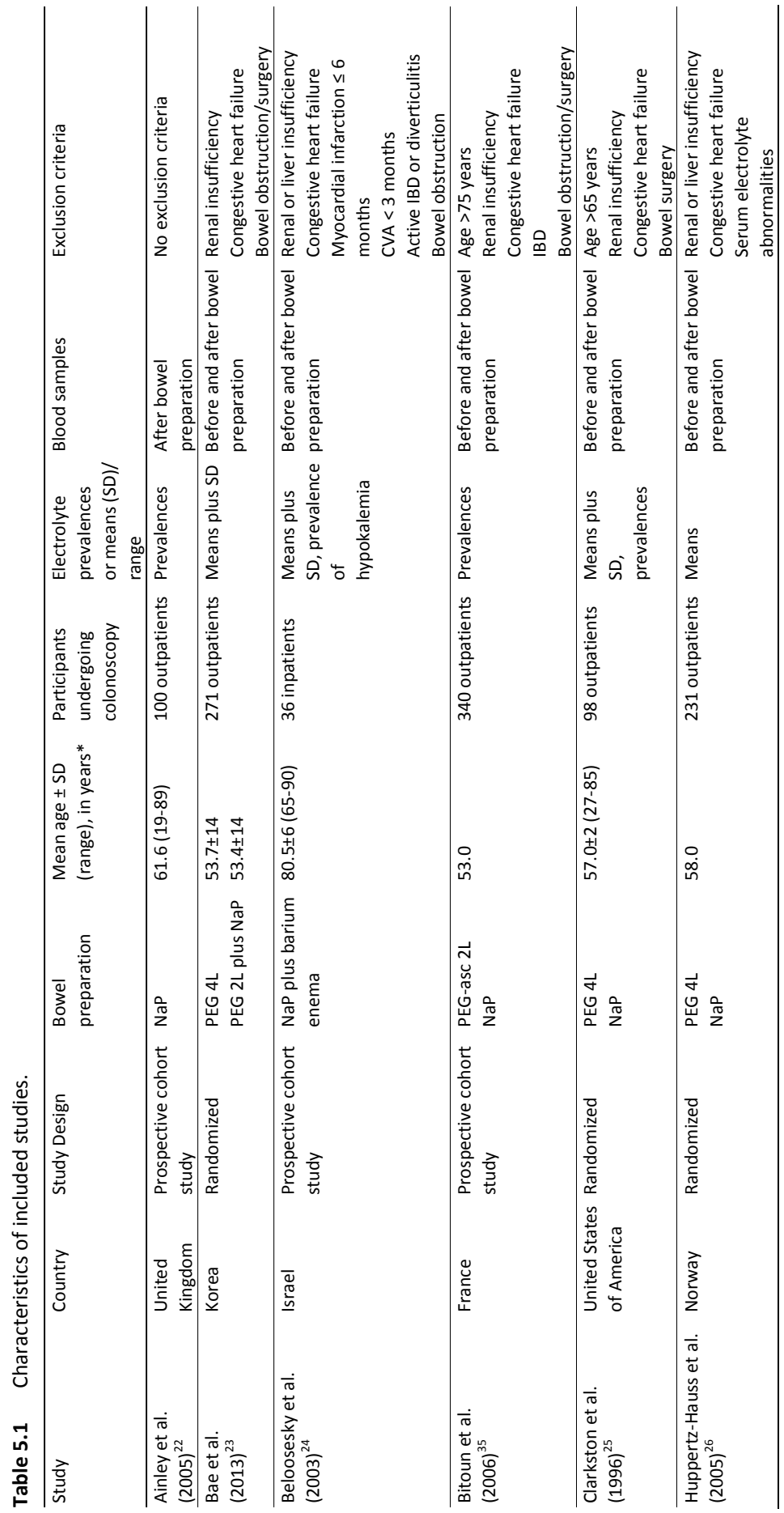




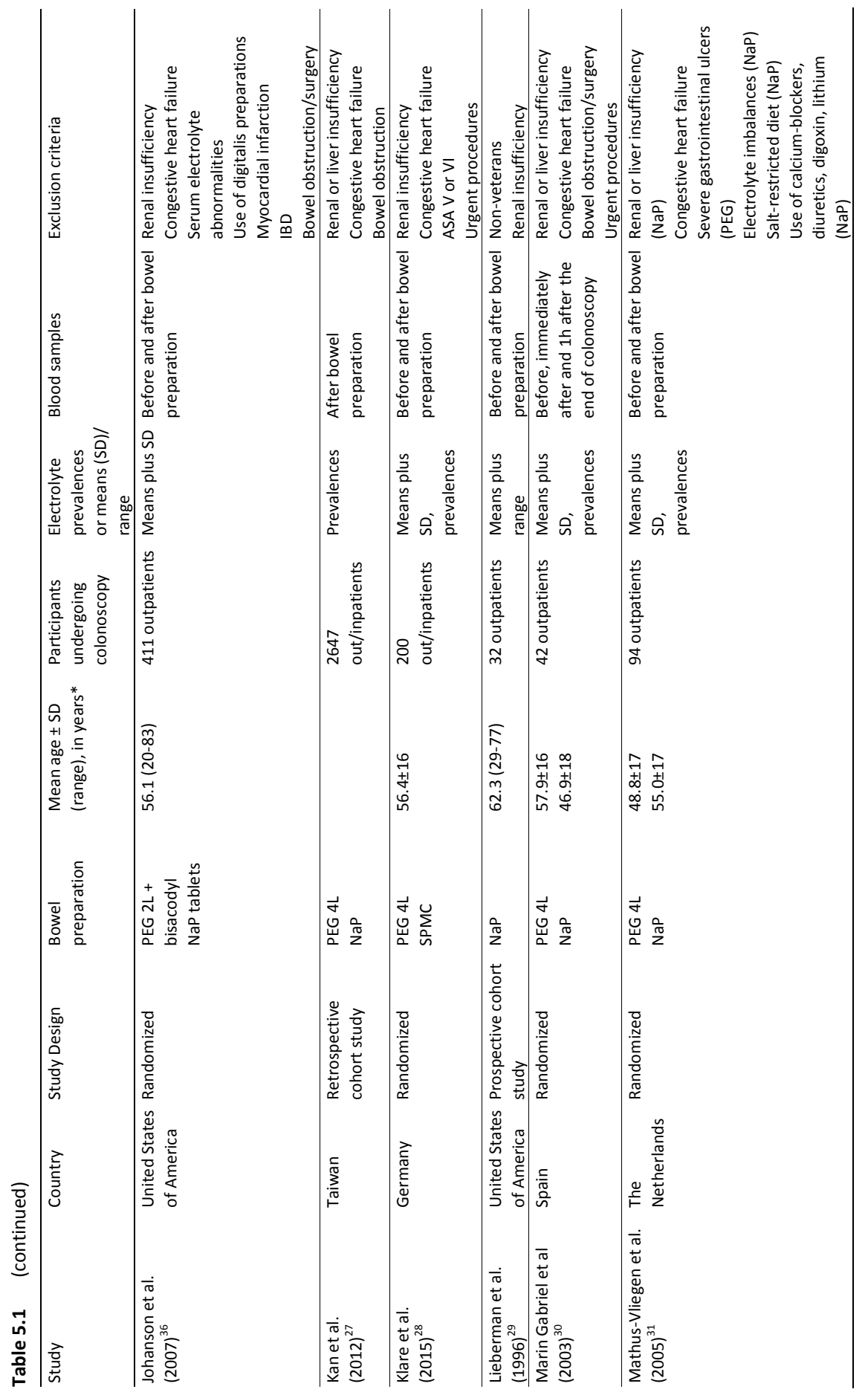




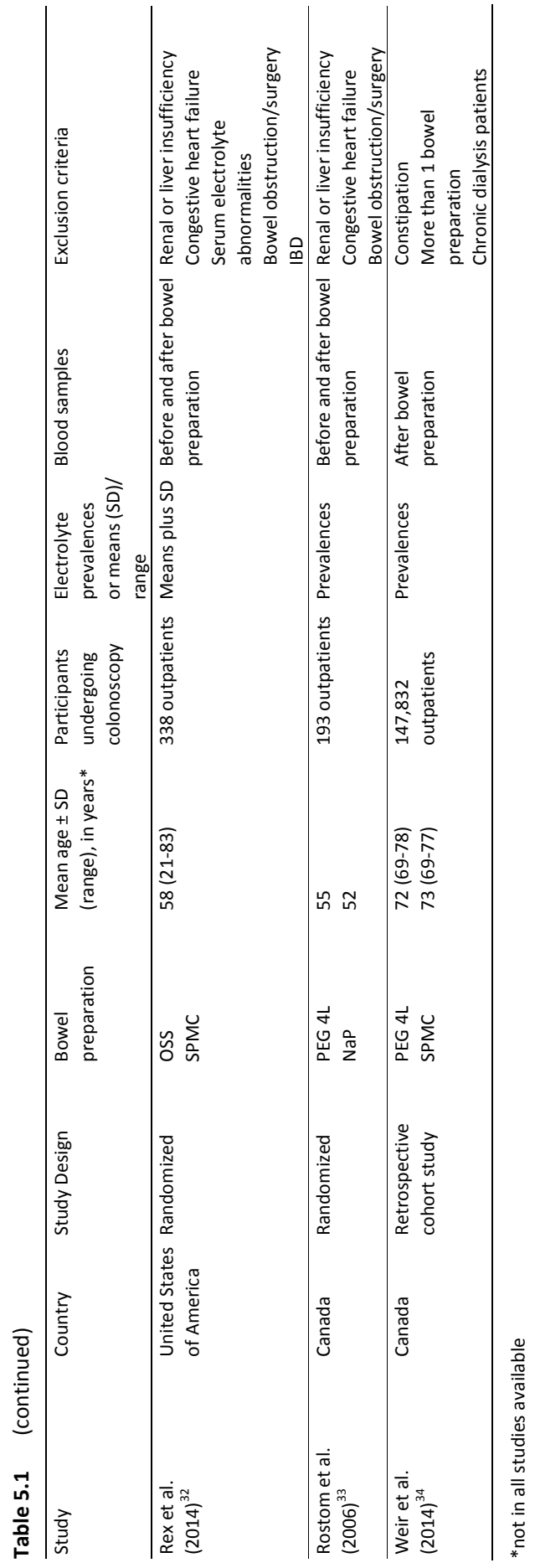


Since there were only two studies on means in $\mathrm{SPMC}^{28,32}$, two prevalence studies on SPMC $^{28,34}$, and one on PEG-asc ${ }^{35}$, a meta-analysis based on these studies was not performed. In the study focusing on PEG-asc, no electrolyte disorders were reported.

\section{POOLED PREVALENCES}

Overall, the prevalence of hypokalemia was $14.6 \%$ (95\% Cl 4.8-28.1) in patients after NaP bowel preparation for colonoscopy. After PEG bowel preparation hypokalemia was present in $3.7 \%(95 \% \mathrm{Cl}$ 0.1-10.4) (Table 5.2 and Figure 5.2). The risk of hypokalemia after NaP was not significantly different from PEG (OR 2.84; 95\% Cl 0.5514.67, $p=0.21$ ). Hyponatremia was found in 3.5\% (95\% $\mathrm{Cl} 0.0-1.5)$ in the NaP group vs. $0.9 \%$ (95\% Cl 0.0-2.8) in the PEG group; hyperphosphatemia in $36.0 \%$ (95\% Cl 18.6$55.5)$ vs. $4.3 \%$ (95\% $\mathrm{Cl} 0.3-11.3$ ); and hypocalcemia in $15.2 \%$ (95\% $\mathrm{Cl} 6.5-26.4$ ) vs. $9.2 \%$ (95\% Cl 4.7, 14.9) (Table 5.2).

Table 5.2 Pooled prevalences of electrolyte disorders after bowel preparation with NaP or PEG.

\begin{tabular}{|c|c|c|c|c|c|}
\hline $\begin{array}{l}\text { Bowel } \\
\text { preparation }\end{array}$ & Electrolyte disorder & $\begin{array}{c}\text { Number of } \\
\text { studies } \\
\text { included in the } \\
\text { analysis }\end{array}$ & $\begin{array}{c}\text { Pooled } \\
\text { prevalence }\end{array}$ & $95 \% \mathrm{Cl}$ & 12 \\
\hline \multicolumn{6}{|l|}{$\mathrm{NaP}$} \\
\hline & Hypokalemia ${ }^{22,24,25,27,30,31,33,35}$ & 8 & $14.60 \%$ & {$[4.83,28.05]$} & $96.4 \%$ \\
\hline & Hyponatremia $^{22,27,30,31,33}$ & 5 & $3.49 \%$ & {$[0.00,1.48]$} & $83.3 \%$ \\
\hline & Hyperphosphatemia ${ }^{22,25,27,29-31,33,35}$ & 8 & $36.01 \%$ & {$[18.62,55.46]$} & $97.5 \%$ \\
\hline & Hypocalcemia ${ }^{22,24,25,27,29-31,33,35}$ & 9 & $15.18 \%$ & {$[6.51,26.39]$} & $95.0 \%$ \\
\hline \multicolumn{6}{|l|}{ PEG } \\
\hline & Hypokalemia $^{25,27,28,30,31,33}$ & 6 & $3.70 \%$ & {$[0.12,10.42]$} & $88.9 \%$ \\
\hline & Hyponatremia $^{27,28,30,31,33,34}$ & 6 & $0.86 \%$ & {$[0.00,2.77]$} & $90.0 \%$ \\
\hline & Hyperphosphatemia $^{27,31,33}$ & 3 & $4.27 \%$ & {$[0.33,11.32]$} & $78.6 \%$ \\
\hline & Hypocalcemia $^{25,27,28,30,31,33}$ & 6 & $9.24 \%$ & {$[4.73-14.90]$} & $73.6 \%$ \\
\hline
\end{tabular}

\section{MEAN DIFFERENCES IN SERUM ELECTROLYTE CONCENTRATIONS}

Table $\mathbf{5 . 3}$ and Figure $\mathbf{5 . 3}$ show a pooled mean difference in serum potassium values of $-0.58 \mathrm{mmol} / \mathrm{L}(95 \% \mathrm{Cl}-0.70--0.45)$ in $\mathrm{NaP}$ patients and $-0.25 \mathrm{mmol} / \mathrm{L}(95 \% \mathrm{Cl}-0.32$ $-0.17)$ in the PEG group. A pooled change in mean sodium of $+2.4 \mathrm{mmol} / \mathrm{L}(95 \% \mathrm{Cl} 1.3-$ 3.5) was found in the NaP vs. $+0.4(95 \% \mathrm{Cl}-0.1-0.9)$ in the PEG group. Magnesium, phosphorus and calcium also showed minor alterations (Table 5.3). The magnitude of potassium decrease after $\mathrm{NaP}$ bowel preparation was significantly increased compared to PEG (mean difference $-0.38 ; 95 \% \mathrm{Cl}-0.49--0.27, p<0.001$ ). 
A Forest plot: NaP - pooled hypokalemia rate

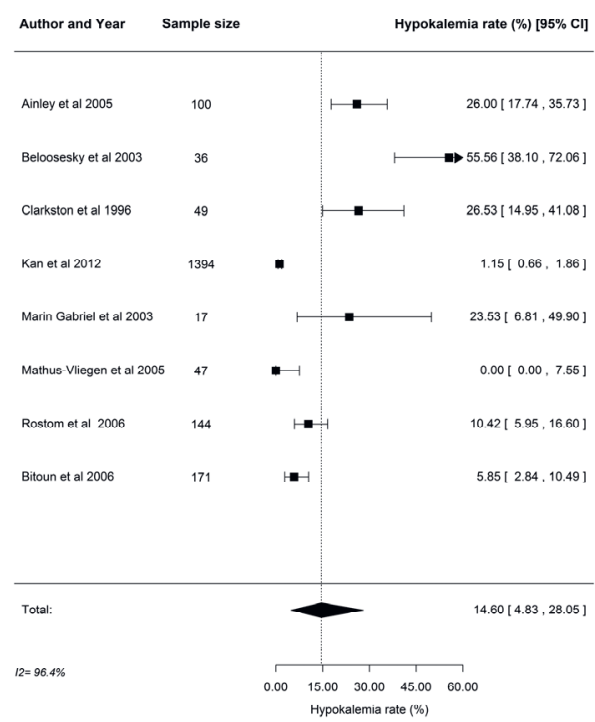

B Forest plot: PEG - pooled hypokalemia rate

C Forest plot: OR bowel preparations: NaP vs PEG
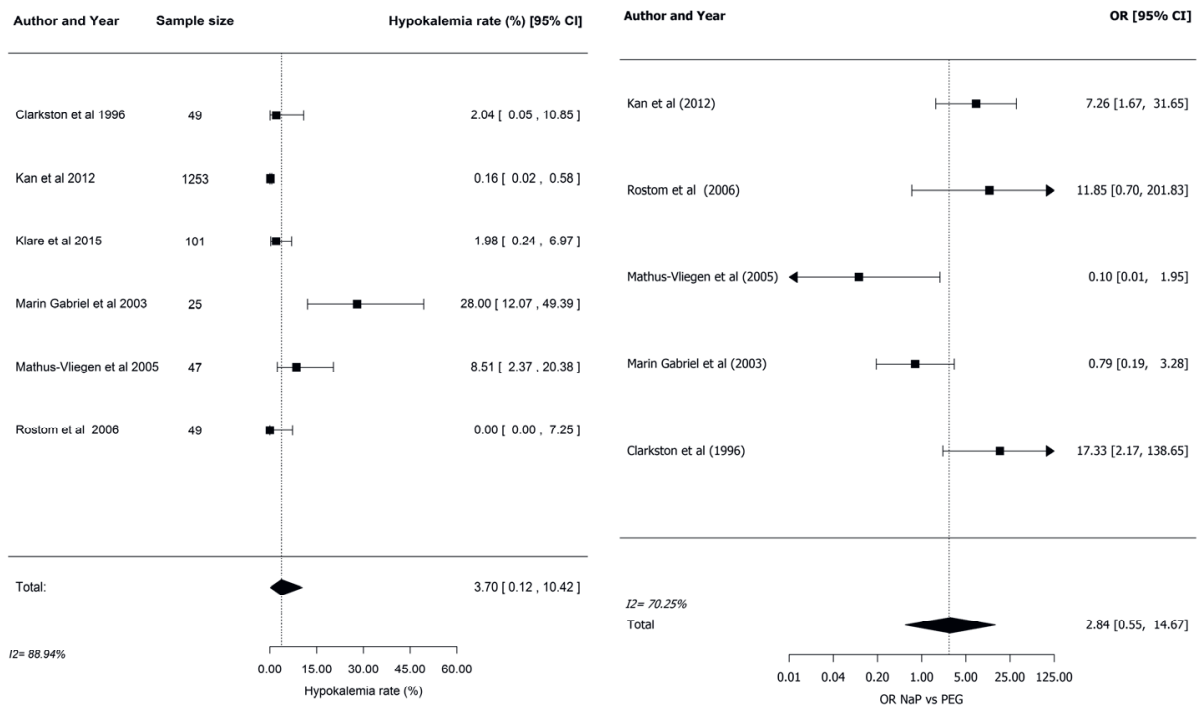

Figure 5.2 Pooled prevalences (\%) of hypokalemia after bowel preparation with NaP (A), PEG (B), and OR for NaP vs PEG (C). 
A Forest plot: NaP - mean potassium difference

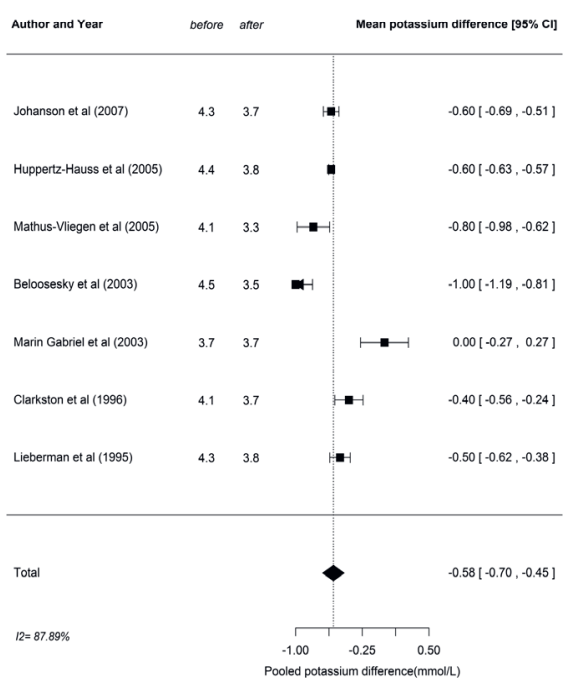

B Forest plot: PEG - mean potassium difference

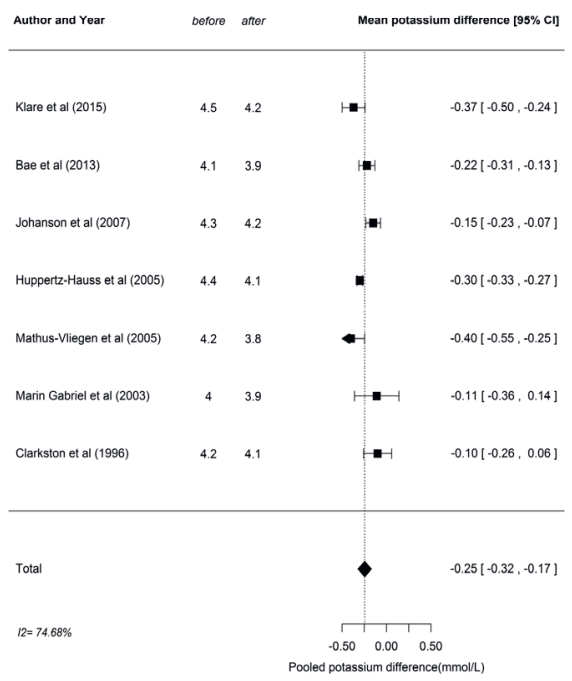

C Forest plot: Mean difference before and after Potassium in NaP vs PEG

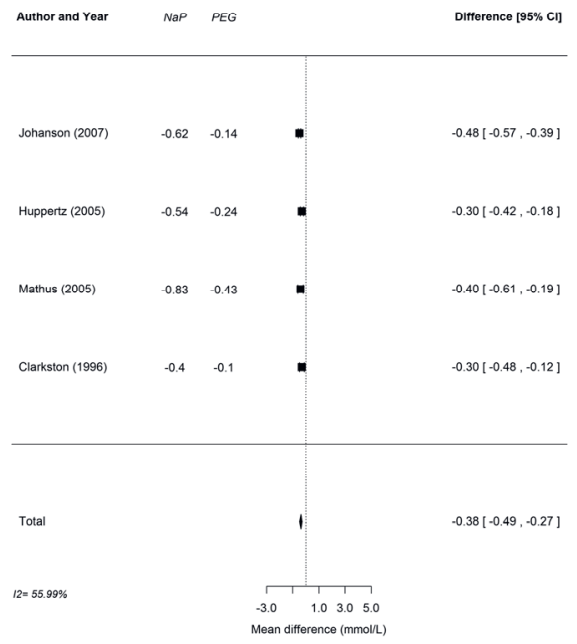

Figure 5.3 Pooled changes in mean potassium values (in $\mathrm{mmol} / \mathrm{L}$ ) after vs. before bowel preparation for $\mathrm{NaP}(\mathrm{A}), \mathrm{PEG}(\mathrm{B})$, and difference in mean change for $\mathrm{NaP}$ vs PEG (C). 
Table 5.3 Pooled changes in mean serum electrolyte values after vs. before bowel preparation for NaP and PEG.

\begin{tabular}{llcccc}
\hline $\begin{array}{l}\text { Bowel } \\
\text { preparation }\end{array}$ & Serum electrolytes & $\begin{array}{c}\text { Number of } \\
\text { studies } \\
\text { included in the } \\
\text { analysis }\end{array}$ & $\begin{array}{c}\text { Pooled change in } \\
\text { means (after } \\
\text { minus before) } \\
\text { [mmol/L] }\end{array}$ & 95\% Cl & I $^{2}$ \\
\hline NaP & Potassium & & \\
& Sodium $^{24-26,29,29-31,36}$ & 7 & -0.58 & {$[-0.70,-0.45]$} & $87.9 \%$ \\
& Magnesium $^{24,31,36}$ & 7 & +2.39 & {$[1.25,3.53]$} & $94.5 \%$ \\
& Phosphorus $^{24-26,29,31,36}$ & 3 & -0.03 & {$[-0.04,-0.02]$} & $0.0 \%$ \\
& Calcium $^{24-26,29,31,36}$ & 6 & +0.91 & {$[0.57,1.25]$} & $99.1 \%$ \\
PEG & Potassium $^{23,25,26,28,30,31,36}$ & 6 & -0.13 & {$[-0.17,-0.09]$} & $92.0 \%$ \\
& Sodium $^{23,25,26,28,30,31,36}$ & 7 & -0.25 & {$[-0.32,-0.17]$} & $74.6 \%$ \\
& Magnesium $^{28,31,36}$ & 7 & +0.41 & {$[-0.05,0.87]$} & $95.7 \%$ \\
& Phosphorus $^{23,25,26,28,31,36}$ & 3 & -0.03 & {$[-0.05,-0.01]$} & $76.8 \%$ \\
& Calcium $^{23,25,26,28,31,36}$ & 6 & -0.02 & {$[-0.08,0.05]$} & $89.9 \%$ \\
& & 6 & -0.06 & {$[-0.12,-0.01]$} & $93.1 \%$ \\
\hline
\end{tabular}

In all of the included studies, heterogeneity was high for the mean changes in electrolytes $\left(I^{2}=74.6-99.1 \%\right.$, Table 5.3), except for magnesium $(0.0 \%)$ in the $\mathrm{NaP}$ group. Heterogeneity was also high for all electrolyte prevalences $\left(I^{2}=73.6-97.5 \%\right.$, Table 5.2). In none of the included studies major complications (e.g. cardiac arrhythmias, epileptic seizures, paralysis, coma, or death) related to electrolyte disturbances after bowel preparation were reported or specified.

\section{DISCUSSION}

This systematic review and meta-analysis examined the safety of bowel preparation for colonoscopy with respect to electrolyte disturbances. A significant proportion of patients developed serum electrolyte disturbances after bowel preparation: 35-360/1,000 patients after NaP vs. 9-92/1,000 patients after PEG. We found a pooled prevalence of hypokalemia of $14.6 \%(95 \% \mathrm{Cl} 4.8,28.1)$ in patients after NaP vs. $3.7 \%$ $(95 \% \mathrm{Cl} 0.12,10.42)$ after PEG bowel preparation.

Practical clinical guidelines recommend to continuously monitor the quality and safety standards in colonoscopy. ${ }^{37,38}$ Since bowel preparation is an essential part of the colonoscopy procedure, quality and safety requirements should be clearly defined and monitored. 
Serum electrolyte values outside the normal range may increase patient and procedure risks. Electrolyte disturbances may vary from asymptomatic via mild and moderate symptoms (i.e. muscle weakness, constipation, nausea, and vomiting), to severe symptoms (i.e. paralysis, seizures, cardiac arrhythmias, coma, and death). ${ }^{4}$

Bowel preparation solutions are supposed to effectively clean the colon with minimal or no side-effects. NaP and PEG were among the most commonly used and studied preparations worldwide. $^{37,38}$ The use of $\mathrm{NaP}$ results in higher prevalences of electrolyte disturbances after bowel preparation compared to $\mathrm{PEG}^{22,24,25,27-31,33-35}$ (Table 5.2). Low-volume preparations, such as SPMC and PEG-asc, are more frequently used nowadays but these preparations may also result in electrolyte disturbances. ${ }^{39-41}$ Up to now, SPMC or PEG-asc induced electrolyte disturbances have not been extensively studied and reported in the literature. ${ }^{5,28,34,35}$ To date, di Nardo et $a l^{5}$, found no significant changes in serum potassium values after PEG-asc bowel preparation in children. Bitoun et al. ${ }^{35}$ reported that the hypokalemia risk was not increased after PEG-asc (Table 5.4). Considering the small number of studies and the small sample sizes, the observed low risk of potassium disturbances after PEG-asc should be interpreted with caution and cannot be considered to reliably represent the real-life population-based risk. Notably, severe hypokalemia and cardiac death in two patients following bowel preparation with low volume PEG-asc, has recently been reported ${ }^{3}$. Based on these cases, a study was undertaken to explore the magnitude of hypokalemia associated with bowel preparation in high risk patients. It was shown that $4.2 \%$ of patients had hypokalemia before bowel preparation and $23.6 \%$ developed hypokalemia after bowel preparation. ${ }^{41}$

In general, post-colonoscopy mortality is very low. ${ }^{42}$ All doctors and medical workers ordering colonoscopies, especially (nurse)endoscopists, should be aware that colonoscopy related morbidity and mortality risks also include effects related to the use of bowel preparation regimens. Current Gastroenterology or Endoscopy based professional guidelines do not recommend to routinely measure serum electrolyte levels prior to colonoscopy. ${ }^{37,38}$ Unfortunately, risk profiles of patients developing hypokalemia after bowel preparation, especially with the low-volume preparations, are lacking. To our knowledge, this is the first systematic review and meta-analysis reporting on prevalences of electrolyte disturbances after use of $\mathrm{NaP}$ and PEG bowel preparations. We provide actual prevalences of electrolyte disturbances and changes in mean electrolytes levels after vs. before bowel preparation. 


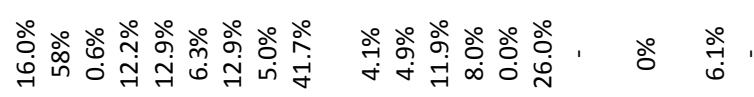

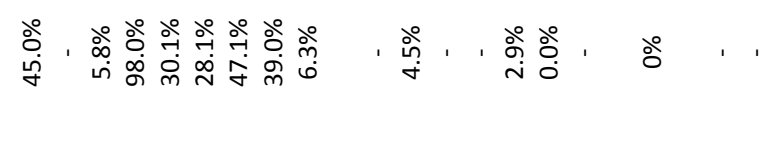

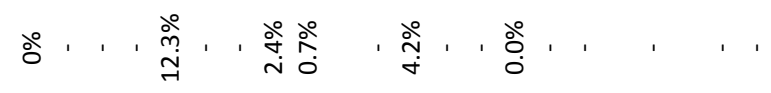

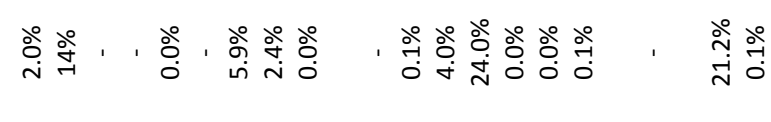

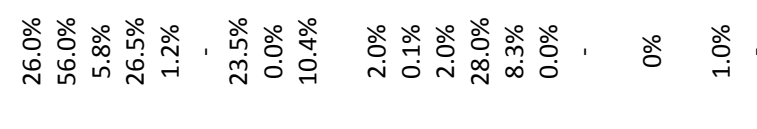

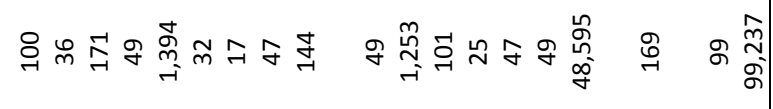

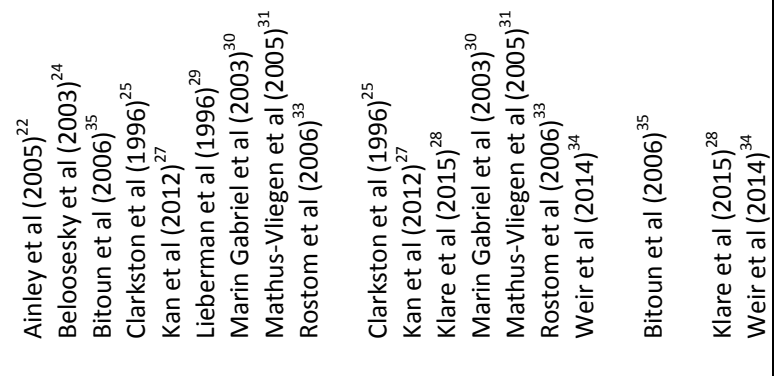


Several limitations should be addressed with respect to our study. First, prevalences of electrolyte disturbances may have been underreported in the separate studies because not all cases could be identified (treatment in other hospital, gastroenterologist did not notify the electrolyte disturbance). Second, as shown in Table 5.1, patients who suffer from renal insufficiency, heart failure, and/or bowel problems have been excluded in almost all studies. These patients run a higher risk for electrolyte disturbances associated with bowel preparation. For example, diuretics are frequently prescribed in heart failure, renal disease, and hypertension. Hypokalemia is a common consequence of specific types of diuretics. ${ }^{43}$ Unfortunately, diuretic use was not specifically reported in the included studies. In real-life, patients with renal insufficiency, heart failure, or bowel problems regularly undergo colonoscopy for diagnostic, screening, or surveillance indications. To be informed about the real-life prevalences of electrolyte disorders, these patient groups should be identified and examined in more detail in future studies. Third, because of the limited amount of data available on SPMC and PEG-asc, we could not present pooled prevalences or mean changes for these bowel preparation regimens. It should be taken into account that heterogeneity was high in most studies. No significant funnel plot asymmetry was seen (Supplementary Figure 5.1) for hypokalemia prevalences.

The most recently published guideline of the ESGE recommends the use of both PEGbased (high volume PEG or low volume PEG with ascorbate, citrate, or bisacodyl) and non-PEG-based (magnesium citrate plus picosulfate [SMPC], oral sulfate sodium) agents taking into account the precisely defined contraindications. ${ }^{6}$ The ESGE recommends against the use of $\mathrm{NaP}$, but this recommendation is based on low quality evidence. Given the high prevalences of electrolyte disturbances reported in this systematic review and meta-analysis, additional high quality evidence is provided to support the ESGE recommendation against use of $\mathrm{NaP}$ based bowel preparation solutions.

Nowadays, SPMC and PEG-asc low-volume bowel preparation regimens are increasingly used instead of $\mathrm{NaP}$ and high-volume $\mathrm{PEG}^{37,38}$. More data on prevalences of electrolyte disturbances after low-volume bowel preparations using SPMC and PEGasc should become available in order to examine pooled risks. Because of rapidly increasing volumes of colonoscopies for population based screening, surveillance, and regular care, the number of elderly patients and patients with comorbidity at risk for electrolyte disturbances will also increase in the near future. Therefore, population based data on patient-specific risk factors for electrolyte disturbances and disorders 
after bowel preparation should become available. Only thereafter, evidence based recommendations on monitoring serum electrolyte levels, especially in high risk patients with specific regimens can be made. Such recommendations are critical to ensure high quality and safety standards in colonoscopy.

In conclusion, electrolyte disturbances in response to bowel preparation have regularly been observed. Hypokalemia was found in $14.6 \%$ of patients after bowel preparation with $\mathrm{NaP}$ and in $3.7 \%$ of patients with PEG, a finding that is clinically relevant with respect to choosing the type of bowel preparation. The magnitude of the potassium decrease after NaP was significantly higher compared to PEG. These data provide the evidence that supports the recommendation of the ESGE against use of NaP for bowel preparation. 


\section{REFERENCES}

1. Aoun E, Abdul-Baki $\mathrm{H}$, Azar $\mathrm{C}$, et al. A randomized single-blind trial of split-dose PEG-electrolyte solution without dietary restriction compared with whole dose PEG-electrolyte solution with dietary restriction for colonoscopy preparation. Gastrointest Endosc. 2005;62:213-218.

2. Jansen SV, Goedhard JG, Winkens B, et al. Preparation before colonoscopy: a randomized controlled trial comparing different regimes. Eur J Gastroenterol Hepatol. 2011;23:897-902.

3. Reumkens A, Masclee AAM, Bakker CM. Postcolonoscopy mortality: Bowel preparation to blame? Gastrointest Endosc 2017;86:744-745.

4. Tan JJ, Tjandra JJ. Which is the optimal bowel preparation for colonoscopy - a meta-analysis. Colorectal Dis. 2006;8:247-258.

5. Di Nardo G, Aloi M, Cucchiara S, et al. Bowel preparations for colonoscopy: an RCT. Pediatrics. 2014; 134:249-256.

6. Hassan C, East J, Radaelli F, et al. Bowel preparation for colonoscopy: European Society of Gastrointestinal Endoscopy (ESGE) Guideline - Update 2019. Endoscopy. 2019;51:775-794.

7. Moher D, Liberati A, Tetzlaff J, et al. Preferred reporting items for systematic reviews and metaanalyses: the PRISMA statement. Int J Surg (London, England). 2010;8:336-341.

8. Voorham QJ, Rondagh EJ, Knol DL, et al. Tracking the molecular features of nonpolypoid colorectal neoplasms: a systematic review and meta-analysis. Am J Gastroenterol. 2013;108:1042-1056.

9. Reumkens A, Rondagh EJ, Bakker CM, et al. Post-Colonoscopy Complications: A Systematic Review, Time Trends, and Meta-Analysis of Population-Based Studies. Am J Gastroenterol. 2016;111(8): 1092-1101.

10. Loney $\mathrm{PL}$, Chambers LW, Bennett KJ, et al. Critical appraisal of the health research literature: prevalence or incidence of a health problem. Chronic Dis Can. 1998;19:170-176.

11. Lovell RM, Ford AC. Prevalence of gastro-esophageal reflux-type symptoms in individuals with irritable bowel syndrome in the community: a meta-analysis. Am J Gastroenterol. 2012;107:17931801; quiz 1802.

12. Singh S, Singh PP, Murad $\mathrm{MH}$, et al. Prevalence, risk factors, and outcomes of interval colorectal cancers: a systematic review and meta-analysis. Am J Gastroenterol. 2014; 109: 1375-1389.

13. Whiting PF, Rutjes AW, Westwood ME, et al. QUADAS-2: a revised tool for the quality assessment of diagnostic accuracy studies. Ann Intern Med. 2011;155:529-536.

14. Miller JJ. The inverse of the Freeman-Tukey double arcsine transformation. American Statistician;32: 138

15. Barendregt JJ, Doi SA, Lee YY, et al. Meta-analysis of prevalence. J Epidemiol Community Health 2013; 67:974-978.

16. Neyeloff JL, Fuchs SC, Moreira LB. Meta-analyses and Forest plots using a microsoft excel spreadsheet: step-by-step guide focusing on descriptive data analysis. BMC Res Notes 2012;5:52.

17. Cochrane. http://handbook.cochrane.org/chapter_16/16_1_3_2_imputing_standard_deviations_for_ changes_from_baseline.htm. DOI:

18. W. V. Conducting meta-analyses in R with the metafor package. J Stat Software 2010;36(3):1-48.

19. Team RC. R: A Language and Environment for Statistical Computing. R Foundation for Statistical Computing; Vienna, Austria:

20. Kastenberg D, Chasen R, Choudhary C, et al. Efficacy and safety of sodium phosphate tablets compared with PEG solution in colon cleansing: two identically designed, randomized, controlled, parallel group, multicenter phase III trials. Gastrointest Endosc. 2001;54:705-713.

21. Holte K, Nielsen KG, Madsen JL, et al. Physiologic effects of bowel preparation. Dis Colon Rectum. 2004;47:1397-1402. 
22. Ainley EJ, Winwood PJ, Begley JP. Measurement of serum electrolytes and phosphate after sodium phosphate colonoscopy bowel preparation: an evaluation. Dig Dis Sci. 2005;50:1319-1323.

23. Bae SE, Kim KJ, Eum JB, et al. A Comparison of $2 \mathrm{~L}$ of Polyethylene Glycol and $45 \mathrm{~mL}$ of Sodium Phosphate versus $4 \mathrm{~L}$ of Polyethylene Glycol for Bowel Cleansing: A Prospective Randomized Trial. Gut Liver 2013;7:423-429.

24. Beloosesky $Y$, Grinblat J, Weiss A, et al. Electrolyte disorders following oral sodium phosphate administration for bowel cleansing in elderly patients. Arch Intern Med. 2003;163:803-808.

25. Clarkston WK, Tsen TN, Dies DF, et al. Oral sodium phosphate versus sulfate-free polyethylene glycol electrolyte lavage solution in outpatient preparation for colonoscopy: a prospective comparison. Gastrointest Endosc. 1996;43:42-48.

26. Huppertz-Hauss G, Bretthauer M, Sauar J et al. Polyethylene glycol versus sodium phosphate in bowel cleansing for colonoscopy: a randomized trial. Endoscopy 2005;37:537-541.

27. Kan WC, Wang HY, Chien CC, et al. Intermediate bioelectrolyte changes after phospho-soda or polyethylene glycol precolonoscopic laxatives in a population undergoing health examinations. Nephrol Dial Transplant. 2012;27:752-757.

28. Klare $\mathrm{P}$, Poloschek $\mathrm{A}$, Walter $\mathrm{B}$, et al. Single-day sodium picosulfate and magnesium citrate versus split-dose polyethylene glycol for bowel cleansing prior to colonoscopy: A prospective randomized endoscopist-blinded trial. J Gastroenterol Hepatol. 2015;30:1627-1634.

29. Lieberman DA, Ghormley J, Flora K. Effect of oral sodium phosphate colon preparation on serum electrolytes in patients with normal serum creatinine. Gastrointest Endosc. 1996;43:467-469.

30. Marin Gabriel JC, Rodriguez Munoz S, de la Cruz Bertolo J, et al. [Electrolytic disturbances and colonoscopy: bowel lavage solutions, age and procedure]. Revista espanola de enfermedades digestivas : organo oficial de la Sociedad Espanola de Patologia Digestiva 2003;95:863-875.

31. Mathus-Vliegen EM, Kemble UM. A prospective randomized blinded comparison of sodium phosphate and polyethylene glycol-electrolyte solution for safe bowel cleansing. Aliment Pharmacol Ther. 2006;23:543-552.

32. Rex DK, DiPalma JA, McGowan J, et al. A comparison of oral sulfate solution with sodium picosulfate: magnesium citrate in split doses as bowel preparation for colonoscopy. Gastrointest Endosc. 2014; 80:1113-1123.

33. Rostom A, Jolicoeur E, Dube C, et al. A randomized prospective trial comparing different regimens of oral sodium phosphate and polyethylene glycol-based lavage solution in the preparation of patients for colonoscopy. Gastrointest Endosc. 2006;64:544-552.

34. Weir MA, Fleet JL, Vinden C, et al. Hyponatremia and sodium picosulfate bowel preparations in older adults. Am J Gastroenterol. 2014;109:686-694.

35. Bitoun A, Ponchon $\mathrm{T}$, Barthet $\mathrm{M}$, et al. Results of a prospective randomised multicentre controlled trial comparing a new 2-L ascorbic acid plus polyethylene glycol and electrolyte solution vs. sodium phosphate solution in patients undergoing elective colonoscopy. Aliment Pharmacol Ther. 2006;24: 1631-1642.

36. Johanson JF, Popp JW, Jr., Cohen LB, et al. A randomized, multicenter study comparing the safety and efficacy of sodium phosphate tablets with $2 \mathrm{~L}$ polyethylene glycol solution plus bisacodyl tablets for colon cleansing. Am J Gastroenterol. 2007;102:2238-2246.

37. Hassan C, Bretthauer M, Kaminski MF, et al. Bowel preparation for colonoscopy: European Society of Gastrointestinal Endoscopy (ESGE) guideline. Endoscopy 2013;45:142-150.

38. Wexner SD, Beck DE, Baron TH, et al. A consensus document on bowel preparation before colonoscopy: prepared by a task force from the American Society of Colon and Rectal Surgeons (ASCRS), the American Society for Gastrointestinal Endoscopy (ASGE), and the Society of American Gastrointestinal and Endoscopic Surgeons (SAGES). Gastrointest Endosc. 2006;63:894-909. 
39. Cohen SM, Wexner SD, Binderow SR, et al. Prospective, randomized, endoscopic-blinded trial comparing precolonoscopy bowel cleansing methods. Dis Colon Rectum. 1994;37:689-696.

40. Tjandra JJ, Chan M, Tagkalidis PP. Oral sodium phosphate (Fleet) is a superior colonoscopy preparation to Picopre (sodium picosulfate-based preparation). Dis Colon Rectum. 2006;49:616-620.

41. Ell C, Fischbach W, Keller R, et al. A randomized, blinded, prospective trial to compare the safety and efficacy of three bowel-cleansing solutions for colonoscopy (HSG-01*). Endoscopy. 2003;35:300-304.

42. Reumkens A, Rondagh EJ, Bakker CM, et al. Post-Colonoscopy Complications: A Systematic Review, Time Trends, and Meta-Analysis of Population-Based Studies. Am J Gastroenterol 2016;111: 1092-1101

43. ZorginstituutNederland. Pharmacotherapeutic Compass. Care Institute of the Netherlands 2016, DOI: www.farmacotherapeutischkompas.nl: 


\section{SUPPLEMENTARY DATA}
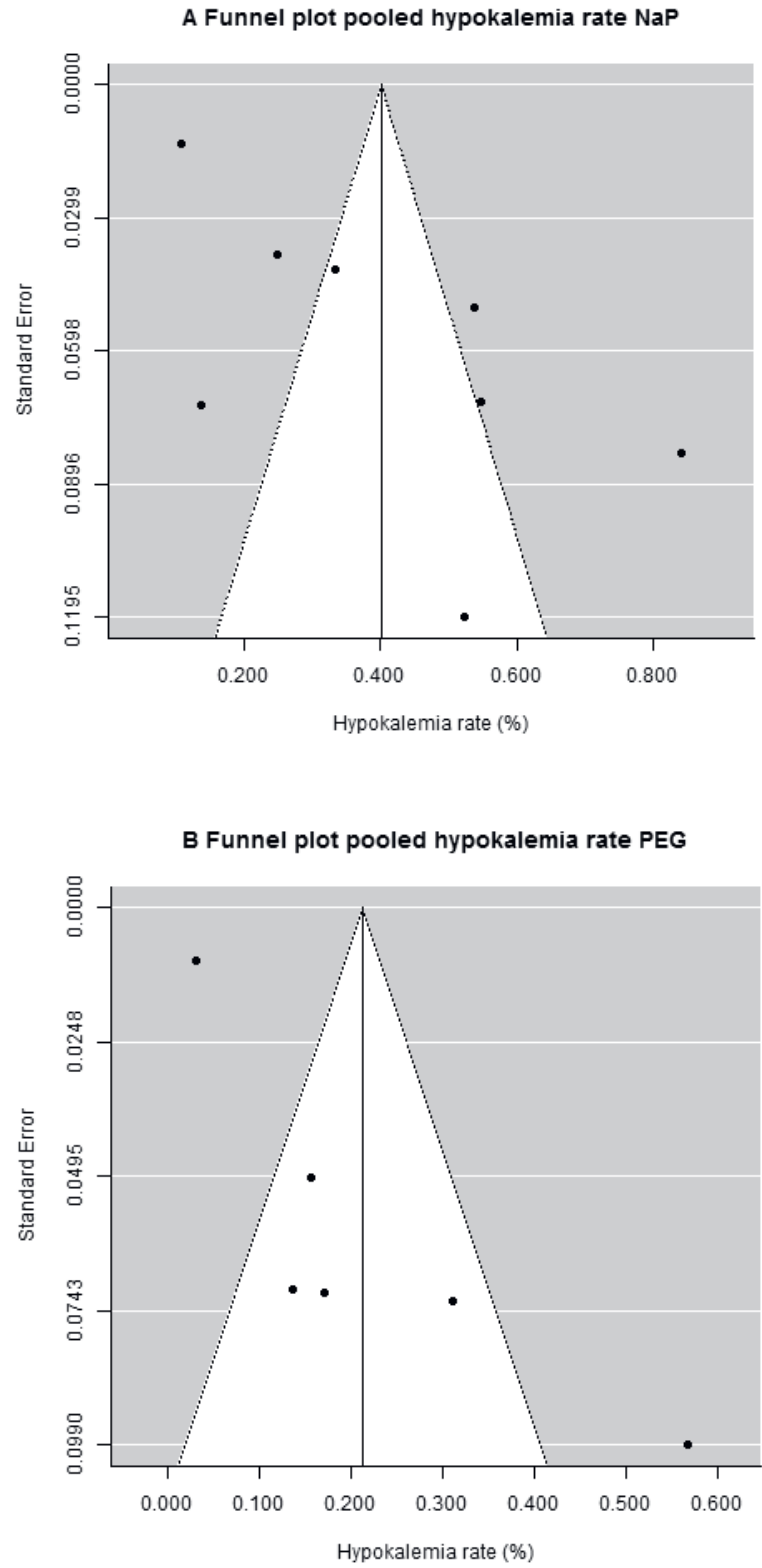

Figure S5.1 Funnel plots pooled hypokalemia rate $\mathrm{NaP}(\mathrm{A})$ and $\mathrm{PEG}(\mathrm{B})$. 


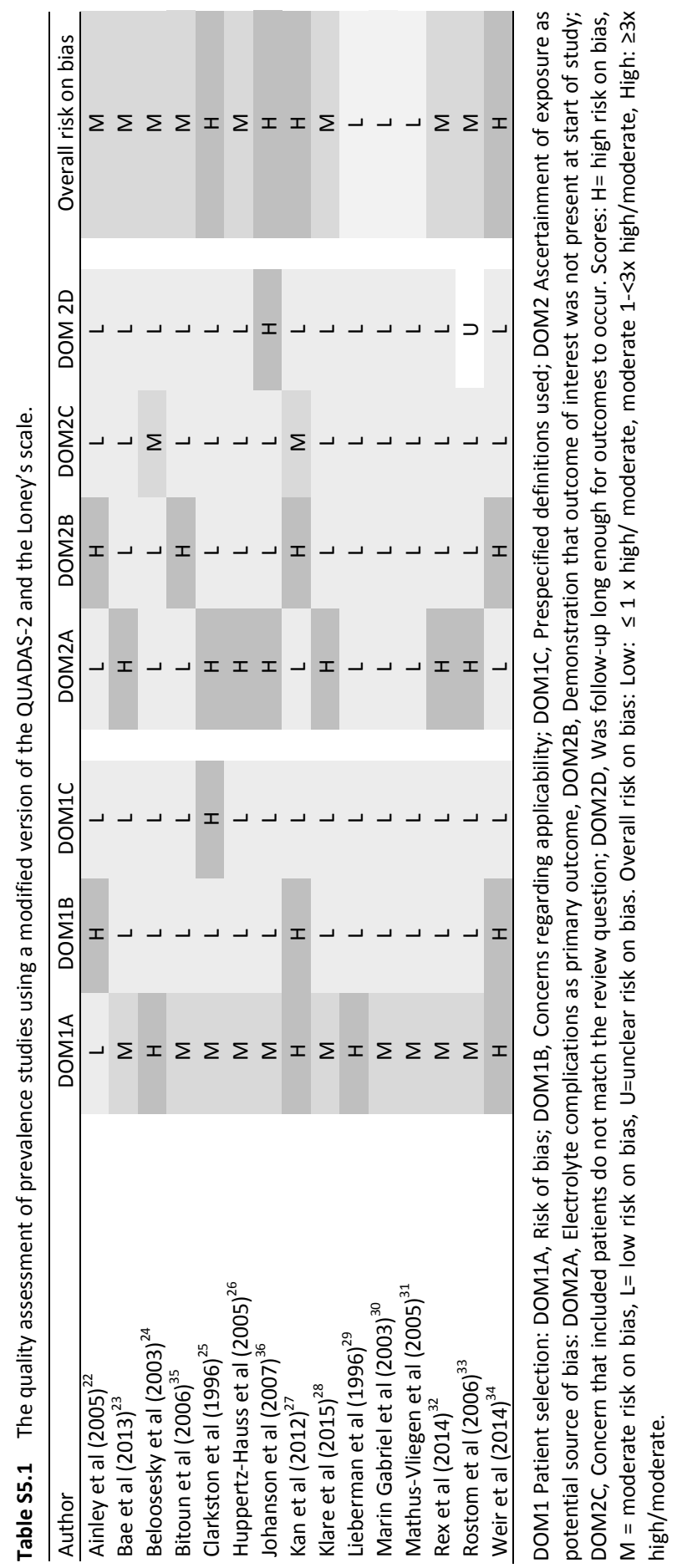




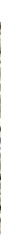




\section{CHAPTER 6}

\section{POST-COLONOSCOPY MORTALITY: BOWEL PREPARATION TO BLAME?}

A. Reumkens, A.A.M. Masclee, C.M. Bakker Adapted from Gastrointest Endosc 2017;86(4):744-745 
CHAPTER 6 
Bowel preparation for colonoscopy should be safe without clinically relevant shifts in serum potassium levels. It has been shown that polyethylene glycol (PEG) solutions may cause hypokalemia, but the prevalence, magnitude and clinical consequences of hypokalemia associated with low-volume PEG bowel preparation are not known. We recently encountered two cases of severe postcolonoscopy hypokalemia with fatal outcome at our secondary care hospital.

Both patients received low-volume PEG solutions prior to colonoscopy. The first case concerns a 72-year old Caucasian woman with a three months history of diarrhea, vomiting and weight loss, referred for colonoscopy. Previous medical history included arterial hypertension and a cerebrovascular event. Medication consisted of a betablocker and hydrochlorothiazide. Colonoscopy after standard bowel preparation (2L low-volume PEG) was interrupted because of insufficient cleansing with fecal retention. The patient resumed her regular diet and a second colonoscopy was performed 5 days later. During the second bowel preparation ingestion of $3 \mathrm{~L}$ lowvolume PEG solution was required to provide adequate bowel cleansing. A repeat examination under optimal bowel preparation revealed extensive terminal ileitis, endoscopically and histologically consistent with Crohn's disease. Oral prednisolone $40 \mathrm{mg}$ was initiated immediately post colonoscopy. Eleven hours after colonoscopy, the patient developed cardiac arrest due to ventricle fibrillation and was resuscitated. Lab examination showed severe acidosis and a potassium $1.2 \mathrm{mmol} / \mathrm{L}$ (normal range: 3.5-5.0 mmol/L) (other findings are not contributing). Serum potassium value immediately prior to colonoscopy was unknown. Large amounts of potassium and magnesium were supplied intravenously. Patient's condition deteriorated rapidly and she deceased within $24 \mathrm{hrs}$ after colonoscopy.

The second case concerns a 77-year old Caucasian woman with weight loss, fever and microcytic anemia, referred for colonoscopy. Medical history included atrial fibrillation and hyperthyroidism. Her medication consisted of digoxin, beta-blocker and a vitamin-K antagonist. The colonoscopy had to be interrupted at rectal level because of fecal retention. She was admitted directly to the clinical ward in order to continue bowel preparation. In total, she received $4 \mathrm{~L}$ low-volume PEG solution $(2 \mathrm{~L}+2 \mathrm{~L}$ within 48 hours), resulting in optimal inspection of the left colon during second colonoscopy. A large stenosing tumor was diagnosed in the distal sigmoid junction. This lesion had not been visualized at the first examination due to severe 
fecal impaction. Patient was discharged. Ten hours after colonoscopy she collapsed at home, was resuscitated successfully and transported by ambulance to the hospital. Electrocardiogram, echo-cardiogram and serum cardiac enzymes were completely normal. Lab results showed serum potassium value of $1.8 \mathrm{mmol} / \mathrm{L}$ and a severe metabolic acidosis. Intravenous potassium and magnesium supplementation was started immediately. The patient was admitted at the intensive care unit. Routine lab one month before colonoscopy had shown normal serum potassium level.

\section{DISCUSSION}

To our knowledge, this is the first report to describe severe hypokalemia with fatal outcome following bowel cleansing for colonoscopy after low-volume PEG solutions. Low-volume PEG solutions have been developed to reduce electrolyte shifts as seen after high-volume PEG-solutions.1,2 Previous studies have reported on potassium decrease related to bowel cleansing (Table 6.1), but not on low-volume PEG and risk factors remain unclear. ${ }^{3-10}$

Hypothetically, in both cases, the etiology of hypokalemia has been multifactorial, as shown in Figure 6.1. The large amount of low-volume PEG solution (5L and $4 \mathrm{~L}$ instead of $2 \mathrm{~L}$ ) administered to achieve sufficient bowel preparation may have aggravated or induced severe hypokalemia. In the first case, potassium depletion may have also resulted from longstanding vomiting, diarrhea, poor intake, initiation of prednisolone therapy and the use of hydrochlorothiazide. Surprisingly, the severe acidosis was accompanied by hypokalemia instead of hyperkalemia, suggesting an extremely low serum potassium level in this patient. Similarly, a mix of factors contributed to hypokalemia in the second case. Prominent amongst these factors, is, again the large volume of bowel preparation. The use of digoxin and possible recurrence of hyperthyroidism (because no recent TSH was measured) may also have contributed. It has been shown that diarrhea causing intestinal potassium loss is associated with the severity of hypokalemia in elderly patients. ${ }^{11}$ 


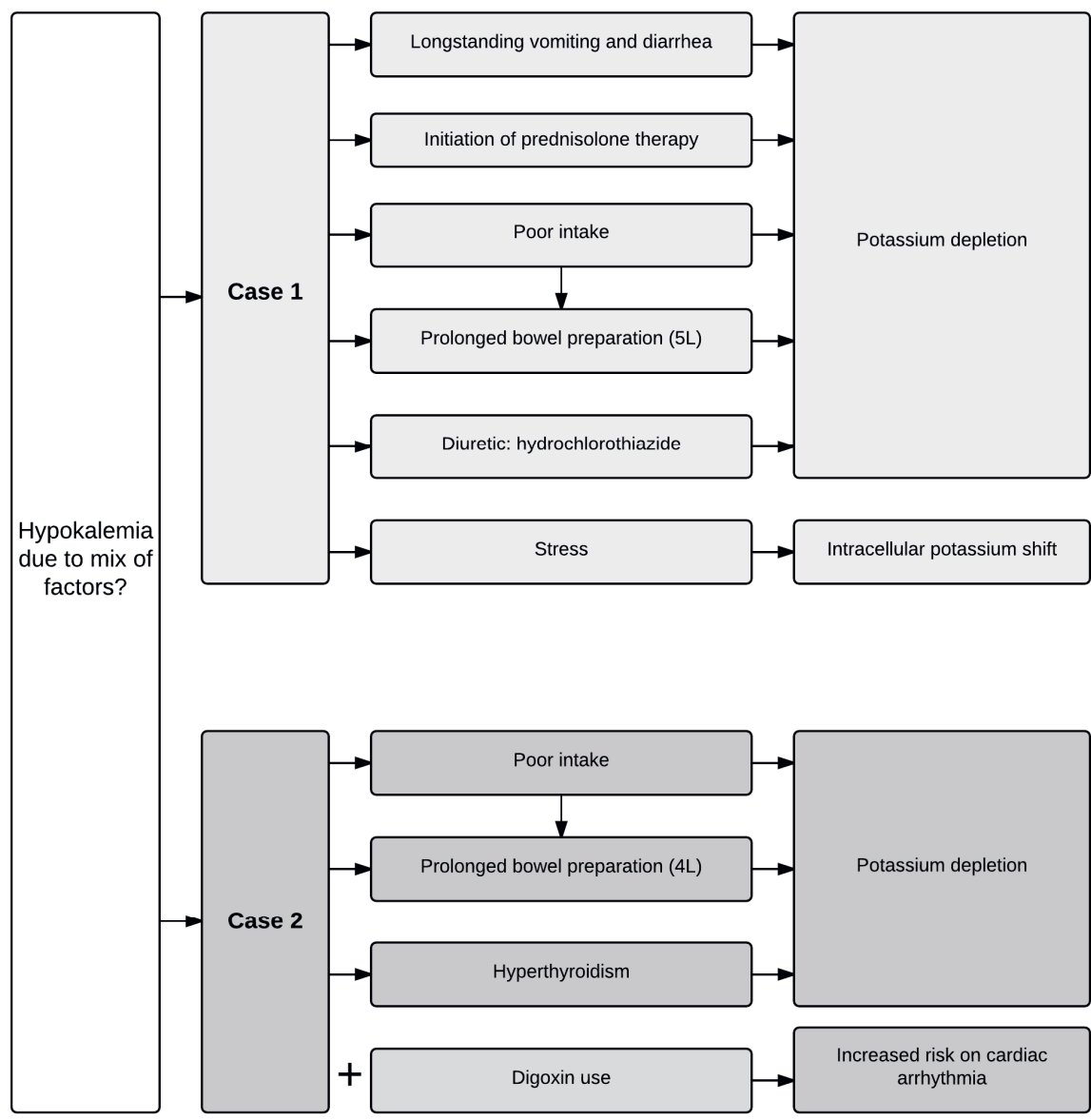

Figure 6.1 Potential factors involved in development of hypokalemia in the two cases. 
Potassium levels before start of bowel preparation were unknown in both cases. Indeed, current colonoscopy guidelines do not recommend to routinely measure serum electrolyte levels, not even in selected (high risk) groups. ${ }^{12,13}$ Bowel preparation is part of the colonoscopy procedure and should meet the highest quality standards and primarily should be safe, especially considering, the increasing number of colonoscopies worldwide due to implementation of colorectal cancer screening, surveillance and diagnostic indications. Also the group of elderly patients, who are at risk for electrolyte disturbances undergoing colonoscopy, is rapidly increasing. ${ }^{11}$ It is therefore of paramount importance to minimize electrolyte disturbances due to bowel preparation. We believe that the two lethal cases urge gastroenterologists and endoscopists to conduct prospective larger scale studies to systematically examine potential risk factors after low-volume PEG bowel preparation. Whilst waiting for further evidence, at our institution we have implemented a protocol for routine measurement of potassium, sodium and creatinine before bowel cleansing in patients referred for colonoscopy. We aim to examine the frequency of such events in routine practice and their underlying etiologic factors. Clearly, to optimize patient safety, protocols are needed in clinical practice, indicating what patient subgroups are at risk, what are safety standards and how to prevent such events.

In conclusion, our case-report includes a 3-fold message. First, endoscopists should be aware that low-volume PEG bowel cleansing solutions can aggravate or possibly induce hypokalemia, with potentially detrimental and fatal consequences. Second, not only high-volume bowel cleansing solutions, but also low-volume bowel cleansing solutions may contribute to hypokalemia. Third, large scale studies are needed to determine the prevalence of post colonoscopy hypokalemia, potential risk factors and indications for screening of subgroups. Whilst more studies are awaited, clinicians should be triggered to monitor potassium values especially in patients at risk for hypokalemia. 


\section{REFERENCES}

1. Aoun E, Abdul-Baki H, Azar C, Mourad F, Barada K, Berro Z, et al. A randomized single-blind trial of split-dose PEG-electrolyte solution without dietary restriction compared with whole dose PEGelectrolyte solution with dietary restriction for colonoscopy preparation. Gastrointest Endosc 2005;62(2):213-218.

2. Jansen SV, Goedhard JG, Winkens B, van Deursen CT. Preparation before colonoscopy: a randomized controlled trial comparing different regimes. Eur J Gastroenterol Hepatol 2011;23(10):897-902.

3. Beloosesky Y, Grinblat J, Weiss A, Grosman B, Gafter U, Chagnac A. Electrolyte disorders following oral sodium phosphate administration for bowel cleansing in elderly patients. Arch Intern Med 2003;163(7):803-808.

4. Di Nardo G, Aloi M, Cucchiara S, Spada C, Hassan C, Civitelli F, et al. Bowel preparations for colonoscopy: an RCT. Pediatrics 2014;134(2):249-256.

5. Huppertz-Hauss G, Bretthauer M, Sauar J, Paulsen J, Kjellevold O, Majak B, et al. Polyethylene glycol versus sodium phosphate in bowel cleansing for colonoscopy: a randomized trial. Endoscopy. 2005;37(6):537-541.

6. Klare P, Poloschek A, Walter B, Rondak IC, Attal S, Weber A, et al. Single-day sodium picosulfate and magnesium citrate versus split-dose polyethylene glycol for bowel cleansing prior to colonoscopy: $A$ prospective randomized endoscopist-blinded trial. J Gastroenterol Hepatol 2015;30(11):1627-1634.

7. Lieberman DA, Ghormley J, Flora K. Effect of oral sodium phosphate colon preparation on serum electrolytes in patients with normal serum creatinine. Gastrointest Endosc 1996;43(5):467-469.

8. Marin Gabriel JC, Rodriguez Munoz S, de la Cruz Bertolo J, Carretero Gomez JF, Munoz Yague MT, Manzano Alonso $\mathrm{ML}$, et al. [Electrolytic disturbances and colonoscopy: bowel lavage solutions, age and procedure]. Rev Esp Enferm Dig 2003;95(12):863-75.

9. Mathus-Vliegen EM, Kemble UM. A prospective randomized blinded comparison of sodium phosphate and polyethylene glycol-electrolyte solution for safe bowel cleansing. Aliment Pharmacol Ther 2006;23(4):543-552.

10. Tan JJ, Tjandra JJ. Which is the optimal bowel preparation for colonoscopy - a meta-analysis. Colorectal Dis 2006;8(4):247-258.

11. Rostom A, Jolicoeur E, Dube C, Gregoire S, Patel D, Saloojee N, et al. A randomized prospective trial comparing different regimens of oral sodium phosphate and polyethylene glycol-based lavage solution in the preparation of patients for colonoscopy. Gastrointest Endosc 2006;64(4):544-552.

12. Hassan C, Bretthauer M, Kaminski MF, Polkowski M, Rembacken B, Saunders B, et al. Bowel preparation for colonoscopy: European Society of Gastrointestinal Endoscopy (ESGE) guideline. Endoscopy. 2013;45(2):142-150.

13. Wexner SD, Beck DE, Baron TH, Fanelli RD, Hyman N, Shen B, et al. A consensus document on bowel preparation before colonoscopy: prepared by a task force from the American Society of Colon and Rectal Surgeons (ASCRS), the American Society for Gastrointestinal Endoscopy (ASGE), and the Society of American Gastrointestinal and Endoscopic Surgeons (SAGES). Gastrointest Endosc 2006;63(7): 894-909. 


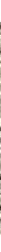




\section{CHAPTER 7}

\section{PREVALENCE OF HYPOKALEMIA BEFORE AND AFTER \\ BOWEL PREPARATION FOR COLONOSCOPY \\ -IN HIGH RISK PATIENTS}

A. Reumkens, A.A.M. Masclee, B. Winkens, C.T. van Deursen, S. Sanduleanu, C.M. Bakker

Gastrointest Endosc 2017;86(4):673-679 


\section{ABSTRACT}

\section{Background and aims}

Bowel preparation for colonoscopy should not cause significant shifts in systemic electrolyte concentrations. We recently encountered two cases of severe postcolonoscopy hypokalemia with fatal consequences, prompting us to conduct a study to explore the magnitude of and risk factors for hypokalemia associated with bowel preparation. We paid specific attention to higher risk subgroups, in particular diuretic users and hospitalized patients.

\section{Methods}

From January 1 to December 31, 2014, we included all patients at risk for hypokalemia (diuretic users and hospitalized patients) who underwent colonoscopy at our institution. We measured serum potassium levels before low-volume polyethylene glycol bowel preparation for colonoscopy. In a random subset of patients who had normal serum potassium levels before bowel cleansing, serum potassium levels after bowel cleansing were also measured.

\section{Results}

In total, 5515 colonoscopies were performed, of which 1822 procedures in diuretic users or hospitalized patients. Of these, 77 (4.2\%) patients had hypokalemia before bowel cleansing. Logistic regression model showed that hospitalized patients were more likely to have hypokalemia than non-hospitalized patients. Of the patients with normokalemia before bowel cleansing, 301 had also potassium controls after bowel cleansing, of whom 71 (23.6\%) developed hypokalemia. Logistic regression model showed that diuretic users were more likely to develop hypokalemia than non-diuretic users.

\section{Conclusions}

Hypokalemia was found in $4.2 \%$ of patients referred for colonoscopy receiving diuretics or being hospitalized. In patients with normal potassium levels before bowel cleansing, 23.6\% developed hypokalemia after bowel cleansing. Severe hypokalemia was seen in $0.4 \%$ before bowel cleansing and $4.0 \%$ after bowel cleansing. 


\section{INTRODUCTION}

Adequate bowel preparation is a prerequisite for colonoscopy in order to achieve optimal visualization of the colonic mucosa. Bowel cleansing preparations should be safe, easily applicable and generally well accepted by patients. The most commonly used regimens are polyethylene glycol (PEG) and sodium phosphate (NaP).

PEG is a non-absorbable electrolyte solution recommended as bowel preparation for colonoscopy by American and European Gastroenterology and Endoscopy societies. ${ }^{1,2}$ PEG solutions include high-volume regimens ( $\geq 3 \mathrm{~L}$ ) that are often not well tolerated by patients. Therefore low-volume regimens have been developed, such as $\mathrm{NaP}$, sodium picosulphate with magnesium citrate (PMC) or low-volume PEG. ${ }^{3}$

The low-volume solution NaP acts via an osmotic effect with water shift towards the colonic lumen. $\mathrm{NaP}$ is contra-indicated in patients with congestive heart failure or renal impairment, because it may result in dehydration and electrolyte imbalances, especially hypokalemia, hypernatremia, hypocalcemia and hyperphosphatemia. ${ }^{4-8}$

Low-volume PEG regimens have been developed to improve patient compliance by modifications in taste and by volume reduction. Instead of $65 \mathrm{~g}$ macrogol in PEG, $90 \mathrm{~g}$ macrogol is included in this regimen. One of the low-volume PEG-solutions is the $2 \mathrm{~L}$ PEG solution with ascorbic acid (PEG-asc). The addition of ascorbic acid allowed the volume of the preparation to be reduced to $2 \mathrm{~L}$. Ascorbic acid is not absorbed, remains in the colon, employing its osmotic effect, synergistically with PEG. ${ }^{9,10}$

Although the efficacy of PEG, NaP, PMC and low-volume PEG with respect to bowel cleansing has been studied extensively ${ }^{1,3,11-15}$, data on electrolyte disturbances are scarce, especially for low-volume PEG. ${ }^{16}$ Hypokalemia is a potentially alarming electrolyte disorder that may be associated with cardiac arrhythmias. Several studies have shown that NaP and PEG may result in hypokalemia., ${ }^{4,17-20}$

At our institution we recently encountered two cases of severe post-colonoscopy hypokalemia with fatal consequences. This prompted us to explore in more detail the magnitude of hypokalemia and risk factors for hypokalemia associated with lowvolume PEG bowel preparation in our large secondary care training hospital in the Netherlands. During one year we prospectively measured potassium levels before and after low-volume bowel preparation in patients referred for colonoscopy. We focused 
on two high risk groups: diuretic users and hospitalized patients. Our aim was to obtain more detailed information on the prevalence of hypokalemia pre bowel cleansing in the two risk groups and on the risk of hypokalemia post bowel cleansing. Secondary aim was to analyze the potential risk factors for hypokalemia in these patients.

\section{METHODS}

From January 1 to December 31, 2014, we prospectively included all patients considered to be at risk for hypokalemia who underwent diagnostic, screening or surveillance colonoscopy at our institution. We defined these risk group as 1) diuretic users and 2) hospitalized patients. Hospitalized patients frequently have several comorbidities, use various medications and are of older age. Serum potassium levels were measured before start of bowel preparation. We collected clinical information including demographic features, indication for colonoscopy and outcome of the examination, comorbidities and medication. In a random subset of $20 \%$ of patients who had normal serum potassium levels before bowel cleansing, serum potassium levels after bowel cleansing were also measured. Patients diagnosed with hypokalemia before bowel cleansing received potassium supplementation according to the local protocol (Figure 7.1).

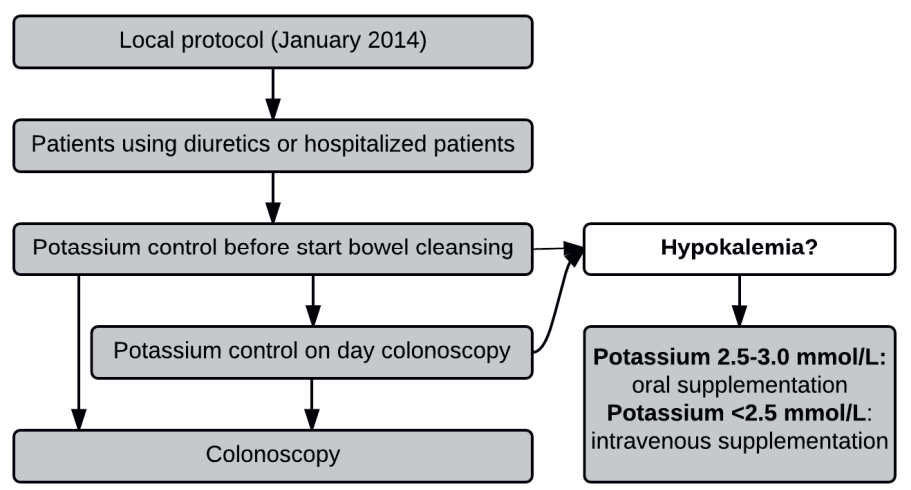

Figure 7.1 Flow chart local protocol. 
All patients received at least $2 \mathrm{~L}$ of low-volume PEG with ascorbic acid for bowel preparation. Prospectively digital colonoscopy reports and medical reports were reviewed. All colonoscopy examinations were documented in a standardized electronic report form.

Prevalences of electrolyte disorders were defined as the prevalence of hypokalemia (potassium value $<3.5 \mathrm{mmol} / \mathrm{L}$ or $\mathrm{mEq} / \mathrm{L}$ ). Moderate hypokalemia was defined as potassium value $<3.0 \mathrm{mmol} / \mathrm{L}$ or $\mathrm{mEq} / \mathrm{L}$; severe hypokalemia as $<2.5 \mathrm{mmol} / \mathrm{L}$ or $\mathrm{mEq} / \mathrm{L}$.

This study was approved by the Institutional Review Board of our hospital and registered in The Netherlands Trial Registry: NTR5400 (http://www.trialregister.nl).

\section{STATISTICAL ANALYSIS}

Prevalences of hypokalemia before bowel preparation were calculated, as well as prevalences after bowel preparation. Differences in categorical values were analyzed using the Chi-square test or Fisher's exact test where appropriate. Multiple logistic regression analysis was used to study whether age, gender, indication (symptoms, screening, and surveillance), diuretic use, and setting (outpatient vs hospitalized) were independent risk factors for hypokalemia. All Odds ratios (OR) are presented with $95 \%$ confidence intervals $(\mathrm{CI})$. $P$-values $\leq 0.05$ were considered statistically significant. Statistical analyses were conducted using IBM SPSS Statistics for Windows version 22 (Armonk, NY, USA).

\section{RESULTS}

In 2014, a total of 5515 colonoscopies were performed at our institution. In 1822 patients, using diuretics or being hospitalized, potassium levels were measured before colonoscopy (Figure 7.2). Of these, 77 (4.2\%) patients had hypokalemia before bowel cleansing (serum potassium level $<3.5 \mathrm{mmol} / \mathrm{L}), 1633$ (89.6\%) normal potassium levels (3.5-5.0 mmol/L) and 112 (6.1\%) hyperkalemia (5.0-6.0 mmol/L). Seven patients $(0.4 \%)$ had severe hypokalemia $(<3.0 \mathrm{mmol} / \mathrm{L})$ before bowel preparation. Multiple logistic regression model, adjusted for age, gender, indication for colonoscopy, and diuretic use, showed that hospitalized patients were significantly more likely to have hypokalemia than non-hospitalized patients (OR 2.78, [95\% Cl 1.64-4.76], $p<0.001$ ) (Table 7.1). 
Of the 1633 patients with normal potassium levels, 301 patients had a potassium control after bowel cleansing, on the day of colonoscopy. Of these patients, 71 (23.6\%) had developed hypokalemia (12 (4.0\%) patients severe hypokalemia) and $5(1.7 \%)$ had developed mild hyperkalemia (5.0-5.5 mmol/L). Multiple logistic regression model, adjusted for age, gender, indication for colonoscopy, and setting showed that hypokalemia was significantly more frequent in the group of diuretic users (OR 2.33, [95\% Cl 1.30-4.00], $p=0.004$ ) (Table 7.2).

No serious adverse events occurred. Hypokalemia was treated according to protocol (Figure 7.1).

Table 7.1 Clinical characteristics of subjects before bowel cleansing.

\begin{tabular}{|c|c|c|c|c|c|c|}
\hline & \multirow{2}{*}{$\begin{array}{l}\text { Hypokalemia } \\
\mathrm{N}=77\end{array}$} & \multirow{2}{*}{$\begin{array}{l}\text { No hypokalemia } \\
\qquad N=1745\end{array}$} & \multicolumn{2}{|c|}{ Unadjusted } & \multicolumn{2}{|l|}{ Adjusted } \\
\hline & & & OR $(95 \% \mathrm{Cl})$ & $p$-value & OR $(95 \% \mathrm{Cl})$ & $p$-value \\
\hline $\begin{array}{l}\text { Age, yrs } \\
\text { (median, range) }\end{array}$ & $65.9(16-95)$ & $66.7(21-93)$ & & 0.64 & $0.99(0.97-1.01)$ & 0.19 \\
\hline $\begin{array}{l}\text { Gender, female } \\
\text { Indication }\end{array}$ & $41(53.2 \%)$ & 873 (50.0\%) & $1.14(0.72-1.80)$ & 0.58 & $1.16(0.74-1.85)$ & 0.51 \\
\hline Symptoms & $52(67.5 \%)$ & $1193(68.4 \%)$ & $0.96(0.59-1.57)$ & 0.88 & 1.00 & Ref \\
\hline Screening & $9(11.7 \%)$ & 255 (14.6\%) & $0.77(0.38-1.57)$ & 0.48 & $1.00(0.47-2.13)$ & 0.99 \\
\hline Surveillance & $16(20.8 \%)$ & $297(17.0 \%)$ & $1.18(0.65-2.14)$ & 0.58 & $1.44(0.77-2.68)$ & 0.26 \\
\hline Diuretic use & $35(45.5 \%)$ & $657(37.7 \%)$ & $1.37(0.87-2.17)$ & 0.17 & $1.56(0.95-2.56)$ & 0.08 \\
\hline Setting & & & & & & \\
\hline Outpatient & $52(67.5 \%)$ & 1465 (84.0\%) & 1.00 & Ref & 1.00 & Ref \\
\hline Hospitalized & $25(32.5 \%)$ & $280(16.0 \%)$ & $2.50(1.54-4.17)$ & $<0.001$ & $2.78(1.64-4.76)$ & $<0.001$ \\
\hline
\end{tabular}

Table 7.2 Clinical characteristics of subjects after bowel cleansing.

\begin{tabular}{lcccccc}
\hline & Hypokalemia & No hypokalemia & \multicolumn{2}{c}{ Unadjusted } & \multicolumn{2}{c}{ Adjusted } \\
& $\mathrm{N}=71$ & $\mathrm{~N}=230$ & $\mathrm{OR}(95 \% \mathrm{Cl})$ & $p$-value & $\mathrm{OR}(95 \% \mathrm{Cl})$ & $p$-value \\
\hline $\begin{array}{l}\text { Age, yrs } \\
\text { (median, range) }\end{array}$ & $70.7(21-91)$ & $70.4(20-93)$ & & 0.85 & $0.99(0.97-1.01)$ & 0.50 \\
$\begin{array}{l}\text { Gender, female } \\
\text { Indication }\end{array}$ & $42(59.1 \%)$ & $117(50.9 \%)$ & $1.40(0.82-2.40)$ & 0.22 & $1.45(0.83-2.50)$ & 0.19 \\
$\quad$ & & & & & & \\
$\quad$ Symptoms & $63(88.7 \%)$ & $197(85.7 \%)$ & $1.32(0.58-3.00)$ & 0.51 & 1.00 & Ref \\
$\quad \begin{array}{l}\text { Screening } \\
\text { Surveillance }\end{array}$ & $3(4.3 \%)$ & $16(6.9 \%)$ & $0.59(0.17-2.09)$ & 0.58 & $0.68(0.18-2.56)$ & 0.57 \\
Diuretic use & $5(7.0 \%)$ & $17(7.4 \%)$ & $0.95(0.34-2.67)$ & 0.92 & $0.94(0.32-2.75)$ & 0.91 \\
Setting & $38(53.5 \%)$ & $81(35.2 \%)$ & $2.13(1.23-3.57)$ & 0.006 & $2.33(1.30-4.00)$ & 0.004 \\
$\quad$ & & & & & & \\
$\quad$ Outpatient & $21(29.6 \%)$ & $85(37.0 \%)$ & 1.00 & Ref & 1.00 & Ref \\
Hospitalized & $50(70.4 \%)$ & $145(63.0 \%)$ & $1.39(0.79-2.50)$ & 0.26 & $1.28(0.70-2.38)$ & 0.42 \\
\hline
\end{tabular}




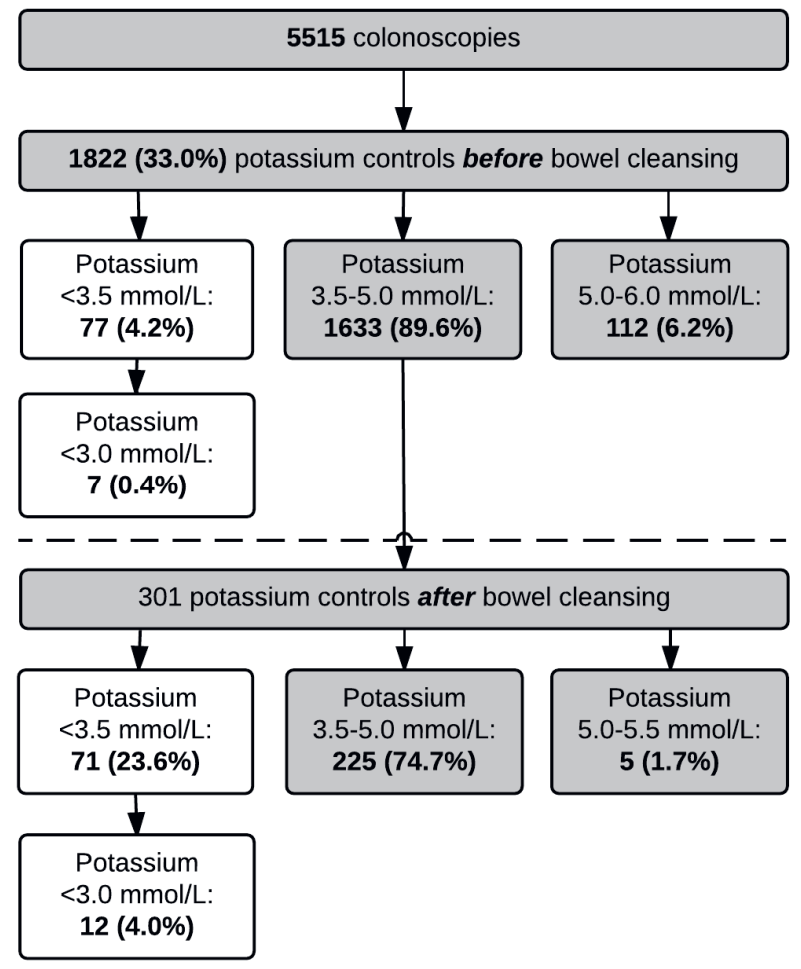

Figure 7.2 Flow chart results.

\section{DISCUSSION}

This study was performed in patients considered to be at risk for hypokalemia. Hypokalemia was present before bowel cleansing in $4.2 \%$ of patients using diuretics or being hospitalized. Hypokalemia was present in $23.6 \%$ of patients after bowel cleansing with low-volume PEG with ascorbic acid who had normal potassium levels pre bowel cleansing. Severe hypokalemia was seen in $0.4 \%$ pre bowel cleansing and in $4.0 \%$ post-bowel cleansing. No serious events occurred; supplementation was provided in all cases of hypokalemia.

In general, hypokalemia is defined as a serum potassium level $<3.5 \mathrm{mmol} / \mathrm{L}$ (or $\mathrm{mEq} / \mathrm{L}$ ) and is divided into mild, moderate and severe. Mild hypokalemia is defined as a serum 
potassium level of 3.0-3.5 mmol/L (or $\mathrm{mEq} / \mathrm{L}$ ), moderate as $2.5-3.0 \mathrm{mmol} / \mathrm{L}$ and severe as $<2.5 \mathrm{mmol} / \mathrm{L}$ (or $\mathrm{mEq} / \mathrm{l}$ ). ${ }^{21,22}$ Hypokalemia may give rise to moderate symptoms such as muscle weakness, constipation, nausea, vomiting, to severe symptoms such as paralysis, seizures, cardiac arrhythmias, coma and even death. Unfortunately, the degree of hypokalemia is not directly related to the severity of symptoms. ${ }^{23}$ In general, mild electrolyte alterations remain asymptomatic, while larger alterations are accompanied by symptoms. ${ }^{3,21}$ Symptoms are more likely to occur with increasing severity of hypokalemia as well as with the rapidity of onset of the decrease in serum potassium values. $^{22}$

Up to now, little is known on serum potassium levels and risk of hypokalemia after use of low-volume PEG. ${ }^{16}$ Low-volume PEG has been developed to minimize electrolyte alterations and includes higher amounts of electrolytes than in the standard 4 L PEG. ${ }^{24}$ A meta-analysis pointed to more frequent occurrence of hypokalemia and hyperphosphatemia after NaP preparation vs. PEG preparation, but did not provide data on overall mean differences in electrolytes before and after bowel preparations. ${ }^{3}$ With respect to hypokalemia and low-volume PEG only one study has been published. That study did not provide evidence for a risk of hypokalemia after use of low-volume PEG, but the number of patients that has been studied was very small $(n=169) .{ }^{25}$

In our study, neither age or gender nor indication for colonoscopy had any influence on the presence of hypokalemia before or after bowel preparation. Hospitalization itself was considered a risk factor associated with an increased risk for hypokalemia before bowel preparation. Hospitalized patients undergoing colonoscopy are usually older; they have comorbidities, and use several medications more frequently.

No data are available on development of hypokalemia after bowel preparation in diuretic users. In our study, diuretics were expected to give a higher hypokalemia risk, especially thiazide diuretics. The prevalence of hypokalemia ranges from $7-56 \%$ in diuretic users. ${ }^{26}$ Our data revealed that hypokalemia after bowel cleansing was more frequently seen in the group of diuretic users.

Current guidelines on bowel preparation for colonoscopy contain only limited recommendations on the risk of electrolyte disturbances associated with $\mathrm{NaP}, \mathrm{PMC}$ and high or low-volume PEG bowel preparation.,10,16 First, the European Society of Gastrointestinal Endoscopy (ESGE) discourages the use of NaP bowel preparation 
because of safety concerns. Feared complications following $\mathrm{NaP}$ are renal failure and acute disruption of electrolyte homeostasis (hypokalemia, hyper- or hyponatremia, hyperphosphatemia or hypocalcemia). NaP should be advised only in individuals assessed to be at low risk of side-effects and includes evaluation of kidney function. Second, the use of PMC is not recommended in patients with renal impairment and in patients using medication that alter electrolyte excretion or the renal blood flow. ${ }^{16}$ Third, high-volume PEG is recommended in patients with inflammatory bowel disease (IBD) and in case urgent colonoscopy is scheduled for lower gastrointestinal bleeding. The ESGE or US multi-society task force did not provide recommendations on electrolyte measurements before or after high-volume PEG bowel preparation. ${ }^{1,10}$ However, severe hypokalemia after high-volume PEG bowel preparation has been described in case reports. ${ }^{28}$ The US multi-society task forces note that iso-osmotic low-volume PEG solutions are preferred preparations in patients who cannot tolerate fluid shifts and electrolyte alterations, like patients with congestive heart failure, advanced liver disease and renal impairment. ${ }^{10}$ Recommendations on electrolyte measurements before and/or after low-volume PEG bowel preparation are lacking, most likely because they are generally considered to be safe. ${ }^{1,10,16}$

To our knowledge, our study is the first to report on prevalences of hypokalemia before and after low-volume PEG preparation in risk groups. Given the fact that this study has been performed in preselected groups of diuretic users and hospitalized patients, specific, more detailed risk factor analysis for hypokalemia cannot be provided. Despite this limitation, our study clearly shows that hypokalemia may develop in a substantial percentage of patients after the ingestion of low-volume PEG. These results should however be interpreted with caution because the prevalence of hypokalemia in patients not being hospitalized and not taking diuretics was not investigated. Therefore, future studies should focus on overall population-based risks to develop hypokalemia after low-volume PEG bowel cleansing. These studies are needed to determine the true prevalence of post colonoscopy hypokalemia, examine risk factors and thereafter consider whether screening of subgroups at risk is indicated.

As bowel cleansing is an integral part of colonoscopy and quality and safety of colonoscopy are highly pursued in daily gastroenterology practice, a systematic assessment of bowel cleansing-related risks is required. Depending on these risks, and 
based on large scale studies, endoscopy societies should consider whether electrolyte measurements before and after bowel cleansing regimens should be advised or not. Since colorectal cancer (CRC) screening programs are implemented worldwide and the number of colonoscopies has been rising, more patients will be exposed to colonoscopy and bowel cleansing-related risks, including hypokalemia. While waiting for more evidence, endoscopists should be aware of the prevalence of hypokalemia post bowel cleansing and potential risks.

In conclusion, our study shows that hypokalemia was present in $4.2 \%$ of hospitalized patients and patients taking diuretics before ingestion of bowel preparation for colonoscopy. Hypokalemia was present in $23.6 \%$ of patients after completing lowvolume PEG cleansing regimen. Thus, hypokalemia after bowel preparation is frequent. Additional large scale studies are needed on the prevalence of hypokalemia in non-selected populations, on potential serious side effects in order to decide on screening of high risk groups in daily clinical practice. 


\section{REFERENCES}

1. Hassan C, Bretthauer M, Kaminski MF, Polkowski M, Rembacken B, Saunders B, et al. Bowel preparation for colonoscopy: European Society of Gastrointestinal Endoscopy (ESGE) guideline. Endoscopy. 2013;45(2):142-150.

2. Wexner SD, Beck DE, Baron TH, Fanelli RD, Hyman N, Shen B, et al. A consensus document on bowel preparation before colonoscopy: prepared by a task force from the American Society of Colon and Rectal Surgeons (ASCRS), the American Society for Gastrointestinal Endoscopy (ASGE), and the Society of American Gastrointestinal and Endoscopic Surgeons (SAGES). Gastrointest Endosc 2006;63(7): 894--909.

3. Tan JJ, Tjandra JJ. Which is the optimal bowel preparation for colonoscopy - a meta-analysis. Colorectal Dis 2006;8(4):247-258.

4. Ainley EJ, Winwood PJ, Begley JP. Measurement of serum electrolytes and phosphate after sodium phosphate colonoscopy bowel preparation: an evaluation. Dig Dis Sci 2005;50(7):1319-1323.

5. Huynh T, Vanner S, Paterson W. Safety profile of 5-h oral sodium phosphate regimen for colonoscopy cleansing: lack of clinically significant hypocalcemia or hypovolemia. Am J Gastroenterol 1995; 90(1):104-107.

6. Golub RW, Kerner BA, Wise WE, Jr., Meesig DM, Hartmann RF, Khanduja KS, et al. Colonoscopic bowel preparations--which one? A blinded, prospective, randomized trial. Dis Colon Rectum 1995;38(6): 594-599.

7. Clarkston WK, Tsen TN, Dies DF, Schratz CL, Vaswani SK, Bjerregaard P. Oral sodium phosphate versus sulfate-free polyethylene glycol electrolyte lavage solution in outpatient preparation for colonoscopy: a prospective comparison. Gastrointest Endosc 1996;43(1):42-48.

8. Korsten MA, Spungen AM, Rosman AR, Ancha HR, Post JB, Shaw S, et al. A prospective assessment of renal impairment after preparation for colonoscopy: oral sodium phosphate appears to be safe in well-hydrated subjects with normal renal status. Dig Dis Sci 2010;55(7):2021-2029.

9. Fujita I, Akagi Y, Hirano J, Nakanishi T, Itoh N, Muto N, et al. Distinct mechanisms of transport of ascorbic acid and dehydroascorbic acid in intestinal epithelial cells (IEC-6). Res Commun Mol Pathol Pharmacol 2000;107(3-4):219-231.

10. Johnson DA, Barkun AN, Cohen LB, Dominitz JA, Kaltenbach T, Martel M, et al. Optimizing adequacy of bowel cleansing for colonoscopy: recommendations from the US multi-society task force on colorectal cancer. Gastroenterology. 2014;147(4):903-924.

11. Jansen SV, Goedhard JG, Winkens B, van Deursen CT. Preparation before colonoscopy: a randomized controlled trial comparing different regimes. Eur J Gastroenterol Hepatol. 2011;23(10):897-902.

12. Rex DK, DiPalma JA, McGowan J, Cleveland M. A comparison of oral sulfate solution with sodium picosulfate: magnesium citrate in split doses as bowel preparation for colonoscopy. Gastrointest Endosc 2014;80(6):1113-1123.

13. Mathus-Vliegen EM, Kemble UM. A prospective randomized blinded comparison of sodium phosphate and polyethylene glycol-electrolyte solution for safe bowel cleansing. Aliment Pharmacol Ther 2006;23(4):543-552.

14. Marin Gabriel JC, Rodriguez Munoz S, de la Cruz Bertolo J, Carretero Gomez JF, Munoz Yague MT, Manzano Alonso ML, et al. [Electrolytic disturbances and colonoscopy: bowel lavage solutions, age and procedure]. Rev Esp Enferm Dig 2003;95(12):863-875.

15. Ell C, Fischbach W, Keller R, Dehe M, Mayer G, Schneider B, et al. A randomized, blinded, prospective trial to compare the safety and efficacy of three bowel-cleansing solutions for colonoscopy (HSG-01*). Endoscopy. 2003;35(4):300-304.

16. Saltzman JR, Cash BD, Pasha SF, Early DS, Muthusamy VR, Khashab MA, et al. Bowel preparation before colonoscopy. Gastrointest Endosc 2015;81(4):781-794.

17. Beloosesky Y, Grinblat J, Weiss A, Grosman B, Gafter U, Chagnac A. Electrolyte disorders following oral sodium phosphate administration for bowel cleansing in elderly patients. Arch Intern Med 2003;163(7):803-808. 
18. Kan WC, Wang HY, Chien CC, Tan CK, Lin CY, Su SB. Intermediate bioelectrolyte changes after phospho-soda or polyethylene glycol precolonoscopic laxatives in a population undergoing health examinations. Nephrol Dial Transplant 2012;27(2):752-757.

19. Rostom A, Jolicoeur E, Dube C, Gregoire S, Patel D, Saloojee N, et al. A randomized prospective trial comparing different regimens of oral sodium phosphate and polyethylene glycol-based lavage solution in the preparation of patients for colonoscopy. Gastrointest Endosc 2006;64(4):544-552.

20. Weir MA, Fleet JL, Vinden C, Shariff SZ, Liu K, Song H, et al. Hyponatremia and sodium picosulfate bowel preparations in older adults. Am J Gastroenterol 2014;109(5):686-694.

21. Hoorn EJ, Tuut MK, Hoorntje SJ, van Saase JL, Zietse R, Geers AB. Dutch guideline for the management of electrolyte disorders--2012 revision. Neth J Med 2013;71(3):153-165.

22. Pepin J, Shields C. Advances in diagnosis and management of hypokalemic and hyperkalemic emergencies. Emerg Med Pract 2012;14(2):1-17; quiz -8.

23. Clayton JA, Rodgers S, Blakey J, Avery A, Hall IP. Thiazide diuretic prescription and electrolyte abnormalities in primary care. Br J Clin Pharmacol 2006;61(1):87-95.

24. https://www.farmacotherapeutischkompas.nl/.

25. Bitoun A, Ponchon T, Barthet M, Coffin B, Dugue C, Halphen M. Results of a prospective randomised multicentre controlled trial comparing a new 2-L ascorbic acid plus polyethylene glycol and electrolyte solution vs. sodium phosphate solution in patients undergoing elective colonoscopy. Aliment Pharmacol Ther 2006;24(11-12):1631-1642.

26. Rodenburg EM, Visser LE, Hoorn EJ, Ruiter R, Lous JJ, Hofman A, et al. Thiazides and the risk of hypokalemia in the general population. J Hypertens 2014;32(10):2092-2097.

27. Franse LV, Pahor M, Di Bari M, Somes GW, Cushman WC, Applegate WB. Hypokalemia associated with diuretic use and cardiovascular events in the Systolic Hypertension in the Elderly Program. Hypertension. 2000;35(5):1025-1030.

28. Belsey J, Epstein O, Heresbach D. Systematic review: adverse event reports for oral sodium phosphate and polyethylene glycol. Aliment Pharmacol Ther 2009;29(1):15-28. 


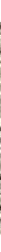




\section{CHAPTER 8}

SAFETY OF LOW-VOLUME PEG-ASC BOWEL

CLEANSING PREPARATION FOR COLONOSCOPY:

IDENTIFYING PATIENTS AT RISK FOR HYPOKALEMIA

IN A PROSPECTIVE COHORT STUDY

A. Reumkens, C.M. Bakker, S.J.W. van Kraaij, B. Winkens, M.T.P. Raijmakers, A.B. van Nunen, C.Th.B.M. van Deursen, A.A.M. Masclee Endosc Int Open 2021 [Accepted] 


\section{ABSTRACT}

\section{Background and study aims}

Bowel cleansing preparation should pursue high quality and safety standards. Previously, we reported that hypokalemia occurred in $23.6 \%$ after bowel preparation in a high-risk population of diuretics or hospitalized referred for colonoscopy. Here we report on a prospective study in a non-selected colonoscopy cohort to identify patients at risk of developing hypokalemia before and after bowel cleansing with lowvolume polyethylene glycol with ascorbic acid (PEG-asc).

\section{Patients and methods}

From January 1 to July 31, 2016, we included all patients undergoing colonoscopy in our institution. Prevalences of hypokalemia before and after PEG-asc bowel cleansing for colonoscopy were calculated and risk factors to develop hypokalemia after PEGasc bowel cleansing were identified.

\section{Results}

In total, 2011 patients were included in the analysis. Of these, $0.8 \%$ had hypokalemia before bowel cleansing with PEG-asc. After bowel preparation, 5.4\% developed hypokalemia. 281 patients were considered to have "high cardiac risk". The combination of "high cardiac risk" and hypokalemia was present in $1 \%$ of the initial colonoscopy population. Female gender, CRC diagnosis and thiazide use were found to be significant predictors of hypokalemia after use of PEG-asc. No arrhythmias or serious adverse events due to hypokalemia occurred.

\section{Conclusion}

Physicians referring patients for colonoscopy should be aware that "high cardiac risk" patients and those on thiazide diuretics undergoing bowel cleansing for colonoscopy are a risk to develop post-cleansing hypokalemia but it remains to be determined whether their risk to develop life-threatening arrhythmias is truly increased. 


\section{INTRODUCTION}

Worldwide, colonoscopy is extensively used for diagnostic and therapeutic indications, for surveillance and in colorectal cancer (CRC) screening programs. ${ }^{1,2}$ High quality and safety of colonoscopy are prerequisites for daily use in endoscopy practice. Bowel cleansing is an inseparable part of the colonoscopy procedure, therefore high quality and safety standards for bowel cleansing have to be met.

Several bowel cleansing preparations are available, including the high-volume regimens ( $(\geq 3 \mathrm{~L})$ polyethylene glycol (PEG) and the low-volume regimens such as sodium phosphate (NaP), sodium picosulphate with magnesium citrate (SPMC) and low-volume PEG. ${ }^{3}$ All PEG-based cleansing preparations have been developed to clean the colonic mucosal surface area without causing significant shifts in systemic fluids and electrolytes. ${ }^{4}$ Therefore, American and European Gastroenterology and Endoscopy Societies recommend PEG as the preferred bowel cleansing preparation in otherwise healthy subjects and in patients with relevant comorbidities, such as renal or cardiovascular disorders. ${ }^{5-7}$ To improve patient compliance, low-volume PEG bowel cleansing preparations have been developed. The addition of ascorbic acid to lowvolume PEG (PEG-asc) has resulted in a reduction of the volume of the preparation to 2L. Ascorbic acid is poorly absorbed, employing an osmotic effect, synergistically with PEG. ${ }^{5,8}$

Previous studies have pointed to the risk of developing hypokalemia after PEG-based bowel cleansing preparations. ${ }^{7,9-11}$ Hypokalemia may increase the risk of ventricular arrhythmia and sudden cardiac death by an imbalance of resting membrane potential difference, depolarization, and cellular hyperpolarity. Mostly, hypokalemia remains asymptomatic due to only mild alterations in serum potassium. ${ }^{3,12,13}$ However, more pronounced alterations in serum potassium can lead to symptoms such as fatigue, muscle weakness, constipation, and, also to life-threating impaired respiration and cardiac arrhythmias. $^{3,12}$

Previously, we reported on two fatal cases of severe hypokalemia after bowel cleansing with low-volume PEG-asc for colonoscopy. ${ }^{9}$ These events challenged us to investigate the prevalence of hypokalemia by measuring serum potassium levels in the setting before and after bowel cleansing in high-risk groups of patients, namely diuretic users and hospitalized patients. In a report on that strategy, we showed that $23.6 \%$ of the "high risk" patients developed hypokalemia after bowel preparation. ${ }^{10}$ It should be noticed that this study has been performed in preselected groups of 
diuretic users and hospitalized patients. Therefore, a detailed risk factor analysis for hypokalemia could not be provided. This prompted us to perform a large prospective study in non-selected patients scheduled for colonoscopy in regular care and screening practice. In this non-selected study population, our primary aim was to obtain data on the prevalence of hypokalemia after bowel cleansing with PEG-asc and to identify patients at a significant risk to develop hypokalemia.

\section{PATIENTS AND METHODS}

From January 1 to July 31, 2016, we prospectively measured serum potassium, sodium, magnesium concentrations and kidney function (serum creatinine) in all patients who underwent colonoscopy at our institution before and after bowel cleansing with low-volume PEG-asc bowel cleansing preparation (Figure 8.1). Magnesium values were measured given the fact that pre-existing hypomagnesemia could lead to hypokalemia. ${ }^{14}$ Clinical information, including demographic features, comorbidities, medication, and data from colonoscopy were retrieved from digital colonoscopy reports and medical charts. All individuals received at least $2 \mathrm{~L}$ of PEG-asc as bowel cleansing preparation.

Hypokalemia is generally defined as a serum potassium value $<3.5 \mathrm{mmol} / \mathrm{L}^{13}$, corresponding with the reference values in the hospital where our study was performed. Severe hypokalemia is defined as potassium values $<2.5 \mathrm{mmol} / \mathrm{L}$, moderate hypokalemia as $2.5-2.9 \mathrm{mmol} / \mathrm{L}$ and mild hypokalemia as $3.0-<3.5 \mathrm{mmol} / \mathrm{L}$. Normal range of serum potassium levels at our institution is between 3.5 and 5.0 $\mathrm{mmol} / \mathrm{L}$. Patients diagnosed with hypokalemia before bowel cleansing were given potassium supplementation. Oral potassium supplementation (3 doses per day of 30 mmol potassium chloride for 5 days) was provided in case of mild or moderate hypokalemia. Intravenous supplementation was provided in case of severe hypokalemia, according to our local protocol (Figure 8.1). The patients with hypokalemia at TO were not included in the secondary analysis. The bowel cleansing preparation was given according to protocol and colonoscopy was performed. Serum potassium levels after the bowel cleansing were sampled and measured on the day the colonoscopy was performed but were not reported to the endoscopists because they were obtained for research purposes. 
In regular care, monitoring of serum potassium values is considered appropriate in patient populations vulnerable to cardiac arrhythmias, such as patients with a history of myocardial infarction, ischemic heart disease, heart failure or those taking digoxin. These subgroups of patients have been included as a separate "high cardiac risk" group in our analysis. This study was approved by the Institutional Review Board of our hospital and registered in The Netherlands Trial Registry: NTR5744 (http://www.trialregister.nl).

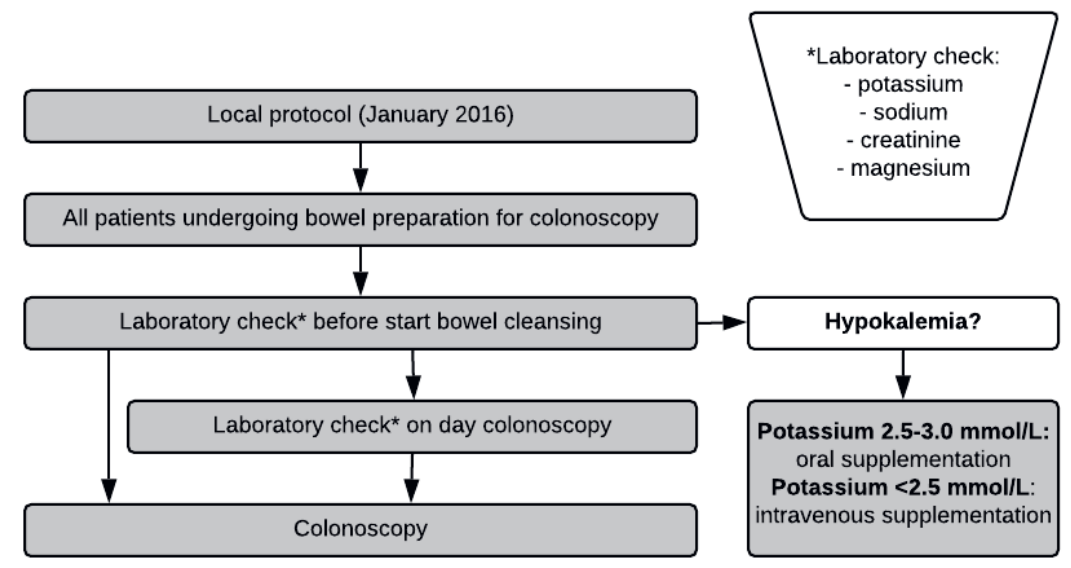

Figure 8.1 Flow chart study protocol.

\section{OUTCOME MEASURES AND STATISTICAL ANALYSIS}

Statistical analyses were conducted using IBM SPSS Statistics for Windows version 26 (Armonk, NY, USA).

Primary outcome. Our primary aim was to determine the prevalence of hypokalemia in patients after low-volume PEG-asc bowel cleansing preparation (T1) and to identify significant risk factors for developing hypokalemia.

Secondary outcome. Our secondary aim was to determine the prevalence of hypokalemia before bowel preparation (TO). The patients who already had hypokalemia before bowel cleansing were excluded from analysis at T1 since 1) actions to correct hypokalemia were undertaken between T0 and T1 and 2) it was not clear whether the risk factors identified at T1 were also present at T0. In addition to potassium, also sodium, magnesium and creatinine levels were measured. 
Numerical variables are expressed as mean \pm standard deviation (SD), where categorical variables are presented as absolute values with percentages. Absolute values in serum electrolyte parameters were compared between T0 and T1 using paired-samples t-test. Differences between groups (hypokalemia versus normokalemia) were analyzed using the Chi-square test or Fisher's exact test where appropriate for categorical variables and the independent-samples t-test for numerical variables. Multiple logistic regression analysis was used to study whether age, gender, ASA-classification, medical history of hypertension, diuretic use (thiazide diuretics), $\beta$-blockers use, use of proton pump inhibitors, hypomagnesemia at T0, CRC diagnosed at colonoscopy, and setting (outpatient vs hospitalized) were independent risk factors for hypokalemia (versus normokalemia; excluding hyperkalemia). All variables with a $p$-value $\leq 0.05$ in the univariable analysis were included in the multivariable analysis. All odds ratios (OR) are presented with $95 \%$ confidence intervals $(\mathrm{Cl})$. Two-sided $p$-values $\leq 0.05$ were considered statistically significant.

\section{RESULTS}

Between January 1 and July 31, 2016, 2720 colonoscopies were performed in our center. We excluded 676 colonoscopies because of incomplete electrolyte measurements or use of bowel-preparations other than PEG-asc bowel cleansing preparation. Of the remaining 2044 colonoscopies, 33 colonoscopies were second colonoscopies within an interval of several weeks for various reasons (therapeutic intervention, technical issue, insufficient bowel cleansing) and were therefore excluded. A total of 2011 unique patients (index colonoscopies) were included in the analysis (Figure 8.2). At baseline (TO) 16 patients $(0.8 \%)$ were found to have hypokalemia compared to 1995 patients without hypokalemia, consisting of 1909 (94.9\%) patients with normal potassium values and 86 (4.3\%) with hyperkalemia.

The mean \pm SD time from T0 until colonoscopy was $12.0 \pm 15.8$ days, range 0-117 days. The sixteen patients with hypokalemia at T0 received potassium supplementation according to protocol, as previously described. Of these sixteen patients, six patients (37.5\%) had hypokalemia at the day of colonoscopy, despite potassium supplementation (mean \pm SD of potassium at T1: $3.3 \pm 0.5 \mathrm{mmol}$, range $2.4-4.3 \mathrm{mmol} / \mathrm{L}$ ). After bowel preparation, 104 out of 1909 patients (5.4\%) had developed hypokalemia on the day of colonoscopy (T1) (Figure 8.2), including $8(0.4 \%)$ with moderate 
hypokalemia and 96 (5.0\%) with mild hypokalemia but no patient with severe hypokalemia. The other 1805 patients (94.6\%) did not develop hypokalemia: 1769 $(92.7 \%)$ with normokalemia and 36 (1.9\%) with hyperkalemia. As a group, potassium levels at T1 declined on average with $0.3( \pm 0.4) \mathrm{mmol} / \mathrm{L}$ compared to potassium levels at TO (Table 8.1). Not only serum potassium levels but also sodium, magnesium and creatinine levels at T1 were significantly lower compare to T0 (Table 8.1).

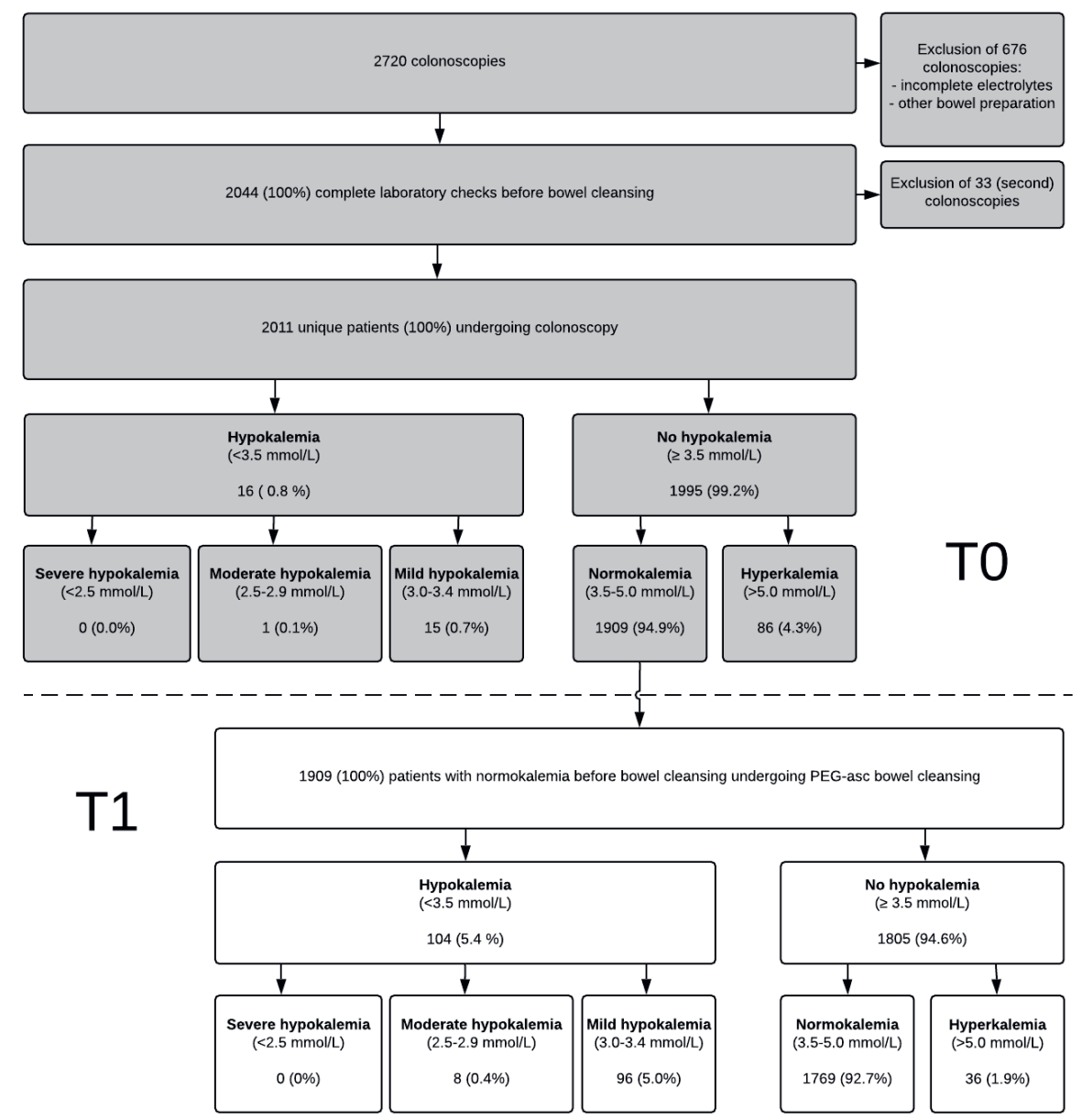

Figure 8.2 Flow chart results of T0 (patients screened before bowel cleansing) and T1 (patients screened after bowel cleansing). 
Table 8.1 Comparison of proportional changes in serum electrolytes before and after bowel preparation with PEG-asc.

\begin{tabular}{|c|c|c|c|c|c|c|c|}
\hline & $\mathbf{N}$ & $\begin{array}{c}\text { Value before intake } \\
\text { (mean } \pm S D, \text { range) }\end{array}$ & $\mathbf{N}$ & $\begin{array}{l}\text { Value after intake } \\
\text { (mean } \pm S D, \text { range) }\end{array}$ & $\mathbf{N}$ & $\begin{array}{c}\text { Change } \\
\text { (mean } \pm S D)\end{array}$ & $p$-value \\
\hline Potassium & 1873 & $4.3 \pm 0.3(3.5-5.0)$ & 1873 & $4.0 \pm 0.4(2.6-5.0)$ & 1824 & $-0.3 \pm 0.4$ & $<0.001$ \\
\hline Sodium & 1828 & $140.6 \pm 2.4(128-154)$ & 1868 & $139.8 \pm 2.9(111-149)$ & 1823 & $-0.7 \pm 4.3$ & $<0.001$ \\
\hline Creatinine & 1877 & $85.1 \pm 29(11-533)$ & 1889 & $79.8 \pm 25$ (23-413) & 1872 & $-5.3 \pm 10.7$ & $<0.001$ \\
\hline Magnesium & 1564 & $0.85 \pm 0.1(0.26-1.14)$ & 1818 & $0.81 \pm 0.08(0.28-1.15)$ & 1547 & $-0.04 \pm 0.08$ & $<0.001$ \\
\hline
\end{tabular}

The multivariable logistic regression model (Table 8.2) showed that hypokalemia was significantly more frequent in the group of thiazide diuretic users compared to nonusers (adjusted OR 3.64, 95\% Cl 1.97-6.70, $\mathrm{p}<0.001$ ), in the group diagnosed with CRC versus no CRC at colonoscopy (adjusted OR 4.42, 95\% $\mathrm{Cl} 1.85-10.53, p=0.001$ ) and in the group with female versus male gender (adjusted OR 1.71, 95\% Cl 1.04-2.81, $p=0.035)$. There was no statistically significant difference in developing hypokalemia at T1 between the single drug thiazide diuretics users and the combination of thiazide diuretics with angiotensin converting enzyme (ACE)- or angiotensin-II inhibitors users $(\mathrm{N}=19)$ (single use vs combination, OR 1.97, 95\% Cl 0.93-4.18, $p=0.08$ ) (data not shown in Table 8.2). While in general hypokalemia can result from hypomagnesemia, multiple logistic regression did not show that hypomagnesemia was significantly more frequent in the hypokalemia group compared to the normokalemia group. Of the 40 patients with hypomagnesemia, $23(57.5 \%)$ were on permanent use of proton pump inhibitors (PPI).

As shown in Tables $\mathbf{8 . 2}$ and 8.3, a total of 281 patients belonged to the "high cardiac risk" group. Of them, 20 patients developed hypokalemia after bowel cleansing. This group with a "high cardiac risk" combined with hypokalemia consists of $1 \%$ (20/1909) of the initial colonoscopy population and is considered to be most prone to develop cardiac arrhythmias. No cardiac arrhythmias or other adverse events occurred in our study population. 
Table 8.2 Clinical characteristics of subjects with hypokalemia versus normokalemia after bowel cleansing - T1

\begin{tabular}{|c|c|c|c|c|c|c|}
\hline & \multirow{2}{*}{$\begin{array}{c}\text { Hypokalemia } \\
\mathrm{N}=104\end{array}$} & \multirow{2}{*}{$\begin{array}{c}\text { Normokalemia } \\
\mathrm{N}=1769\end{array}$} & \multicolumn{2}{|c|}{ Unadjusted } & \multicolumn{2}{|c|}{ Adjusted } \\
\hline & & & OR (95\% Cl) & $p$-value & OR $(95 \% \mathrm{Cl})$ & $p$-value \\
\hline Age, yrs (mean $\pm S D)$ & $65.6 \pm 13.5$ & $61.1 \pm 14.6$ & $1.02(1.01-1.04)$ & $0.003^{*}$ & $0.99(0.98-1.02)$ & 0.81 \\
\hline Gender, female & $64(61.5 \%)$ & $826(46.7 \%)$ & $1.84(1.23-2.76)$ & $0.003 *$ & $1.71(1.04-2.81)$ & $0.035^{*}$ \\
\hline ASA & & & & $0.03^{*}$ & & 0.45 \\
\hline 1 & $25(24.0 \%)$ & 585 (33.1\%) & Ref & & Ref & \\
\hline 2 & $70(67.3 \%)$ & $1110(67.3 \%)$ & $1.48(0.93-2.35)$ & 0.10 & $1.07(0.58-1.99)$ & 0.82 \\
\hline 3 & $9(8.7 \%)$ & $74(4.2 \%)$ & $2.85(1.28-6.33)$ & $0.01^{*}$ & $1.99(0.65-6.07)$ & 0.23 \\
\hline Setting, hospitalized & $8(7.7 \%)$ & $55(3.1 \%)$ & $2.60(1.20-5.61)$ & $0.015^{*}$ & $1.22(0.24-6.14)$ & 0.81 \\
\hline Indication & & & & 0.91 & & \\
\hline Symptoms & 59 (56.7\%) & 1005 (56.8\%) & Ref & & & \\
\hline Screening & $21(20.2 \%)$ & 311 (17.6\%) & $1.15(0.69-1.92)$ & 0.60 & & \\
\hline Surveillance & $24(23.1 \%)$ & $446(25.2 \%)$ & $0.92(0.56-1.49)$ & 0.73 & & \\
\hline Therapeutic & $0(0 \%)$ & $7(0.4 \%)$ & + & 1.00 & & \\
\hline \multicolumn{7}{|l|}{ Indication, symptoms } \\
\hline Stool change & $13(12.5 \%)$ & $239(13.5 \%)$ & $0.92(0.50-1.66)$ & 0.77 & & \\
\hline Anemia & $3(2.9 \%)$ & $39(2.2 \%)$ & + & 0.65 & & \\
\hline Hematochezia & $22(21.2 \%)$ & $397(22.4 \%)$ & $0.93(0.57-1.50)$ & 0.76 & & \\
\hline Diarrhea & $13(12.5 \%)$ & $182(10.3 \%)$ & $1.25(0.68-2.27)$ & 0.47 & & \\
\hline Abdominal pain/discomfort & $8(7.7 \%)$ & $148(8.4 \%)$ & $0.91(0.44-1.91)$ & 0.81 & & \\
\hline \multicolumn{7}{|l|}{ Laboratory findings TO } \\
\hline Hypomagnesemia ( $N=1548)$ & $7(9.1 \%)$ & $33(2.2 \%)$ & $4.36(1.86-10.20)$ & $0.001^{*}$ & $2.32(0.86-6.25)$ & 0.097 \\
\hline CKD, MDRD $<30$ & $0(0 \%)$ & $14(0.8 \%)$ & + & 1.00 & & \\
\hline \multicolumn{7}{|l|}{ Colonoscopy findings } \\
\hline BBPS $\geq 6$ & $91(87.5 \%)$ & $1613(91.2 \%)$ & $0.68(0.37-1.24)$ & 0.21 & & \\
\hline Adenoma & $26(25.0 \%)$ & $517(29.2 \%)$ & $0.81(0.51-1.27)$ & 0.36 & & \\
\hline Diverticulosis & $26(4.5 \%)$ & $549(31.1 \%)$ & $0.74(0.47-1.17)$ & 0.20 & & \\
\hline $\mathrm{CRC}$ & $10(9.6 \%)$ & $64(3.6 \%)$ & $2.68(1.33-5.36)$ & $0.006^{*}$ & $4.42(1.85-10.53)$ & $0.001 *$ \\
\hline Active IBD & $98(94.2 \%)$ & $1710(96.7 \%)$ & $0.56(0.24-1.34)$ & 0.19 & & \\
\hline \multicolumn{7}{|l|}{ Medication } \\
\hline Thiazide diuretics & $34(32.7 \%)$ & $182(10.3 \%)$ & $4.28(2.76-6.63)$ & $<0.001^{*}$ & $3.64(1.97-6.70)$ & $<0.001^{*}$ \\
\hline Loop diuretics & $9(8.7 \%)$ & $80(4.5 \%)$ & $2.02(0.98-4.14)$ & 0.056 & & \\
\hline Beta-blockers & $40(38.5 \%)$ & $358(20.2 \%)$ & $2.45(1.62-3.70)$ & $<0.001^{*}$ & $1.27(0.70-2.30)$ & 0.43 \\
\hline RAAS activators & $34(32.7 \%)$ & $452(25.6 \%)$ & $1.40(0.92-2.14)$ & 0.12 & & \\
\hline Protonpumpinhibitors & $40(38.5 \%)$ & $507(28.7 \%)$ & $1.56(1.03-2.34)$ & $0.034^{*}$ & $1.30(0.77-2.19)$ & 0.33 \\
\hline \multicolumn{7}{|l|}{ Medical History } \\
\hline IBD & $4(3.8 \%)$ & $48(2.7 \%)$ & + & 0.50 & & \\
\hline CRC & $8(7.7 \%)$ & $115(6.5 \%)$ & $1.20(0.57-2.53)$ & 0.63 & & \\
\hline Hypertension & $56(53.8 \%)$ & $610(34.5 \%)$ & $2.22(1.49-3.30)$ & $<0.001^{*}$ & $1.35(0.70-2.61)$ & 0.37 \\
\hline Diabetes mellitus & $11(10.6 \%)$ & $196(11.1 \%)$ & $0.95(0.50-1.80)$ & 0.87 & & \\
\hline High cardiac risk $\ddagger$ & $20(19.2 \%)$ & $261(14.8 \%)$ & $1.38(0.83-2.28)$ & 0.22 & & \\
\hline
\end{tabular}

* $p$-value <0.05; † Fisher's exact test used; † Patients vulnerable to cardiac arrhythmias, see also Table 8.3. 
Table 8.3 High cardiac risk- at T1 hypokalemia vs normokalemia after bowel cleansing.

\begin{tabular}{lcccc}
\hline & Hypokalemia & Normokalemia & \multicolumn{2}{c}{ Unadjusted } \\
& $\mathbf{N = 1 0 4}$ & $\mathbf{N = 1 7 6 9}$ & OR (95\% CI) & $p$-value \\
\hline Congestive heart failure & $4(3.8 \%)$ & $40(2.3 \%)$ & $\dagger$ & 0.31 \\
Ischemic heart disease & $10(9.6 \%)$ & $142(8.0 \%)$ & $1.22(0.62-2.39)$ & 0.57 \\
Serious arrhythmias & & & & \\
$\quad$ Atrial tachycardia + & $10(9.6 \%)$ & $128(7.2 \%)$ & $1.36(0.69-2.68)$ & 0.37 \\
Ventricular tachycardia $§$ & 0 & $1(0.6 \%)$ & - & 1.00 \\
Bradycardia & 0 & $2(0.1 \%)$ & - & 1.00 \\
Digoxin use & 0 & $19(1.1 \%)$ & - & 1.00 \\
\hline
\end{tabular}

$\dagger$ Fisher's exact test used; $\div$ Tachycardias originating in the atria in this study include atrial fibrillation $(\mathrm{N}=135)$, atrial flutter $(\mathrm{N}=3)$, supraventricular tachycardia $(\mathrm{N}=0)$, Wolff-Parkinson-White Syndrome $(\mathrm{N}=0) ; \S$ Tachycardias in the ventricles include ventricular tachycardia $(\mathrm{N}=0)$, ventricular fibrillation $(\mathrm{N}=1)$, long QTsyndrome $(\mathrm{N}=0)$. Note: some patients are included in $\geq 1$ risk category (compared to high cardiac risk in Table 8.1)

\section{DISCUSSION}

This real-life evaluation in regular endoscopy practice showed a prevalence of hypokalemia in the non-selected group of patients referred for colonoscopy was: 1) $0.8 \%$ in patients before start of bowel cleansing for colonoscopy (TO) and 2) $5.4 \%$ in patients after bowel cleansing with low-volume PEG-asc (T1) who had normal potassium levels before bowel cleansing. In our non-selected group, the prevalence of post-cleansing hypokalemia appeared to be low with only cases of mild (5.0\%) and moderate $(0.4 \%)$ hypokalemia, without any case of severe hypokalemia.

With respect to risk factors for hypokalemia: patients developed hypokalemia after bowel cleansing significantly more frequent if they were female, had a diagnosis of CRC confirmed during colonoscopy and/or were using a thiazide diuretic. Female gender has previously been described as a predictor of hypokalemia, possibly related to lower lean body mass compared to male gender. ${ }^{15,16}$ In general, up to $40 \%$ of all patients treated with thiazide diuretics develop hypokalemia. ${ }^{13,17}$. Thus, hypokalemia is a regularly occurring consequence of use of thiazide diuretics. ${ }^{18}$ CRC diagnosis appeared to be a third risk factor in our analysis. Hypokalemia is very common in cancer patients and is multifactorial in origin, resulting from reduced intake (cancer cachexia), increased losses (vomiting, diarrhea, renal loss) and redistribution of potassium into intracellular compartment of tumor cells. ${ }^{19}$

Hypokalemia is one of the most frequently encountered electrolyte abnormalities in daily clinical practice: up to $20 \%$ of hospitalized patients are diagnosed with 
hypokalemia, but only in $4-5 \%$ hypokalemia becomes symptomatic with symptoms ranging from mild and moderate (muscle weakness, nausea, vomiting, constipation) to severe (seizures, paralysis, arrhythmias, coma and mortality). ${ }^{15,20-22}$

It is well documented that patients with congestive heart failure, ischemia or a history of arrhythmias have a much higher risk to develop life-threatening arrhythmias when they are hypokalemic. ${ }^{13}$ Of the initial colonoscopy population, 281 patients (15\%) belonged to the "cardiac high risk" group. Of these, 20 patients $(7.1 \%)$ developed hypokalemia after bowel cleansing (Table 8.2 and Table 8.3) and $40 \%$ of these 20 patients used thiazide diuretics (OR $3.4895 \% \mathrm{Cl} 1.34-9.02$ ), $p=0.010$ ). This group with high cardiac risk and hypokalemia is considered to have an additive, significantly higher risk to develop cardiac arrhythmias but is very small and consists of only $1 \%$ of the initial colonoscopy population.

In general, potassium monitoring is considered appropriate in populations that are more prone to develop cardiac arrhythmias, such as patients with a history of ischemic heart disease or myocardial infarction, heart failure or those taking digoxin and in patients at risk to develop hypokalemia.

Magnesium is an important cofactor to maintain intracellular potassium levels within normal limits. In particular magnesium depletion results in secondary potassium depletion. ${ }^{23}$ In our study, no significant association was found between hypokalemia and PPI-use or hypomagnesemia (Table 8.2). In general, screening for hypomagnesemia in chronic PPI users is not recommended. ${ }^{24}$ However, $^{2}$ hypomagnesemia should be considered in case of clinically relevant hypokalemia, since prevalences up to $50 \%$ have been reported. ${ }^{21}$

In daily endoscopy practice, data on cardiac arrhythmia events and electrolyte disturbances are lacking. These missing data are necessary before any recommendation on screening for hypokalemia in endoscopy practice can be made. Therefore, complications due to bowel cleansing, such as electrolyte disturbances and cardiac rhythm disturbances should be more systematically reported.

A strength of our analysis is the complete capture of all patients undergoing colonoscopy in a certain time interval. The current study is the first prospective, population-based and unselected study reporting prevalences of hypokalemia before and after PEG-asc preparation in a regular colonoscopy population.

Some limitations also have to be taken into account. First, we did not systematically screen for symptoms of hypokalemia in our study. Second, in patients with hypokalemia at TO, short-term supplementation of potassium was provided but 
further management was handed over to their general practitioner. A significant proportion (37.5\%) of these patients, again, appeared to have hypokalemia at T1. None of these patients had a "high cardiac risk" profile. In case hypokalemia is diagnosed and treatment is initiated, follow up with potassium measurement after supplementation is indicated before further actions such as bowel cleansing and colonoscopy are undertaken. Third, due to the moderate number of 104 cases with hypokalemia out of a total of 1909 cases, only the variables with a $p$-value $<0.05$ in the univariable analysis were included in the multivariable analysis.

From a practical clinical point of view: the data generated in this study do not provide sufficient evidence for additional screening for hypokalemia in patients undergoing bowel cleansing and colonoscopy apart from general recommendations. However, special awareness is needed in the group of patients with hypokalemia prior to bowel preparation $(0.8 \%)$, because they could be more prone to develop life-threatening arrhythmias. In our study, this group received potassium supplementation and this may have influenced the zero adverse events.

In conclusion, in this large colonoscopy- population-based study we have shown that hypokalemia was present in 1) $0.8 \%$ of patients before bowel cleansing with PEG-asc and 2 ) in $5.4 \%$ of patients after completing bowel cleansing with PEG-asc who had normal potassium values before bowel cleansing. Female gender, CRC diagnosis and thiazide use were found to be significant predictors of hypokalemia after use of PEGasc. Physicians referring patients for colonoscopy should be aware that "high cardiac risk" patients and those on thiazide diuretics undergoing bowel cleansing for colonoscopy are a risk to develop post-cleansing hypokalemia but it remains to be determined whether their risk to develop life-threatening arrhythmias is truly increased. 


\section{REFERENCES}

1. Rex DK, Schoenfeld PS, Cohen J, et al. Quality indicators for colonoscopy. Gastrointest Endosc 2015; 81: 31-53.

2. Stock C, Haug U, Brenner H. Population-based prevalence estimates of history of colonoscopy or sigmoidoscopy: review and analysis of recent trends. Gastrointest Endosc 2010;71:366-381.e362.

3. Tan JJ, Tjandra JJ. Which is the optimal bowel preparation for colonoscopy - a meta-analysis. Colorectal Dis 2006;8:247-258.

4. Fordtran JS, Hofmann AF. Seventy Years of Polyethylene Glycols in Gastroenterology: The Journey of PEG 4000 and 3350 From Nonabsorbable Marker to Colonoscopy Preparation to Osmotic Laxative. Gastroenterology 2017;152:675-680.

5. Johnson DA, Barkun AN, Cohen LB, et al. Optimizing adequacy of bowel cleansing for colonoscopy: recommendations from the US multi-society task force on colorectal cancer. Gastroenterology 2014; 147:903-924.

6. Hassan C, East J, Radaelli F, et al. Bowel preparation for colonoscopy: European Society of Gastrointestinal Endoscopy (ESGE) Guideline - Update 2019. Endoscopy 2019;51:775-794.

7. Saltzman JR, Cash BD, Pasha SF et al. Bowel preparation before colonoscopy. Gastrointest Endosc 2015;81:781-794.

8. Fujita I, Akagi Y, Hirano J, et al. Distinct mechanisms of transport of ascorbic acid and dehydroascorbic acid in intestinal epithelial cells (IEC-6). Res Commun Mol Pathol Pharmacol 2000;107:219-231

9. Reumkens A, Masclee AAM, Bakker CM. Postcolonoscopy mortality: Bowel preparation to blame? Gastrointest Endosc 2017;86:744-745.

10. Reumkens A, Masclee AA, Winkens B, et al. Prevalence of hypokalemia before and after bowel preparation for colonoscopy in high-risk patients. Gastrointest Endosc 2017;86:673-679.

11. Ho JM, Juurlink DN, Cavalcanti RB. Hypokalemia following polyethylene glycol-based bowel preparation for colonoscopy in older hospitalized patients with significant comorbidities. Ann Pharmacother 2010;44:466-470.

12. Hoorn EJ, Tuut MK, Hoorntje SJ, et al. Dutch guideline for the management of electrolyte disorders2012 revision. Neth J Med 2013;71:153-165.

13. Cohn JN, Kowey PR, Whelton PK, et al. New guidelines for potassium replacement in clinical practice: a contemporary review by the National Council on Potassium in Clinical Practice. Arch Intern Med 2000;160:2429-2436.

14. Ayuk J, Gittoes NJ. How should hypomagnesaemia be investigated and treated? Clin Endocrinol 2011; 75:743-746.

15. Nilsson E, Gasparini A, Arnlov J, et al. Incidence and determinants of hyperkalemia and hypokalemia in a large healthcare system. Int J Cardiol 2017;245:277-284.

16. Kleinfeld M, Borra S, Gavani S, et al. Hypokalemia: are elderly females more vulnerable? J Natl Med Assoc 1993;85:861-864.

17. Gennari FJ. Hypokalemia. N Engl J Med 1998;339:451-458.

18. Ellison DH, Loffing J. Thiazide effects and adverse effects: insights from molecular genetics. Hypertension 2009;54:196-202.

19. Liamis G, Filippatos TD, Elisaf MS. Electrolyte disorders associated with the use of anticancer drugs. Eur J Pharmacol 2016;777:78-87.

20. Pepin J, Shields C. Advances in diagnosis and management of hypokalemic and hyperkalemic emergencies. Emerg Med Pract 2012;14:1-17; quiz 17-18.

21. Udensi UK, Tchounwou PB. Potassium Homeostasis, Oxidative Stress, and Human Disease. Int J Clin Exp Physiol 2017;4:111-122. 
22. Clayton JA, Rodgers S, Blakey J et al. Thiazide diuretic prescription and electrolyte abnormalities in primary care. Br J Clin Pharmacol 2006;61:87-95.

23. Whang $\mathrm{R}$, Whang $\mathrm{DD}$, Ryan MP. Refractory potassium repletion. A consequence of magnesium deficiency. Arch Intern Med 1992;152:40-45.

24. Freedberg DE, Kim LS, Yang YX. The Risks and Benefits of Long-term Use of Proton Pump Inhibitors: Expert Review and Best Practice Advice From the American Gastroenterological Association. Gastroenterology 2017;152:706-715. 


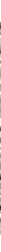




\section{CHAPTER 9}

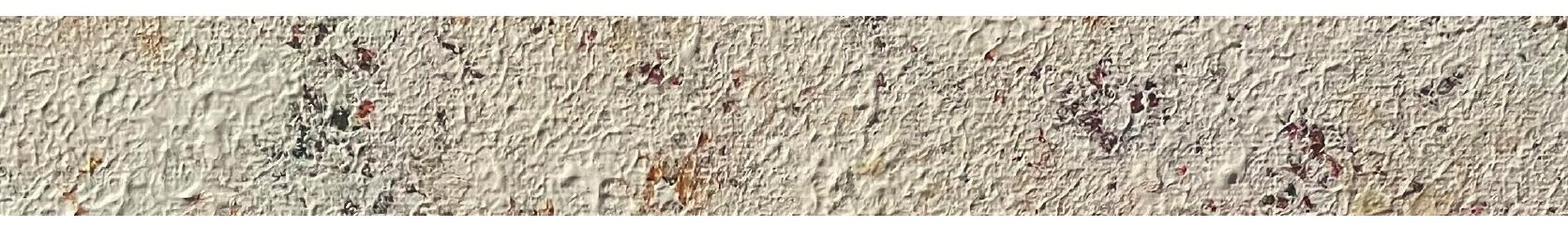

GENERAL DISCUSSION 
CHAPTER 9 


\section{GENERAL DISCUSSION}

This is 2021, about 50 years after the introduction of diagnostic colonoscopy and polypectomy. ${ }^{1}$ Worldwide, colonoscopy is one of the most commonly performed examinations in gastroenterology. Quality and safety, are unarguably, a prerequisite. Colonoscopy is used to evaluate patients with colorectal symptoms, including hematochezia, changes in stool pattern and stool consistency and abdominal pain or, weight loss, iron deficiency anemia, patients with positive fecal occult blood tests, patients with a substantially increased risk for colorectal cancer (CRC), and patient with signs and symptoms of colorectal inflammation. ${ }^{2}$ No other currently available imaging technique approaches the sensitivity of colonoscopy in effective detection and resection of precancerous lesions and thereby CRC prevention. ${ }^{3}$ Despite its strengths, colonoscopy has certain disadvantages and limitations. Quality related disadvantages are the relatively long learning curve, training in polyp detection, training in polyp resection, the use of appropriate surveillance intervals and the quality of the bowel cleansing. ${ }^{4,5}$ Colonoscopy carries safety risks associated with bowel preparation, sedation, aspiration, perforation, and bleeding. Delivering highquality and high-safety colonoscopies should be the aim of all endoscopists.

In this thesis, we focused on clinical important aspects of quality and safety of colonoscopy. In the quality part, we investigated two aspects of quality of colonoscopy. The first aspect was related to recognizing colorectal neuroendocrine neoplasms (NEN) by focusing on epidemiology, clinical, and endoscopic features in a unique cohort of colorectal neoplasms. The second aspect was related to use and validation of a personalized smartphone application to optimize bowel cleansing. In the safety part, we focused on post-colonoscopy complications, especially bowel cleansing related electrolyte disorders with focus on hypokalemia. Aims and outlines of the various chapters have been stated in chapter 1. 


\section{QUALITY: COLORECTAL NEUROENDOCRINE NEOPLASMS \& IMPROVING BOWEL PREPARATION}

\section{COLORECTAL NEUROENDOCRINE NEOPLASMS}

In Chapter 2 we provided a detailed analysis of a unique population based cohort of colorectal NENs with respect to epidemiological, clinical and endoscopic aspects according to the updated 2019 WHO-classification. ${ }^{6}$ As confirmed in our study, rectal NETs present as small sessile yellowish, lipoma-like lesions with regular surface (Figure 2.3). Colonic NETs present as larger sessile lesions, with irregular surface in $25 \%$, prominent vessels, and more often darker (than background), than yellowish or lipoma-like (Figure 2.4). NECs present as darker (than background) larger lesions with ulcerative-necrotizing features, both for rectal and colonic NECs (Figure 2.5). The incidence of colorectal NENs is rising based on reports from Asia and the US and this is due to an increase in the number of colonoscopies. ${ }^{7-9}$ We observed an average of 1 NEN per 1,666 colonoscopies. Our data are comparable to the study of Korse et al, which reported an incidence of 0.43 colorectal NENs per 1,000 colonoscopies (0.33/1000 for NETs and 0.10/1000 for NECs), in the Netherlands in 2001-2010 (Figure 2.2). ${ }^{10}$ Colonoscopy numbers are rising but the incidence of colorectal NEN per 1000 colonoscopies remained stable during the 15 years observation in our study cohort. Because the rising NEN numbers and the observation that at the time of diagnosis $30-40 \%$ of colorectal NENs are metastasized it is time to focus on more early endoscopic recognition.

\section{IMPROVING BOWEL PREPARATION}

The efficacy and safety of colonoscopy is related to the quality of the preinvestigational bowel preparation. Inadequate bowel preparation is associated with the risk of missing clinically relevant lesions, procedural difficulties, prolonged procedural time, an increased number of interval colorectal carcinomas, and additional healthcare costs. ${ }^{11-16}$ In chapter $\mathbf{3}$ we aimed to compare a personalized smartphone application in addition to verbal instructions and printed written instructions for bowel preparation in improving bowel preparation quality. Key finding of this study is the significantly higher mean total BBPS in patients using a personalized smartphone application for bowel preparation instructions compared to patients using regular verbal and written information (Table 3.2). Patient satisfaction 
did not further improve for smartphone application users compared to patients receiving regular written instructions. For patients $\geq 65$ years, no significant differences in mean BBPS were found, although their number was low. The European Society of Gastrointestinal Endoscopy (ESGE) recommends the use of enhanced instructions for bowel preparation. Methods such as telephone calls, visual aids, educational videos, and SMS reminders help to improve bowel preparation quality compared to regular instructions. ${ }^{11,12,14,17-21}$ The group of smartphone users will only increase in the future, making smartphone applications for bowel preparation a valuable tool for the improvement of bowel preparation quality. Further research focusing on elderly patients ( $\geq 65$ years old) is needed to investigate the usefulness of a smartphone application among those patients.

\section{SAFETY: POST-COLONOSCOPY COMPLICATIONS}

In the second part (Chapters 4-8) of this thesis we focused on monitoring and reporting of post-colonoscopy complications in routine endoscopic practice.

\section{BLEEDING, PERFORATION AND MORTALITY}

In chapter 4 we confirmed in our population-based systematic review and metaanalysis that colonoscopy is a safe procedure worldwide. Because of the increasing volume and technical difficulty of the examinations in the era of CRC screening and post-polypectomy surveillance, it is important to continuously monitor safety metrics in colonoscopy practice, and, where possible, to improve. Temporal variability should be assessed to retrace performance gaps and solve them. Time-trends analysis showed that the post-colonoscopy bleeding rate decreased from 6.4 to $1.0 / 1,000$ colonoscopies, while perforation and mortality rates remained stable low over the past 15 years (Figure 4.4). Noteworthy, we found that post-colonoscopy complication rate vary widely according to colonoscopy indication. For example, post-colonoscopy bleeding occurs in 2.6/1,000; 2.4/1,000; 4.6/1,000; and 9.8/1,000 colonoscopies (irrespective of indication); screening/surveillance; symptoms; and post-polypectomy procedures. An important finding of this systematic review is the clinical decline in post-colonoscopy bleeding over the past 15 years. This is in contrast with the substantial rise of the overall polypectomy rate, especially endoscopic resection of larger non-pedunculated polyps (previously referred for surgical resection). Such 
outcomes are most likely due to continuous improvement in colonoscopy equipment (i.e. adoption of high-definition colonoscopes), techniques (i.e. introduction of $\mathrm{CO} 2$ instead of air insufflation) and especially better training including knowledge and technical skills. ${ }^{22-25}$ Nowadays, submucosal saline solution injection and clipping are more frequently employed to prevent or treat bleeding or perforation. Notwithstanding, training and proficiency in performance of endoscopic resection techniques vary greatly even amongst experienced colonoscopists. ${ }^{26,27}$

However, there is a possibility that complications have been underreported in this study. Complication rates varied widely, possibly due to indication, polyp size, and polypectomy technique, but could also rely on the underreporting of complications. Noteworthy, not all studies used uniform definitions to describe complications. In future studies, it is important that uniform complications are pursued. We studied perforations, bleeding and mortality in this systematic review and meta-analysis, but post-colonoscopy complications also comprise: post-polypectomy syndrome, cardiopulmonary complications, serious electrolyte disturbances and postcolonoscopy colorectal cancer (PCCRC). Accurate registration of complications is important to continuously monitor safety.

\section{ELECTROLYTE DISTURBANCES}

Bowel preparation solutions should not cause clinically important shifts in systemic electrolytes, in fluids, or in patient comfort. In chapter 6, we report two cases of severe post-colonoscopy hypokalemia with fatal outcome at our secondary care hospital. This was the basis to initiate studies on hypokalemia before and after bowel cleansing. To start these studies, we conducted a systematic review and meta-analysis of 15 population-based studies examining the pooled prevalence rate of electrolyte disturbances after bowel preparation (chapter 5). A significant proportion of patients developed serum electrolyte disturbances after bowel preparation: 35-360/1,000 patients after sodium phosphate (NaP) vs. 9-92/1,000 patients after polyethylene glycol (PEG). We found a pooled prevalence of hypokalemia of $14.6 \%$ (95\% Cl 4.8, $28.1)$ in patients after NaP vs. $3.7 \%(95 \% \mathrm{Cl} 0.12,10.42)$ after PEG bowel preparation. The ESGE recommends against the use of $\mathrm{NaP}$, but this recommendation is based on low quality evidence. Given the high prevalences of electrolyte disturbances reported in this systematic review and meta-analysis, additional high quality evidence is provided to support the ESGE recommendation against use of $\mathrm{NaP}$ based bowel preparation solutions. Nowadays, sodium picosulfate with magnesium citrate 
(SPMC) and polyethylene glycol with ascorbic acid (PEG-asc) low-volume bowel preparation regimens are increasingly used instead of $\mathrm{NaP}$ and high-volume PEG. ${ }^{28,29}$ More data on prevalences of electrolyte disturbances after low-volume bowel preparations using SPMC and PEG-asc should become available in order to examine pooled risks.

As mentioned above, chapter 6 was the basis to initiate chapter 5, chapter 7 and chapter 8. In chapter 6 we describe severe hypokalemia with fatal outcome following bowel cleansing for colonoscopy with low-volume PEG-solutions. Hypothetically, in both cases, the etiology of hypokalemia was multifactorial (Figure 6.1). The large amount of low-volume PEG solution ( $5 \mathrm{~L}$ and $4 \mathrm{~L}$ instead of $2 \mathrm{~L}$ ) administered to achieve sufficient bowel preparation may have aggravated or induced severe hypokalemia. In the first case, potassium depletion may have also resulted from a combination of factors: longstanding vomiting, diarrhea, poor oral intake, prednisolone therapy and the use of hydrochlorothiazide. Similarly, a mix of factors contributed to hypokalemia in the second case. Prominent amongst these factors, is, again the large volume of bowel preparation. The use of digoxin and possible recurrence of hyperthyroidism (because no recent TSH was measured) may also have contributed. It has been shown that diarrhea causing intestinal potassium loss is associated with the severity of hypokalemia in elderly patients. ${ }^{30}$

At that point, little was known about the prevalence of hypokalemia after low-volume PEG bowel cleansing solutions, its risk factors and the clinical, potentially fatal consequences. Large scale studies were needed to determine the prevalence of post colonoscopy hypokalemia, the potential risk factors, occurrence of (near) fatal consequences. Only thereafter clinical recommendations can be made.

\section{HYPOKALEMIA}

The above described cases, prompted us to explore in more detail the magnitude of hypokalemia and risk factors for hypokalemia associated with low-volume PEG bowel preparation in our large secondary care training hospital in the Netherlands (chapter 7). During one year we prospectively measured potassium levels before and after lowvolume bowel preparation in patients referred for colonoscopy in a single, large volume, colonoscopy center. We focused on two high risk groups: diuretic users and hospitalized patients. Our aim was to obtain more detailed information 1 ) on the 
prevalence of hypokalemia pre-bowel cleansing in the two risk groups and 2) on the risk of hypokalemia post bowel cleansing. Secondary aim was to analyse the potential risk factors for hypokalemia in these patients. Hypokalemia was present before bowel cleansing in $4.2 \%$ of patients using diuretics or being hospitalized. Hypokalemia was present in $23.6 \%$ of patients after bowel cleansing with low-volume PEG with ascorbic acid who had normal potassium levels pre bowel cleansing (Figure 7.2). Severe hypokalemia was seen in $0.4 \%$ pre-bowel cleansing and in $4.0 \%$ post-bowel cleansing. No serious events occurred; supplementation was provided in all cases of hypokalemia.

Given the fact that this study has been performed in preselected groups of diuretic users and hospitalized patients, specific, more detailed risk factor analysis for hypokalemia could not be provided. Despite this limitation, our study clearly showed that hypokalemia may develop in a substantial percentage of patients after the ingestion of low-volume PEG. These results should however be interpreted with caution because the prevalence of hypokalemia in patients not being hospitalized and not taking diuretics was not investigated. Therefore, future studies should focus on overall population-based risks to develop hypokalemia after low-volume PEG bowel cleansing. These studies are needed to determine the true prevalence of post colonoscopy hypokalemia, examine risk factors and thereafter consider whether screening of subgroups at risk is indicated. Since colorectal cancer (CRC) screening programs are implemented worldwide and the number of colonoscopies has been rising, more patients will be exposed to colonoscopy and bowel cleansing-related risks, including hypokalemia. While waiting for more evidence, endoscopists should be aware of the prevalence of hypokalemia post bowel cleansing and potential risks.

It should be noticed that the study in chapter 7 has been performed in preselected groups of diuretic users and hospitalized patients. Therefore, a detailed risk factor analysis for hypokalemia could not be provided. This prompted us to perform a large prospective study in non-selected patients scheduled for colonoscopy in regular care and screening practice. In this non-selected study population, our primary aim was to obtain data on the prevalence of hypokalemia after bowel cleansing with PEG-asc and to identify patients at a significant risk to develop hypokalemia (chapter 8). This reallife evaluation in regular endoscopy practice showed a prevalence of hypokalemia in the non-selected group of patients referred for colonoscopy was: 1) $0.8 \%$ in patients before start of bowel cleansing for colonoscopy (TO) and 2) 5.4\% in patients after 
bowel cleansing with low-volume PEG-asc (T1) who had normal potassium levels before bowel cleansing (Figure 8.2). In our non-selected group, the prevalence of post-cleansing hypokalemia appeared to be low with only cases of mild $(5.0 \%)$ and moderate $(0.4 \%)$ hypokalemia, without any case of severe hypokalemia.

From a practical clinical point of view: the data generated in this study do not provide sufficient evidence for additional screening for hypokalemia in patients undergoing bowel cleansing and colonoscopy apart from general recommendations. However, special awareness is needed in the group of patients with hypokalemia prior to bowel preparation $(0.8 \%)$, because they could be more prone to develop life-threatening arrhythmias. In our study, this group received potassium supplementation and this may have prevented the occurrence of serious adverse events.

\section{IMPLICATIONS FOR THE CLINICAL PRACTICE AND SUGGESTIONS FOR FUTURE RESEARCH}

\section{QUALITY}

To assume high quality levels in NEN detection, ENET members have started to develop a training program in well-differentiated NEN recognition for endoscopists. ${ }^{31}$ To initiate high-quality training programs, high definition imaging, which was not standard implemented in our study period (2001-2015), is necessary in future studies. Following all colorectal lesion classifications ${ }^{32-34}$, a NEN-classification could be helpful to better and more early recognize NENs. In the near future, artificial intelligence could help endoscopists to improve the quality of recognizing NENs during colonoscopy, since it will compensate for humans' errors and limited capabilities by bringing more accuracy, consistency, and, higher speed, making colonoscopy procedures of higher quality and more efficient. ${ }^{35}$ Training of endoscopists in recognition of NENs using videos and e-learnings will provide the basis for appropriate endoscopic diagnosis and resection and evidence-based surveillance recommendations.

To improve the quality of bowel preparation, E-health and smartphone applications should be implemented in bowel preparation and colonoscopy information procedures. 


\section{SAFETY}

Because of rapidly increasing volumes of colonoscopies for population based screening, surveillance, and regular care, the number of elderly patients and patients with comorbidity at risk for electrolyte disturbances will also increase in the near future. It is well documented that patients with congestive heart failure, ischemia or a history of arrhythmias have a much higher risk to develop life-threatening arrhythmias when they are hypokalemic. ${ }^{36}$ This group with high cardiac risk and hypokalemia is considered to have an additive, significantly higher risk to develop cardiac arrhythmias. Fortunately, this group is very small and consists of only $1 \%$ of the initial colonoscopy population. In general, potassium monitoring is considered appropriate in populations that are more prone to develop cardiac arrhythmias, such as patients with a history of ischemic heart disease or myocardial infarction, heart failure or those taking digoxin and in patients at risk to develop hypokalemia. Physicians referring patients for colonoscopy should be aware that "high cardiac risk" patients and those on thiazide diuretics undergoing bowel cleansing for colonoscopy are a risk to develop post-cleansing hypokalemia but it remains to be determined whether their risk to develop life-threatening arrhythmias is truly increased. A flowchart, whom to screen before and after low-volume bowel cleansing preparation with PEG-asc is provided in

\section{Figure 9.1.}

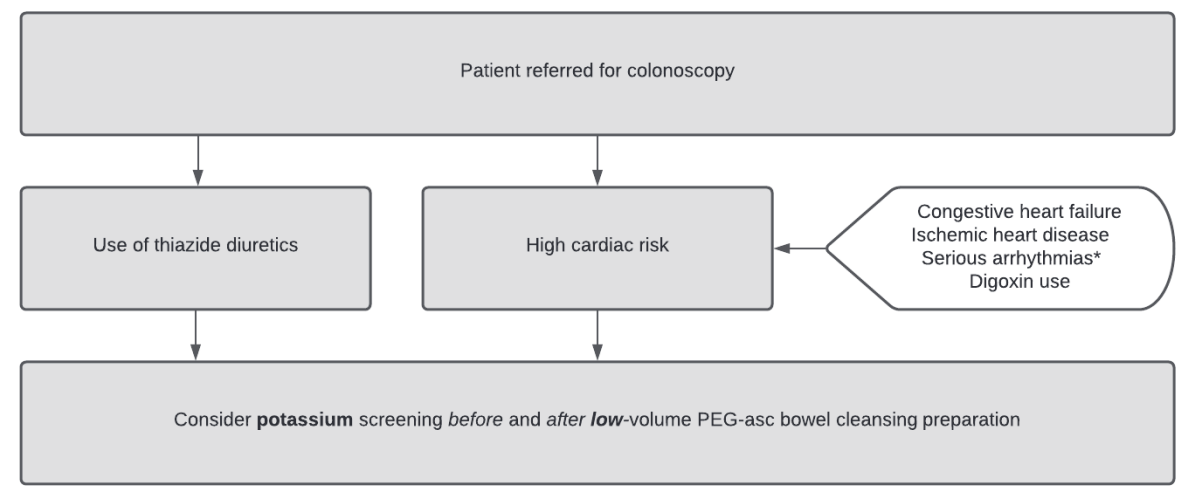

Figure 9.1 Whom to screen for hypokalemia - before and after bowel preparation. *Serious arrhythmias: atrial tachycardia, ventricular tachycardia, bradycardia 


\section{KEY MESSAGES OF THIS THESIS}

What are the new findings?

- Endoscopic features of NENs: Rectal NETs mainly present as sessile small yellowish lipoma-like lesions and colonic NETs present as larger darker than the background colored, sessile lesions. The number of NENs diagnosed remained stable over time with 1.0 NEN per 1,666 colonoscopies.

- Smart Phone application in the procedure of bowel preparation: A significantly higher mean total BBPS in patients using a personalized smartphone application for bowel preparation instructions compared to patients using regular verbal and written information

- Colonoscopy complications: In our meta-analysis, prevalences for perforation, post-colonoscopy bleeding and mortality were $0.5 / 1,000 ; 2.6 / 1,000$ and 2.9/100,000.

- Bowel cleansing and hypokalemia:

A) In high-risk patients, $23.6 \%$ developed hypokalemia after bowel cleansing with PEG-asc.

B) In the overall colonoscopy population, 5.4\% developed hypokalemia after bowel cleansing with PEG-asc.

C) The combination of high-cardiac risk and hypokalemia was present in $1 \%$ of the overall colonoscopy population.

How might these results impact clinical practice in the future?

- High-quality imaging of colorectal NENs and developing training programs are necessary to recognize and optimize treatment of NEN lesions.

- Use of e-health and smartphone apps is "booming" in daily medical practice and should also be implemented in bowel preparation for colonoscopy.

- Uniformity in complication databases is the first step to compare outcomes in the future

- Next, monitoring complication rates is critical and underreporting complication should be prevented

- Physicians referring patients for colonoscopy should be aware that "high cardiac risk" patients and those on thiazide diuretics undergoing bowel cleansing for colonoscopy are a risk to develop post-cleansing hypokalemia 


\section{REFERENCES}

1. Wolff WI, Shinya H. Colonofiberoscopy. JAMA. 1971;217:1509-1512

2. Robertson DJ, Lee JK, Boland CR et al. Recommendations on Fecal Immunochemical Testing to Screen for Colorectal Neoplasia: A Consensus Statement by the US Multi-Society Task Force on Colorectal Cancer. Gastroenterology. 2017;152:1217-1237.e1213.

3. JE IJ, Tutein Nolthenius CJ, Kuipers EJ et al. CT-Colonography vs. Colonoscopy for Detection of HighRisk Sessile Serrated Polyps. Am J Gastroenterol. 2016;111:516-522.

4. Mysliwiec PA, Brown ML, Klabunde CN et al. Are physicians doing too much colonoscopy? A national survey of colorectal surveillance after polypectomy. Ann Intern Med. 2004;141:264-271.

5. Barclay RL, Vicari JJ, Doughty AS et al. Colonoscopic withdrawal times and adenoma detection during screening colonoscopy. N Engl J Med. 2006;355:2533-2541.

6. Nagtegaal ID, Odze RD, Klimstra D et al. The 2019 WHO classification of tumours of the digestive system. Histopathology. 2020;76:182-188.

7. Memon MA, Nelson H. Gastrointestinal carcinoid tumors: current management strategies. Dis Colon Rectum. 1997;40:1101-1118

8. Jung YS, Yun KE, Chang $Y$ et al. Risk factors associated with rectal neuroendocrine tumors: a crosssectional study. Cancer Epidemiol Biomarkers Prev. 2014;23:1406-1413.

9. Taghavi S, Jayarajan SN, Powers BD et al. Examining rectal carcinoids in the era of screening colonoscopy: a surveillance, epidemiology, and end results analysis. Dis Colon Rectum. 2013;56: 952-959.

10. Korse CM, Taal BG, van Velthuysen ML et al. Incidence and survival of neuroendocrine tumours in the Netherlands according to histological grade: experience of two decades of cancer registry. Eur $J$ Cancer (Oxford, England : 1990). 2013;49:1975-1983.

11. Hassan C, East J, Radaelli F et al. Bowel preparation for colonoscopy: European Society of Gastrointestinal Endoscopy (ESGE) Guideline - Update 2019. Endoscopy. 2019;51(8):775-794.

12. Cho J, Lee S, Shin JA et al. The Impact of Patient Education with a Smartphone Application on the Quality of Bowel Preparation for Screening Colonoscopy. Clin Endosc. 2017;50:479-485.

13. Clark BT, Rustagi T, Laine L. What level of bowel prep quality requires early repeat colonoscopy: systematic review and meta-analysis of the impact of preparation quality on adenoma detection rate. Am J Gastroenterol. 2014;109:1714-1723; quiz 1724.

14. Guo X, Yang Z, Zhao L et al. Enhanced instructions improve the quality of bowel preparation for colonoscopy: a meta-analysis of randomized controlled trials. Gastrointest Endosc. 2017;85:90-97.e96.

15. Chokshi RV, Hovis CE, Hollander T et al. Prevalence of missed adenomas in patients with inadequate bowel preparation on screening colonoscopy. Gastrointest Endosc. 2012;75:1197-1203.

16. le Clercq CM, Bouwens MW, Rondagh EJ et al. Postcolonoscopy colorectal cancers are preventable: a population-based study. Gut. 2014;63:957-963.

17. Liu Z, Zhang MM, Li YY et al. Enhanced education for bowel preparation before colonoscopy: A stateof-the-art review. J Dig Dis. 2017;18:84-91.

18. Sharara Al, Chalhoub JM, Beydoun $\mathrm{M}$ et al. A Customized Mobile Application in Colonoscopy Preparation: A Randomized Controlled Trial. Clin Transl Gastroenterol. 2017;8:e211.

19. Lorenzo-Zuniga V, Moreno de Vega V, Marin I et al. Improving the quality of colonoscopy bowel preparation using a smart phone application: a randomized trial. Dig Endosc. 2015;27:590-595.

20. Jeon SC, Kim JH, Kim SJ et al. Effect of Sending Educational Video Clips via Smartphone Mobile Messenger on Bowel Preparation before Colonoscopy. Clin Endosc. 2019;52:53-58.

21. Walter B, Klare $\mathrm{P}$, Strehle K et al. Improving the quality and acceptance of colonoscopy preparation by reinforced patient education with short message service: results from a randomized, multicenter study (PERICLES-II). Gastrointest Endosc. 2019;89:506-513.e504.

22. Gupta AK, Melton LJ, 3rd, Petersen GM et al. Changing trends in the incidence, stage, survival, and screen-detection of colorectal cancer: a population-based study. Clin Gastroenterol Hepatol 2005;3: 150-158. 
23. Anderloni A, Jovani M, Hassan C et al. Advances, problems, and complications of polypectomy. Clin Exp Gastroenterol. 2014;7:285-296.

24. Bielawska B, Day AG, Lieberman DA et al. Risk factors for early colonoscopic perforation include nongastroenterologist endoscopists: a multivariable analysis. Clin Gastroenterol Hepatol. 2014;12:85-92.

25. Leyden JE, Doherty GA, Hanley A et al. Quality of colonoscopy performance among gastroenterology and surgical trainees: a need for common training standards for all trainees? Endoscopy. 2011;43: 935-940.

26. Pohl H, Srivastava A, Bensen SP et al. Incomplete polyp resection during colonoscopy-results of the complete adenoma resection (CARE) study. Gastroenterology. 2013;144:74-80 e71.

27. Asfaha S, Alqahtani S, Hilsden RJ et al. Assessment of endoscopic training of general surgery residents in a North American health region. Gastrointest Endosc. 2008;68:1056-1062.

28. Hassan C, Bretthauer M, Kaminski MF et al. Bowel preparation for colonoscopy: European Society of Gastrointestinal Endoscopy (ESGE) guideline. Endoscopy. 2013;45:142-150.

29. Wexner SD, Beck DE, Baron TH et al. A consensus document on bowel preparation before colonoscopy: prepared by a task force from the American Society of Colon and Rectal Surgeons (ASCRS), the American Society for Gastrointestinal Endoscopy (ASGE), and the Society of American Gastrointestinal and Endoscopic Surgeons (SAGES). Gastrointest Endosc. 2006;63:894-909.

30. Rostom A, Jolicoeur $E$, Dube $C$ et al. A randomized prospective trial comparing different regimens of oral sodium phosphate and polyethylene glycol-based lavage solution in the preparation of patients for colonoscopy. Gastrointest Endosc. 2006;64:544-552.

31. Ramage JK, Valle JW, Nieveen van Dijkum EJM et al. Colorectal Neuroendocrine Neoplasms: Areas of Unmet Need. Neuroendocrinology 2019;108:45-53.

32. Bisschops R, Hassan C, Bhandari P et al. BASIC (BLI Adenoma Serrated International Classification) classification for colorectal polyp characterization with blue light imaging. Endoscopy. 2018;50: 211-220.

33. [Anonym]. Update on the paris classification of superficial neoplastic lesions in the digestive tract. Endoscopy. 2005;37:570-578.

34. Patrun J, Okreša L, Iveković H et al. Diagnostic Accuracy of NICE Classification System for Optical Recognition of Predictive Morphology of Colorectal Polyps. Gastroenterol Res Pract. 2018;2018: 7531368.

35. El Hajjar A, Rey JF. Artificial intelligence in gastrointestinal endoscopy: general overview. Chin Med J (Engl). 2020;133:326-334.

36. Cohn JN, Kowey PR, Whelton PK et al. New guidelines for potassium replacement in clinical practice: a contemporary review by the National Council on Potassium in Clinical Practice. Arch Intern Med. 2000; 160:2429-2436. 


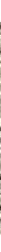




\section{ADDENDUM}

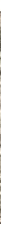


ADDENDUM

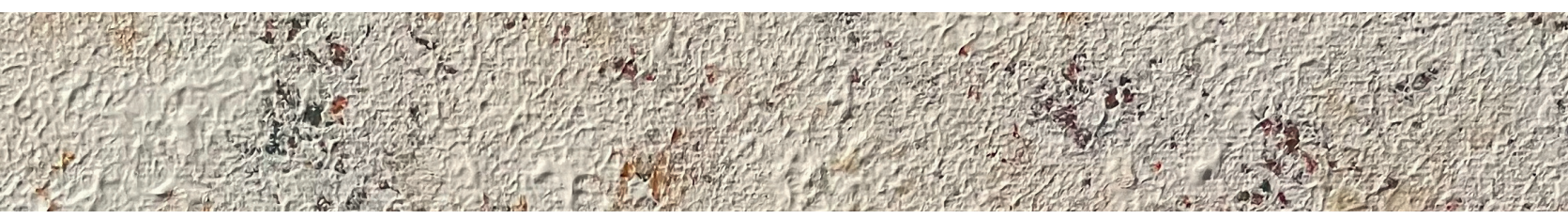




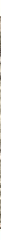

SUMMARY 
ADDENDUM 


\section{SUMMARY}

Worldwide, colonoscopy is one of the most commonly performed examinations. Since colonoscopy is the primary and follow-up screening modality for colorectal cancer (CRC diagnosis, high quality and safety levels are required. Bowel cleansing is an inseparable part of colonoscopy and should be adequate to optimize visualization of the entire colonic mucosa during colonoscopy. Bowel preparation is a burdensome procedure for patients, involving diet modifications and laxative use based on subject's needs. Ideally, bowel cleansing should clear the complete colon of all solid material and mucus and cause no damage to the colonic mucosa. The safety and efficacy of the colonoscopy are related to the quality of the pre-investigational bowel preparation. The Boston Bowel Preparation Scale (BBPS) is a bowel preparation rating scale that relies on the summation of three individual colonic segment scores for the right, transverse and left colon (Table 10.1). It indicates the degree of bowel visualization. Total BBPS scores have been associated with clinical outcomes such as polyp and adenoma detection rates, surveillance advice, colonoscope insertion and withdrawal times. The BBPS is a validated and reliable instrument for assessing bowel preparation during colonoscopy.

Table 10.1 Boston Bowel Preparation Scale.

\begin{tabular}{ll}
\hline Score & Definition \\
\hline 0 & $\begin{array}{l}\text { Unprepared colon segment with mucosa not seen due to solid stool that cannot be cleared } \\
1\end{array}$ \\
$\begin{array}{l}\text { Portion of mucosa of the colon segment seen, but other areas of the colon segment not well seen } \\
\text { due to staining, residual stool and/or opaque liquid }\end{array}$ \\
$\begin{array}{l}\text { Minor amount of residual staining, small fragments of stool and/or opaque liquid, but mucosa of } \\
\text { colon segment seen well } \\
\text { Entire mucosa of colon segment seen well with no residual staining, small fragments of stool or } \\
\text { opaque liquid }\end{array}$ \\
\hline
\end{tabular}

Colonoscopy carries safety risks associated with bowel preparation, sedation, aspiration, perforation, and bleeding. Delivering high-quality and high-safety colonoscopies should be the aim of all endoscopists, endoscopy teams and endoscopy units.

In this thesis, we aimed to investigate clinical important aspects of quality and safety of colonoscopy. In the quality part, we investigated two aspects of quality of 
colonoscopy. The first aspect was related to recognizing a low prevalent but characteristic and clinically relevant set of disorders, colorectal neuroendocrine neoplasms (NEN), by focusing on epidemiology, clinical, and endoscopic features in a unique cohort of colorectal neoplasms. The second aspect was related to use and validation of a personalized smartphone application to optimize bowel cleansing. In the safety part, we focused on post-colonoscopy complications, especially bowel cleansing related electrolyte disorders with focus on hypokalemia. Aims and outlines of the various chapters have been stated in chapter 1.

\section{PART 1: QUALITY}

In Chapter $\mathbf{2}$ we provided a detailed analysis of a unique population based cohort of colorectal NENs with respect to epidemiological, clinical and endoscopic aspects according to the updated 2019 WHO-classification. It was shown that rectal NETs present as small sessile yellowish, lipoma-like lesions with regular surface. Colonic NETs present as larger sessile lesions, with irregular surface in $25 \%$, prominent vessels, and more often darker (than background), than yellowish or lipoma-like. NECs present as darker (than background) larger lesions with ulcerative-necrotizing features, both for rectal and colonic NECs. We observed an average of 1 NEN per 1,666 colonoscopies. Colonoscopy numbers are rising but the incidence of colorectal NEN per 1000 colonoscopies remained stable during the 15 years observation in our study cohort.

The efficacy and safety of colonoscopy is related to the quality of the preinvestigational bowel preparation. Inadequate bowel preparation is associated with the risk of missing clinically relevant lesions, procedural difficulties, prolonged procedural time, an increased number of interval colorectal carcinomas, and additional healthcare costs. In Chapter $\mathbf{3}$ we compared a personalized smartphone application in addition to verbal instructions and printed written instructions for bowel preparation in improving bowel preparation quality. Key finding of this study was the significantly higher mean total BBPS in patients using a personalized smartphone application for bowel preparation instructions compared to patients using regular verbal and written information. Patient satisfaction did not further improve for smartphone application users compared to patients receiving regular written instructions. 


\section{PART 2: SAFETY}

In chapter 4 we confirmed in our population-based systematic review and metaanalysis that colonoscopy is a safe procedure, worldwide. Time-trends analysis showed that the post-colonoscopy bleeding rate has decreased from 6.4 to $1.0 / 1,000$ colonoscopies, while perforation and mortality rates remained stable but low over the past 15 years. Noteworthy, we found that post-colonoscopy complication rates vary widely according to colonoscopy indications. For example, post-colonoscopy bleeding occurs in 2.6/1,000, 2.4/1,000,4.6/1,000, and 9.8/1,000 colonoscopies respectively in screening setting, surveillance setting, symptoms based setting and post-polypectomy setting. An important finding of this systematic review is the decline in postcolonoscopy bleedings over the past 15 years. This is in contrast with the substantial rise in overall polypectomy rates, especially of endoscopic resections of larger nonpedunculated polyps (previously referred for surgical resection). Such progress in outcome is most likely due to continuous improvement in colonoscopy equipment, techniques and especially better training including knowledge and technical skills.

Bowel preparation solutions should not cause clinically relevant shifts in systemic electrolytes, in fluids, or in clinical outcome. In Chapter 6, we report two cases of severe post-colonoscopy hypokalemia with fatal outcome in a large, secondary care hospital. This was the basis to initiate studies on the prevalence of hypokalemia before and after bowel cleansing. Before initiating these studies, we conducted a systematic review and meta-analysis of 15 population-based studies examining the pooled prevalence rate of electrolyte disturbances after bowel preparation (Chapter 5). We found a pooled prevalence of hypokalemia of $14.6 \%(95 \% \mathrm{Cl} 4.8,28.1)$ in patients after $\mathrm{NaP}$ vs. $3.7 \%(95 \% \mathrm{Cl} 0.12,10.42)$ after PEG bowel preparation. The ESGE recommends against the use of $\mathrm{NaP}$, but this recommendation is based on low quality evidence. Given the high prevalences of electrolyte disturbances reported in this systematic review and meta-analysis, additional high quality evidence is provided to support the ESGE recommendation against use of $\mathrm{NaP}$ based bowel preparation solutions.

The described cases in chapter 6, prompted us to explore in more detail the magnitude of hypokalemia and risk factors for hypokalemia associated with lowvolume PEG bowel preparation in our large secondary care training hospital in the 
Netherlands (Chapter 7). During one year we prospectively measured potassium levels before and after low-volume bowel preparation in diuretic users and hospitalized patients referred for colonoscopy in a single, large volume, colonoscopy center. Hypokalemia was present before bowel cleansing in $4.2 \%$ of patients using diuretics or being hospitalized. Hypokalemia was present in $23.6 \%$ of patients after bowel cleansing with low-volume PEG with ascorbic acid who had normal potassium levels pre bowel cleansing. Severe hypokalemia was seen in $0.4 \%$ pre-bowel cleansing and in $4.0 \%$ post-bowel cleansing. No serious events occurred.

It should be noticed that the study in chapter $\mathbf{7}$ has been performed in preselected groups of patients undergoing bowel preparation, that is in diuretic users and in hospitalized patients. Therefore, a detailed risk factor analysis for hypokalemia could not be provided. This prompted us to perform a large prospective study in nonselected patients scheduled for colonoscopy in regular care and screening practice (chapter 8). This real-life evaluation in regular endoscopy practice showed a prevalence of hypokalemia in the non-selected group of patients referred for colonoscopy of $0.8 \%$ in patients before start of bowel cleansing for colonoscopy (T0) and of $5.4 \%$ in patients after bowel cleansing with low-volume PEG-asc (T1) who had normal potassium levels before bowel cleansing. From a practical, clinical perspective: the data generated in this study do not provide sufficient evidence for additional screening for hypokalemia in patients undergoing bowel cleansing and colonoscopy apart from general recommendations. It is well documented that patients with a cardiac high risk (i.e. congestive heart failure, ischemia or a history of arrhythmias) have a much higher risk to develop life-threatening arrhythmias when they are hypokalemic. Of the initial colonoscopy population, 281 patients $(15 \%)$ belonged to the "cardiac high risk" group. Of these, 20 patients (7.1\%) developed hypokalemia after bowel cleansing. This group with high cardiac risk and hypokalemia is considered to have an additive, significantly higher risk to develop cardiac arrhythmias but is very small and consists of only $1 \%$ of the initial colonoscopy population. However, special awareness is needed in the group of patients with hypokalemia prior to bowel preparation $(0.8 \%)$, because they could be more prone to develop life-threatening arrhythmias.

Finally, in chapter 9, the conclusions of all studies were put into perspective. First, quality aspects in NEN detection were discussed, including initiating high-quality 
training programs, high definition imaging, necessary in future studies. An endoscopic NEN-classification could be helpful to better and more early recognize NENs, probably in the near future, artificial intelligence may prove to be helpful to improve the quality of recognizing NENs during colonoscopy. To further improve quality of bowel preparation, E-health and smartphone applications should be implemented in bowel preparation and colonoscopy information procedures.

Second, because of rapidly increasing volumes of colonoscopies for population-based screening, surveillance, and regular care, the number of elderly patients and patients with comorbidity at risk for electrolyte disturbances will also increase in the near future. Physicians referring patients for colonoscopy should be aware that "high cardiac risk" patients and those on thiazide diuretics undergoing bowel cleansing for colonoscopy are a risk to develop post-cleansing hypokalemia but it remains to be determined whether their risk to develop life-threatening arrhythmias is truly increased. A flowchart, which patients should be considered for potassium screening before and after low-volume bowel cleansing preparation with PEG-asc is provided in Figure 9.1. In conclusion, uniformity in definitions and classifications is necessary to optimize quality and safety of colonoscopy in the near future. 
ADDENDUM

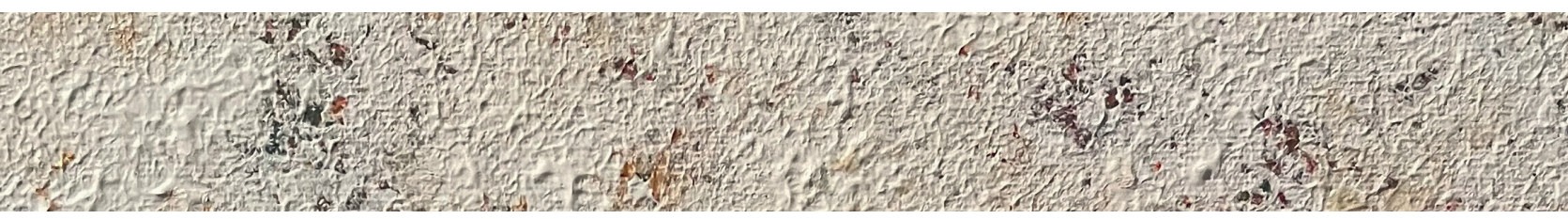




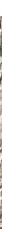

SAMENVATTING 
ADDENDUM 


\section{SAMENVATTING}

Coloscopie is een belangrijk onderzoek voor de diagnose en behandeling van (voorlopers van) dikke darmkanker. Een coloscopie is een dikke darmonderzoek waarbij er met een flexibele kijkbuis (coloscoop) in de dikke darm gekeken wordt. Alvorens een coloscopie kan plaats vinden, moet de darm gereinigd worden met laxeermiddel. Hiervan zijn verschillende soorten en types op de markt beschikbaar. Nadat de darm goed gereinigd is, kan de dikke darm - en het laatste stukje van de dunne darm - met behulp van een coloscoop volledig worden bekeken.

De kwaliteit van de mate van reiniging van de dikke darm wordt in Nederland beoordeeld met behulp van de Boston Bowel Preparation Scale (BBPS) waarbij we de dikke darm (het colon) in 3 onderdelen oftewel segmenten verdelen: het rechter colon, het transversum (dwarsliggend deel colon) en het linker colon (Figuur 11.1). Aan elk segment wordt één van de scores uit Tabel 11.1 toegekend na maximaal schoonspoelen van de darm. Vervolgens worden de 3 scores bij elkaar opgeteld. Een voldoende schoon colon heeft een BBPS van 6 of meer (maximale score is 9).

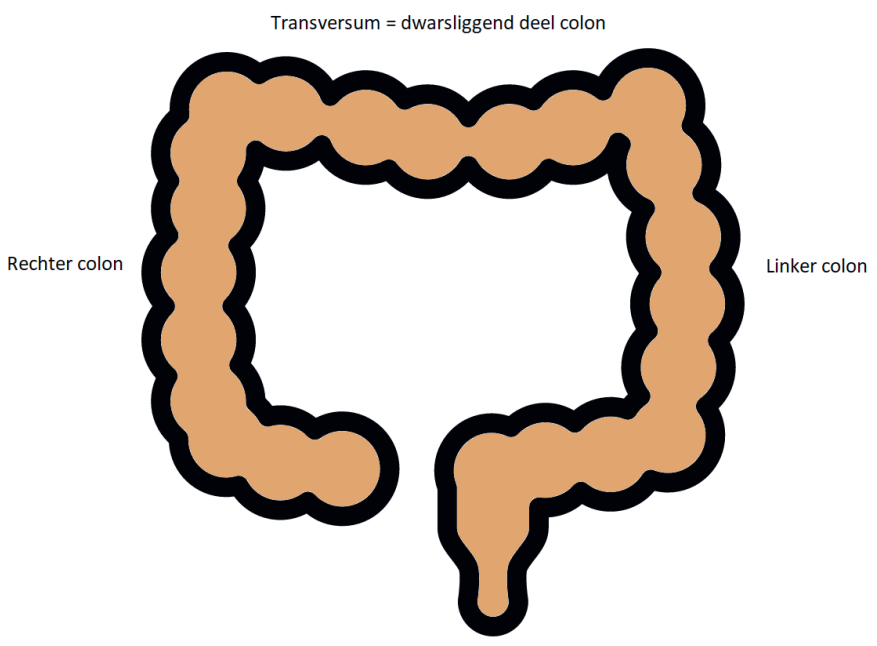

Figuur 11.1 BBPS en colonsegmenten. 
Tabel 11.1 De Boston Bowel Preparation Scale (BBPS).

\begin{tabular}{|l|l|}
\hline \multicolumn{2}{|l|}{ Boston Bowel Preparation Scale (BBPS) } \\
\hline 0 & $\begin{array}{l}\text { Niet voorbereid segment van het colon; het slijmvlies kan niet worden beoordeeld vanwege vaste } \\
\text { ontlasting die niet kan worden verwijderd. }\end{array}$ \\
\hline 1 & $\begin{array}{l}\text { Een gedeelte van het slijmvlies van het segment wordt gezien, maar andere delen niet als gevolg van } \\
\text { residuele ontlasting en/of ondoorzichtige vloeistof. }\end{array}$ \\
\hline 2 & $\begin{array}{l}\text { Kleine hoeveelheid residuele ontlasting en/of ondoorzichtige vloeistof, maar het overige slijmvlies is } \\
\text { goed te beoordelen. }\end{array}$ \\
\hline 3 & $\begin{array}{l}\text { Volledige slijmvlies van het segment is goed te zien, zonder residuele ontlasting en/of ondoorzichtige } \\
\text { vloeistof. }\end{array}$ \\
\hline
\end{tabular}

Jaarlijks ondergaan minimaal 280.000 Nederlanders een coloscopie om hun dikke darm te laten onderzoeken. Naast het verrichten van coloscopieën bij mensen met klachten is in 2014 het bevolkingsonderzoek naar darmkanker van start gegaan bij mensen van 55-75 jaar. Hiermee is het jaarlijks aantal coloscopieën nog verder toegenomen. Daar coloscopieën invasieve procedures zijn en frequent worden toegepast wordt, zijn hoge kwaliteits- en veiligheidseisen nodig.

Dit proefschrift: 'Various aspects of quality and safety of colonoscopy', oftewel in het Nederlands: 'Verschillende aspecten van kwaliteit en veiligheid van coloscopieën', richt zich op klinisch relevante aspecten van kwaliteit (DEEL 1) en veiligheid (DEEL 2) van coloscopieën.

\section{DEEL 1: KWALITEIT}

In hoofdstuk 2 beschrijven we verschillende kenmerken van neuroendocriene neoplasieën (NEN) in de dikke darm. NEN zijn zeldzame tumoren die hun oorsprong hebben in het neuro-endocriene systeem. Neuro-endocriene cellen zitten in veel weefsels in het lichaam. Bij NEN groeien deze cellen ongeremd en kunnen ze hormonen en hormoonachtige stoffen produceren. NEN kunnen overal in het lichaam voorkomen, maar ontstaan meestal in het maag-darm kanaal, de alvleesklier en de longen. Soms wordt een tumor bij toeval ontdekt, tijdens een coloscopie en soms naar aanleiding van klachten die de patiënt beschrijft. Met de implementatie van het bevolkingsonderzoek naar dikke darmkanker is de verwachting dat we NEN steeds vaker per toeval gaan vinden. Zoals dat het geval is bij kwaadaardige tumoren kunnen NEN's ook uitzaaien naar andere organen. Er zijn 2 soorten NEN's, namelijk neuroendocriene tumoren (NET) en neuroendocriene carcinomen (NEC). Bij NET groeien de tumorcellen niet snel, zodat ook bij uitzaaiingen de overlevingskansen nog 
redelijk zijn. Bij NEC groeien de tumorcellen sneller en zijn de overlevingskansen op het moment van stellen van de diagnose, mede door het vaker voorkomen van uitzaaiingen, beperkt.

In hoofdstuk 2 beschrijven we 85 NEN-patiënten die gedurende 15 jaar in de regio Zuid-Limburg werden gediagnosticeerd. We beschrijven hoe NETs en NECs er meestal uitzien bij coloscopie, waarbij met name opvalt dat NETs in de endeldarm (rectum) zich vaak presenteren als een gelige bolvormige structuur, waarbij ze veel op lipomen (vetbolletje: goedaardig gezwel van vetweefselcellen) lijken. Het is belangrijk om NETs te onderscheiden van lipomen, omdat ze in tegenstelling tot lipomen, wél kunnen uitzaaien. NECs in de dikke darm zijn vaak grote tumoren, met zweren en deze NECs zien er op het eerste oog al kwaadaardig uit. We zien dat het aantal gediagnosticeerde NENs per 1000 coloscopieën gelijk blijft. Omdat het aantal coloscopieën op landelijk niveau jaarlijks toeneemt is op populatieniveau de incidentie van NENs over de jaren heen toegenomen.

Zoals eerder al kort is benoemd, is de kwaliteit en veiligheid van coloscopie gerelateerd aan de kwaliteit van de darmvoorbereiding. In hoofdstuk 3 beschrijven we hoe een gepersonaliseerde smartphone applicatie (app) - met instructies hoe de darmvoorbereiding te verrichten - resulteert in hogere BBPS-scores en dus betere darmvoorbereiding. De smartphone app werd vergeleken met alleen mondelinge en schriftelijke uitleg. De patiënttevredenheid was in beide groepen gelijk.

\section{DEEL 2: VEILIGHEID}

In deel 2 beschrijven we de veiligheid van coloscopie, beginnend met hoofdstuk 4, waarin we een uitgebreid literatuuronderzoek met analyse van complicaties rondom coloscopie hebben uitgevoerd. De complicaties waar we in dit onderzoek naar gekeken hebben zijn:

- Perforatie (gaatje in de darm door coloscopie of poliep verwijdering)

- Bloeding

- Overlijden

Het optreden van deze complicaties bij patiënten is vervolgd tot 30 dagen na coloscopie. Alle studies die we onderzocht hebben lieten samenvattend in 0,05\% van alle coloscopieën perforaties zien, in $0,26 \%$ van alle coloscopieën bloedingen en resulteerden in $0,0029 \%$ van alle coloscopieën in het overlijden van de patiënt. In 15 
jaar tijd, zien we dat het percentage bloedingen duidelijk is afgenomen, terwijl we steeds vaker grotere, uitgebreidere en moeilijk gelegen poliepen verwijderen. Het is belangrijk dat we complicaties goed blijven registreren en niet alleen aandacht hebben voor perforaties, bloedingen en overlijden, maar ook voor bijvoorbeeld buikpijn na het verwijderen van een poliep (post-poliepectomie syndroom), voor dikke darmkanker welke is ontstaan na een volledige coloscopie in een tijdsbestek (meestal wordt hier 10 jaar aangehouden) dat je dit eigenlijk niet zou verwachten (post-coloscopie colorectaal carcinoom (PCCRC)) en stoornissen in de mineraal/ zouthuishouding welke kunnen leiden tot hinderlijke, serieuze klachten met soms zelfs fatale gevolgen (ook wel elektrolytstoornissen genoemd).

Als voorbereiding op de laatste hoofdstukken van dit proefschrift, beschrijven we in hoofdstuk $\mathbf{5}$ het literatuuronderzoek en de analyse over het ontstaan van verschillende soorten mineraalstoornissen na het gebruik van darmvoorbereiding (nodig voor coloscopie). Hierbij wordt er onder andere gekeken naar te lage en te hoge kaliumwaardes (hypokaliëmie/hyperkaliëmie) en te lage en te hoge natriumwaardes (hyponatriëmie/hypernatriëmie) na het gebruik van verschillende soorten darmvoorbereiding (laxeermiddel).

In hoofdstuk 6 beschrijven we twee patiënten, welke overleden zijn aan de gevolgen van een zeer laag kalium in het bloed na darmvoorbereiding. Na analyse van de casuïstiek, leek de oorzaak niet op een factor te berusten maar multifactorieel te zijn. Aan de hand hiervan onderzochten we in een grote groep patiënten het voorkomen van een laag kalium in hoog risicogroepen patiënten (hoofdstuk 7). Deze hoog risicogroepen betroffen opgenomen patiënten en patiënten die diuretica gebruiken (ook wel plastabletten in de volksmond genoemd). In deze hoog risicogroep bleek dat $4,2 \%$ van de patiënten een te laag kalium vóór het starten met darmvoorbereiding en $23,6 \%$ ontwikkelde een te laag kalium na darmvoorbereiding.

Omdat we in hoofdstuk 7 onderzoek hebben verricht in een geselecteerde groep patiënten, rees de vraag hoe vaak een te laag kaliumgehalte zou kunnen optreden in de algemene coloscopiepopulatie. Deze populatie hebben we onderzocht in hoofdstuk 8. Hierbij zagen we dat een te laag kalium al aanwezig was bij 0,8\% van de patiënten die nog moesten starten met darmvoorbereiding. Bij patiënten die bij start van de darmvoorbereiding een normaal kalium hadden, ontwikkelde 5,4\% een te laag 
kalium (hypokaliëmie) na darmspoelen. Patiënten die een hoger dan gemiddeld risico hebben op het ontwikkelen van een te laag kalium na darmvoorbereiding zijn: vrouwen, thiazidediuretica-gebruikers (soort plastablet) en patiënten die de diagnose dikke darmkanker (colorectaal carcinoom) kregen. Het is hier relevant om te vermelden dat $1 \%$ van de patiëntenpopulatie een hoog risico heeft op het ontstaan van hartritmestoornissen, hartinfarct of hartfalen (dit noemen we ook wel hoog cardiaal risico). Patiënten met zo'n toegenomen cardiaal risico, zijn bij optreden van een laag kaliumgehalte in het bloed extra vatbaar voor het optreden van ritmestoornissen of zelfs hartstilstand en daarmee in een reanimatiesetting te belanden. Derhalve is het belangrijk om alert te zijn op het ontstaan van een te laag kalium in deze risicogroep, vooral tijdens/na darmvoorbereiding voor coloscopie.

Tot slot worden in hoofdstuk 9 de conclusies van alle hoofdstukken besproken en in perspectief geplaatst. Allereerst werd het belang van kwaliteit van coloscopie besproken, in de vorm van het herkennen van afwijkingen (neuroendocriene neoplasie/tumoren) en een zo optimaal mogelijke darmvoorbereiding om daardoor afwijkingen zo goed mogelijk te kunnen herkennen (BBPS optimaliseren). Gezien de innovatie in E-Health, smartphones en daarmee smartphone apps, is een app met betrekking tot darmvoorbereiding een waardevolle toevoeging om darmvoorbereiding verder te verbeteren.

In het tweede deel van de discussie onderstreepten we het belang van veiligheid van coloscopie. Complicatierisico's werden onderzocht, waarbij het belang van uniformiteit in definities van complicaties werd onderstreept. Dit laatste kan ervoor gezorgd hebben dat complicaties in studies onder gerapporteerd zijn. Specifieke aandacht voor mineraalstoornissen, met name een te laag kalium werden uitvoerig onderzocht en besproken. Als complicaties en mineraalstoornissen meer uniform gerapporteerd worden, kunnen we ook meer inzicht krijgen in het voorkomen ervan. Daar een aantal patiënten ernstige gevolgen van een te laag kalium na darmvoorbereiding zouden kunnen ondervinden, hebben we een advies geformuleerd bij welke subgroep van patiënten overwogen kan worden om het kaliumgehalte voor en na darmvoorbereiding eventueel te controleren in de nabije toekomst. Verder is het van belang dat onderzoek naar complicaties en complicatierisico's van coloscopieën gebruik maakt van uniforme en algemeen geaccepteerde definities om kwaliteit en veiligheid rondom coloscopieprocedures verder te verbeteren. 
ADDENDUM

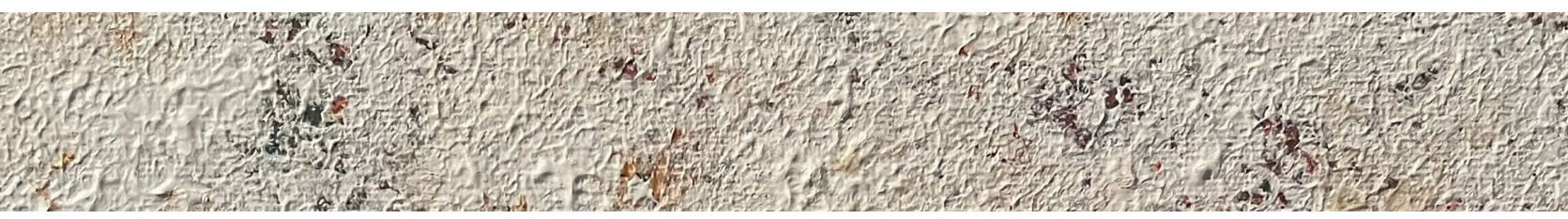




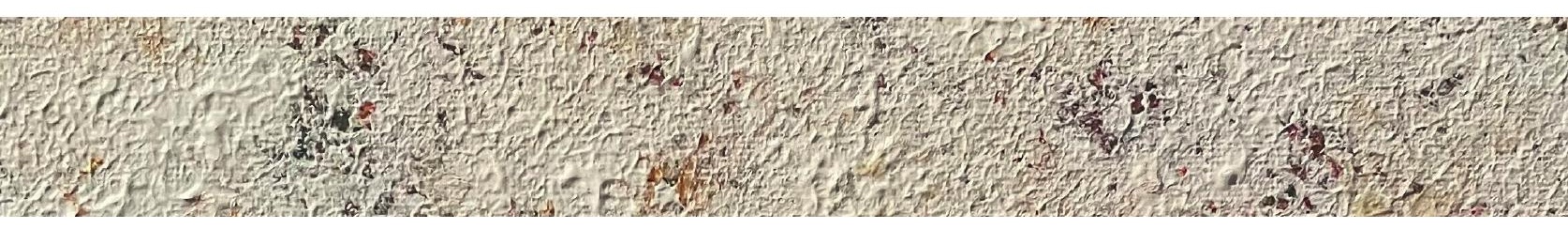

IMPACT PARAGRAPH 
ADDENDUM 


\section{IMPACHT PARAGRAPH}

Worldwide, colorectal cancer (CRC) is the third most common cancer in men and the second most common cancer in women. Colonoscopy is the gold standard for the detection of CRC and its precursor lesions. Colorectal cancer screening programs have been implemented worldwide, and thereby colonoscopy surveillance numbers have been rapidly increasing. ${ }^{1}$ Colonoscopy remains an invasive procedure associated with significant risks. Therefore, high quality and safety, are unarguably, a prerequisite and should be the aim of all endoscopists. ${ }^{2,3}$ However, colonoscopy as a tool will never be perfect, its safety is critical and should be monitored. It is important to establish evidence-based metrics for post-colonoscopy complications (i.e. i.e. post-colonoscopy bleeding, perforation and mortality) to better inform patients and obtain consent for colonoscopy. $^{4,5}$

Bowel cleansing is an inseparable part of colonoscopy. The bowel-cleansing regimen is regarded as burden-some by many patients. ${ }^{6}$ The optimal bowel cleansing preparation is effective, well tolerated, and safe, even for individuals with (multiple) comorbidities. Inadequate bowel cleansing has a detrimental effect on all aspects of colonoscopy. ${ }^{7}$ Up to now, little is known on the effect of the type of patient information and education on the quality of bowel preparation. Numerous strategies to improve bowel preparation have been developed and studied. Most of these strategies aim to inform the patient more extensively about the bowel preparation procedure, remind the patient when action is needed during the days prior to colonoscopy (i.e. start of diet modifications or intake of purgatives) or do both. Several of these strategies, including visual aids, educational videos and SMS reminders, have been shown to improve bowel preparation scores when compared to regular instructions. ${ }^{8}$

To improve patient compliance, low-volume PEG bowel cleansing preparations have been developed. The addition of ascorbic acid to low-volume PEG (PEG-asc) has resulted in a reduction of the volume of the preparation to $2 \mathrm{~L}$. Ascorbic acid is poorly absorbed, employing an osmotic effect, synergistically with PEG. ${ }^{9,10}$

In this thesis, we have focused on clinical important aspects of quality and safety of colonoscopy. In the quality part, we investigated two aspects of quality of colonoscopy. The first aspect was related to recognizing colorectal neuroendocrine 
neoplasms (NEN) by focusing on epidemiology, clinical, and endoscopic features in a unique cohort of colorectal neoplasms. The second aspect was related to use and validation of a personalized smartphone application to optimize bowel cleansing. In the safety part, we focused on post-colonoscopy complications, especially bowel cleansing related electrolyte disorders with focus on hypokalemia.

\section{QUALITY}

In the first part, on quality matters, we provided a detailed analysis of a unique population based cohort of colorectal NENs with respect to epidemiological, clinical and endoscopic aspects according to the updated 2019 WHO-classification. ${ }^{11}$ As confirmed in our study, rectal NETs present as small sessile/submucosal yellowish, lipoma-like lesions with regular surface. It is important to distinguish rectal NETs from other lipomatous lesions, to optimize treatment and survival and quality of life outcomes. This is especially important, since colonoscopy numbers are rising with the worldwide implementation of CRC screening programs and therefore more NENs will be found coincidentally. The photo documentation and the described characteristics of the colorectal NEN will help endoscopists to recognize these lesions and could contribute to training programs and e-learnings on colorectal NEN. ENET members have already started to develop a training program in well-differentiated NEN recognition for endoscopists. ${ }^{12}$

The efficacy and safety of colonoscopy is also related to the quality of the preinvestigational bowel preparation. One of the most commonly used scales is the Boston Bowel Preparation Scale (BBPS). ${ }^{13}$ Key finding of our study is the significantly higher mean total BBPS in patients using a personalized smartphone application for bowel preparation instructions compared to patients using regular verbal and written information. Patient satisfaction did not further improve for smartphone application users compared to patients receiving regular written instructions. Our studied showed, that to improve the quality of bowel preparation, E-health and smartphone applications should be implemented in bowel preparation and colonoscopy information procedures. These findings are relevant for patients, and every doctor who refers patients for colonoscopy procedures. 


\section{SAFETY}

The second part, on safety matters, started with a population-based systematic review and meta-analysis on post-colonoscopy complications. Overall, pooled prevalences for perforation, post-colonoscopy bleeding and mortality were $0.05 \%$ $0.26 \%$ and $0.0029 \%$ per colonoscopy. Time-trends analysis showed that the postcolonoscopy bleeding rate decreased, while perforation and mortality rates remained low and stable over the past 15 years despite a substantial rise of the overall polypectomy rate, especially of endoscopic resections of larger polyps. Such outcomes are most likely due to continuous improvement in colonoscopy equipment, techniques and especially better training including knowledge and technical skills. ${ }^{5,14-}$

${ }^{16}$ We studied perforations, bleeding and mortality in this systematic review and metaanalysis, but post-colonoscopy complications also comprise: post-polypectomy syndrome, cardiopulmonary complications, serious electrolyte disturbances and postcolonoscopy colorectal cancer (PCCRC). Accurate and uniform registration of complications is important to continuously monitor safety. The findings of this metaanalysis encourage endoscopists to continue their efforts to achieve and maintain safety targets in colonoscopy practice.

As inseparable part of post-colonoscopy complications, we paid attention to electrolyte disturbances. We reported on two fatal cases of severe hypokalemia after bowel cleansing with a low-volume bowel cleansing preparation (PEG-asc) for colonoscopy. We concluded that in both cases, the etiology of hypokalemia was multifactorial. These two cases prompted us to explore the prevalence of hypokalemia and the potential risk factors associated with hypokalemia after a specific low-volume bowel cleansing preparation (PEG-asc). Hypokalemia was present before bowel cleansing in $4.2 \%$ of patients using diuretics or being hospitalized. Hypokalemia was present in $23.6 \%$ of patients after bowel cleansing who had normal potassium levels before bowel cleansing. Since this study has been performed in preselected groups of diuretic users and hospitalized patients, a detailed risk factor analysis for hypokalemia could not be provided. This prompted us to perform a large prospective study in non-selected patients scheduled for colonoscopy in regular care and screening practice. In this non-selected study population was showed that hypokalemia occurs in 1) $0.8 \%$ in patients before start of bowel cleansing for colonoscopy (T0) and 2) 5.4\% in patients after bowel cleansing with low-volume PEGasc (T1) who had normal potassium levels before bowel cleansing. 
Because of rapidly increasing volumes of colonoscopies for population based screening, surveillance, and regular care, the number of elderly patients and patients with comorbidity at risk for electrolyte disturbances will also increase in the near future. It is well documented that patients with congestive heart failure, ischemia or a history of arrhythmias have a much higher risk to develop life-threatening arrhythmias when they are hypokalemic. ${ }^{17}$ This group with high cardiac risk and hypokalemia is considered to have an additive, significantly higher risk to develop cardiac arrhythmias. Fortunately, this group is very small in numbers and consists of only $1 \%$ of the initial colonoscopy population. In general, potassium monitoring is considered appropriate in populations that are more prone to develop cardiac arrhythmias, such as patients with a history of ischemic heart disease or myocardial infarction, heart failure or those taking digoxin and in patients at risk to develop hypokalemia. Physicians referring patients for colonoscopy should be aware that "high cardiac risk" patients and those on thiazide diuretics undergoing bowel cleansing for colonoscopy are a risk to develop post-cleansing hypokalemia but it remains to be determined whether their risk to develop life-threatening arrhythmias is truly increased.

In conclusion, the studies performed within the framework of this thesis provide additional, new information regarding several aspects of colonoscopy: recognition and more early detection of neuroendocrine neoplasms, use of smartphone applications to improve bowel preparation, choosing the optimal bowel preparation solution, reducing risks for bowel preparation associated hypokalemia and a large scale systematic review on procedure related colonoscopy complications. 


\section{REFERENCES}

1. Schreuders EH, Ruco A, Rabeneck $L$ et al. Colorectal cancer screening: a global overview of existing programmes. Gut. 2015;64:1637-1649.

2. Calderwood $\mathrm{AH}$, Jacobson BC. Colonoscopy quality: metrics and implementation. Gastroenterol Clin North Am. 2013;42:599-618.

3. Kim SY, Kim HS, Park HJ. Adverse events related to colonoscopy: Global trends and future challenges. World J Gastroenterol. 2019;25:190-204.

4. Iqbal CW, Chun YS, Farley DR. Colonoscopic perforations: a retrospective review. J Gastrointest Surg. 2005;9:1229-1235: discussion 1236.

5. Anderloni A, Jovani M, Hassan C et al. Advances, problems, and complications of polypectomy. Clin Exp Gastroenterol. 2014;7:285-296.

6. Dekker E, Rex DK. Advances in CRC Prevention: Screening and Surveillance. Gastroenterology. 2018; 154:1970-1984.

7. Hassan C, East J, Radaelli F et al. Bowel preparation for colonoscopy: European Society of Gastrointestinal Endoscopy (ESGE) Guideline - Update 2019. Endoscopy. 2019;51:775-794.

8. Liu Z, Zhang MM, Li YY et al. Enhanced education for bowel preparation before colonoscopy: A stateof-the-art review. J Dig Dis. 2017;18:84-91.

9. Fujita I, Akagi Y, Hirano J et al. Distinct mechanisms of transport of ascorbic acid and dehydroascorbic acid in intestinal epithelial cells (IEC-6). Res Commun Mol Pathol Pharmacol. 2000;107:219-231.

10. Johnson DA, Barkun AN, Cohen LB et al. Optimizing adequacy of bowel cleansing for colonoscopy: recommendations from the US multi-society task force on colorectal cancer. Gastroenterology. 2014; 147:903-924.

11. Nagtegaal ID, Odze RD, Klimstra D et al. The 2019 WHO classification of tumours of the digestive system. Histopathology. 2020;76:182-188.

12. Ramage JK, Valle JW, Nieveen van Dijkum EJM et al. Colorectal Neuroendocrine Neoplasms: Areas of Unmet Need. Neuroendocrinology. 2019;108:45-53.

13. Calderwood $\mathrm{AH}$, Jacobson BC. Comprehensive validation of the Boston Bowel Preparation Scale. Gastrointest Endosc. 2010;72:686-692.

14. Gupta AK, Melton LJ, 3rd, Petersen GM et al. Changing trends in the incidence, stage, survival, and screen-detection of colorectal cancer: a population-based study. Clin Gastroenterol Hepatol. 2005;3: 150-158.

15. Bielawska B, Day AG, Lieberman DA et al. Risk factors for early colonoscopic perforation include nongastroenterologist endoscopists: a multivariable analysis. Clin Gastroenterol Hepatol. 2014;12:85-92.

16. Leyden JE, Doherty GA, Hanley A et al. Quality of colonoscopy performance among gastroenterology and surgical trainees: a need for common training standards for all trainees? Endoscopy. 2011;43: 935-940.

17. Cohn JN, Kowey PR, Whelton PK et al. New guidelines for potassium replacement in clinical practice: a contemporary review by the National Council on Potassium in Clinical Practice. Arch Intern Med. 2000;160:2429-2436. 
ADDENDUM

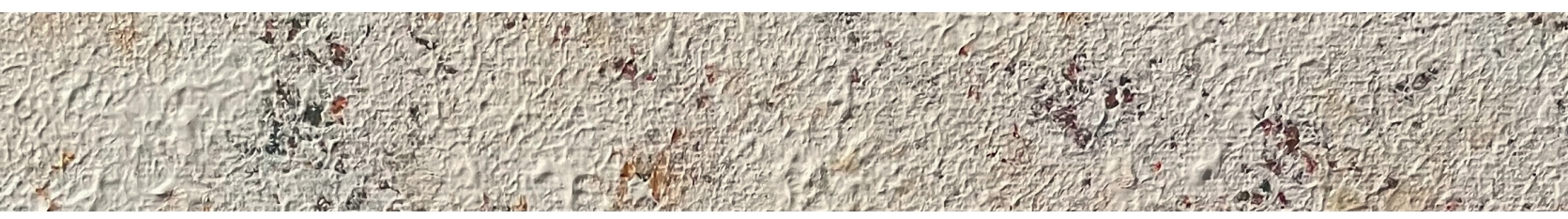




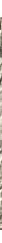

\section{LIST OF PUBLICATIONS}


ADDENDUM 


\section{PUBLISHED ARTICLES}

Reumkens A., Rondagh E.J., Bakker C.M., Winkens B., Masclee A.A., Sanduleanu S. Post-colonoscopy complications: a systematic review, time trends, and meta-analysis of population-based studies. Am J Gastroenterol. 2016 Aug;111(8):1092-101.

Reumkens A., Masclee A.A.M., Bakker C.M. Postcolonoscopy mortality: bowel preparation to blame? Gastrointest Endosc. 2017 Oct;86(4):744-745.

Reumkens A., Masclee A.A.M., Winkens B, van Deursen C.T., Sanduleanu S., Bakker C.M. Prevalence of hypokalemia before and after bowel preparation for colonoscopy in high-risk patients. Gastrointest Endosc. 2017 Oct:86(4)673-679.

van de Wetering A.J.P., Meulen L.W.T., Bogie R.M.M., van der Zander Q.E.W., Reumkens A., Winkens B., Cheng H.R., Straathof J.A., Dekker E., Keulen E., Bakker C.M., Hoge C., de Ridder R., Masclee A.A.M., Sanduleanu-Dascalescu S. Optical diagnosis of diminutive polyps in the Dutch Bowel Cancer Screening Program: Are we ready to start? Endosc Int Open. 2020 Mar;8(3):E257-265

Reumkens A., Bakker C.M., van Kraaij S., Winkens B., Raijmakers M.T.P., van Nunen A.B., van Deursen C.Th.B.M., Masclee A.A.M. Safety of low-volume PEG-asc bowel cleansing preparation for colonoscopy: identifying patients at risk for hypokalemia in a prospective cohort study. Accepted Endoscopy International Open 2021.

van der Zander Q.E.W., Reumkens A., van de Valk B., Winkens B., Masclee A.A.M., de Ridder R.J.J. The effects of a personalized smartphone application on bowel preparation quality: a randomized controlled trial. Accepted JMIR Mhealth and Uhealth 2021.

\section{SUBMITTED MANUSCRIPTS}

Reumkens A., Sastrowijoto P., Grabsch H.I., Goudkade D., le Clercq C.M.C., Bakker C.M., Keulen E.T.P., de Ridder R.J.J., de Herder W.W., Winkens B., Sanduleanu S., de 
Vos-Geelen J., Masclee A.A.M. Epidemiological, clinical and endoscopic characteristics of colorectal neuroendocrine neoplasms: a population-based study in the Netherlands.

Reumkens A., van der Zander Q.E.W., Winkens B., Bogie R.M., Bakker C.M., Sanduleanu S., Masclee A.A.M. Electrolyte disturbances after bowel preparation for colonoscopy: a systematic review and meta-analysis.

\section{ABSTRACTS (selection)}

Reumkens A., Bakker M., Masclee A., Sanduleanu S. Su1077 Hazards and complications of colonoscopy: a systematic review and meta-analysis. Gastroenterology 2015; 148: S-401

Reumkens A., le Clercq C., Bakker M., Winkens B., Grabsch H., Keulen E., Masclee A., Sanduleanu S. 1055 Incidence and endoscopic appearance of colorectal neuroendocrine tumors: a population-based study. Gastroenterology 2016; 150: S207

Reumkens A., Sanduleanu S., Winkens B., van Deursen C., Masclee A., Bakker M. Mo114 Bowel preparation for colonoscopy and risk of hypokalemia: a pilot study. Gastroenterology 2016; 150: S639

\section{SCIENTIFIC PRESENTATIONS}

18.04.2013 NIV-dagen

Oral presentation: Tuberculosis in a Crohn patient with immunosuppressiva

17.05.2015 DDW Washington, USA

Poster presentation: Post-colonoscopy complications: a systematic review, time trends, and meta-analysis of population-based studies

17.03.2016 NVGE voorjaarscongres

Oral presentation: Bowel preparation for colonoscopy and risk of hypokalemia: a pilot study 
18.03.2016 NVGE voorjaarscongres

Oral presentation: Colorectal Neuroendocrine Tumors

28.05.2016 DDW San Diego, USA

Oral presentation: Colorectal Neuroendocrine Neoplasms 
ADDENDUM

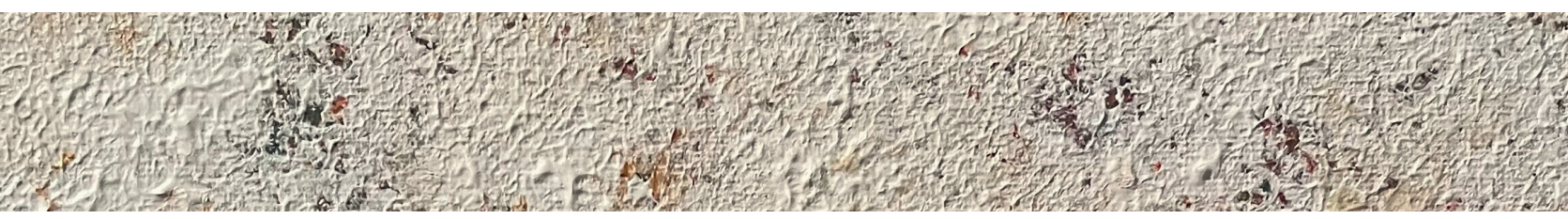


CURRICULUM VITAE 
ADDENDUM 


\section{CURRICULUM VITAE}

Ankie Reumkens was born on November $18^{\text {th }}, 1988$ in Heerlen, The Netherlands. She graduated from secondary school at Sintermeerten College in Heerlen in 2006 and continued medical school at Maastricht University, Faculty of Health, Medicine and Life Sciences. During medical school she finished clinical and scientific traineeships at the Department of Internal Medicine/Medical oncology, Maastricht University Medical Center, The Netherlands. After graduating in 2012, she started with her residency in Internal Medicine under supervision of Dr. J. Buijs (Internal

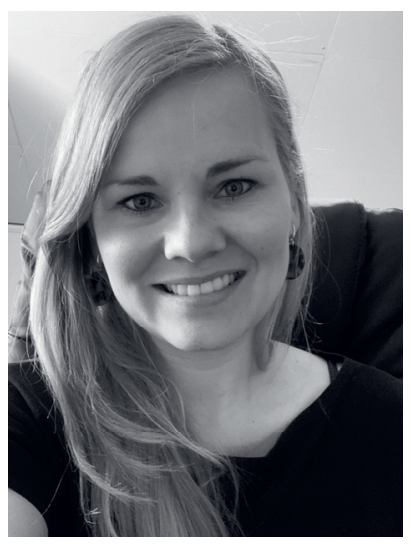
Medicine, Atrium Medical Center, Heerlen, The Netherlands). She spended the first six months of her residency on the department of Gastroenterology, under supervision of Dr. C.M. Bakker. After fulfilling 2 years of preliminary training in Internal Medicine, Ankie changed her residency to Gastroenterology and Hepatology, under supervision of Prof. dr. A.A.M. Masclee (Maastricht University Medical Centert, Maastricht, The Netherlands). Ankie interrupted her residency between 2014 and 2016 to work as a PhD student affiliated to the Division of Gastroenterology and Hepatology of Maastricht University Medical Center, the Department of Internal Medicine and Gastroenterology, Zuyderland Medical Center, Sittard-Heerlen, the Netherlands, and NUTRIM, School for Nutrition, Toxicology and Metabolism, Maastricht University Medical Center, Maastricht, the Netherlands (Promotor: Prof.dr. A.A.M. Masclee, copromotors: Dr. S. Sanduleanu, and Dr. C.M. Bakker). From November 2016 she continued her gastroenterology fellowship under supervision of Dr. C.M. Bakker and Dr. J.C.A. Keulemans (Gastroenterology, Zuyderland Medical Center). She is currently working at the Division of Gastroenterology and Hepatology under supervision of Dr. J.W. Kruimel and Prof. dr. A.A.M. Masclee (Maastricht University Medical Center+, Maastricht, The Netherlands). From July 2021 to January 2022 she will continue and finish her gastroenterology fellowship at the Zuyderland Medical Center (under supervision of Dr. J.C.A. Keulemans). 
ADDENDUM

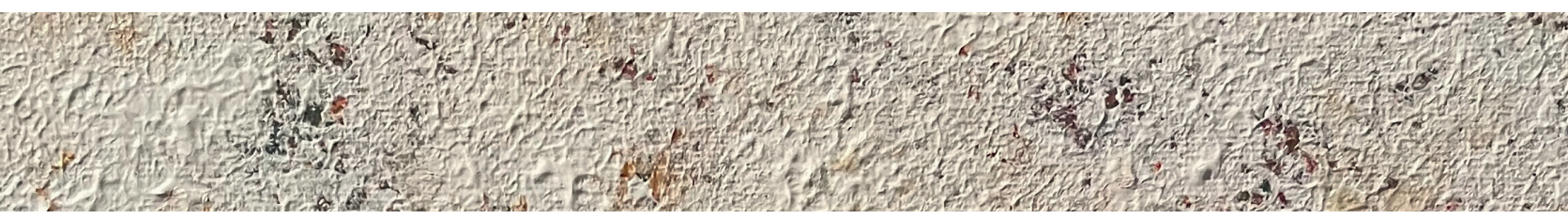




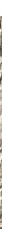

DANKWOORD 
ADDENDUM 


\title{
DANKWOORD
}

\author{
PHINALLY \\ DONE
}

Lieve allemaal, het zit erop... Toen ik mijn opleiding MDL in november 2014 pauzeerde voor een promotietraject, was het de bedoeling om op een rijdende trein te stappen en dit binnen een paar jaar af te ronden. Dat is iets anders gelopen, zoals jullie inmiddels weten. De rijdende trein werd ingewisseld voor eigen wagons met een nieuwe locomotief. De trein heeft wat extra tussenstops gemaakt, maar ging weer rijden, in een iets langzamer tempo en werd gecombineerd met de MDL-opleiding. In deze rare covid-tijd -6,5 jaar na start, en bijna klaar als MDL-arts- ben ik trots, dat ik samen met alle hulp en steun van jullie het eindstation heb bereikt. Derhalve, is dit dankwoord - net zoals de promotietijd - langer geworden, dan van tevoren beoogd.

Prof. dr. Masclee, beste $A d$, in 2013 maakten we samen de keuze om mijn opleiding interne voort te zetten in de opleiding $\mathrm{MDL}$, met daarbij een gecombineerd onderzoekstraject. Wat mij betreft is dat nog steeds de beste keuze die we hadden kunnen maken. Het heeft mij gevormd tot wie ik nu ben als (bijna) MDL-arts en onderzoeker. Mijn proefschrift omvat, precies wat jij reeds vaker gezegd hebt: 'denk aan twee dingen: kwaliteit en veiligheid'... Ad, ik heb ontzettend veel aan je te danken, waar ik je oprecht dankbaar voor ben. 2021 is voor ons beiden een bijzonder jaar: als een van de laatste onderzoekers ga ik mijn proefschrift onder jouw promotorschap verdedigen. Eind dit jaar gaat het welverdiende pensioen voor jou beginnen, en hoop ik te kunnen starten als MDL-arts. Nogmaals bedankt voor de afgelopen jaren, voor de wetenschappelijke input en de supervisie in de kliniek. Ik wens je het allerbeste.

Dr. Sanduleanu, beste Silvia, toen ik in 2013 bij Ad en Yolande op gesprek was geweest, werden we aan elkaar voorgesteld. Kort nadien startte ik met de eerste paper, nog tijdens de vooropleiding interne geneeskunde. Het meewerken aan bestaande databases werd verruild voor het opstarten van 5 nieuwe databases. Jouw gedrevenheid en enthousiasme werkten aanstekelijk en mede daardoor zijn de artikelen tot een beduidend hoger niveau getild. Bedankt dat je mijn wetenschappelijke blik hebt verruimd en dat je onze 'oral presentation' hebt verzorgd op de DDW te San Diego in 2016, terwijl ik hoogzwanger was van Lucas. 
Dr. Bakker, beste Minke, mede door jouw geloof in mij, ben ik nu bijna MDL-arts. Annick en jij zagen dat ik beter paste in de MDL-wereld en hebben mij geholpen om deze stap te maken. Mede door jou ontstond de hele 'kalium-lijn' in dit proefschrift en kreeg dit proefschrift nog meer klinische relevantie. Ik heb je altijd enorm gewaardeerd als opleider en persoon. $\mathrm{Na}$ de jaren in het Atrium $\mathrm{MC} /$ Zuyderland vervolgde je je weg dichtbij je gezin in Amsterdam. $\mathrm{Na}$ je tijd in het Slotervaartziekenhuis en het OLVG, kwamen we elkaar weer tegen in het MUMC+. Bedankt voor de prettige gesprekken, je kritische blik, al je hulp en koffiemomenten de afgelopen jaren.

Dr. Winkens, Bjorn, jouw hulp en statistische kennis waren onmisbaar bij dit proefschrift. Ik heb veel van je geleerd. Heel erg bedankt voor al je hulp en de fijne samenwerking.

De leden van de beoordelingscommissie, te weten Prof. Dr. L.P.S. Stassen, Prof. Dr. R.J.M.W. Rennenberg, Prof. dr. E.J. Schoon, Prof. Dr. M.C.W. Spaander en dr. L.M.G. Moons wil ik graag bedanken voor het kritisch beoordelen van dit proefschrift.

Tevens wil ik de pathologen bedanken voor hun bijdrage aan het onderzoek. Prof.dr. Grabsch, beste Heike, samen met Silvia ontstond het idee voor hoofdstuk 2, waarbij alle coupes opgevraagd en gereviseerd moesten worden. Bedankt voor je kritische blik en hulp gedurende dit lange traject. Dr. Sastrowijoto, beste Prapto, dank voor je hulp bij de PALGA-search, je geduld en uitleg tijdens de revisies en uiteraard je suggesties met betrekking tot hoofdstuk 2. Dr. Goudkade, beste Danny, bedankt voor de (logistieke) hulp met betrekking tot onze search in het MUMC+.

Graag wil ik alle MDL-artsen van het MUMC+ bedanken voor de erg fijne en vooral leerzame opleidingstijd: José Conchillo, Tom Gevers, Jeoffrey Haans, Matthijs Kramer, Ger Koek en Joanna Kruimel. Chantal Hoge, bedankt voor je altijd luisterende oor en onze fijne gesprekken. Bovendien bedankt voor de bijdrage aan mijn onderzoek.

Rian Nijmeijer, ondanks de korte periode die je het MUMC+ mocht werken, heb ik veel aan je gehad. Ik hoop dat ook jij je verdiende plek gaat vinden.

Daniel Keszthelyi, je inzichten zijn van grote waarde. Ik hoop dat je de AIOS en AIO's laagdrempelig blijft adviseren, zoals je bij mij ook gedaan hebt. Oh ja, wat ik nog wilde zeggen: je hebt gelijk... meestal dan ;-). Marieke Pierik, bedankt voor alles wat ik van 
je geleerd heb, gedurende opleiding, onderzoekstijd en het waardegedreven zorgproject.

Rogier de Ridder, bedankt voor je steun, vertrouwen en bijdrage aan mijn manuscripten.

Jan Willem Straathof, bedankt voor je rust tijdens het uitvoeren van (moeilijke) procedures. Ik heb veel van je geleerd. Uiteraard ook bedankt voor je bijdrage aan mijn onderzoek.

Aan alle endoscopieverpleegkundigen van het $\mathrm{MUMC+}$, ik ga jullie bijna verlaten en wil jullie bedanken voor de tijd samen op de endoscopie. Ik heb ontzettend prettig samen gewerkt! Fijn dat ik een aantal van jullie binnenkort nog op het terras zal treffen.

Bij het opzetten van onderzoek, hoort ook het opzetten van databases. Samen met Roel maakte ik het begin van de BVO-database en al snel hadden we hulp van een ijverige WESP-studente. Quirine, we leerden elkaar kennen tijdens je WESP-stage. Bedankt voor de samenwerking aan de database, maar vooral aan 2 artikelen die in dit proefschrift zijn opgenomen. Ik ben blij dat je een collega MDL-arts gaat worden!

Judith de Vos-Geelen, ik ben blij dat ik van je kennis en kunde met betrekking tot de neuroendocrine tumoren gebruik kon maken. Bedankt dat je deur altijd open stond en mij over de eindstreep hebt geholpen.

Gedurende mijn MUMC+-tijd heb ik ondersteuning gehad en fijn samengewerkt met verpleegkundig specialisten, Mia, Ilse en Myron, bedankt voor alles. Ik ga jullie missen.

Nienke, jij hebt veel voor en met mij geregeld, waarvoor ik je ontzettend wil bedanken. Je bent er een uit duizenden...! Ook Mietsie, Elly en Audrey wil ik bedanken voor alle secretariële ondersteuning.

Ik wil Tiny Wouters voor haar werk aan de lay-out van dit proefschrift. Toen ik opgenomen was in het ziekenhuis, zorgde je er samen met Ad voor dat het laatste puntje op de 'i' kwam en mijn boekje toch op tijd naar de beoordelingscommissie kon. Beste Tiny, bedankt! 
Het Zuyderland MC wil ik bedanken voor het aangaan van het gecombineerde opleidings-onderzoekstraject en bijbehorende financiering.

Alle internisten, klinisch geriaters en arts-assistenten wil ik hartelijk bedanken voor de fijne tijd tijdens mijn vooropleiding interne. Graag wil ik Jacqueline Buijs speciaal bedanken als opleider tijdens mijn opleiding interne, wat later mijn vooropleiding MDL werd. Dank je wel voor je vertrouwen en hulp bij de juiste keuze maken. Tevens wil ik je bedanken dat je je zoon Bas van Kraaij aan mij voorstelde, die behoorlijk wat uren aan de laatste kaliumdatabase gewerkt heeft. Bas, mijn dank is groot!

Alle MDL-artsen van het Zuyderland MC: Ad van Bodegraven, Paul Bours, Renske Deutz, Liekele Oostenbrug, Mariëlle Romberg, Jennifer Wilbrink, en destijds ook Marc de Bièvre, bedankt voor mijn bijzonder fijne opleidingstijd in het Zuyderland. Annick van Nunen, zonder jou zou ik nu niet zijn waar ik nu sta. Je weet wat ik bedoel. Dank je wel voor alles. Yolande Keulemans, na het vertrek van Minke werd je de nieuwe opleider in het Zuyderland. Ik ben heel blij dat je mijn pad (meermaals) heb gekruist en me hebt gecoacht daar waar nodig. Mijn dank is groot... Jürgen Emontsbotz, zelden trof ik zo'n geduldige leermeester als jij. Navigeren is een kunst, maar voor jou een peulenschil. Bedankt ook voor je steun tijdens de kaliumstudie. Eric Keulen, bedankt voor je hulp en klinisch relevante blik op de manuscripten. Cees van Deursen, ik leerde je in 2009 kennen en heb met je mogen werken tot aan je pensioen, en zelfs daarna kwam ik je nog tegen in het MUMC+. Je bent een voorbeeld voor me. Bedankt voor je hulp bij het schrijven van de onderzoeksprotocollen. Ik hoop dat je nog lang van je pensioen mag genieten. Eveline Rondagh, jij hebt me geholpen om mijn eerste manuscript op poten te krijgen. We kwamen elkaar daarna weer tegen in de MDLopleiding en daarna werd jij MDL-arts, waarbij we samen met Paul, veel cappuccino/espresso genoten hebben. Bedankt voor de fijne tijd! Khalida Soufidi, ik ben blij dat ik je heb leren kennen. Ik waardeer je enorm als MDL-arts en vooral als vriendin. Bedankt voor alles wat ik van je geleerd heb en je bijdrage aan mijn laatste manuscript. Mijn laatste maanden opleidingstijd in het Zuyderland gaan (terwijl ik dit schrijf) bijna van start en ik kijk ernaar uit om met jullie allemaal weer samen te mogen werken.

Een speciaal woord van dank aan alle endoscopie-verpleegkundigen, verpleegkundigen van dagverpleging $B$ en verpleegkundig specialisten van het Zuyderland MC. Jullie hebben heel wat elektrolyten geprikt en bekeken! Carmen, 
Carina en Astrid: ondanks dat ik al even uit het zicht ben, bleef ons contact bestaan. Tot snel!

Maarten Raijmakers, wat was het fijn om jou als klinisch chemicus aan boord te hebben tijdens de laatste kaliumstudie. Mede dankzij jou is deze studie (logistiek) geslaagd! Bedankt!

Beste MDL-collega's van de UM, het MUMC+ en het Zuyderland. Mede door jullie kijk ik met een grote glimlach terug op mijn promotie- en opleidingstijd. Doordat zowel opleiding als promotie de afgelopen jaren verworven waren, kwam ik de meeste van jullie ook weer tegen in het MDL-deel van den kliniek. Beste Annick, Bas, Bouke, Carmen, Corinne, Daisy, Devina, Dion, Fabiënne, Fedde, Frank, Freddy, Golnar, Hao Ran, Helena, Kirsten vd B, Kirsten $P$, Lisa, Lonne, Marie-Claire, Marin, Marlous, Montserrat, Paul, Paulien, Pauline, Renske, Sander, Steven, Susan, Tim, Tim, Wesley, Wiesje, Yala en Zsa Zsa, allemaal bedankt voor de plezierige samenwerking, adviezen en gezelligheid. Mede door jullie was het een prachtige tijd!

Een aantal collega's dienen echter apart genoemd te worden. Om te beginnen met mijn kamergenoten, Mark (van Avesaat) en Ellen, respectievelijk prof.dr. Monkey seed en Wilma. Onder superviserend oog van dr. Kätzi aan het plafond, werd het halve magazijn van senior arts-onderzoeker Mark verruild voor deze (destijds) junior artsonderzoeker. Ellen, jij zat met Mark samen op een kamer, toen er plek gemaakt moest worden voor deze derde Limburger. En wat was ik op mijn plek bij jullie. Het was een fantastische tijd, met als hoogtepunt toch echt de DDW in Washington (samen met Bouke, Bram, Chantal, Fedde, Kirsten, Selwyn en Steven), alwaar ik ook mijn bijnaam kreeg (the First Lady of Voerendaal) en mijn 'huismus'-stempel ook voor de laatste twijfelaars verloor. De feestjes (waaronder de R\&B-club...), de gin-tonics, long island iced teas, guilty pleasures, de gelakte teennagels van Selwyn en jouw 'man bun' Mark... om zomaar eens wat te noemen. Om die bewuste mailwisseling met betrekking tot mogelijke studiedeelname maar even buiten beschouwing te laten...;-)

Uiteraard was ik er niet gekomen zonder support van Team Silvia: Chantal (Chanti voor intimi), bedankt dat je me in een warm bad hebt verwelkomd. Je introduceerde me in de onderzoekswereld en alles wat daarbij kwam kijken. Later in de opleiding kon ik dat voor je terug doen. Samen hebben we vele feestjes, congressen en werktijd 
gespendeerd. Ik ga je missen. Heel veel succes als MDL-arts! Roel, zonder het 'whizzkid' in jou, had ik nu nog steeds niets van ' $R$ ' gesnapt. Bedankt dat je dit programma uitvoerbaar maakte en je droge grappen met ons deelde. Ik hoop voor Evelien, dat je thuis een hele hoge kast hebt, want je pogingen om menigeen op de kast te jagen zijn eindeloos... Je hebt mij 'gesuperviseerd' tijdens de AIO-tijd en tijdens de AIOS-tijd werd het opeens vice versa. Chanti en Roel, dat etentje gaan we plannen, zodra het weer mag.

En dan in het bijzonder de 'Class of 2021': Zlatan, Susan, Mark, Chantal, Brecht en Marie-Claire. Allemaal klaar als MDL-arts dit jaar. Wat hebben wij vele hilarische en bijzondere momenten samen beleefd. Zowel tijdens onderzoeks- als opleidingstijd. Zlatan, jij werd van collega arts-onderzoeker, collega AIOS en uiteindelijk zelfs dit jaar mijn baas. Onze eerste dienst samen (jij als MDL-arts, ik als AIOS) was een geslaagde! Bedankt voor je interesse en hulp in mij als persoon en onderzoeker. Susan, poffer, al sinds onze start bij de interne in het Atrium MC kunnen wij het goed met elkaar vinden. Ik ben zo blij voor je dat je je plek in Boxmeer hebt gevonden. Ik verheug me op onze volgende date. Brecht, ik ben OPBRECHT blij dat jij onderdeel was van mijn MUMC+-tijd. Ondanks dat je grappen soms op de 'grens' waren, kan ik je humor OPBRECHT waarderen. Het ga je goed in Leuven en straks als baas in Antwerpen. Marie-Claire, $2 x$ tegelijk zwanger geweest en veel samen gedeeld. Tijdens onze interne tijd in het Zuyderland hoopten we steeds dat we later samen mochten werken, en dat is uiteindelijk, toch soort van gelukt in de MDL-tijd. Hoe mooi zou het zijn, als dat uiteindelijk toch nog lukt in de grote MDL-wereld. Heel veel succes in Aachen... en wie weet.

Linda, we leerden elkaar kennen tijdens onze MDL-tijd in het Zuyderland en konden het bijzonder goed vinden. $\mathrm{lk}$ heb in de afgelopen jaren eerst als collega en later als vriendin veel van je kunnen leren. Ik waardeer je nuchtere blik op het leven. Mariëlle, nadat Linda als MDL-arts in Roermond aan de slag ging, kwam jij in het Zuyderland werken. Ik denk met plezier terug aan die tijd. En nu werk je samen met Linda in Roermond. Dank je wel voor de koffiemomenten. Veel succes in de toekomst! Mark van Boekel, wat heb ik een prettige collega aan jou gehad in het MUMC+. Je bent alweer bijna een jaar aan de slag in Weert... 'and the best is yet to come'. Ik ben blij dat ons contact is gebleven. Rianne, het voelt alsof ik je al jaren ken. lets met dezelfde 
golflengte, ambities, principes en koffierituelen. Ik hoop dat onze paden zich nog vaak blijven kruisen.

In het Atrium MC heb ik tijdens de vooropleiding interne geneeskunde intens samen gewerkt met een heleboel fijne collega's. Aniek, Suzanne en Jeantine, met jullie was het op en buiten het werk een feest. En wat heerlijk dat jullie ook op onze Toscaanse bruiloft aanwezig waren. Ik heb met Aniek besproken dat we binnenkort weer een reünie zullen organiseren.

Ellis, Stijn, Noortje en Monica, jullie volgden hetzelfde traject als ik, onderbraken jullie opleiding voor een promotietraject... Tijdens de opleiding, maar ook tijdens onderzoekstijd waren de onderbrekingen met jullie altijd enorm plezierig. We zien elkaar, nu met name door covid, wat minder vaak buiten werktijd, maar hopelijk kunnen we dat snel inhalen.

Natuurlijk mogen ook mijn vrienden en (schoon)familie niet vergeten worden. Vrienden zijn de familie die je kiest. Bedankt dat jullie leuke herinneringen met ons willen maken.

Barbara en Eva, sinds onze studietijd zijn we bevriend. Helaas, zien we ons momenteel door onze drukke agenda's en corona, niet zo vaak zien als we zouden willen, maar weet dat ik jullie mis. Koen, Jesse, Finn, Ruud, Teun, Floor, Céline, Koen, Laurens, Rico, Sandra, Fenna, Tess, Jella, Steward (kleinigheidje hou je altijd), Naomi, Benthe, Ward, Anouk, Zoë, Xam, Claudia, Tim, Carlo, Joep, Berry, Ria, Marco, Almanda, Alice en Jarno, ik ben jullie allemaal onwijs dankbaar voor jullie betrokkenheid, interesse, begrip en vooral ook de gezelligheid en het maken van mooie herinneringen tijdens de afgelopen jaren. Jullie hebben jaren uitgekeken naar mijn promotiefeest, maar covid maakt dit een stuk lastiger... wie weet!

Een aantal heeft aandeel gehad in mijn keuze om geneeskunde te gaan studeren, maar is helaas gaandeweg overleden. Lenie, Trees, Jo(pie), Henny, Liesbeth, Anja en Jan, ik zal jullie nooit vergeten. - Toast to the ones here today, toast to the ones that we've lost on the way-

En dan mijn paranimfen...

Anouk en Sanne, mijn besties, ik ben heel blij dat jullie naast mij staan op deze belangrijke dag en dat in het jaar van ons 15 -jarig jubileum als vriendinnen. Vers van 
de middelbare school, leerden we elkaar kennen tijdens in het $1^{\mathrm{e}}$ studiejaar Geneeskunde. Wat hebben we veel en intens met elkaar gedeeld. Ik ben trots dat ik peettante mag zijn van Jesse en Floor en dat jullie peettante zijn van onze kinderen. Ik hoop dat onze onafscheidelijke 3-eenheid zal blijven bestaan tot in het rollatortijdperk.

Heel veel dank aan mijn familieleden voor al hun steun. Mijn zus(je) Saskia, ik kan soms niet met je, maar zeker ook niet zonder je (als kat en muis ;-)...). Ik ben trots op wat je bereikt hebt in je leven en dat je me tante hebt gemaakt van Merel. Ik hoop dat jullie samen met mijn gekke schoonbroertje Marc een zonnige toekomst tegemoet gaan in jullie net verbouwde huis.

Ruud, mijn schoonbroer, de ingenieur van de familie en bijna net zo (suf)geleerd als ik, aldus je vader. Ik hoop dat je het interessant vindt om (een deel van) mijn werk te lezen.

Lei en Willy, mijn schoonouders, al vanaf het eerste uur erbij. Altijd oprecht geïnteresseerd in mijn verhalen (ook over de snijzaal, tijdens het avondeten...) Bedankt voor al jullie hulp en steun de afgelopen jaren en alle keren dat jullie extra kwamen oppassen, omdat Tim en ik bezig waren met onze opleidingen of mijn onderzoek. Lucas en Stijn zijn dol op jullie en ik kan me geen betere schoonouders wensen.

Mam, zonder je onvoorwaardelijke steun, vertrouwen en geduld zou ik nooit zover gekomen zijn als ik nu ben. Ook al is het lastig om soms uit te leggen wat promoveren nu precies inhoudt, je doet je best om te begrijpen waar het over gaat. Toen je mijn Nederlandse samenvatting onder je neus kreeg, begreep je pas echt wat ik nou die afgelopen 7 jaar - tussen werk, opleiding en kinderen opvoeden- door heb gedaan. Bedankt dat je er altijd voor mij, Tim en onze kinderen bent. We zijn allemaal heel blij met jou als (schoon)moeder en oma!

Opa Max, ik zal u nooit vergeten. -Because dreams bring back all the memories$U$ heeft mij al die tijd gesteund en was ontzettend trots op alle mijlpalen gedurende mijn studie en opleiding. Gelukkig heeft $u$ het begin van mijn promotietijd mogen meemaken, en was $u$ heel erg blij toen mijn eerste artikel gepubliceerd werd. Ik had $u$ 
maar al te graag nu aan het einde van mijn promotietijd in de zaal gehad, maar hoop dat $u$ daarboven op de eerste rang plaats zal nemen.

De laatste alinea van dit proefschrift is voor de 3 belangrijkste mannen in mijn leven. Tim, je bent de liefde van mijn leven, mijn levenspartner en mijn allerbeste vriend. Samen zijn we het beste team dat er bestaat. We hebben vele heuvels en dalen gezien en dit heeft ons alleen maar sterker gemaakt. Jij hebt aan 'het papa zijn' meer liefde gegeven dan ik ooit gekend heb. Ik verheug me om samen met onze 2 zoontjes nog heel veel mooie herinneringen te maken en dat we alles wat we kunnen vieren, samen mogen vieren in het leven. Bedankt dat je altijd achter én naast me staat en me op alle vlakken hebt geholpen dit proefschrift tot een goed eind te brengen. Ik hou van je! Lieve Lucas en Stijn, jullie herinneren mij elke dag aan wat er echt belangrijk is in het leven. Jullie houden allebei enorm veel van boekjes lezen, maar dit boekje is misschien iets voor later... Ik ben enorm trots dat ik jullie mama ben. Ik hou van jullie...! 
